Pacific Northwest

National Laboratory

Operated by Battelle for the

U.S. Department of Energy

\title{
Thermal Stability Studies of Candidate Decontamination Agents for Hanford's Plutonium Finishing Plant Plutonium- Contaminated Gloveboxes
}

\author{
R. D. Scheele (a) \\ D. S. Trent(a) \\ T. D. Cooper(b) \\ M. K. Edwards(a) \\ S. A. Jones (a) \\ A. E. Kozelisky(a) \\ J. R. Ewalt(b) \\ P. A. Scott(a) \\ J. A. Compton (b) \\ M. J. Minette(b) \\ (a) Pacific Northwest National Laboratory, Richland, WA \\ (b) Fluor Hanford, Richland, WA
}

September 2005

Prepared for the U.S. Department of Energy

under Contract DE-AC05-76RL01830 


\title{
DISCLAIMER
}

This report was prepared as an account of work sponsored by an agency of the United States Government. Neither the United States Government nor any agency thereof, nor Battelle Memorial Institute, nor any of their employees, makes any warranty, express or implied, or assumes any legal liability or responsibility for the accuracy, completeness, or usefulness of any information, apparatus, product, or process disclosed, or represents that its use would not infringe privately owned rights. Reference herein to any specific commercial product, process, or service by trade name, trademark, manufacturer, or otherwise does not necessarily constitute or imply its endorsement, recommendation, or favoring by the United States Government or any agency thereof, or Battelle Memorial Institute. The views and opinions of authors expressed herein do not necessarily state or reflect those of the United States Government or any agency thereof.

\author{
PACIFIC NORTHWEST NATIONAL LABORATORY \\ operated by \\ BATTELLE \\ for the \\ UNITED STATES DEPARTMENT OF ENERGY \\ under Contract DE-ACO5-76RL01830
}




\title{
Thermal Stability Studies of Candidate Decontamination Agents for Hanford's Plutonium Finishing Plant Plutonium-Contaminated Gloveboxes
}

\author{
R. D. Scheele ${ }^{\text {(a) }}$ \\ T. D. Cooper ${ }^{(b)}$ \\ S. A. Jones ${ }^{(a)}$ \\ J. R. Ewalt ${ }^{(b)}$ \\ J. A. Compton ${ }^{(b)}$ \\ D. S. Trent ${ }^{(a)}$ \\ M. K. Edwards ${ }^{(a)}$ \\ A. E. Kozelisky ${ }^{(a)}$ \\ P. A. Scott ${ }^{(a)}$ \\ M. J. Minette ${ }^{(b)}$
}

(a) Pacific Northwest National Laboratory, Richland, WA

(b) Fluor Hanford, Richland, WA

September 2005

Prepared for the U.S. Department of Energy

under Contract DE-AC05-76RL01830

Pacific Northwest National Laboratory

Richland, WA 99352 


\section{Summary}

Fluor Hanford (Fluor) is in the early stages of decommissioning the Plutonium Finishing Plant (PFP) at the Department of Energy's (DOE) Hanford site located in Southeastern Washington State. Beginning in 1949, the PFP purified plutonium solutions from Hanford's nuclear fuel reprocessing facilities and plutonium scrap from Hanford and other DOE sites to produce metal and oxide products for the nation's defense mission. Most of these chemical operations were conducted in gloveboxes fabricated of stainless steel, glass, and plastic, which must now be decontaminated of plutonium and the accompanying americium before disposal as non-transuranic (non-TRU) waste. The PFP has over 200 of these contaminated gloveboxes.

This report provides a technical basis for safely disposing of proposed chemical decontamination agents and other materials, such as cloth rags and vacuum cleaner filters used to remove the decontamination agents and contained plutonium and americium, from the gloveboxes. The safety of this waste is a concern because the chemicals are generally very chemically reactive, and in combination with cloth in certain conditions, could conceivably develop a self-heating reaction, including the possibility of a fire or rapid propagating reaction.

This safety concern was brought into the forefront following a fire at Rocky Flats in 2003 (Beyler 2004). The fire occurred in a glove box that had been treated with ceric nitrate, which is one of the decontamination chemicals that Fluor has proposed to use. The cause of the event was obscured by the copious quantities of chemicals and water used to extinguish the fire and hence the cause of the fire was inconclusive. However, the reviewers noted that cloths were found in the glove box, suggesting that the combination of cloths and the ceric nitrate may have contributed to the fire. With that uncertainty, Fluor began an investigation into the potential for self-heating reactions when using and disposing of the chemicals and materials in the decontamination process.

We used laboratory thermoanalytical methods and thermal modeling of 210-L (55-gallon) drum waste packages to evaluate the behavior of the combinations of decontamination chemicals and waste removal/packaging materials. To evaluate the thermal reactivity of the waste with respect to safety, we used guidance recommended by the Center for Chemical Process Safety (CCPS) of the American Institute of Chemical Engineers (CCPS 1995). For the differential thermal analysis (DTA), thermal reactivity is of potential concern if the DTA-measured onset temperature is within $100^{\circ} \mathrm{C}$ of the maximum process operating temperature, where onset temperature is the temperature where the reaction is first detected. For the ARC, thermal reactivity is of potential concern if the maximum operating temperature is within $50^{\circ} \mathrm{C}$ of the ARC-measured onset temperature. If operations may encroach on a recommended safety margin, potential paths forward include 1) further investigation using more sensitive calorimetric instruments to better predict the reaction onset temperature and assess the risk, 2) modeling the thermokinetic behavior of the system, and 3) implementing engineering or administrative controls to assure that the maximum temperature of the system is never within the safety margin assigned for the instrument's measured onset temperature.

Candidate decontamination agents evaluated in this study include 1) aqueous ceric $\left(\mathrm{Ce}^{4+}\right)$ nitrate/nitric acid, 2) a proprietary set of commercial aqueous solutions marketed by EAI RadPro ${ }^{\circledR}$ containing acids, degreasers, and sequestering agents, and 3) commercial inorganic-based gels (Glygel ${ }^{\circledR}$ and Aspigel $^{\circledR}$ ) using ceric ammonium nitrate/nitric acid as the active agent. 
The procedures to be used for the aqueous decontamination solutions and the decontamination gels differ. The solution(s) are to be applied onto the contaminated surfaces as sprays, the now transuranic (TRU)bearing solutions absorbed into cloths, the cloths possibly chemically treated to neutralize or reduce chemical reactivity, and the TRU-bearing cloths then packaged for disposal as TRU waste. Cotton and synthetic cloth materials are being considered for this operation. The nominal process for the decontamination gels involves spraying or painting the ceric-laced gels onto the contaminated surface, allowing them to dry and to fall off or be scraped or brushed off, recovering the dried gels by sweeping or vacuuming using small hand-held vacuums, and packaging the TRU-laden gels and vacuum filters as TRU-wastes will be packaged in 210-L (55-gal) TRU waste drums and stored at the Hanford site for an undefined interim storage period. Each of the resulting decontamination wastes thus will contain chemically intimate mixtures of oxidizers (nitrate from the nitric acid, ceric nitrate, and ceric ammonium nitrate) and fuel (cloths, complexants, sequestering agents, surfactants, and ammonium ion) varying according to the process used.

We used laboratory thermoanalytical methods and thermal modeling of $210 \mathrm{~L}$ (55-gal) drum waste packages to evaluate the behavior of the combinations of decontamination chemicals and waste removal/packaging materials. The significant results and recommendations from these studies follow:

\section{Ceric Nitrate-Nitric Acid and Cloth Process Wastes}

- A potential thermal hazard exists for wastes arising from the use of $80 \%$ cotton/ $14 \%$ polyester cloths;

- The thermal reactivity of ferrous-reduced and sodium hydroxide neutralized nominal cotton cloth waste depends on age. Initially reactivity increases through 114 days but then diminishes after 149 days;

- Synthetic $20 \% / 80 \%$ or $50 \% / 50 \%$ polyamide/polyester cloths exhibit significantly less thermal sensitivity than cotton-based cloths; use of the synthetic cloths are a potential approach for mitigating the thermal reactivity risk.

\section{Recommendations:}

- Avoid $86 \%$ cotton $/ 14 \%$ polyester cloths to remove decontamination solution; rather

- Use polyamide/polyester cloths to remove decontamination solution.

\section{RadPro $^{\circledR}$ and Cloth Wastes}

- A potential thermal hazard exists for wastes from using $100 \%$ cotton cloths with RadPro ${ }^{\circledR}$ decontamination solution (the expected most reactive waste form);

- Neutralizing RadPro decontamination solution cotton cloths with sodium hydroxide or sodium carbonate reduced the thermal sensitivity by increasing the ARC-measured onset temperature;

- $\quad$ Substituting synthetic polyamide-polyester cloths for cotton cloths alone did not improve the thermal behavior of potential decontamination solution/cloth waste;

- Neutralizing synthetic polyamide-polyester did provide some short-term benefits, delaying the ARCmeasured onset temperature and slowing the reaction rates; however, after 300 days, the onset temperature drops to $95^{\circ} \mathrm{C}$; 
- DTA/TGA studies of RadPro emulsifier/cloth wastes indicate wastes should be thermally stable at expected storage conditions.

\section{Recommendations:}

- Use cotton cloths and neutralize;

- Neutralize RadPro solution/cotton cloth wastes with sodium hydroxide or sodium carbonate before packaging wastes for disposal;

- Use environmental controls to assure that neutralized waste temperatures remain more than $50^{\circ} \mathrm{C}$ from the observed $110^{\circ} \mathrm{C}$ reaction onset temperature (e.g., maintain temperature at less than $60^{\circ} \mathrm{C}$ ) and/or maintain cloths moist; and

- Perform ARC studies to more fully evaluate thermal stability of emulsifier-cloth wastes; note, however, that extrapolation of experience gained with decontamination solution wastes indicates that neutralization should be sufficient.

\section{Ceric Ammonium Nitrate/HNO ${ }_{3}$-Gel-Carried Decontamination Systems}

- Organic surfactants, as are found in Glygel, contribute to potentially vigorous self-sustaining reactions even without other oxidizable materials such as cotton cloths

- Organic-free Aspigel wastes are susceptible to low energy self-sustaining reactions with ARCobserved onset reactions near $70^{\circ} \mathrm{C}$; results are confounded by organic degreaser on stainless steel coupons used to prepare test material;

- Neutralization with sodium carbonate increases the ARC-measured onset temperature for pure Aspigel from $70^{\circ} \mathrm{C}$ to $130^{\circ} \mathrm{C}$ and the ARC-measured onset temperature for Aspigel/DataVac 3 vacuum filter from $50^{\circ} \mathrm{C}$ to between $85^{\circ} \mathrm{C}$ and $100^{\circ} \mathrm{C}$;

- Mixtures of Aspigel and vacuum cleaner filters, with ARC-measured onset temperatures near $50^{\circ} \mathrm{C}$, are more thermally sensitive and react faster and more energetically than Aspigel alone;

- Neutralization with sodium carbonate slows the reaction rate for both Aspigel alone and the Aspigel/DataVac 3 filter mixture;

- Neutralization also delays reaction onset for Aspigel-saturated cotton cloth.

- A third party test heated a simulated waste package of Aspigel to $55.5^{\circ} \mathrm{C}$ for 7 days. The bench test did not identify an exothermic reaction within the Aspigel waste flakes.

\section{Recommendations:}

- Avoid gels requiring organic surfactants;

- Neutralize Aspigel for disposal to delay reaction onset temperature;

- Neutralize mixtures of Aspigel and Data Vac vacuum filters and use environmental controls to limit temperature consistent with CCPS recommendations and maintain high levels of moisture;

- Neutralize cotton cloths used to collect Aspigel;

- Use environmental controls to assure that Aspigel flakes and the Aspigel/cotton cloth waste storage temperature remain more than $50^{\circ} \mathrm{C}$ from $70^{\circ} \mathrm{C}$ (e.g., maintain temperature at less than $20^{\circ} \mathrm{C}$ ) and/or assure that Aspigel/cloth remains moist. 


\section{References}

Center for Chemical Process Safety (CCPS). 1995. Guidelines for Chemical Reactivity Evaluation and Application to Process Design. American Institute of Chemical Engineers, New York, NY.

Beyler, C. 2004. Analysis of the Cause of the Fire in Glovebox 8, Room 2325, Building 371 at RFETS on 6 May 2003. Hughes Associates, Inc. Baltimore, MD. 


\section{Acronyms}

$\begin{array}{ll}\text { ARC } & \text { Accelerating Rate Calorimetry } \\ \text { CCPS } & \text { Center for Chemical Process Safety } \\ \text { CWC } & \text { Central Waste Complex } \\ \text { DOE } & \text { Department Of Energy } \\ \text { DSC } & \text { Differential Scanning Calorimeter } \\ \text { DTA } & \text { differential thermal analysis } \\ \text { EAI } & \text { Environmental Alternatives, Inc. } \\ \text { Fluor } & \text { Fluor Hanford } \\ \text { HEPA } & \text { high-efficiency particulate air } \\ \text { MS } & \text { mass spectrometry } \\ \text { MSDS } & \text { Material Safety Data Sheets } \\ \text { PFP } & \text { Plutonium Finishing Plant } \\ \text { PNNL } & \text { Pacific Northwest National Laboratory } \\ \text { PVC } & \text { polyvinyl chloride } \\ \text { SST } & \text { stainless steel } \\ \text { TC } & \text { Thermocouple } \\ \text { TGA } & \text { Thermogravimetric Analyzer } \\ \text { TG } & \text { Thermogravimetry } \\ \text { TOC } & \text { total organic carbon } \\ \text { TRU } & \text { Transuranic } \\ \text { Waste Isolation Pilot Plant }\end{array}$





\section{Acknowledgments}

The authors would like to thank Cal Delegard for his valuable assistance in his technical review that resulted in needed expansions, enhancements, and clarifications and Wayne Cosby for formatting the report and providing editorial support into the late hours of the night. 



\section{Contents}

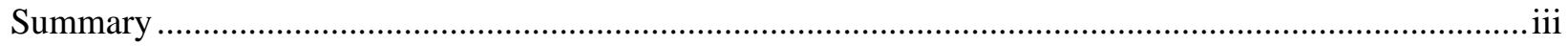

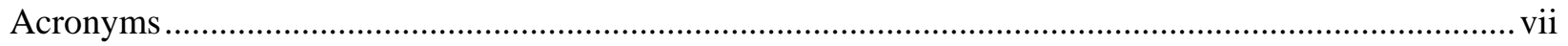

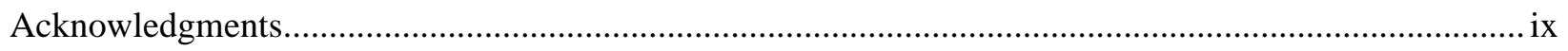

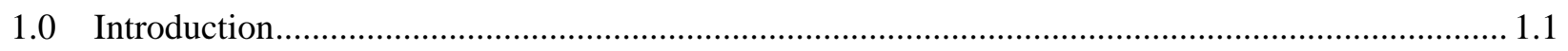

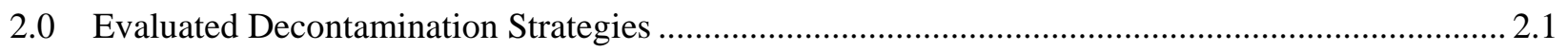

2.1 Cerium Nitrate Decontamination Process Description ....................................................... 2.1

2.2 RadPro ${ }^{\circledR}$ Decontamination Process Description ................................................................... 2.3

2.3 Glygel Decontamination Process Description ................................................................ 2.4

2.4 Aspigel Decontamination Process Description............................................................... 2.5

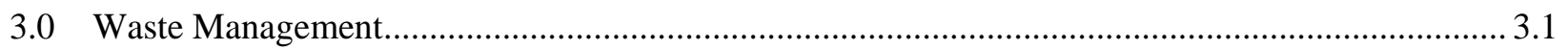

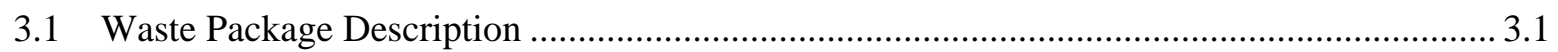

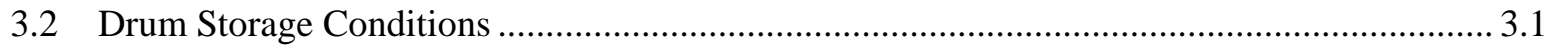

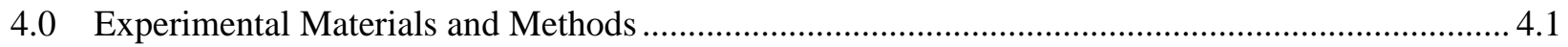

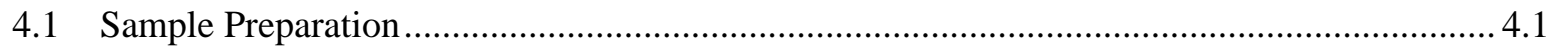

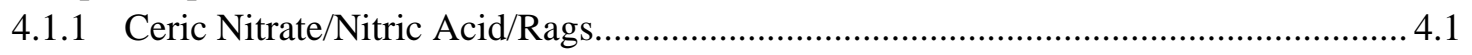

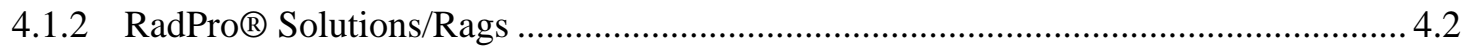

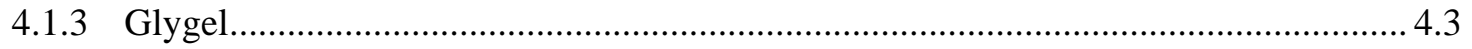

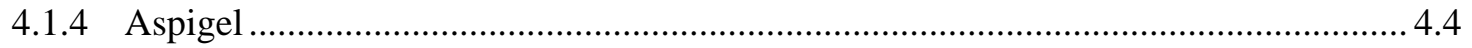

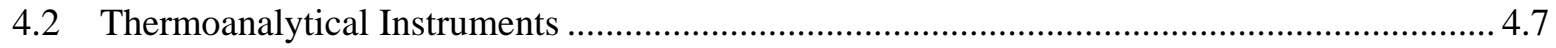

4.2.1 Differential Thermal Analysis/Thermogravimetry ............................................. 4.8

4.2.2 Accelerating Rate Calorimetry.......................................................................... 4.9

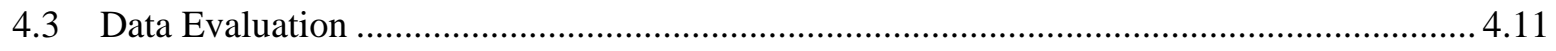

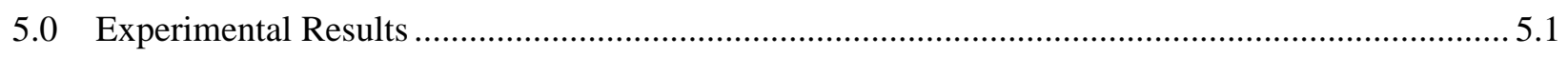

5.1 Thermal Reactivity of Simulated Cloth Decontamination Wastes Arising from Use

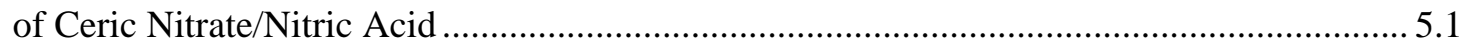

5.1.1 Thermal Reactivity of Simulated 86\% Cotton/14\% Polyester Cloth Wastes Arising from Use of Ceric Nitrate/Nitric Acid Decontamination Technology ............. 5.1

5.1.2 Thermal Reactivity of Ceric Nitrate/Nitric Acid Synthetic Cloths ............................ 5.17

5.1.3 Conclusions Regarding Thermal Reactivity of Cloth Wastes Arising from Ceric Nitrate/Nitric Acid Decontamination of Gloveboxes .............................................. 5.20

5.2 Thermal Behavior of Simulated Potential Wastes Arising from the Use of RadPro®

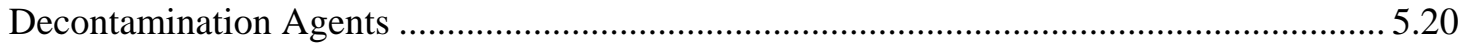

5.2.1 Thermal Behavior of Dried RadPro ${ }^{\circledR}$ Decontamination Solution (RadPro A) with Saturated Cotton Cloth..................................................................................... 5.21 
5.2.2 Thermal Behavior of Neutralized RadPro ${ }^{\circledR}$ Decontamination Solution Saturated Cotton Cloth.

5.2.3 Thermal Behavior of Dried RadPro ${ }^{\circledR}$ Decontamination + Rinsate Saturated Cotton

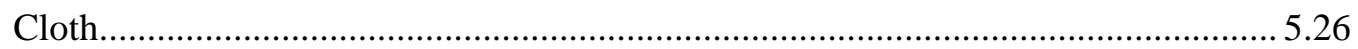

5.2.4 Thermal Behavior of RadPro ${ }^{\circledR}$ Rinsate (RadPro C) Saturated Cotton Cloth ............ 5.28

5.2.5 Thermal Behavior of Dried RadPro ${ }^{\circledR} 01$ Saturated Cotton Cloth ............................. 5.29

5.2.6 Thermal Behavior of Dried, RadPro ${ }^{\circledR}$ Emulsifier + Rinsate Saturated Cotton

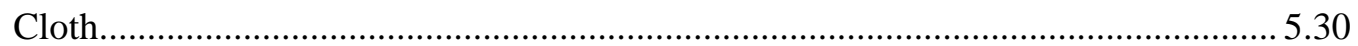

5.2.7 Thermal Behavior of Nominal Mixture of Cloth Wastes Arising from RadPro

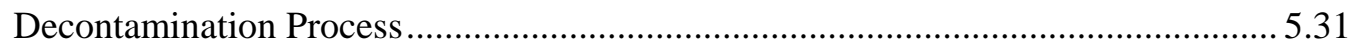

5.2.8 Thermal Behavior of RadPro® Solutions Saturated Synthetic Cloth ........................ 5.32

5.2.9 Summary/Conclusions Regarding Thermal Sensitivity of RadPro Wastes ............... 5.40

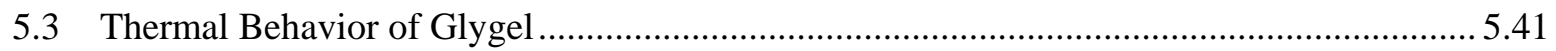

5.3.1 Thermal Behavior of Ceric Ammonium Nitrate ...................................................... 5.41

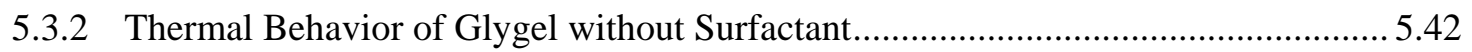

5.3.3 ARC-Measured Thermal Behavior of Glygel with surfactant .................................. 5.46

5.3.4 Conclusions Regarding the Thermal Stability of Potential Glygel Decontamination Process Wastes .............................................................................. 5.55

5.4 Thermal Behavior of Simulated Aspigel Wastes..................................................................5.56

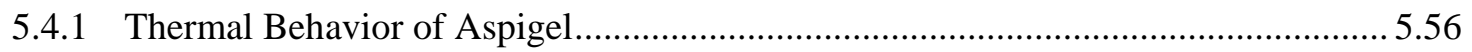

5.4.2 Thermal Behavior of Sodium Carbonate-Neutralized Aspigel ................................. 5.60

5.4.3 Thermal Behavior of Aspigel Sorbed on Cotton Cloth.............................................. 5.61

5.4.4 Thermal Sensitivity of Aspigel Mixed with Vacuum Filter Media ............................ 5.63

5.4.5 Bench Scale Testing of the Aspigel Waste ............................................................... 5.68

5.4.6 Conclusions Regarding Aspigel Thermal Stability ................................................ 5.68

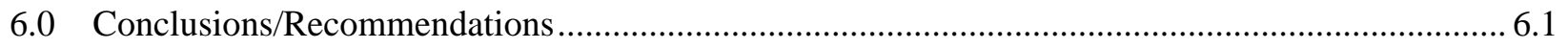

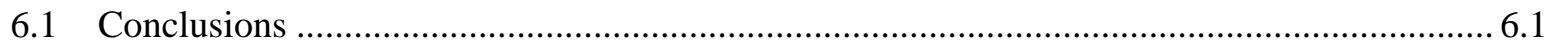

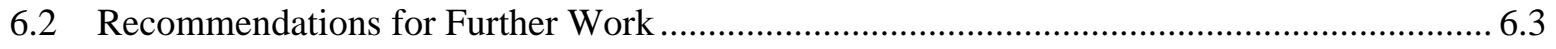

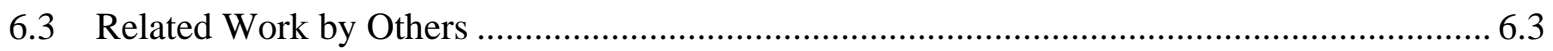

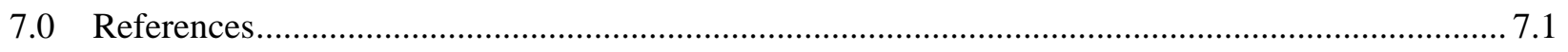

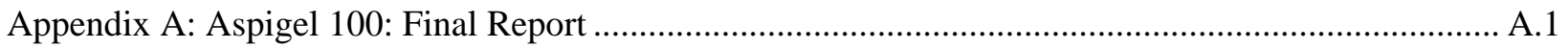




\section{Figures}

1.1. Hanford's Plutonium Finishing Plant (Richland 2005) 1.1

4.1. Representative Ceric Nitrate/Nitric Acid/Cotton Rag Decontamination Waste After Reduction and Neutralization

4.2. Reduced and Neutralized Ceric Nitrate/Nitric Acid/50\% Polyamide-50\% Polyester Rag 4.2

4.3. Preparation of RadPro A 4.3

4.4. Untreated Cotton Rag 4.3

4.5. RadPro A/ Cotton Rag 4.3

4.6. RadPro B/Cotton Rag

4.7. RadPro C/Cotton Rag 4.3

4.8. RadPro D/ Cotton Rag . 4.3

4.9. RadPro E/Cotton Rag. 4.3

4.10. Dried, Spent Glygel Decontamination Gel 4.4

4.11. Preparation of Aspigel 100 for Decontamination Treatment.

4.12. Mock-Up Glovebox Used for Application of Aspigel 100 Decontamination Treatment 4.6

4.13. Stainless Steel Coupons with Freshly Applied Aspigel 100. 4.6

4.14. Stainless Steel Panel Sprayed with Aspigel 100 and Air-Dried Overnight 4.7

4.15. Close-Up View of Crackling and Flaking in Dried Aspigel 100. 4.7

4.16. Partially Scraped and Vacuumed Aspigel-Treated Panel on Panel..... 4.8

4.17. Close-Up of Partially Scraped and Vacuumed Aspigel-Treated Panel. 4.8

4.18. Schematic of Accelerating Rate Calorimeter. 4.10

5.1. TG/DTA-Measured Thermal Behavior of $86 \%$ Cotton/14\% Polyester Cloth in Argon 5.2

5.2. TG/DTA-Measured Thermal Behavior of As-Received 86\% Cotton/14\% Polyester Cloth in Air ... 5.3

5.3. Arrhenius Plot of ARC-Measured Thermal Sensitivity of As-Received $86 \%$ Cotton/14\% Polyester Cloth in Residual Air

5.4. TGA/DTA-Measured Thermal Behavior in Argon of 42 day- old, Simulated Stabilized Ceric Nitrate/Nitric Acid Cotton Cloth Waste

5.5. Arrhenius Plot of ARC-Measured Thermal Behavior of Simulated 2-Day and 13-Day Old Stabilized Ceric Nitrate/Nitric Acid Cotton Cloth Waste.....

5.6. TGA/DTA-Measured Thermal Sensitivity in Argon of Simulated Stabilized Ceric Nitrate/ Nitric Acid Cotton Cloth Waste over 146 Days 
5.7. Arrhenius Plot of ARC-Measured Thermal Sensitivity of Dried, Ferrous Sulfate-Reduced, Sodium Hydroxide-Neutralized Ceric Nitrate/Nitric Acid/86\% Cotton/14\% Polyester Cloth After Aging 3, 14, 114, and 149 Days

5.8. Predicted Temperature for Drum of Cerium-Cotton Waste.

5.9. TGA/DTA-Measured Thermal Behavior of Stabilized Ceric Nitrate/Nitric Acid Cotton Cloth at $2^{\circ} \mathrm{C} / \mathrm{min}$.

5.10. DTA-Measured Thermal Behavior of Stabilized Ceric Nitrate/Nitric Acid Cotton Cloth at $5^{\circ} \mathrm{C} / \mathrm{min}$

5.11. DTA-Measured Thermal Behavior of Stabilized Ceric Nitrate/Nitric Acid Cotton Cloth at $10^{\circ} \mathrm{C} / \mathrm{min}$

5.12. DTA-Measured Thermal Behavior of Stabilized Ceric Nitrate/Nitric Acid Cotton Cloth at $20^{\circ} \mathrm{C} / \mathrm{min}$

5.13. Arrhenius Plot for DTA-Observed Exothermic Reaction 1 for Stabilized Ceric Nitrate/ Nitric Acid Cloth Waste

5.14. Arrhenius Plot for DTA-Observed Exothermic Reaction 2 for Stabilized Ceric Nitrate/ Nitric Acid Cloth Waste

5.15. TGA/DTA-Measured Thermal Behavior of 2-Day Old, Dried, Ceric Nitrate/Nitric Acid Cotton Cloth in Air at $10^{\circ} \mathrm{C} / \mathrm{min}$.....

5.16. ARC-Measured Thermal Behavior of Air-Dried Ceric Nitrate/Nitric Acid 86\%

Cotton/14\% Polyester Cloths as Measured by ARC.

5.17. TGA/DTA-Measured Thermal Behavior of As-Received 50\% Polyamide/50\% Polyester Cloth at $10^{\circ} \mathrm{C} / \mathrm{min}$

5.18. DTA-Measured Thermal Behavior of Stabilized Ceric Nitrate/Nitric Acid 50\% Polyamide $/ 50 \%$ Polyester Cloth at $10^{\circ} \mathrm{C} / \mathrm{min}$.

5.19. ARC-Measured Thermal Behavior of Dried, Stabilized Ceric Nitrate/Nitric Acid Soaked 50\% Polyamide/50\% Polyester Cloth

5.20. ARC-Measured Thermal Behavior of Ceric Nitrate/ Nitric Acid 20\% Polyamide/80\% Polyester Cloth.

5.21. TGA/DTA-Measured Thermal Sensitivity of Simulated RadPro A Decontamination Solution Waste at $10^{\circ} \mathrm{C} / \mathrm{min}$

5.22. ARC-Measured Thermal Sensitivity of Dried RadPro Decontamination Solution Saturated $100 \%$ Cotton Cloth

5.23. ARC-Measured Thermal Behaviors of Dried, Sodium Hydroxide Neutralized RadPro ${ }^{\circledR}$ Decontamination Solution Saturated Cotton Cloth.

5.24. ARC-Measured Thermal Behavior of Sodium Carbonate Neutralized RadPro Decontamination Solution Saturated Cotton Cloth.

5.25. TGA/DTA-Measured Thermal Behavior of 33\% RadPro ${ }^{\circledR}$ Decontamination/ $67 \%$ Rinsate Saturated Cotton Cloth Waste at $10^{\circ} \mathrm{C} / \mathrm{min}$. 5.26 
5.26. TGA/DTA-Measured Thermal Behavior of Dried RadPro ${ }^{\circledR}$ Decontamination + Rinsate (RadPro B) After Treating Stainless Steel Saturated Cotton Cloth at $10^{\circ} \mathrm{C} / \mathrm{min}$

5.27. ARC-Measured Thermal Sensitivity of Dried Cotton Cloths Saturated with 33\% RadPro Decontamination/67\% Rinsate Solution Either by Soaking or by Removing from an SST Coupon

5.28. TGA/DTA-Measured Thermal Behavior of RadPro ${ }^{\circledR}$ Rinsate Saturated Cotton Cloth at $10^{\circ} \mathrm{C} / \mathrm{min}$ in Air

5.29. TGA/DTA-Measured Thermal Behavior of Dried, RadPro ${ }^{\circledR} 01$ Saturated Cotton Cloth at $10^{\circ} \mathrm{C} / \mathrm{min}$

5.30. TGA/DTA-Measured Thermal Behavior of Dried RadPro ${ }^{\circledR}$ Emulsifier + Rinsate Saturated Cotton Cloth at $10^{\circ} \mathrm{C} / \mathrm{min}$ in Air

5.31. ARC-Measured Thermal Behavior of a Mixture of $1.26 \mathrm{~g}$ Dried RadPro 0100 Saturated Cotton Cloth + Sodium Hydroxide-Neutralized RadPro Decontamination Solution (RadPro A) Saturated Cotton Cloth

5.32. ARC-Measured Thermal Behavior of Dried, RadPro Decontamination Solution Saturated 20\% Polyamide/80\% Polyester Cloth

5.33. Arrhenius Plot of ARC-Measured Thermal Sensitivity of 4 and 304-Day Old Sodium Carbonate-Neutralized RadPro Decontamination Solution (RadPro A) Saturated 20\% Polyamide/80\% Polyester Synthetic Cloth

5.34. TGA/DTA-Measured Thermal Behavior of RadPro ${ }^{\circledR}$ Decontamination Solution Saturated $50 \%$ Polyamide $/ 50 \%$ Polyester Synthetic Cloth at $10^{\circ} \mathrm{C} / \mathrm{min}$

5.35. DTA-Measured Thermal Behavior of Air-Dried RadPro Decontamination Solution Saturated 50\% Polyamide/50\% Polyester Cloth at 6, 18, and 42 Days

5.36. TGA/DTA-Measured Thermal Behavior of Mixed RadPro Decontamination-Rinsate Solution at $10^{\circ} \mathrm{C} / \mathrm{min}$

5.37. TGA/DTA-Measured Thermal Behavior of Dried RadPro Rinsate Saturated $50 \%$ Polyamide $/ 50 \%$ Polyester Cloth at $10^{\circ} \mathrm{C} / \mathrm{min}$

5.38. ARC-Measured Thermal Behavior of RadPro Decontamination-Rinsate Solution Saturated 50\% Polyamide/50\% Polyester Cloth

5.39. TGA/DTA-Measured Thermal Behavior of RadPro 0100 Saturated 50\% Polyamide-50\% Polyester at $10^{\circ} \mathrm{C} / \mathrm{min}$ in Air.

5.40. TGA/DTA-Measured Thermal Behavior of RadPro Emulsifier-Rinsate Solution Saturated $50 \%$ Polyamide- $50 \%$ Polyester Cloth at $10^{\circ} \mathrm{C} / \mathrm{min}$ in Air

5.41. TGA/DTA-Measured Thermal Behavior of Ceric Ammonium Nitrate at $5{ }^{\circ} \mathrm{C} / \mathrm{min}$ in Air 5.42

5.42. ARC-Measured Thermal Behavior of Ceric Ammonium Nitrate 5.43

5.43. TGA/DTA-Measured Thermal Behavior of Glygel Without Surfactant in Air at $10^{\circ} \mathrm{C} / \mathrm{min}$ 5.44

5.44. MS-Measured Evolved Gas Composition from Glygel Without Surfactant in Air at $10^{\circ} \mathrm{C} / \mathrm{min} . . .5 .44$ 
5.45. Arrhenius Plot of ARC-Measured Thermal Sensitivity of Air-Dried and Freeze-Dried

Glygel Without Surfactant 5.45

5.46. TGA/DTA-Measured Thermal Behavior of Glygel with Surfactant in Air at $10^{\circ} \mathrm{C} / \mathrm{min}$ 5.46

5.47. TGA/DTA Measured Thermal Behavior of Glygel with surfactant at $5^{\circ} \mathrm{C} / \mathrm{min}$ in $\mathrm{Ar}$ 5.47

5.48. Masses $18\left(\mathrm{H}_{2} \mathrm{O}\right), 30(\mathrm{NO}), 40\left(\mathrm{C}_{3} \mathrm{H}_{4}\right)$, and $44\left(\mathrm{CO}_{2}, \mathrm{~N}_{2} \mathrm{O}, \mathrm{C}_{3} \mathrm{H}_{8}\right)$ in Evolved Gas During

TGA/DTA Analysis of Glygel with Surfactant in Air at $10^{\circ} \mathrm{C} / \mathrm{min}$

5.49. Arrhenius Plot of ARC-Measured Thermal Behavior of Dried PFP-Supplied Glygel with Surfactant.

5.50. Arrhenius Plot Comparison of ARC-Measured Thermal Sensitivity of Freeze-Dried Glygel with Surfactant

5.51. Arrhenius Plot of ARC-Measured Thermal Sensitivity of PFP-Supplied Glygel with

Surfactant in a 1:1 Mass Ratio Mixture with Sodium Carbonate

5.52. TGA/DTA-Measured Thermal Behavior of Mixture of Glygel with Surfactant and Filter Media

5.53. Masses $12(\mathrm{C}), 18\left(\mathrm{H}_{2} \mathrm{O}\right), 30(\mathrm{NO}), 44\left(\mathrm{CO}_{2}, \mathrm{~N}_{2} \mathrm{O}, \mathrm{C}_{3} \mathrm{H}_{8}\right)$, and $46\left(\mathrm{NO}_{2}\right)$ in Evolved Gas During TGA/DTA Analysis of Glygel with Surfactant/Filter Media in Ar at $10^{\circ} \mathrm{C} / \mathrm{min}$ 5.53

5.54. Arrhenius Plot of ARC-Measured Thermal Sensitivity of Dried Glygel with Filter Media 5.54

5.55. Sample Container After 8-g ARC Analysis of Glygel-Filter Media Mixture 5.54

5.56. Sample Container after 2-g ARC Analysis of Glygel-Filter Media Mixture. 5.54

5.57. Arrhenius Plot of ARC-Measured Thermal Sensitivity of Glygel on Cotton Cloth 5.55

5.58. Fluor TGA/DTA Measured Thermal Behavior of Aspigel at $10^{\circ} \mathrm{C} / \mathrm{min}$ in Argon .... 5.57

5.59. Selected MS-Identified Components Produced During TGA/DTA of Aspigel at $10^{\circ} \mathrm{C} / \mathrm{min}$ in Argon 5.58

5.60. PNNL TGA/DTA-Measured Thermal Behavior of Aspigel at $5^{\circ} \mathrm{C} / \mathrm{min}$ 5.59

5.61. Arrhenius plot of ARC-Measured Thermal Sensitivity of Aspigel Samples..... 5.60

5.62. Arrhenius Plot of ARC-Measured Thermal Sensitivity of Sodium Carbonate-Neutralized Aspigel Recovered from DataVac3 Filter.

5.63. Arrhenius Plot of ARC-Measured Thermal Behavior of Aspigel Sorbed in Cotton Cloth. 5.62

5.64. Arrhenius Plot of ARC-Measured Thermal Sensitivity of Neutralized 90-day old Aspigel on Cotton Cloth Used to Clean Mixing Rotor

5.65. Arrhenius Plot of ARC-Measured Thermal Behavior of Aspigel with DataVac 3 Inner and Outer Filters

5.66. Arrhenius Plot of ARC-Measured Thermal Behavior of Aspigel on DataVac 3 Inner Filter. 5.65

5.67. Arrhenius Plot of ARC-Measured Thermal Sensitivity of Sodium Carbonate-Neutralized Aspigel and Sodium Carbonate-Neutralized DataVac 3 Filter. 
5.68. Arrhenius Plot of ARC-Measured Thermal Behavior of Aspigel with and Without Shark Vacuum Cleaner Filter.

5.69. FTIR Spectra of Gas Following ARC Runs of Aspigel with Shark Filter, Cotton Cloth, and Neutralized Data Vac Filters.. 


\section{Tables}

2.1. Half-Cell Reactions for Ceric Ion Treatment (Lide 2004, Fuger \& Oetting 1976,

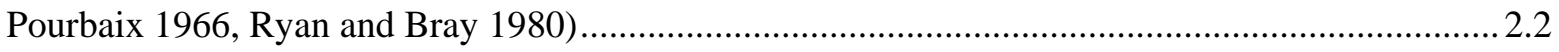

2.2. MSDS-Provided Compositions of RadPro ${ }^{\circledR}$ Solutions ................................................................. 2.3

4.1. Composition of RadPro Solutions Used for Testing....................................................................... 4.2

5.1. Peak Maxima for DTA-Observed Exotherms for Simulated Stabilized Ceric Nitrate/Nitric Acid Cotton Cloth Decontamination Waste ............................................................................. 5.12

5.2. Reaction Rate Constants at Various Temperatures for DTA-Observed Exothermic Reactions for Stabilized Ceric Nitrate/Nitric Acid Cloths ............................................................................ 5.14

5.3. Representative RadPro Solutions Used for Testing ...................................................................... 5.21

5.4. MSDS-Provided Compositions of RadPro ${ }^{\circledR}$ Solutions ................................................................... 5.22

5.5. Mass Spectrometer Observed Masses of Potential Gaseous Species from Glygel .........................5.48 


\subsection{Introduction}

Fluor Hanford (Fluor) is preparing to decommission the Plutonium Finishing Plant (PFP) at the Department of Energy's (DOE) Hanford Site located in Southeastern Washington State. Operations began at the PFP in 1949. The PFP obtained plutonium (Pu) nitrate solutions from Hanford's nuclear fuel reprocessing facilities and also received plutonium scrap from Hanford and other DOE sites. The PFP purified the scrap by solvent extraction processes and then converted the purified plutonium into solid metal ingots or oxide powder. The metal ingots were then shipped to other government site's weapons fabrication facilities. Some metal also was fabricated into weapons shapes at the PFP. Much of the oxide powder was used for reactor fuels. Figure 1.1 provides a picture of the PFP.

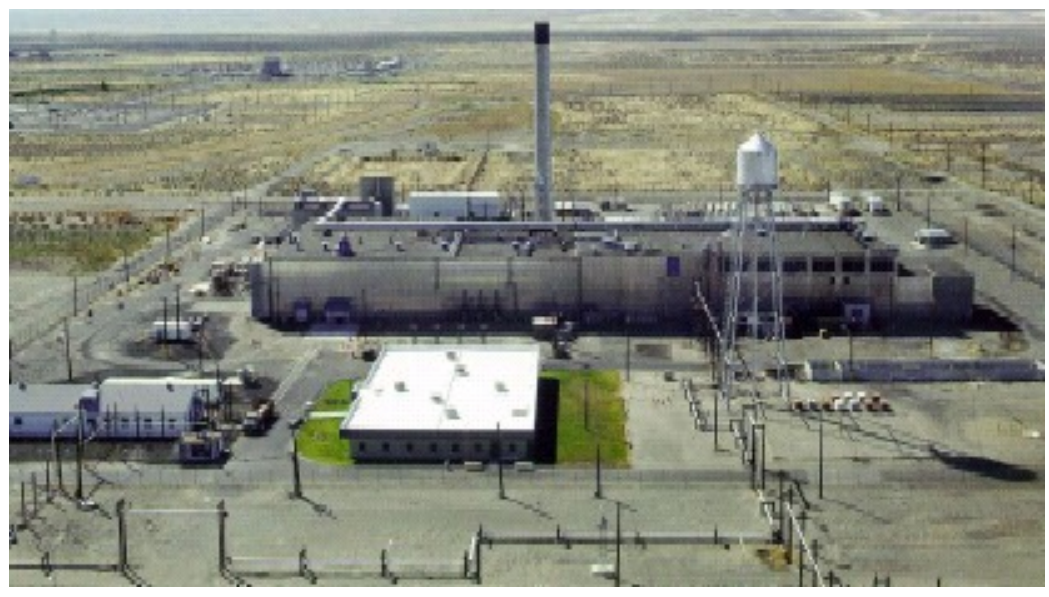

Figure 1.1. Hanford’s Plutonium Finishing Plant (Richland 2005)

To decommission the PFP, the Pu-contaminated gloveboxes used for these operations must be decontaminated for disposal as non-transuranic (TRU) waste. The contamination is present on the inside stainless steel glovebox surfaces as loose powder and as material sorbed more intimately in the stainless steel. Decontamination agents that can dissolve both the Pu and the surface layers of the stainless steel have been shown to be effective decontamination agents. Potential decontamination agents for these Pucontaminated gloveboxes include 1$)$ aqueous ceric $\left(\mathrm{Ce}^{4+}\right)$ nitrate/nitric acid, 2) a proprietary commercial aqueous solution, RadPro, containing acids, degreasers, and sequestering agents, and 3) commercial inorganic-based gels (Glygel ${ }^{\circledR}$ and Aspigel ${ }^{\circledR}$ ) using ceric ammonium nitrate/nitric acid as the active agent. All three agents work primarily by converting the Pu to a nitric acid soluble oxidation state or by etching or removing the top layer of the metal.

Fluor is considering two basic types of decontamination agents, aqueous solutions and gels. In general, 1) Fluor will apply the decontaminating solution as a spray onto the contaminated surfaces, 2) the TRUbearing solution will be removed from the glovebox surface using cloth rags, 3) the ceric ion will be reduced by ferrous sulfate, 4) the acid in the rags will be neutralized, and then 5) the TRU-laden rags will be packaged for disposal as TRU waste. The nominal process for the decontamination gels involves 
- spraying or painting the ceric-laced gel onto the contaminated surface

- $\quad$ allowing the gel to dry

- allowing it to fall off or to scrape or brush the loose dried gel from the surface

- collecting the dried gel by sweeping or vacuuming using a small hand-held vacuum

- packaging the TRU-laden gel and vacuum filter, as applicable, as TRU waste.

These wastes will be collected in 210-L (55-gal) TRU waste drums and stored at the Hanford Site until they can be disposed of to the Waste Isolation Pilot Plant (WIPP).

Each of the resulting decontamination wastes will contain chemically intimate mixtures of oxidizers (ceric ion and nitrate from the nitric acid, ceric nitrate, and ceric ammonium nitrate) and fuel (rags, ammonium ion, and organic complexants, sequestering agents, and surfactants). A fire involving ceric nitrate-containing cotton rags occurred at Rocky Flats in 2003 (Beyler 2004). Because of this fire and the potential for chemical reactions between the oxidizers and fuel in the similar candidate decontamination wastes, Fluor has safety concerns regarding self-sustaining reactions during decontamination operations and during interim storage of the resulting wastes. The storage safety is further compromised on the Hanford site where temperatures at Pacific Northwest National Laboratory's (PNNL's) Hanford Meteorological Station have reached a maximum $45^{\circ} \mathrm{C}\left(113^{\circ} \mathrm{F}\right)$ (PNNL 2005). The higher temperatures can help inititate and accelerate the reactions of the oxidizers and fuel present in the decontamination wastes.

The investigation to determine the cause of the 2003 Rocky Flats fire was inconclusive because it was hampered by the copious use of chemicals and water used to extinguish the fire. This compromised the conditions of the materials that had been burning. However, the investigators determined that the fire originated within the debris pile in the glovebox. The debris included both cerium- and nitric acidcontaining cotton rags and leaded glovebox gloves, suggesting that the combination of rags and chemicals may have contributed to the fire (Beyler 2004). Beyler (2004) postulated that the most likely cause was impact ignition of nitric acid-degraded leaded gloves.

With the uncertainty regarding the cause of the fire and the proposed use at PFP of ceric decontamination agents, Fluor assembled a team of its own operations staff and scientists and PNNL researchers to investigate the potential for fire or self-sustaining reactions for decontamination waste materials when using the Rocky Flats waste management approach.

This report provides the results of our studies to characterize the stability of decontamination process wastes and a strategy for providing a chemically stable TRU decontamination waste form at potential Hanford storage conditions. To achieve our goals, we used an empirical investigation to determine the thermal sensitivity of potential waste compositions composed of the aforementioned decontamination agents, bases for neutralizing the acid, ferrous sulfate for reducing the ceric ion, absorbent materials, and vacuum filter media at and above expected interim storage conditions. In particular, we attempted to identify a strategy that prevents or mitigates any low-temperature self-heating reactions. We also used chemical modeling of low temperature reactivity to predict the behavior of the decontamination wastes during storage. 


\subsection{Evaluated Decontamination Strategies}

Glovebox decontamination procedures are tailored for the specific chemicals used, but each of them has the following basic steps:

- The decontaminating agent or decontaminating system (a solution, or sequence of solutions, or gel) is applied to the contaminated surface, generally by spraying or brushing;

- The decontamination agent(s) is allowed to dwell on the surface either for a specified period of time or until an observable chemical or physical change occurs to assure maximum transfer of the contamination into the decontamination agent(s);

- The residual decontamination agent(s) is removed, generally by absorption on towels or rags or by vacuuming;

- The contaminated towels or rags or residual material are packaged in plastic bags, sealed out of the glovebox, and disposed of into 210-L (55-gal) waste drums.

Fluor has considered four different decontamination methods. Three of these methods are based on ceric ion and nitric acid, and the fourth uses a combination of organic complexants, nitric and hydrochloric acids, and organic sequestering agents. The four decontamination processes are described briefly in the following sections.

\subsection{Cerium Nitrate Decontamination Process Description}

The ceric nitrate/nitric acid decontamination method involves spraying a solution of $0.25 \underline{\mathrm{M}}$ ceric nitrate/ $1 \underline{\mathrm{M}}$ nitric acid onto the walls of a contaminated glovebox, allowing the solution to react, and then wiping off the solution. The rags used to remove the decontamination solution from glovebox surfaces have been towels or cloths typically made of $86 \%$ cotton with $14 \%$ polyester.

Once a rag is mostly damp from absorbing the decontamination solution, it is treated with a $0.3 \underline{\mathrm{M}}$ ferrous sulfate $\left(\mathrm{FeSO}_{4}\right)$ solution to reduce the highly oxidizing ceric ion $\left(\mathrm{Ce}^{+4}\right)$ to the non-oxidizing cerous ion $\left(\mathrm{Ce}^{+3}\right)$ whereas the ferrous ion $\left(\mathrm{Fe}^{+2}\right)$ from the $\mathrm{FeSO}_{4}$ is oxidized to ferric ion $\left(\mathrm{Fe}^{+3}\right)$. The $\mathrm{FeSO}_{4}$ treatment thus supposedly decreases the hazard of having the strong $\mathrm{Ce}^{+4}$ oxidant remain in continued contact with the fuel present as the rag. At this point, the rag is saturated with the decontamination and $\mathrm{FeSO}_{4}$ and $\mathrm{Fe}\left(\mathrm{NO}_{3}\right)_{3}$ solutions. Excess liquid is wrung from the rag with the wringing also serving to distribute the chemicals more evenly throughout the rag. The remaining nitric acid in the rag is then neutralized with a $2.6 \underline{\mathrm{M}}$ sodium hydroxide solution (or 2 normal sodium carbonate). This alkaline treatment is sufficient to neutralize the acid and furnish enough hydroxide ion to precipitate the cerous and ferric ions as their respective hydroxides or hydrous oxides. The total volume of alkaline solution is the same volume as that of the combined ceric/nitric decontamination solution and ferrous sulfate solution.

The waste from this process would be rags holding solution having a nominal composition of $0.25 \underline{\mathrm{M}}$ $\mathrm{Ce}(\mathrm{OH})_{3}, 1.25 \underline{\mathrm{M}} \mathrm{NaNO}_{3}, 0.25 \underline{\mathrm{M}} \mathrm{Fe}(\mathrm{OH})_{3}, 0.05 \underline{\mathrm{M}} \mathrm{Fe}(\mathrm{OH})_{2}, 0.3 \underline{\mathrm{M}} \mathrm{NaSO}_{4}$, and excess $\mathrm{NaOH}$ or $\mathrm{Na}_{2} \mathrm{CO}_{3}$, assuming that the $\mathrm{Pu}$ is compositionally insignificant. These rags would then be sealed out of the glovebox into a waste drum. The nitrate and the rag material comprise the reactive materials of concern in this system. The hydrous oxides, the sodium sulfate, and the residual water are chemically inert. However, these inert constituents can absorb heat produced by potential reactions between nitrate 
and the organic rag and thus mitigate the risk from a potential self-sustaining reaction. Water is the most effective heat absorber in this system because of its high heat capacity $\left(4.184 \mathrm{~J} / \mathrm{g}-{ }^{\circ} \mathrm{C}\right)$ and especially by its heat absorption caused by evaporation at temperatures up to $100^{\circ} \mathrm{C}(\sim 2450 \mathrm{~J} / \mathrm{g})$.

The steps in the decontamination process are easy to implement and verify in the field. The decontamination solution imparts an orange shade to the rag, typical of ceric solutions. The ferrous sulfate solution eliminates the ceric ion color (cerous ion is colorless) with a shift toward the beige because of the ferrous and ferric ions. The sodium hydroxide addition initially turns the rags dark bluish green, but this color turns to the red-orange of rust as the excess ferrous compounds oxidize and convert to ferric oxides during drying. The color changes allow workers to see both how well the chemicals have covered the rags and how well they are mixed in the rags.

The chemical basis for the PNNL-developed ceric/nitric acid process (Kurath et al. 1997a; 1997b) is that the $\mathrm{Ce}^{4+}$ oxidatively dissolves the $\mathrm{PuO}_{2}$ solids (the most common form of contamination on the glovebox surfaces) to form dissolved $\mathrm{Pu}(\mathrm{VI})$. The ceric-based process has the added advantage that the glovebox stainless steel metal oxide surface layer also is dissolved, freeing any Pu that has permeated the metal surface. Scheele et al. (2005) provides additional details about the use of ceric ion as a decontaminating agent for various radioactively contaminated items, including stainless steel tanks from Hanford's Critical Mass Laboratory.

The key to the ceric ion technology's decontamination effectiveness is ceric ion's high oxidizing potential $\left(\mathrm{E}^{0}=1.72\right.$ volts). This potential is greater than that of most materials, including $\mathrm{PuO}_{2}$. As provided in Table 2.1, the metals commonly used in industry (such as stainless and carbon steels and nickel) and even the $\mathrm{Cr}_{2} \mathrm{O}_{3}$ protective layer afforded by stainless steel should be oxidized by $\mathrm{Ce}^{4+}$. Thus, in addition to oxidizing the $\mathrm{Pu}$ in $\mathrm{PuO}_{2}$, ceric ion treatment oxidizes and dissolves the underlying metal surface, allowing the ceric ion access to contaminants ingrained within the metal surface. For stainless steel, the transpassive potential for corrosion in $1 \underline{\mathrm{M}} \mathrm{HNO}_{3}$ is $1.219 \mathrm{~V}$ (Suresh et al. 2003) which is near the reduction potential for dichromate of $1.242 \mathrm{~V}$. The ceric ion works by dissolving the $\mathrm{Cr}_{2} \mathrm{O}_{3}$ passive layer by imparting a potential higher than the transpassive potential for the stainless steel.

Table 2.1. Half-Cell Reactions for Ceric Ion Treatment (Lide 2004, Fuger and Oetting 1976, Pourbaix1966, Ryan and Bray 1980)

\begin{tabular}{|c|c|}
\hline Half-Cell Reaction & $\mathbf{E}^{\mathbf{0}}$, Volts \\
\hline $\mathrm{PuO}_{2}{ }^{2+}+2 \mathrm{e}^{-} \rightleftarrows \mathrm{Pu}^{4+}$ & 1.032 \\
\hline $\mathrm{PuO}_{2}{ }^{2+}+2 \mathrm{e}^{-} \rightleftarrows \mathrm{PuO}_{2}$ & 1.24 \\
\hline $\mathrm{Ce}^{4+}+\mathrm{e}^{-} \rightleftarrows \mathrm{Ce}^{3+}$ & 1.72 \\
\hline $\mathrm{Cr}^{2+}+2 \mathrm{e}^{-} \rightleftarrows \mathrm{Cr}$ & -0.913 \\
\hline $\mathrm{Cr}^{3+}+3 \mathrm{e}^{-} \rightleftarrows \mathrm{Cr}$ & -0.744 \\
\hline $\mathrm{Fe}^{2+}+2 \mathrm{e}^{-} \rightleftarrows \mathrm{Fe}$ & -0.447 \\
\hline $\mathrm{Fe}^{3+}+3 \mathrm{e}^{-} \rightleftarrows \mathrm{Fe}$ & -0.037 \\
\hline $\mathrm{Ni}^{2+}+2 \mathrm{e}^{-} \rightleftarrows \mathrm{Ni}$ & -0.257 \\
\hline $\mathrm{Cr}_{2} \mathrm{O}_{7}{ }^{2-}+4 \mathrm{e}^{-} \rightleftarrows 2 \mathrm{Cr}_{2} \mathrm{O}_{3}$ & 1.242 \\
\hline
\end{tabular}




\subsection{RadPro ${ }^{\circledR}$ Decontamination Process Description}

The RadPro ${ }^{\circledR}$ decontamination process, like the ceric nitrate/nitric acid process, uses aqueous solutions of active chemicals that will effectively dissolve $\mathrm{PuO}_{2}$ and other transuranics. The RadPro ${ }^{\circledR}$ system, however, uses proprietary chemicals; Table 2.2 shows the Material Safety Data Sheets (MSDS)-provided composition of the three solutions used in the RadPro ${ }^{\circledR}$ system. Without ceric ion, however, the mechanism of contaminant dissolution in RadPro differs from that of the ceric nitrate/nitric acid process.

Table 2.2. MSDS-Provided Compositions of RadPro ${ }^{\circledR}$ Solutions

\begin{tabular}{|c|c|c|c|c|c|}
\hline \multicolumn{6}{|c|}{ RadPro ${ }^{\circledR}$ Solutions } \\
\hline \multicolumn{2}{|c|}{ RadPro $^{\circledR} 0100$} & \multicolumn{2}{|c|}{ RadPro $^{\circledR} 0200$} & \multicolumn{2}{|c|}{ RadPro $^{\circledR} 0300$} \\
\hline Ingredient & $\begin{array}{c}\text { Concentration, } \\
\%\end{array}$ & Ingredient & $\begin{array}{c}\text { Concentration, } \\
\%\end{array}$ & Ingredient & $\begin{array}{c}\text { Concentration, } \\
\%\end{array}$ \\
\hline $\begin{array}{l}\text { Ethylene } \\
\text { glycol } \\
\text { monobutyl } \\
\text { ether }\end{array}$ & $5-15$ & $\begin{array}{c}\text { Hydrochloric } \\
\text { acid }\end{array}$ & $1-5$ & Nitric Acid & $5-25$ \\
\hline Triethylamine & $0-1$ & $\begin{array}{l}\text { Ammonium } \\
\text { fluoride }\end{array}$ & $2-5$ & $\begin{array}{l}\text { Chemical } \\
\text { buffering } \\
\text { agents and } \\
\text { water }\end{array}$ & ? \\
\hline Isopropanol & $0-2$ & Citric acid & $1-3$ & & \\
\hline $\begin{array}{l}\text { Potassium } \\
\text { hydroxide }\end{array}$ & $1-5$ & & & & \\
\hline $\begin{array}{l}\text { Other } \\
\text { emulisifiers, } \\
\text { surfactants, } \\
\text { organic } \\
\text { sequestrants, } \\
\text { and water }\end{array}$ & ? & & & & \\
\hline
\end{tabular}

These three solutions are used in various combinations or alone in the specific sequence:

- $\quad$ A buffered acidic degreaser (75\% RadPro ${ }^{\circledR} 0200,25 \%$ RadPro $\left.{ }^{\circledR} 0300\right)$ is sprayed onto the glovebox interior surfaces and lightly scrubbed (decontamination solution).

- After the specified dwell time, the interior is thoroughly rinsed with a nitric acid-based rinsate solution (10\% RadPro ${ }^{\circledR} 0300,90 \%$ demineralized water) (rinsate). The process is repeated as necessary, and the residual liquid is absorbed on cotton towels, neutralized with sodium carbonate, and packaged as waste (rinsate).

- An emulsifying solution (RadPro ${ }^{\circledR} 0100$ ) is then sprayed onto the glovebox interior surfaces and allowed to dwell. 
- After the specified dwell time, the interior is thoroughly rinsed with the rinsate solution (10\% RadPro $^{\circledR} 0300,90 \%$ demineralized water). The process is repeated as necessary, and the residual liquid is absorbed on cotton towels, neutralized with sodium carbonate, and packaged as waste.

On their website http://www.eai-inc.com/corporate/tech-leadership.asp\#1, Environmental Alternatives, Inc. (EAI), the manufacturer of RadPro ${ }^{\circledR}$, describes their decontamination technology as a process to extract and encapsulate all radionuclide contaminants up to 2 inches below the substrate surface. EAI claims the process can be used for decontaminating concrete, cinder block, brick, tile, asphalt, transite, wood, cast iron, steel, stainless steel, and other metals including exotic metals. The mentioned metals, in particular, the steel and stainless steel, will be contaminated components of the glovebox. Although not specifically mentioned, the process appears applicable to glass, the other major component of gloveboxes, based on the silicate materials identified.

The wastes from the RadPro ${ }^{\circledR}$ decontamination process will be rags containing decontamination solution (RadPro 0200 and 0300) mixed with rinsate and RadPro ${ }^{\circledR} 0100$ mixed with rinsate. Both solutions contain mixtures of organic fuels and oxidizer nitrate.

The combined decontamination and rinsate solution and rag mixture will contain nitrate, ammonium ion, and citrate; the nature of the buffering agents in RadPro ${ }^{\circledR} 0300$ is unknown to us. Although citrate likely is a small contributor to the RadPro ${ }^{\circledR}$ waste, citrate can react with nitrate. Scheele et al. (1995) reported exothermic reactions beginning near $50^{\circ} \mathrm{C}$ using accelerating rate calorimetry (ARC) for 1-g samples containing 6 mass\% total organic carbon (TOC) in mixtures of sodium citrate and sodium nitrate.

The RadPro ${ }^{\circledR} 0100$ and rinsate mixture will also contain nitrate and organic fuels, although the nitrate concentration should be much less than that of the decontamination/rinsate solution. This mixture could contain ethylene glycol monobutyl ether, triethylamine, isopropanol, organic sequestrants, and surfactants as fuel with the nitrate.

Overall, the same nitrate/rag reaction risk exists for the RadPro ${ }^{\circledR}$ decontamination solution-containing rag waste as with the ceric nitrate/nitric process rag waste; the relative risk should depend on the nitrate content and the other organic content. The contributions of the various organics to the thermal reactivity are unknown.

\subsection{Glygel Decontamination Process Description}

The MSDS provided by RJ Lee Group of Pasco, WA, describes Glygel Ox (Glygel) as a gel for nuclear decontamination of stainless steels. Glygel is composed of ammonium cerium (IV) nitrate [( $\left.\left(\mathrm{NH}_{4}\right)_{2} \mathrm{Ce}\left(\mathrm{NO}_{3}\right)_{6}\right]$, nitric acid, and fumed silica. The material Surfactant TA-96, which is described by its MSDS as diethylene glycol monohexyl ether, is added to the Glygel just before use.

The expected procedure for use of the Glygel decontamination process is to:

- Mix Glygel Ox with Surfactant TA-96;

- Apply by brushing or spraying onto surface; the gel must be applied before the Surfactant TA-96 consumes the active $\mathrm{Ce}^{4+}$. 
- Allow Glygel to work and dry for 24 hours; a color change from the characteristic $\mathrm{Ce}^{4+}$ orange to white indicates completion of the treatment.

- Remove dried Glygel by scraping or brushing;

- Recover Glygel particles using handheld vacuums or sweeping.

The chemical decontamination technology employed by the Glygel decontamination process is similar to that of ceric nitrate/nitric acid. Ceric ion is used to oxidizatively dissolve the $\mathrm{PuO}_{2}$ and surface stainless steel layer. The added feature of the Glygel process is the use of fumed silica to cause the $\mathrm{Ce}^{4+}$ to adhere to the target surfaces and to absorb the Pu-containing nitric acid solution to facilitate removal. In comparison to the ceric nitrate/nitric acid technology, the Glygel process introduces an organic surfactant to improve adsorption onto the surface to be decontaminated and uses ceric ammonium nitrate, which introduces ammonium ion into the system.

The waste arising from the proposed PFP Glygel decontamination process will consist of the spent silica gel containing the $\mathrm{Pu}$, metal ions from the stainless steel, ammonium ion, cerous nitrate, nitric acid, the surfactant, and the vacuum filter, assuming that the filter is not separated from the spent gel. The oxidizers in this waste are nitrate and possible residual ceric ion. The fuels are ammonium ion, the surfactant, and the vacuum filter. The silica is not an oxidant or fuel and serves as a diluent to decrease the rate of any reaction that might occur. The $\mathrm{Pu}, \mathrm{Ce}$, and other metal ions could act as catalysts.

The MSDS recommends treating the waste with ferrous sulfate until the orange color vanishes (to reduce the excess ceric ion), neutralizing with soda (sodium carbonate or bicarbonate) or sodium hydroxide, filtering, and treating the filtrate to $\mathrm{pH} 6.5$.

\subsection{Aspigel Decontamination Process Description}

The Aspigel 100 (Aspigel) decontamination process was added after thermal stability studies of the Glygel process, with its surfactant, showed increased reactivity at lower temperatures compared with the ceric nitrate/nitric acid process. According to the MSDS provided by CEA VALRHO for Aspigel 100, the Aspigel composition is similar to that of Glygel but has no organic surfactant and has added alumina $\left(\mathrm{Al}_{2} \mathrm{O}_{3}\right)$.

The chemistry used by the Aspigel process is the same as that of the Glygel process. Based on a comparison of the two MSDS provided compositions, the alumina provides the surface adhesion afforded by the surfactant in Glygel and thus increases the contact residence time of the ceric ion on the glovebox surface.

The expected procedure for use of Aspigel at PFP is the same as that for Glygel with the exception that the surfactant will not be added, and the application time is not controlled by the surfactant consumption of the $\mathrm{Ce}^{4+}$.

The waste arising from the proposed Aspigel decontamination process will consist of the spent mixed silica/alumina gel containing $\mathrm{Pu}$, metal ions from the stainless steel, ammonium ion, cerous ion, residual ceric ion, nitric acid, and the vacuum filter, assuming the filter remains with the recovered gel. The oxidizers in this waste are nitrate and any residual ceric ion. The fuels are ammonium ion, the surfactant, 
and the vacuum filter. The silica and alumina serve as diluents and will reduce the rate of any reaction that might occur. The metal ions could act as catalysts.

The MSDS for Aspigel 100 suggests a similar disposal strategy to that for Glygel. Instead of the ferrous sulfate used in the Glygel process to eliminate the excess ceric, the Aspigel process calls for hydrogen peroxide. The residue then is acid-neutralized with calcium carbonate or sodium hydroxide and filtered, and the filtrate is adjusted to $\mathrm{pH} 7$. 


\subsection{Waste Management}

The waste management strategy to be used for the TRU wastes arising from decontaminating PFP gloveboxes is dictated by regulations, radiological conditions, environmental conditions, and complications from glovebox operations. This section describes the waste package and expected storage conditions at the Hanford Site.

\subsection{Waste Package Description}

The PFP gloveboxes have ports with 12-mil polyvinyl chloride (PVC) bags attached to seal out waste. The port size varies from 8 to 36 inches, and typical sizes are 8-, 11-, and 15-inch diameter. All seal out bags contain NucFil high-efficiency particulate air (HEPA) filters on the bag, and the drums are vented with NucFil HEPA filters to prevent the accumulation of gases within the drum or storage boxes. Depending on the path of waste from the glovebox to the drum, additional vented bag(s) may be placed over the original sealout bag. In all cases, a vent path is maintained.

Waste drums are limited to a maximum of 1 vol\% free liquids in accordance with WIPP acceptance criteria. To assure this, additional absorbent (such as kitty litter or zeolite) is typically added. Wet and wrung-out rags are acceptable for disposal to the waste package. The drum or storage boxes can contain multiple bags of sealed out waste. Drums with contents designated as “corrosive” have a 90-mil polyethylene liner. The maximum practical loading (from PFP experience) is 66 pounds (30 kg) of rags, although a more typical loading would be about 33 pounds $(15 \mathrm{~kg})$ of rags per drum. Each seal out bag contains air space, and air spaces are left between the individual seal out bag packages and between the drum or storage box sides. These air gaps serve as insulation and limit the heat rejection capabilities of the drum or storage boxes.

\subsection{Drum Storage Conditions}

Once the drums are loaded, they will be stored temporarily at PFP until they can be shipped to Hanford's Central Waste Complex (CWC). The envisioned storage condition at PFP would be outside unshielded in open air. Storage inside the ventilated 234-5Z building is available if necessary. Once the drums are at CWC, they are stored on metal pallets with four drums to the pallet, and the pallets are stacked three high to make a two by two by three configuration. Two sides of the drum must be accessible for waste inspections. The drums at CWC are stored in an enclosed building lacking temperature control. The maximum reported temperature recorded at Hanford's metrological site is $45^{\circ} \mathrm{C}\left(113^{\circ} \mathrm{F}\right)$. 


\subsection{Experimental Materials and Methods}

We determined the thermal sensitivity of the ceric nitrate/nitric acid, RadPro ${ }^{\circledR}$, Glygel, and Aspigel characteristic wastes and component materials. We used the thermoanalytical methods differential thermal analysis (DTA), thermogravimetry (TG), and ARC. This section describes the preparation of the test samples and the instruments used to determine their thermal sensitivities.

\subsection{Sample Preparation}

This section describes how we prepared the simulated wastes arising from the various decontamination processes. Simpler combinations of test materials also were prepared for testing to identify the underlying reactive components.

\subsubsection{Ceric Nitrate/Nitric Acid/Rags}

For the initial studies with cotton rags, the Fluor-PNNL team prepared three batches of ceric nitrate/nitric acid/cotton rags for testing. Two batches were prepared to be representative of expected wastes and included treatment with ferrous sulfate to reduce the ceric to cerous and neutralization of the nitric acid with sodium hydroxide based on the procedure provided by Rocky Flats. We prepared the third batch to be representative of rags before the reduction and neutralization treatment to determine the hazards associated with rags after wipe-down and to provide comparative information on the effects of the reduction and neutralization steps. After our initial thermal sensitivity studies found the ceric/cotton rags to be susceptible to low-temperature reactions, we prepared additional similar representative synthetic rags/ceric wastes.

To prepare the ceric nitrate/nitric acid saturated rags, 1$)$ the rags were soaked in $0.25 \underline{\mathrm{M}} \mathrm{Ce}\left(\mathrm{NO}_{3}\right)_{4}-1 \underline{\mathrm{M}}$ $\mathrm{HNO}_{3}$, 2) the rags were drained to remove excess liquid, 3) using the residual volume of ceric nitrate solution as a basis and assuming that all of the $\mathrm{Ce}^{4+}$ remained, the rags were soaked with the requisite

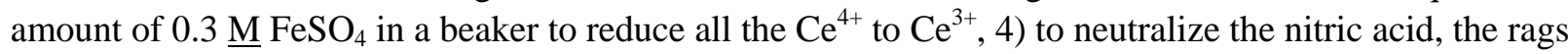
were saturated with the requisite amount of $2.6 \mathrm{M} \mathrm{NaOH}$, and 5) the rags were air dried in a fume hood. The resulting representative ceric nitrate/cotton rag waste is rust-colored as shown in Figure 4.1. The ceric nitrate/nitric acid-treated rag is essentially unchanged in appearance from the untreated rag.

Synthetic rags also were investigated as an alternative after the initial studies on ceric nitrate/cotton rags. Using the same approach as used for the cotton rags, synthetic rags of 50\% polyamide (nylon)-50\% polyester with ceric nitrate/nitric acid, reduced and neutralized, and 20\% polyamide/80\% polyester with ceric nitrate/nitric acid were prepared. The originally aqua-blue $50 \%$ polyamide $/ 50 \%$ polyester rag lost most of its original color and took on a slightly rusty color as shown in Figure 4.2. The ceric nitrate/nitric acid soaked yellow $20 \%$ polyamide/ $80 \%$ polyester rag was tan after drying. 


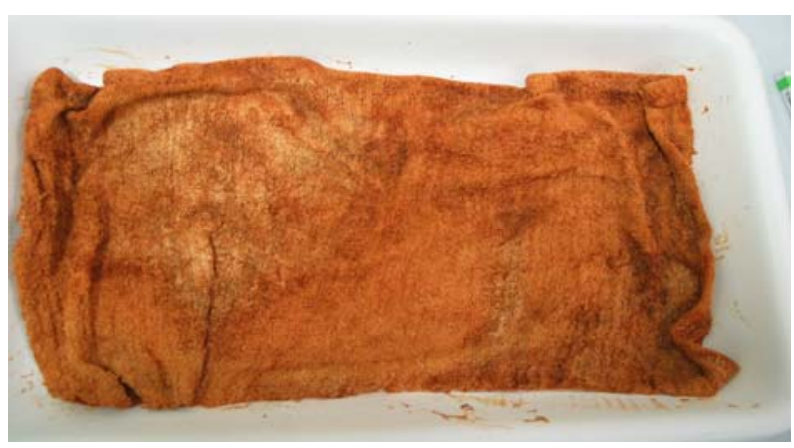

Figure 4.1. Representative Ceric Nitrate/Nitric Acid/Cotton Rag Decontamination Waste After Reduction and Neutralization

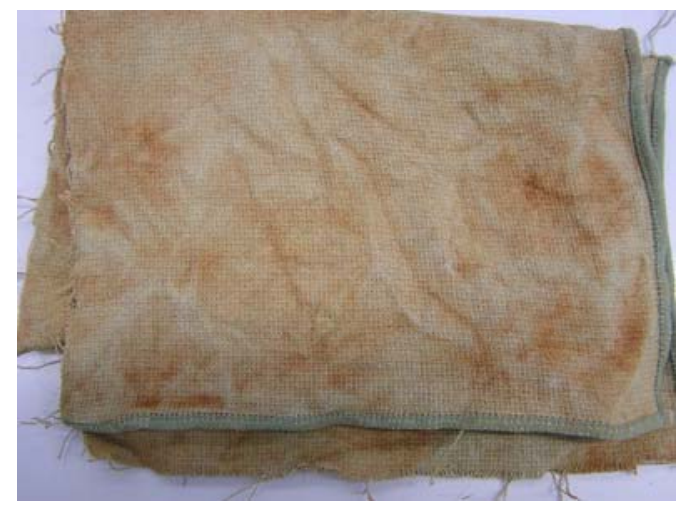

Figure 4.2. Reduced and Neutralized Ceric Nitrate/Nitric Acid/50\% Polyamide-50\% Polyester Rag

\subsubsection{RadPro ${ }^{\circledR}$ Solutions/Rags}

To evaluate the thermal sensitivity of potential RadPro ${ }^{\circledR}$ wastes, we saturated the standard $100 \%$ cotton rag and a 50\% polyamide/50\% polyester rag in the solutions listed in Table 4.1 . To prepare the RadPro A solution, we treated a 304 stainless steel sheet to introduce any trace metals and wiped the sheet until the rag was saturated; Figure 4.3 shows a PNNL staff member using the RadPro decontamination solution to scrub the steel sheet. To investigate the effects of the synthetic rag composition, we also prepared a $20 \%$ polyamide/80\% polyester rag soaked in RadPro A and used it to treat a steel sheet.

Table 4.1. Composition of RadPro Solutions Used for Testing

\begin{tabular}{||l|l|l||}
\hline Solution Identification & Solution Composition, vol\% & Description \\
\hline RadPro A & $75 \%$ RadPro ${ }^{\circledR}$ 0200/25\% RadPro ${ }^{\circledR} 0300$ & Decontamination Solution \\
\hline RadPro B & $33 \%$ RadPro A/67\% RadPro C & Decontamination + Rinsate \\
\hline RadPro C & $10 \%$ RadPro ${ }^{\circledR} 0300 / 90 \%$ DIW & Rinsate \\
\hline RadPro D & RadPro $^{\circledR} 0100$ & Emulsifying Solution \\
\hline RadPro E & $67 \%$ RadPro C/33\% RadPro D & Emulsifier + Rinsate \\
\hline \hline
\end{tabular}




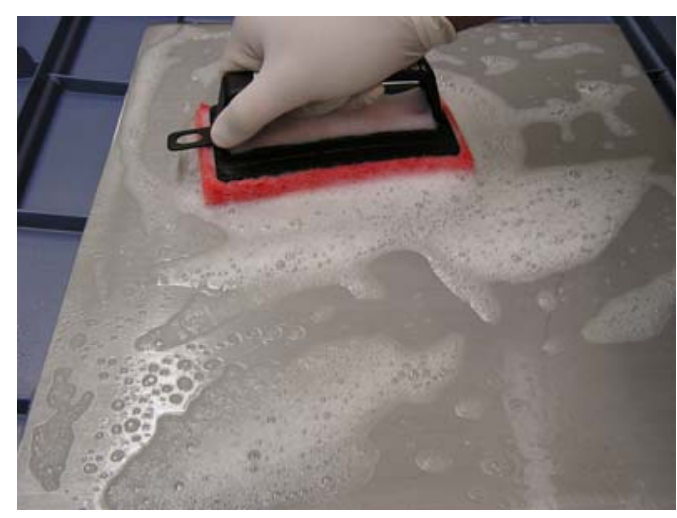

Figure 4.3. Preparation of RadPro A

Pictures of an untreated cotton rag and the dried cotton rags previously soaked with RadPro solutions A, B, C, D, and E are provided in Figure 4.4 through Figure 4.9, respectively. The light gray 50\% polyamide/50\% polyester rag provided by Fluor to PNNL did not change colors with any of the treatments.

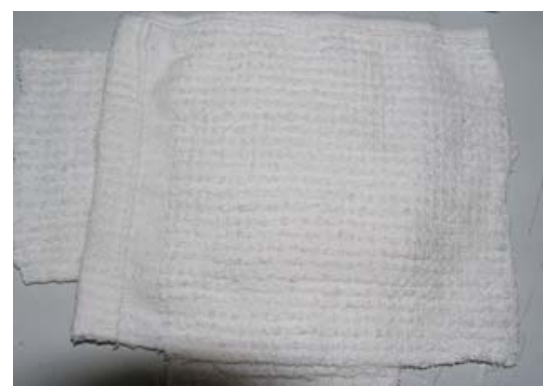

Figure 4.4. Untreated Cotton Rag

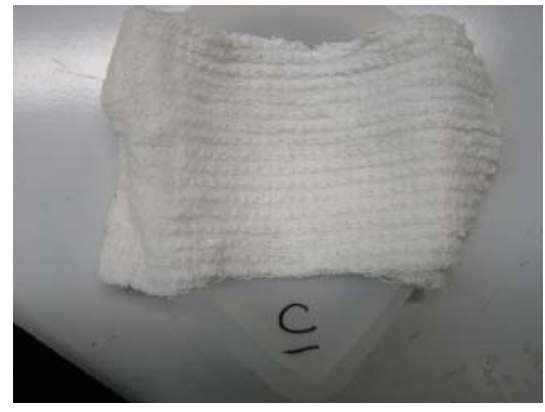

Figure 4.7. RadPro C/Cotton Rag

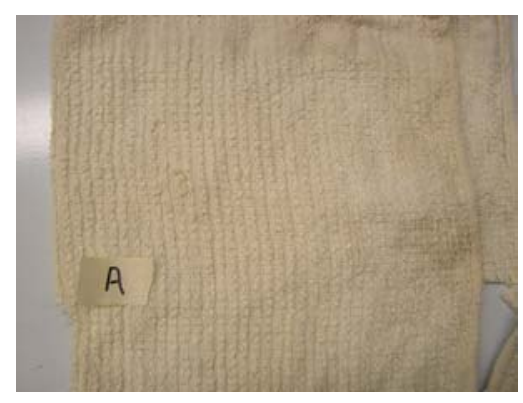

Figure 4.5. RadPro A/ Cotton Rag

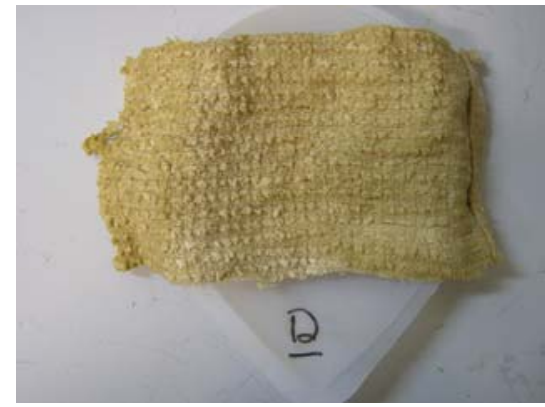

Figure 4.8. RadPro D/ Cotton Rag

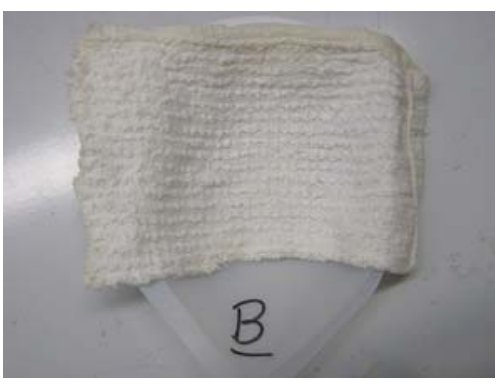

Figure 4.6. RadPro B/Cotton Rag

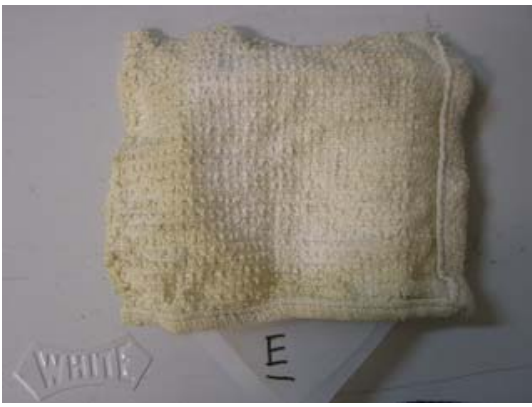

Figure 4.9. RadPro E/Cotton Rag

\subsubsection{Glygel}

To determine the thermal stability of the waste arising from the Glygel process, we prepared two batches of representative spent Glygel gel and one representative of Glygel gel without the surfactant. Fluor staff 
prepared the first batch on a glovebox scale similar to the process illustrated in detail later in the section describing the Aspigel process. For both preparations, Fluor staff used a proprietary degreaser before applying the decontamination gel. The degreaser contained $<10 \%$ sodium hydroxide and $<10 \%$

2-butoxyethanol according to its MSDS. The impact of this treatment on the gel's thermal reactivity is unknown, although another organic or fuel is added to the system. Fluor used handheld Shark ${ }^{\mathrm{TM}}$ and Data $\mathrm{Vac}^{\mathrm{TM}}$ vacuum cleaners to collect the dried Glygel. The dried gel and vacuum cleaner filter bags were provided to PNNL for testing. PNNL prepared a second representative batch of spent Glygel gel and the Glygel without surfactant but did not use the proprietary degreaser before the gel application to the 304 stainless steel coupon.

In addition to the supporting supplemental studies, PNNL staff prepared the representative Glygel waste and Glygel without surfactant, under the guidance of the supplier. We combined and mixed Glygel OX Oxidizing Gel with the surfactant (Glygel OX Surface Active Agent, TA 96) per the manufacturer's instructions to prepare the decontaminating treatment. This was applied to a 304 stainless steel metal sheet, dried for 23 hours, and recovered as a dry, orange solid for study. Figure 4.10 shows the dried Glygel on the steel coupon. To prepare the Glygel without surfactant, we repeated this process on the cleaned steel coupon with the exception that we did not mix the Glygel OX Oxidizing Gel with its surfactant before the application. To assess the effect of retained water, we freeze-dried a portion of the spent Glygel treatment gel.

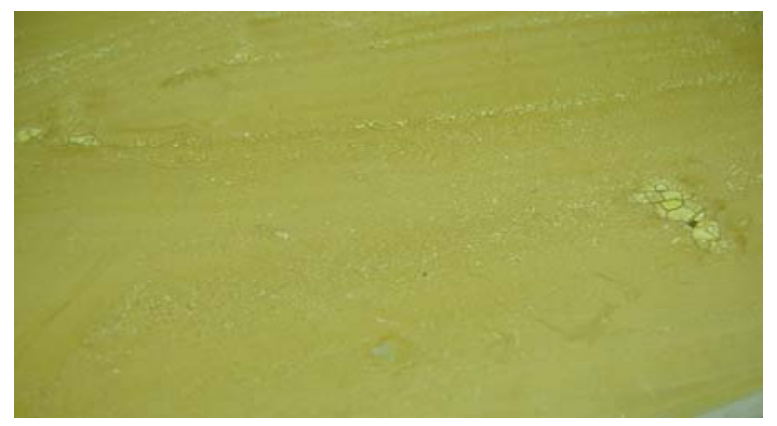

Figure 4.10. Dried, Spent Glygel Decontamination Gel

\subsubsection{Aspigel}

A glovebox mock-up with stainless steel panel inserts was used to test the application and removal of Aspigel 100 decontamination reagent and to prepare representative spent Aspigel waste for thermal stability testing. Application in the mock-up was tested April 26, 2005, with dried sample collection the following day, April 27, 2005. The test area was open to the outside. Daytime temperatures reached a maximum of approximately $75^{\circ} \mathrm{F}$ during testing.

Aspigel 100 was stirred to liquefy before application as shown in Figure 4.11. The transition from gel to liquid was evident by the appearance of a vortex in the mixture. The Aspigel 100 was a bright yellow to orange-yellow color. 


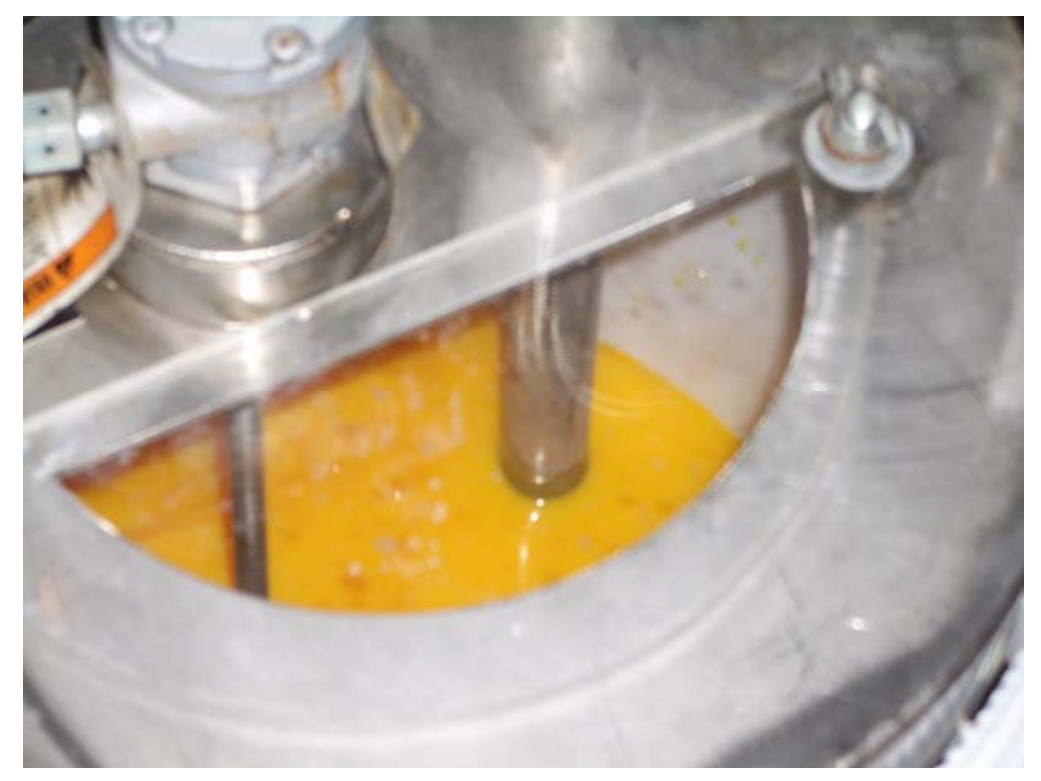

Figure 4.11. Preparation of Aspigel 100 for Decontamination Treatment

Fluor staff used a mock-up glovebox with exhaust ventilation to vent the nitric acid vapors arising from the preparation, application, and testing of the Aspigel 100. Figure 4.12 shows the glovebox. Stainless steel panels used in this testing previously had been cleaned with a proprietary degreaser containing $<10 \%$ sodium hydroxide and $<10 \%$ 2-butoxyethanol (based on the MSDS). The impact of the degreaser on the thermal reactivity of the spent gel is unknown, but it added another organic fuel to the spent gel. A stainless steel panel was placed inside the mock-up, Aspigel 100 was sprayed onto the panel using several passes of the sprayer, and the panel was removed from the mock-up and placed on a plastic tarp. Four panels were sprayed. The fourth panel was left in the mock-up enclosure to test the effect of leaving Aspigel 100 on a panel for an extended period of approximately 48 hours.

The Hanford cotton rag ( $86 \%$ cotton/14\% polyester) was used to clean the mixer rotor after application. The rag was collected as a sample for analysis.

Figure 4.13 shows the appearance of the stainless steel panel inside the glovebox mock-up after being freshly sprayed with Aspigel 100. Runs in the reagent and drips from the bottom of the panel are visible. Using a \#19 nozzle produced a 12-mil gel thickness after the first coat and 18-mil total after three coats (Note: $1 \mathrm{mil}=0.001$ inch $=25.4 \mu \mathrm{m}$ ).

In an attempt to achieve a more even coat, a 7-mil coat thickness was achieved by using a smaller spray tip for application. Subsequent coats had a 10- to 12-mil thickness with a final 14-mil total thickness after the third coat. The coating thickness on panel three was 10 to 12 mil, and panel four was 8 to 10 mil. Even with the lighter application, some running of Aspigel 100 down the panel was observed on panel four. 


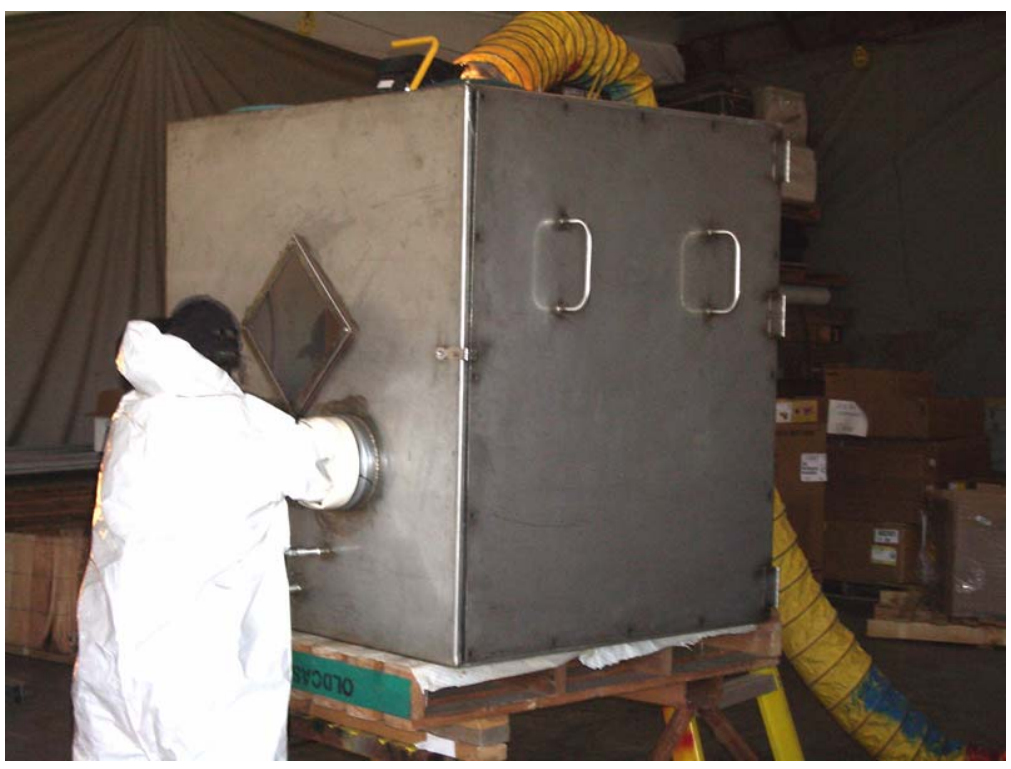

Figure 4.12. Mock-Up Glovebox Used for Application of Aspigel 100 Decontamination Treatment

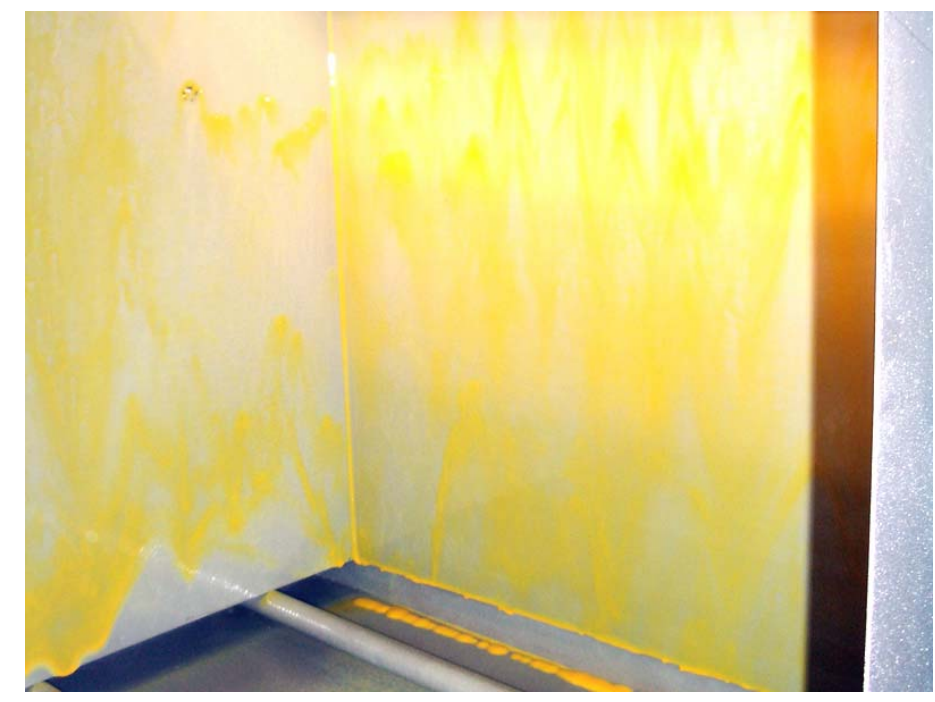

Figure 4.13. Stainless Steel Coupons with Freshly Applied Aspigel 100

Figure 4.14 shows how the stainless steel panel sprayed with Aspigel 100 and air-dried overnight appears. Figure 4.15 provides a close-up of the dried Aspigel. The yellow flakes of Aspigel 100 visible in Figure 4.14 on the white plastic tarp underneath the panel separated from the panel and fell off during the drying period to leave bare panel sections. The bare sections were shiny and appeared to be clean. Samples of the flakes were collected from the tarp. Areas of thinner Aspigel 100 application appeared to be white or pale yellow, suggesting complete or nearly complete reaction of the ceric ion with the metal. The dried Aspigel was scraped from the panel and collected as a fraction that seemed to have reacted more of the cerium(IV) than the darker yellow sections. 


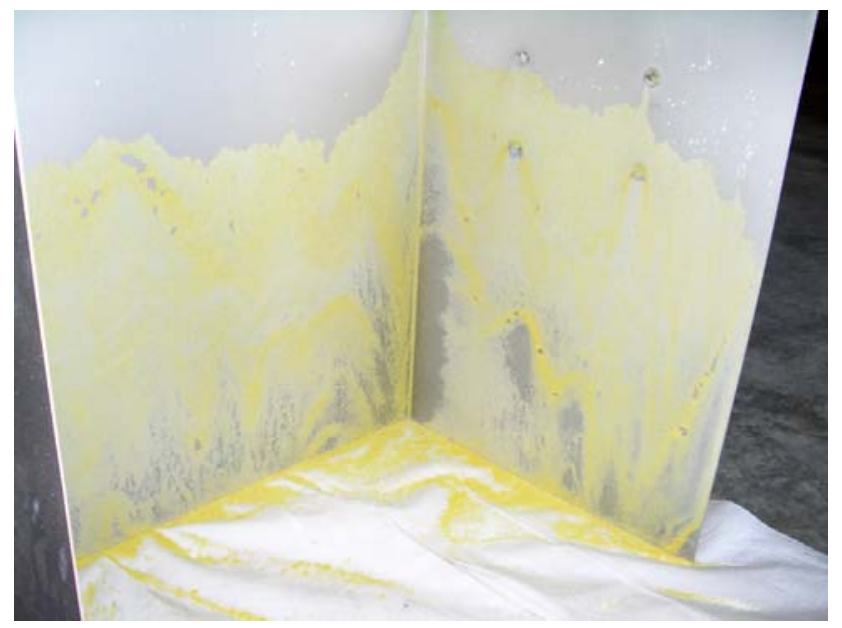

Figure 4.14. Stainless Steel Panel Sprayed with Aspigel 100 and Air-Dried Overnight

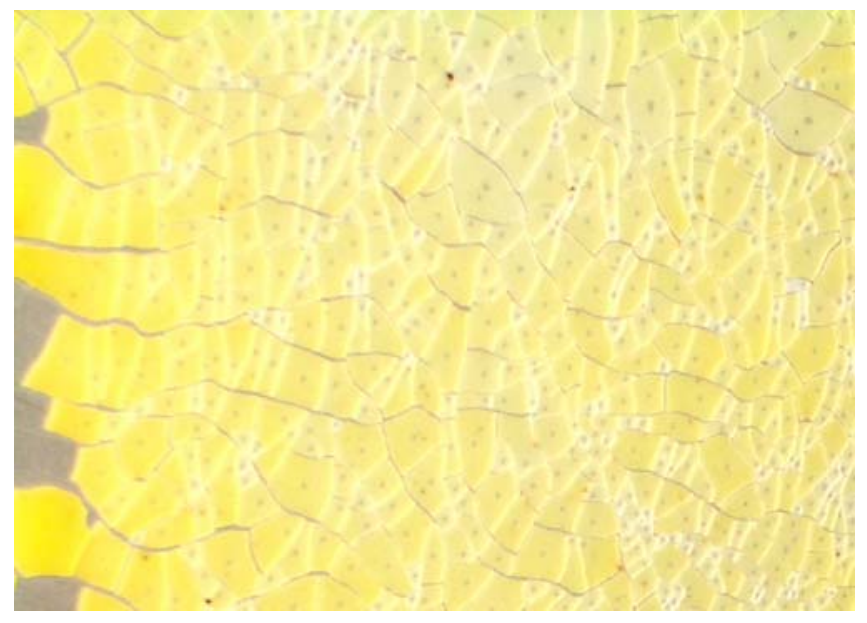

Figure 4.15. Close-Up View of Crackling and Flaking in Dried Aspigel 100

A brush and a plastic scraper were used to remove the dried Aspigel 100. Thin layers of dried Aspigel reagent could not be removed in this manner as shown in Figure 4.16 and Figure 4.17. It is believed that taking more time and using other attachments with the vacuum cleaner would remove more material, but it is uncertain whether adequate removal is possible by vacuuming alone or if a secondary method such as wiping with damp cloths may be necessary. The close-up view in Figure 4.17 shows darker lines that indicate places where Aspigel 100 removal was more complete.

Shark ${ }^{\mathrm{TM}}$ and DataVac ${ }^{\mathrm{TM}}$ hand-held vacuum cleaners were used to remove the Aspigel from the metal coupons. Both vacuums were taken to the laboratory for sample removal of the contents and filter media.

We measured the masses of recovered Aspigel and the filter media without the plastic ring in both vacuum cleaners that was filled with dried Aspigel. We used these mass ratios to prepare the mixtures of Aspigel and filter media used in our thermal testing.

\subsection{Thermoanalytical Instruments}

To assess the thermal sensitivity of potential waste products arising from decontamination of PFP Pucontaminated gloveboxes, we used two analytical instruments with three analytical capabilities:

- $\quad$ simultaneous DTA/TG

- $\quad$ ARC.

The DTA/TG is typically used as a screening tool to determine the onset temperature of a reaction and to determine whether that reaction produces or requires chemical heat (enthalpy). The ARC was originally developed by Dow Chemical to determine safe process operating temperatures for tested materials. The ARC measures the rate of temperature and/or pressure increases that occur for the tested materials maintained at adiabatic conditions. Additional details about the performances of these two instrumental methods and uses in our evaluation are described in this section. 


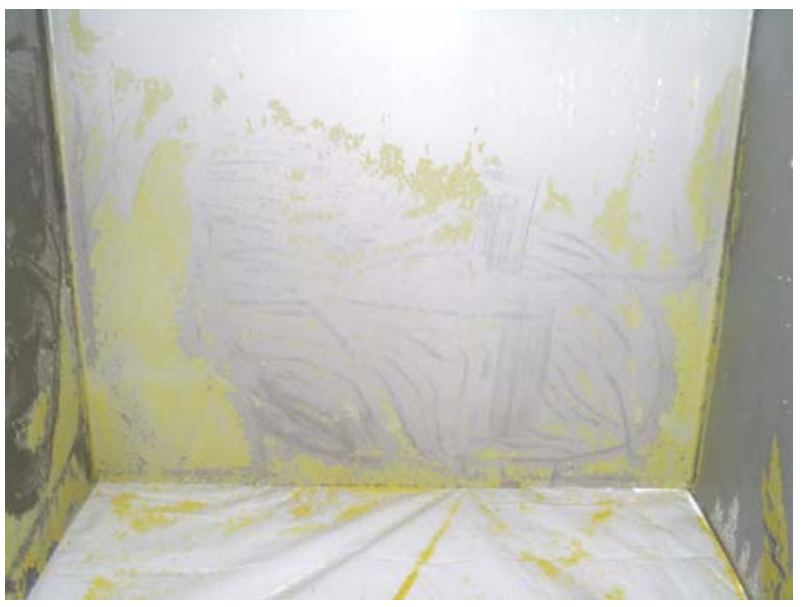

Figure 4.16. Partially Scraped and Vacuumed Aspigel-Treated Panel on Panel

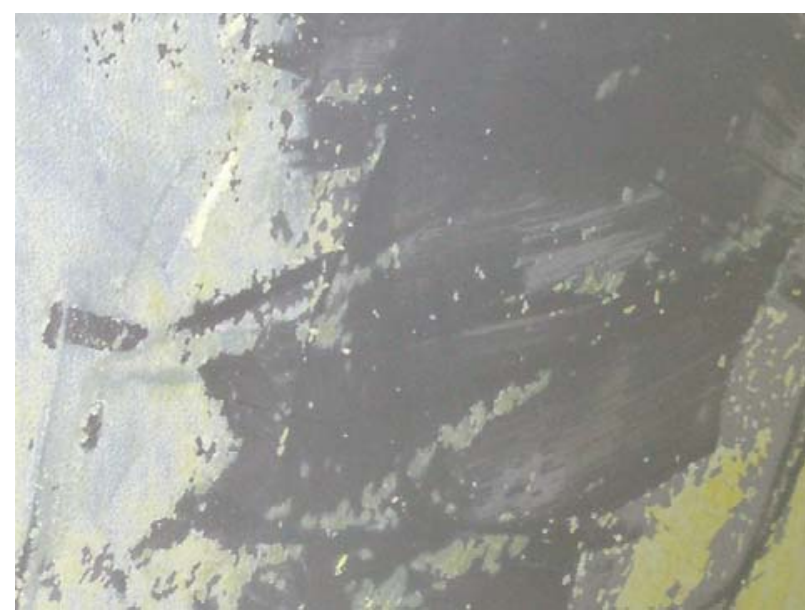

Figure 4.17. Close-Up of Partially Scraped and Vacuumed Aspigel-Treated Panel

\subsubsection{Differential Thermal Analysis/Thermogravimetry}

Thermoanalytical methods are typically used as screening tools to determine whether a chemical system exhibits exothermic and gas-producing reactivity. The DTA and its cousin differential scanning calorimetry (DSC) can be used as a first measure whether a thermal hazard exists at the needed operating temperature. A rule-of-thumb for DSC testing results is that if the observed exothermic reaction onset temperature is $100^{\circ} \mathrm{C}$ greater than the highest process temperature, the system is indicated to be sufficiently stable; of course, exceptions have been shown to exist (CCPS 1995). Although less sensitive than DSC, the combined DTA/TG should provide nominally the same sensitivity as the DSC, thus allowing application of the DSC DSCrule-of-thumb for operational safety.

For these studies, we used a Netzsch 409C combination DTA and thermogravimetric analyzer (TGA). This DTA/TG provides simultaneous measurement of mass and sample enthalpy changes. The instrument can be used to provide these changes either as a function of temperature as the sample is heated or cooled at a known controlled rate (temperature scanning) or as a function of time at temperature (isothermal). In these studies, we used the DTA/TG to characterize the materials as a function of temperature.

Differential thermal analysis measures whether a reaction is endothermic (requires heat) or is exothermic (produces heat). The DTA measures temperature differences between the 1- to 1000-mg sample and an inert reference material of the same approximate mass. The DTA can be used to measure reaction kinetics and enthalpy changes $(\Delta \mathrm{H})$, although it is challenged to quantitatively measure $\Delta \mathrm{H}$ by gasproducing exothermic reactions because released gases carry away unknown amounts of heat that are left unmeasured by the instrument. Quantifying $\Delta \mathrm{H}$ for endothermic gas-producing reactions is easily accomplished for these instruments because the heat required to cause the reaction will be observed by the instrument. 
Thermogravimetry quantitatively measures mass changes. The instrument is thus useful for observing reactions for which mass changes occur. The TGA can also be used to measure reaction kinetics for those reactions involving a mass change.

The Netzsch TGA-DTA instrument contains a precision balance supporting a vertical 3-mm diameter, $25-\mathrm{cm}$ long ceramic rod. At the top of the rod is a cross member from which project two vertical stubs. A small crucible is placed on each of the stubs. The available crucible volumes range from 0.5 to $5 \mathrm{~mL}$. A small thermocouple (TC) projects upward from the center of each stub to touch the bottom of each crucible. A thermally stable non-reactive reference material such as aluminum oxide is placed in the reference crucible and the sample in the other. The DTA measures the temperature difference between these two thermocouples whereas the precision balance measures the weight loss of the system. The observed weight loss is ascribed to the sample as the reference material and the ceramic rod, cross member, stubs, and crucibles lose no weight.

\subsubsection{Accelerating Rate Calorimetry}

For this study, we used a Columbia Scientific Instruments ARC. The ARC provides a more sensitive measure of the reaction onset temperature than does the DTA. The rule-of-thumb for assessing a thermal reactivity hazard based on ARC results is that the maximum process temperature should be more than $50^{\circ} \mathrm{C}$ below the ARC-observed reaction onset temperature; we assume this rule-of-thumb would require determining the onset temperature using the maximum sample size of $10 \mathrm{~mL}$ or nominally $10 \mathrm{~g}$; we typically used $<3$ g.

The ARC is a closed adiabatic (no heat loss or gain) calorimeter typically operated using a heat-waitsearch strategy for samples nominally weighing up to $10 \mathrm{~g}$. We used 10-mL, nominal 7-g titanium spherical containers. In this strategy, the sample is heated to an operator-selected temperature, the sample is equilibrated for an operator-selected time, and the temperature of the sample/container is monitored at the outside of the container's equator to detect an exothermic reaction as measured by its self-heating rate. If the reaction rate does not exceed a criteria of $0.01^{\circ} \mathrm{C} / \mathrm{min}$, the instrument repeats the heat-wait-search operation. If heating is observed, the calorimeter maintains a temperature the same as the sample container to simulate adiabatic conditions until the exothermic reaction stops. It then reenters the heatwait-search mode until the operator-set final temperature is reached or the pressure within the closed vessel exceeds an operator-set pressure.

As shown in Figure 4.18, the ARC is simply a sample container (bomb) surrounded by an oven having multiple zone heating elements. The heating is controlled by type $\mathrm{N}$ thermocouples distributed to assure uniform temperature throughout the calorimetric chamber. The combined sample and bomb temperature is measured at the 10-mL bomb's equator. The oven's temperature is maintained at the same temperature as the sample and bomb to provide an adiabatic (no heat loss from the sample) environment for the sample. The ARC uses a pressure transducer to measure pressure. The ARC can heat to $450^{\circ} \mathrm{C}$ and can maintain adiabatic conditions up to heating rates no more than $15^{\circ} \mathrm{C} / \mathrm{min}$; i.e., the calorimeter cannot follow sample heating rates greater than $15^{\circ} \mathrm{C} / \mathrm{min}$. 


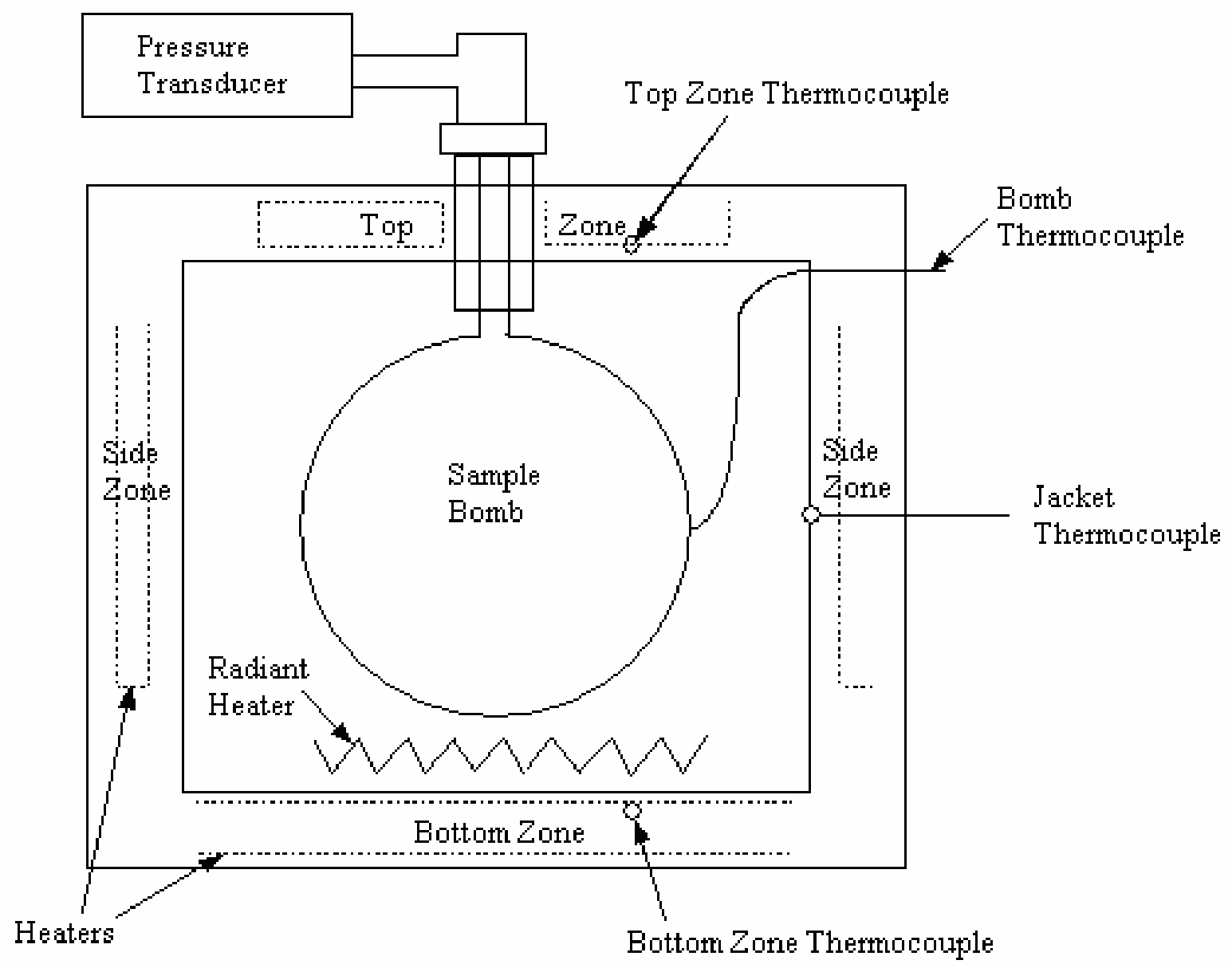

Figure 4.18. Schematic of Accelerating Rate Calorimeter

Because the ARC is adiabatic, all heat produced by the sample will go into heating the sample. This feature provides a realistic model for systems that will not lose heat should a reaction begin. Such systems include large chemical process tanks, large chemical storage tanks, or, for the present purposes, a 210-L TRU waste drum. We did an engineering thermal analysis for the $210-\mathrm{L}$ waste drum to determine whether the heat-dissipation rate from the drum would exceed the heat-production rate from the tested materials.

The ARC maintains the oven temperature at the combined sample and bomb's temperature. The additional thermal mass of the titanium bomb, $7 \mathrm{~g} \times 0.524 \mathrm{~J} /\left(\mathrm{g}-{ }^{\circ} \mathrm{C}\right)$ or $\sim 3.67 \mathrm{~J} /{ }^{\circ} \mathrm{C}$, causes the observed heating rate to be slower than the sample would be by itself. This added thermal inertia is accounted for by multiplying the measured self-heat rate by the so-called $\Phi$-factor calculated by Equation 4.1.

$$
\Phi=1+\frac{\left(C_{p(\text { container })} X \text { Mass }_{\text {container }}\right)}{\left(C_{p(\text { sample })} X \text { Mass }_{\text {sample }}\right)}
$$

where $\mathrm{C}_{\mathrm{p}(\mathrm{container})}$ is heat capacity of the titanium bomb. 
The ARC is often used after performing thermodynamic calculations to estimate the potential reaction energy density and/or DTA evaluation of the system's potential thermal reactivity and sensitivity (CCPS 1995). Because the ARC is a constant volume system, energy change ( $\Delta \mathrm{E})$ can be measured as opposed to enthalpy (heat) change obtained with DTA or a DSC.

\subsection{Data Evaluation}

When evaluating the data from our testing, we needed to assure ourselves the decontamination waste could be safely stored. The Center for Chemical Process Safety (CCPS) provides rules-of-thumb for the margin that should be maintained between the highest expected temperature and the observed onset temperature of a self-sustaining exothermic reaction. For the ARC, the rule-of-thumb is a $50^{\circ} \mathrm{C}$ margin; for the DTA, the rule-of-thumb is a $100^{\circ} \mathrm{C}$ margin. The highest observed Hanford temperature is $45^{\circ} \mathrm{C}$. When measured with the ARC, the minimum acceptable onset temperature for a self-sustaining exothermic reaction must be greater than $95^{\circ} \mathrm{C}$. When measured with the DTA, the minimum acceptable onset temperature for a self-sustaining exothermic reaction must be greater than $145^{\circ} \mathrm{C}$.

When evaluating the testing results and relating those results to the final waste configuration of being inside vented bags inside of a vented drum, the ARC and the DTA provide two views of the waste package. The ARC provides the behavior of a fully closed, sealed, and adiabatic waste configuration whose heating rate is driven by the heat produced by the material itself. In contrast, the DTA provides a view of a fully vented waste configuration whose behavior is driven by an instrument at a relatively fast rate. The ARC provides a more representative model because of the size of the vent filters, the random orientation of the waste packages (torturous path), and the resulting low heat and gas-exchange rate between the contents of the waste drum and the environment. The DTA data were used to evaluate some of the tested mitigating strategies because of its ability detect endothermic reactions.

Two different instruments can produce apparently contradictory results because of their differing open and closed designs. In the TGA/DTA and TGA/mass spectrometry (MS) systems, the sample cell is open, gases produced through evaporation or reaction are removed with the sweep gas, and the system pressure remains constant. Loss of starting material may decrease the overall energy produced by sweeping away reactive gases. Because the ARC is a closed system, all gases produced stay in the sample cell unless the container fails. Vaporization is suppressed by the increased pressure in the reaction vessel. Dissociative reactions that are endothermic and vapor pressure dependent are suppressed. Consequently, self-heating reactions may be observed at lower temperatures than for open systems. Turcotte et al. (2003) found differences in ammonium nitrate behavior in open and closed systems. In open systems, ammonium nitrate vaporization can occur easily, and significant loss of the starting material can occur, preventing a well-known self-propagating reaction. They also report that onset temperatures for vented systems are lower than for closed systems, but the times to runaway are also longer in general. 


\subsection{Experimental Results}

This section provides the results of our thermoanalytical studies to determine the thermal stability of potential wastes arising from the use of the Pu-glovebox decontamination technologies ceric nitrate/nitric acid, the aqueous proprietary decontamination system RadPro ${ }^{\circledR}$, Glygel, and Aspigel.

\subsection{Thermal Reactivity of Simulated Cloth Decontamination Wastes Arising from Use of Ceric Nitrate/Nitric Acid}

As described earlier, the planned strategy for using the ceric nitrate/nitric acid decontamination technology is to apply the solution to the glovebox walls, remove it using cloths, and stabilize the waste cloths by reducing the residual ceric ion to cerous using ferrous sulfate and neutralizing the nitric acid using sodium hydroxide. In addition to eliminating the oxidizing hazard from ceric ion and reducing the reactivity of the nitric acid, the stabilization treatment adds thermal mass to the cellulose/nitrate mixture of a fuel and oxidant that will mitigate the consequences of any self-reaction. This treatment should help prevent or eliminate the capability of this potentially reactive mixture to support a self-sustaining reaction. The studies described in this section were to determine if self-sustaining reactions could occur and what risk mitigation strategies might be available.

During the course of our studies, we investigated 1) the effects of reducing the ceric to cerous, neutralizing the acid to near $\mathrm{pH} \mathrm{10,2)} \mathrm{the} \mathrm{composition} \mathrm{of} \mathrm{the} \mathrm{cloth} \mathrm{(cotton} \mathrm{vs} \mathrm{synthetic)} \mathrm{used} \mathrm{to} \mathrm{remove}$ the ceric nitrate/nitric acid, and 3) aging. This section provides the results of these ARC and TGA/DTA studies of these variables.

In addition to our experimental studies, we used kinetic data developed using the TGA/DTA to predict the thermal behavior of ferrous-reduced and hydroxide-neutralized ceric nitrate/nitric acid saturated 86\% cotton/14\% polyester cloth stored in 210-L (55-gal) TRU waste drums. We performed this analysis based on adiabatic testing using the ARC to determine, under potential Hanford storage conditions, whether the heat production rate from ceric nitrate/nitric acid decontamination waste would be faster than the heat dissipation rate from the waste drum.

\subsubsection{Thermal Reactivity of Simulated 86\% Cotton/14\% Polyester Cloth Wastes Arising from Use of Ceric Nitrate/Nitric Acid Decontamination Technology}

The original operational plan was to use $86 \%$ cotton/14\% polyester (cotton) cloths to remove the Pubearing ceric nitrate/nitric acid from the glovebox walls. This section provides the results of our thermoanalytical experiments investigating the behavior of ferrous-reduced, hydroxide-neutralized ceric nitrate/nitric acid cotton cloths and our thermal modeling results of the behavior of the cotton-based waste. These experimental studies include thermoanalyses of the as-received cotton cloth, air-dried ceric nitrate/nitric acid saturated cotton cloths, and the expected ferrous reduced and hydroxide neutralized ceric nitrate/nitric acid cotton cloth wastes.

\subsubsection{Thermal Behavior of As-Received $86 \%$ Cotton/14\% Polyester Cloth}

The original implementation plan for using ceric nitrate/nitric acid decontamination technology was to use the cotton cloth that is ubiquitous throughout the Hanford site to collect the Pu-containing 
decontamination solution. The cotton cloth used for testing in the ceric nitrate/nitric acid waste study was $86 \%$ cotton/14\% polyester. We measured its thermal behavior by TGA/DTA and ARC.

When heated in argon, the cotton cloth decomposes endothermically in two major decompositions as measured by the TG/DTA at 10-C/min heating rates. As the mass curve in Figure 5.1 shows, the cloth immediately begins to lose its mass endothermically such that 40 mass $\%$ is lost by $150^{\circ} \mathrm{C}$. Losses at these temperatures are typically caused by loss of sorbed water or loosely bound waters of hydration. Given that there are no known oxidants in the cloth and this same behavior is seen for the chemically inert alumina, the initial apparent exothermic behavior as suggested by a positive heat flow is likely caused by the instrument bringing itself into control. Many instruments require a few minutes to stabilize the relationship between the sample and reference thermocouples. The small endotherm at $250^{\circ} \mathrm{C}$ likely is a result of the polyester melting. A second strong endothermic mass loss begins at $300^{\circ} \mathrm{C}$, resulting in loss of the remaining mass.

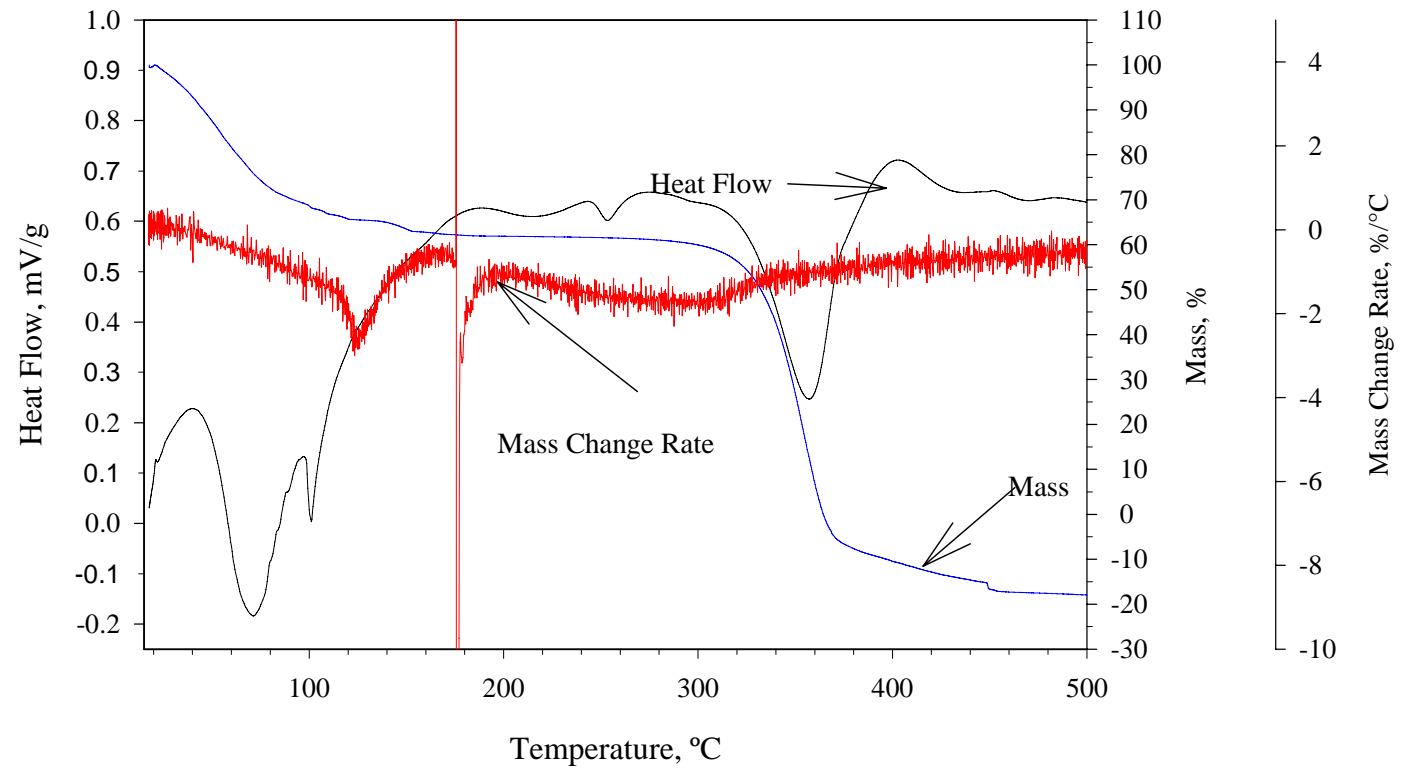

Figure 5.1. TG/DTA-Measured Thermal Behavior of 86\% Cotton/14\% Polyester Cloth in Argon

As shown in Figure 5.2, when heated in air at $10^{\circ} \mathrm{C} / \mathrm{min}$, the as-received cloth 1) endothermically begins to lose mass immediately, 2) experiences a second small $250^{\circ} \mathrm{C}$ endotherm as we saw in $\mathrm{Ar}$ with no corresponding increase in mass change rate, and 3) begins to oxidize exothermically at $350^{\circ} \mathrm{C}$. In this experiment, the TGA reported a catastrophic mass loss at $175^{\circ} \mathrm{C}$ without a corresponding DTA-observed reaction; normally this type of behavior in unlikely and occurs when an instrument is bumped or disturbed, so this mass change event is probably not real. The exothermic reaction between 340 and $500^{\circ} \mathrm{C}$ is likely caused by oxygen reacting vigorously with cotton's cellulose substrate. The differences between Figure 5.1 and Figure 5.2 above $300^{\circ} \mathrm{C}$ clearly show the effect of oxygen gas upon the cellulose. 


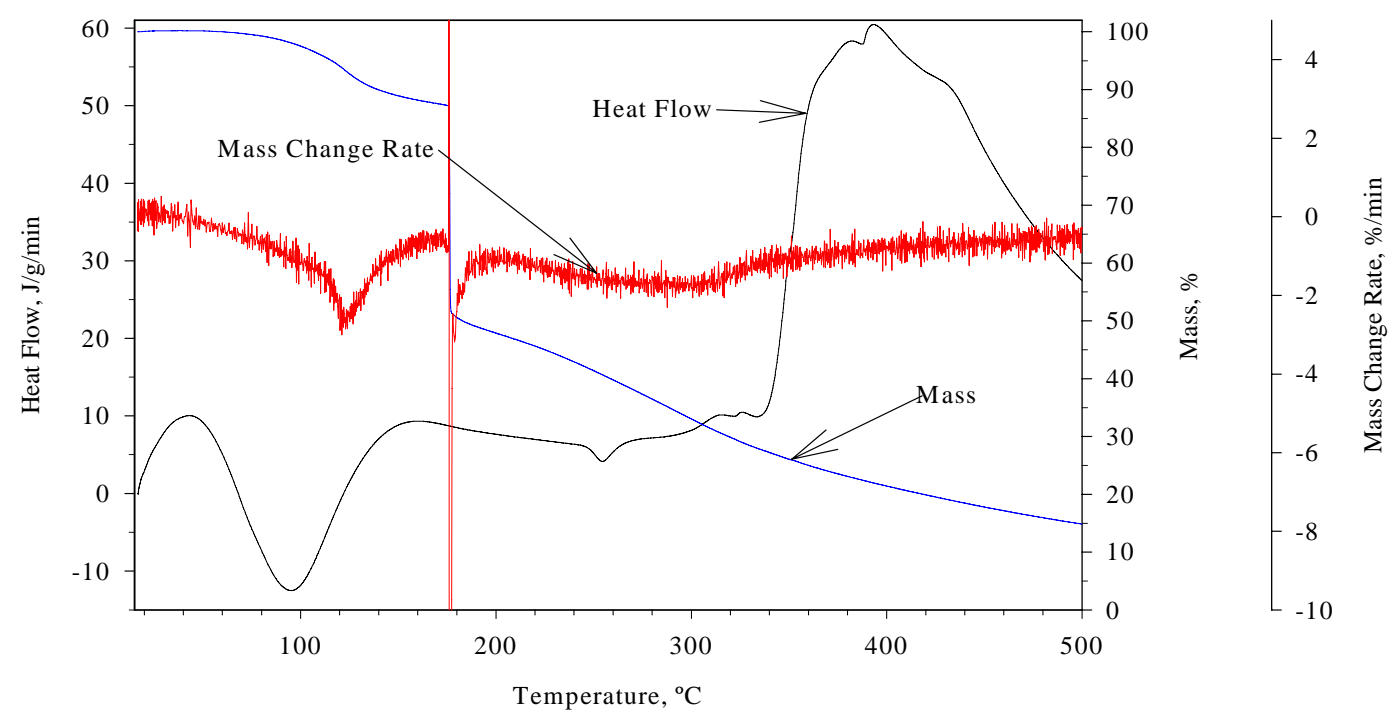

Figure 5.2. TG/DTA-Measured Thermal Behavior of As-Received 86\% Cotton/14\% Polyester Cloth in Air

The ARC analysis of the cotton/polyester cloth performed without an argon purge of the 10-mL sample exhibited some exothermic behavior as shown in the Arrhenius plot presented in Figure 5.3. The ARC observes a self-sustaining reaction beginning at $150^{\circ} \mathrm{C}$. There appears to be a second reaction beginning near $225^{\circ} \mathrm{C}$. In an Arrhenius plot, which plots natural log self-heat rate versus $1 / \mathrm{T}$ where $\mathrm{T}$ is in $\mathrm{K}$, a linear relationship exists per Equation 5.1 where $\mathrm{k}$ is the reaction rate constant, $\mathrm{A}$ is the Arrhenius pre-exponential or frequency factor, $\mathrm{E}_{\mathrm{a}}$ is the activation energy, and $\mathrm{R}$ is the gas constant.

$$
\ln k=A \exp \left(\frac{-E_{a}}{R T}\right)
$$

We have chosen to plot the common log (factor of $1 / 2.3$ of the natural log) of the self-heat rate rather than the natural log to improve the presentation.

The capability of the cotton cloth to undergo a self-sustaining reaction was unexpected because there was little oxygen in the $10-\mathrm{mL}$ bomb $\left(0.08 \mathrm{mmol} \mathrm{O}_{2}\right)$ compared to the nominal $0.2 \mathrm{mmol}$ of $\mathrm{CH}$ present in the cloth. This suggests that there is a residual oxidant in the cloth itself, although a significant temperature is required to initiate a self-sustaining reaction under adiabatic conditions. 


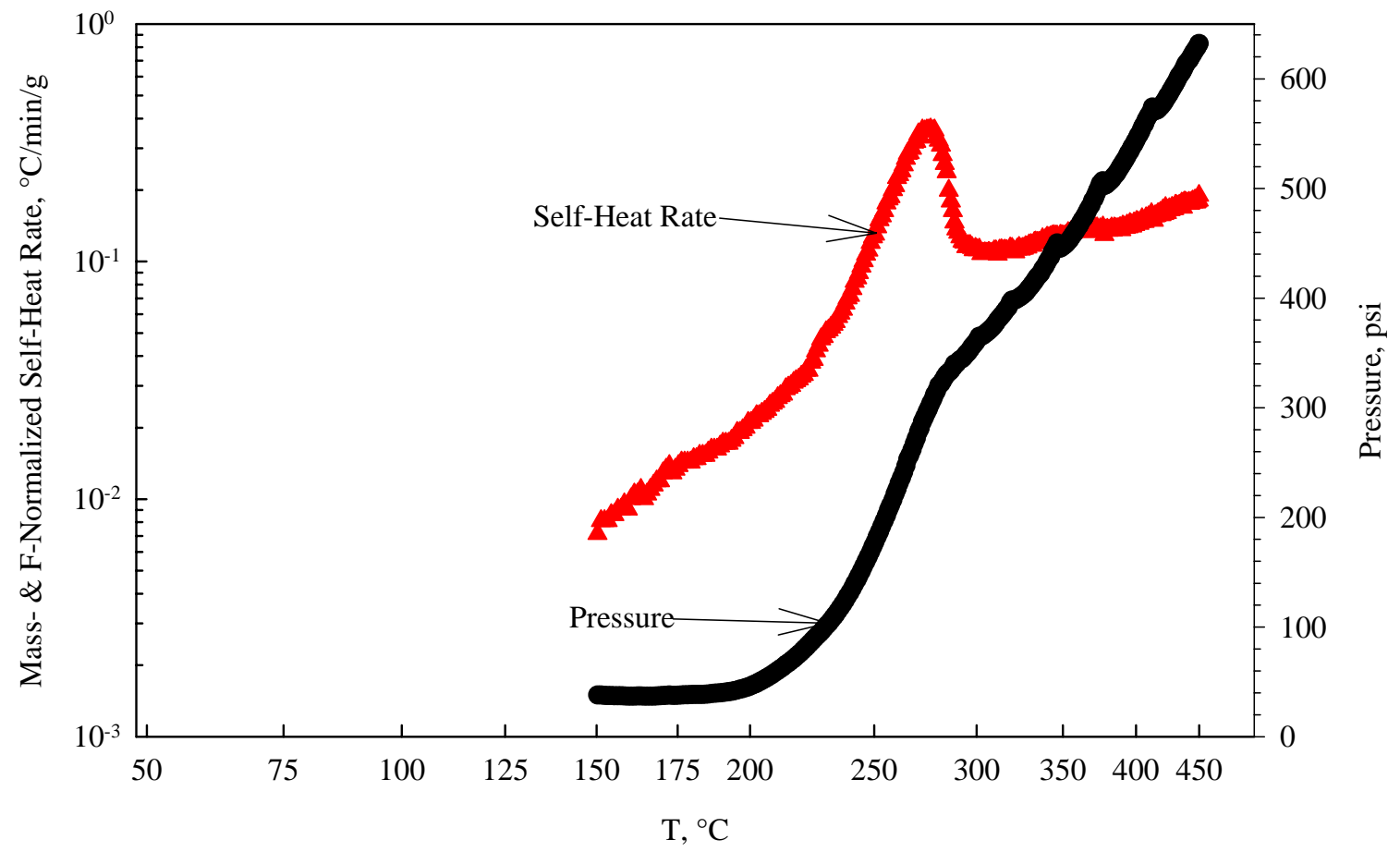

Figure 5.3. Arrhenius Plot of ARC-Measured Thermal Sensitivity of As-Received 86\% Cotton/14\% Polyester Cloth in Residual Air

Our thermoanalytical studies indicate that $86 \%$ cotton/14\% polyester cloth can support a self-sustaining reaction if heated to high temperatures, much greater than the $45^{\circ} \mathrm{C}\left(113^{\circ} \mathrm{F}\right)$ maximum temperature observed at Hanford.

\subsubsection{Thermal Reactivity of Simulated Stabilized Ceric Nitrate/Nitric Acid with $86 \%$ Cotton/14\% Polyester Cloth Decontamination Wastes}

Our thermoanalytical studies of the stabilized ceric nitrate/nitric acid waste cloths investigated age, the effect of stabilizing the cloth waste by reducing the $\mathrm{Ce}^{4+}$ with ferrous sulfate, and neutralization with sodium hydroxide.

The thermal sensitivity of a 42-day-old PFP-prepared sample of simulated stabilized ceric nitrate/nitric acid cotton cloth waste as measured by TGA/DTA is provided in Figure 5.4. The stabilized material endothermically loses 7 mass\% between 50 and $220^{\circ} \mathrm{C}$; this is likely because of residual water loss. This material then exothermically loses mass at $220^{\circ} \mathrm{C}$ via two reactions as indicated by the inflection in the TGA curve at $270^{\circ} \mathrm{C}$. This exothermicity is likely caused by reaction of the cloth (cellulose) with the nitrate; we did not analyze released gases with MS for the ceric nitrate/nitric acid waste evaluations. 


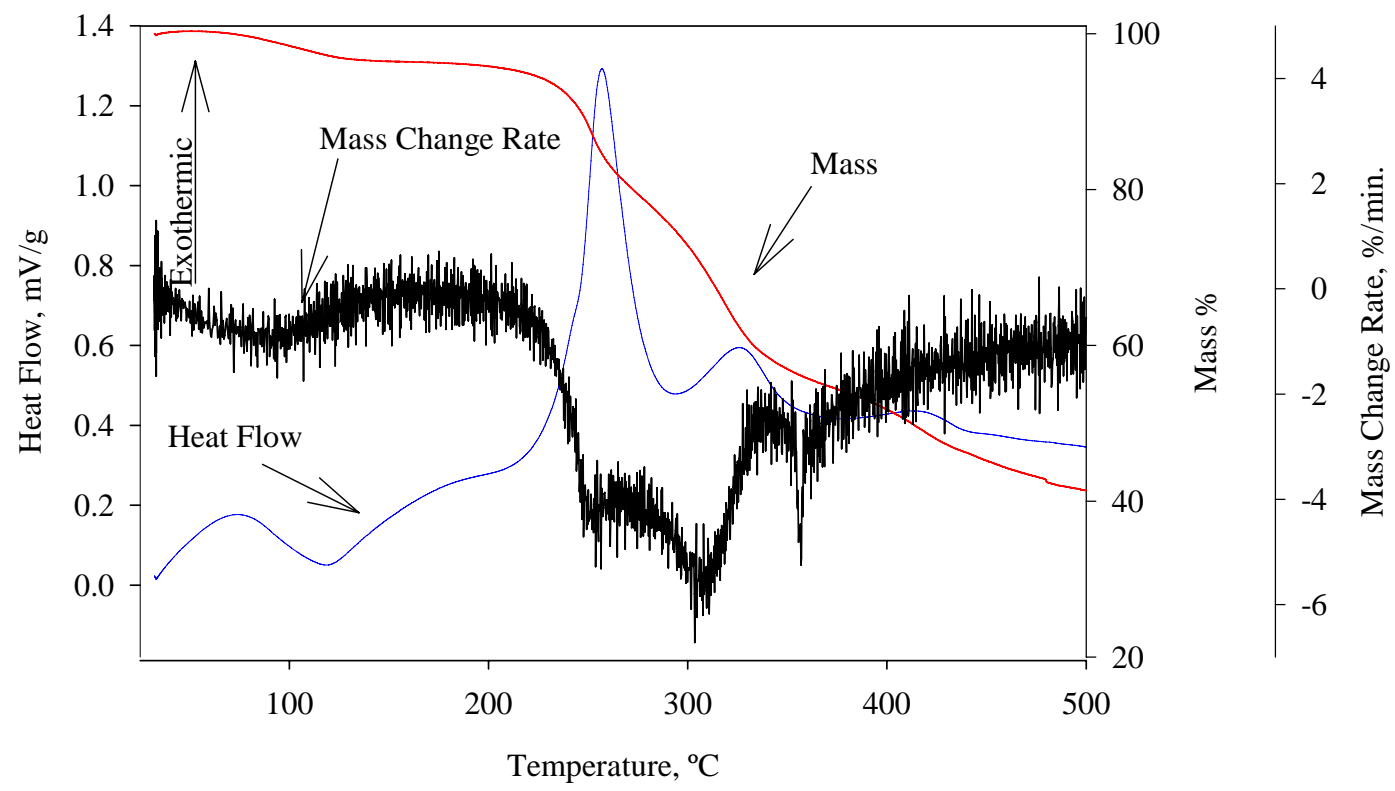

Figure 5.4. TGA/DTA-Measured Thermal Behavior in Argon of 42 day- old, Simulated Stabilized Ceric Nitrate/Nitric Acid Cotton Cloth Waste

As shown in Figure 5.5, the ARC-observed exothermic behavior begins almost immediately at $30^{\circ} \mathrm{C}$ for the stabilized ceric nitrate/nitric acid cotton cloths prepared by PNNL. These analyses, using 2.5 and $2.7 \mathrm{~g}$ samples, were performed immediately after air drying (2 days after treatment) and when 13 days old, respectively. Exothermic behavior begins for both runs shortly after the experiment begins at ambient temperatures. Heating the younger cloth initiates a reaction that dies shortly after starting, likely because of residual water evaporating and cooling the reaction; we suspect that a larger sample would allow this low temperature reaction to continue. After the ARC heats another operator-selected 10 to $20^{\circ} \mathrm{C}$ and waits for $10 \mathrm{~min}$ at temperature before monitoring the temperature, the reaction begins again and then dies, repeating this process until it reaches $110^{\circ} \mathrm{C}$. The observed behavior in both ARC analyses indicates that 2- to 13-day old waste composed of stabilized ceric nitrate/nitric acid cotton cloth will begin self-reacting near ambient temperatures under adiabatic conditions. 


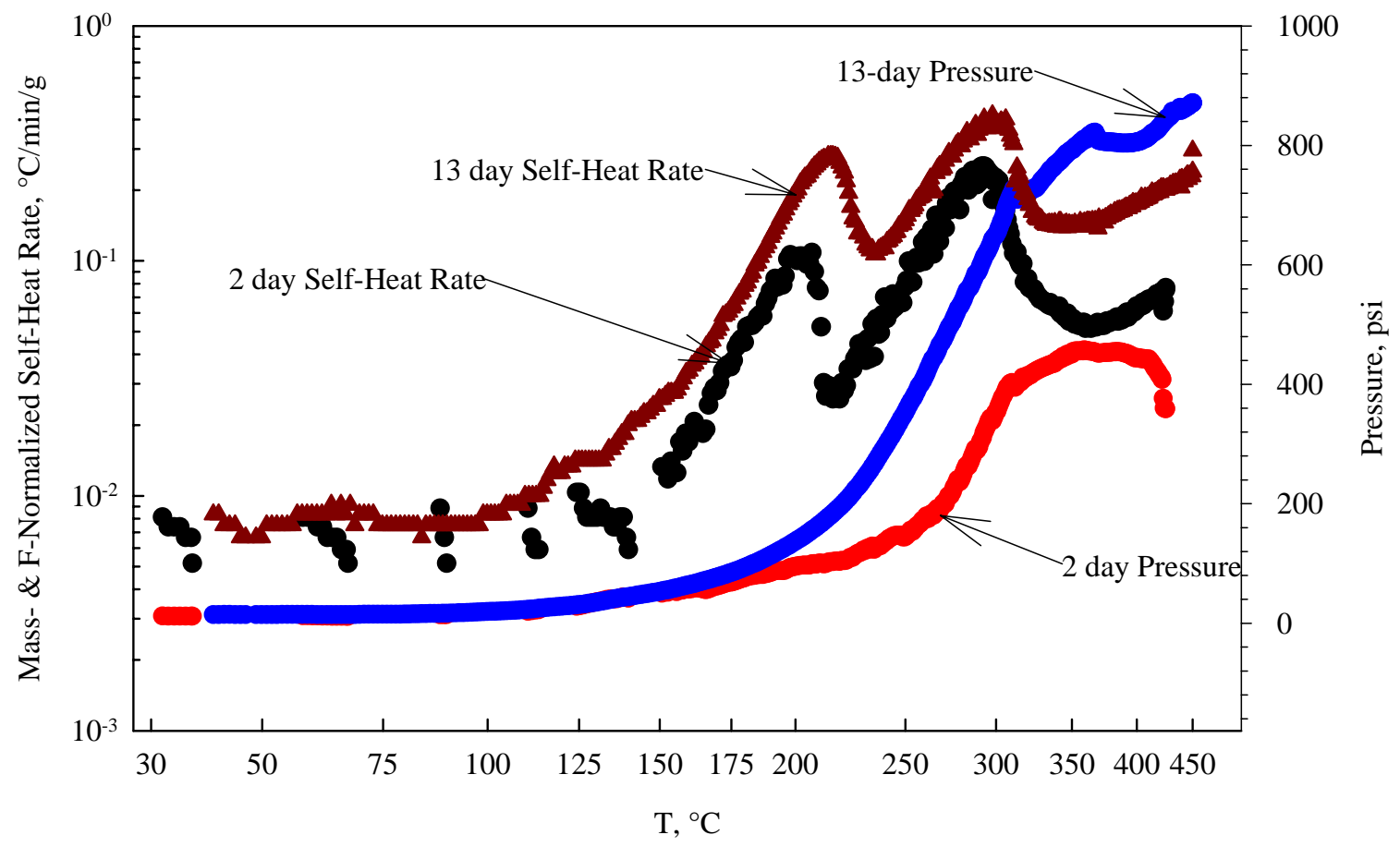

Figure 5.5. Arrhenius Plot of ARC-Measured Thermal Behavior of Simulated 2-Day and 13-Day Old Stabilized Ceric Nitrate/Nitric Acid Cotton Cloth Waste

As we performed replicate experiments with the stabilized cotton cloths, we saw that the reactivity was changing, suggesting that age might be affecting the overall thermal sensitivity and reactivity hazard. Figure 5.6 and Figure 5.7 show the effects of age on the reactivity of the stabilized cotton cloths.

The TGA/DTA analyses presented in Figure 5.6 show effects of aging on the thermal stability of stabilized ceric nitrate/nitric acid cotton waste. Although exothermic reactions immediately upon starting the analysis are suggested by the DTA for the 47- and 112-day old cloths, this is likely an artifact of the instrument as it brings itself into operational equilibrium. In all cases, the stabilized cloth begins to react exothermically near $210^{\circ} \mathrm{C}$; the 47 - and 112 -day old cloths have very sharp narrow exothermic peaks at $\sim 250^{\circ} \mathrm{C}$ followed by a broader peak at $280^{\circ} \mathrm{C}$ while the 12 - and 146 -day old cloths merge these two reactions. The second reaction completes later for the 47- and 112-day cloths. The last exothermic reaction occurs at 380 to $400^{\circ} \mathrm{C}$ for the different ages. The 47 - and 112-day old samples have greater exothermic enthalpies than the 12- and 146-day old samples, suggesting that the released heat reaches a maximum and then decreases. 


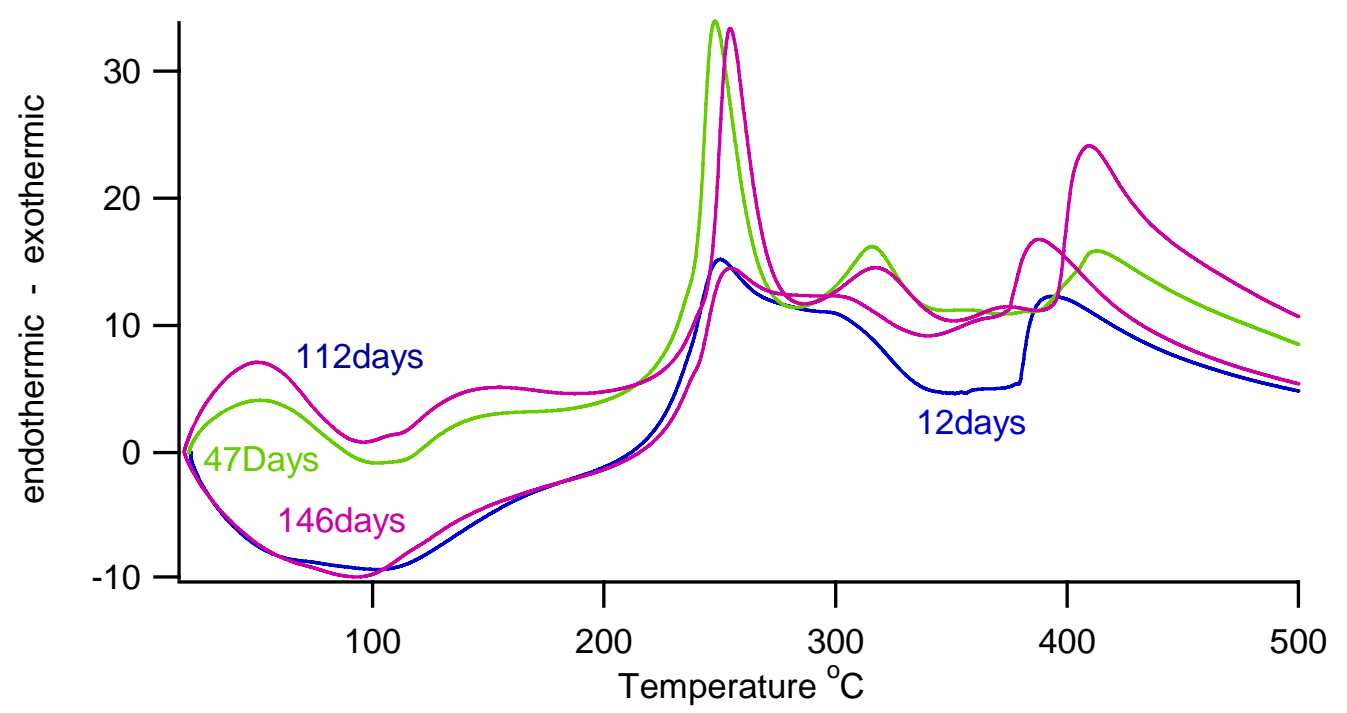

Figure 5.6. TGA/DTA-Measured Thermal Sensitivity in Argon of Simulated Stabilized Ceric Nitrate/Nitric Acid Cotton Cloth Waste over 146 Days

The ARC analyses for stabilized cotton cloths presented in Figure 5.7 indicate that with age, the low temperature reactivity declines and the stabilized ceric nitrate/nitric acid/cotton cloth's thermal stability increases. At 2 days, the onset temperature is $30^{\circ} \mathrm{C}$; at 14 days, it is $40^{\circ} \mathrm{C}$ (which may or may not be a significant increase in onset temperature); at 114 days, it is $70^{\circ} \mathrm{C}$; and finally at 149 days, it is $165^{\circ} \mathrm{C}$. Note that the 149 -day onset temperature of $165^{\circ} \mathrm{C}$ is much greater than the CCPS-recommended $50^{\circ} \mathrm{C}$ margin above the Hanford maximum observed temperature of $45^{\circ} \mathrm{C}$.

The apparent increase in reaction rate observed in Figure 5.7 for the 114-day-old material indicates that the reactivity hazard (considering both onset temperature and reaction rate) increases to a maximum before declining with additional aging. This is indicated by the very rapid increase in the 114-day old sample's self-reaction rate and the significant gas production sufficient to exceed 2000 psi. The ARC results also suggest that the reactivity hazard with respect to disposal and interim storage at the Hanford site of these stabilized ceric nitrate/nitric acid cotton wastes will diminish and will eventually no longer pose a risk; however, this is based on a single analysis on a single sample.

Our thermoanalytical studies indicate that a thermal reactivity hazard exists for stabilized ceric nitrate/nitric acid/cotton cloth wastes, and, as such, we thermally modeled drum storage of these stabilized ceric nitrate/nitric acid cotton wastes. This is discussed in the next section.

\subsubsection{Thermal Modeling of Stabilized Cerium Nitrate/Nitric Acid Cotton Waste}

The laboratory results show that slow exothermic reactions take place at room temperature when cerium nitrate is used with cotton cloths. To gain a greater understanding of the reactivity risk, we modeled the thermal behavior of a nominal drum containing cerium cloths using ARC-measured initial reaction rates. We did not model any rate acceleration or the results showing that much more energetic reactions can be initiated at higher temperatures. 


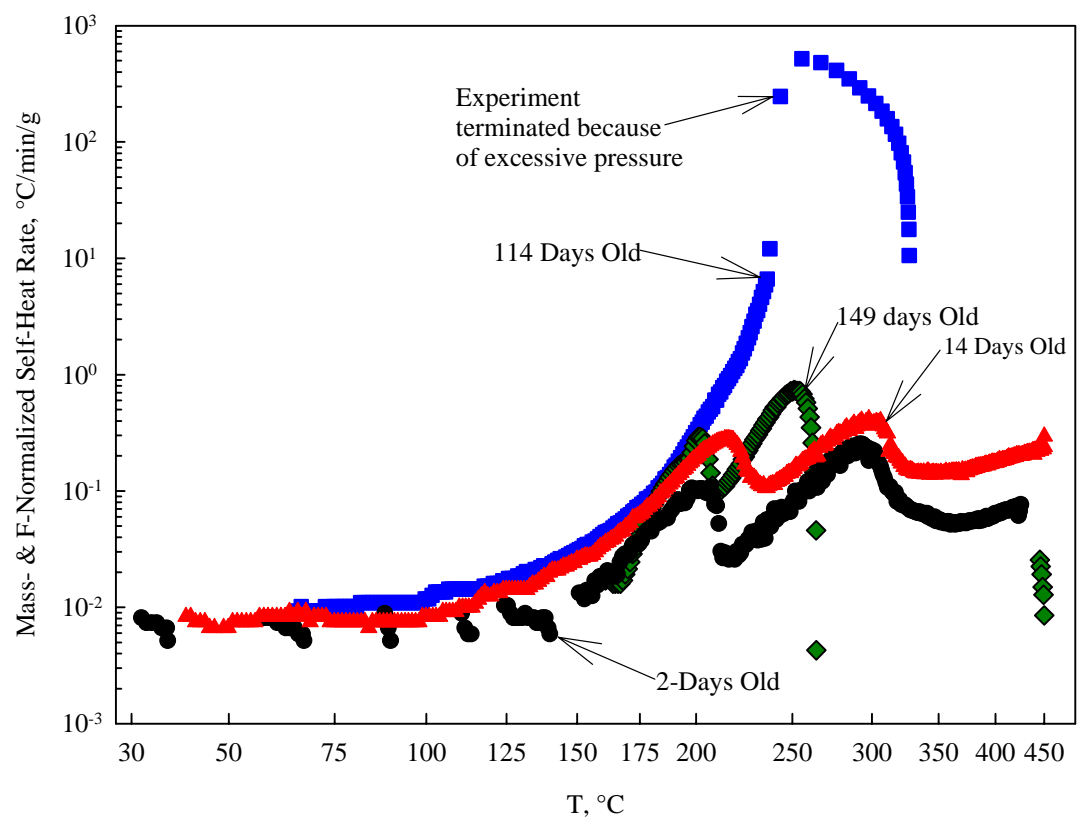

Figure 5.7. Arrhenius Plot of ARC-Measured Thermal Sensitivity of Dried, Ferrous Sulfate-Reduced, Sodium Hydroxide-Neutralized Ceric Nitrate/Nitric Acid/86\% Cotton/14\% Polyester Cloth After Aging 3, 14, 114, and 149 Days

That relationship is of great concern because the insulating effects of packaging may result in unacceptable temperatures if even a small heat-generating reaction is taking place inside a waste drum. If drum temperatures were allowed to reach about $180^{\circ} \mathrm{C}$, a runaway reaction could result. The objective of the thermal modeling is to estimate the internal temperature distribution of a drum loaded with cotton cloths used for decontamination with cerium nitrate solution.

The modeling was conducted using two- and three-dimensional numerical simulations of drums arranged in a $3 \times 3$ array. The key assumptions included:

Heat load (from chemical reactions)

Mass load of cloths in drum

Effective thermal conductivity of cloths in bags

Ambient temperature

Natural convection only

Drum surface radiation neglected (no solar insulation) $=\quad 125$ watts

$=\quad 66$ pounds

$=\quad 0.046 \mathrm{Btu} / \mathrm{hr}-\mathrm{ft}-{ }^{\circ} \mathrm{F}$

$=\quad 45^{\circ} \mathrm{C}\left(113^{\circ} \mathrm{F}\right)$

No evaporative heat loss. 
Figure 5.8 shows how the maximum (centerline) temperature of the drum increases as more cloths are packed inside. During the period that the cloths are reacting with the residual decontamination solution, each cloth contributes a small amount of heat to the drum. A typical fully loaded drum would be predicted to generate about 125 watts.

Drum Temperature vs. Heat Load

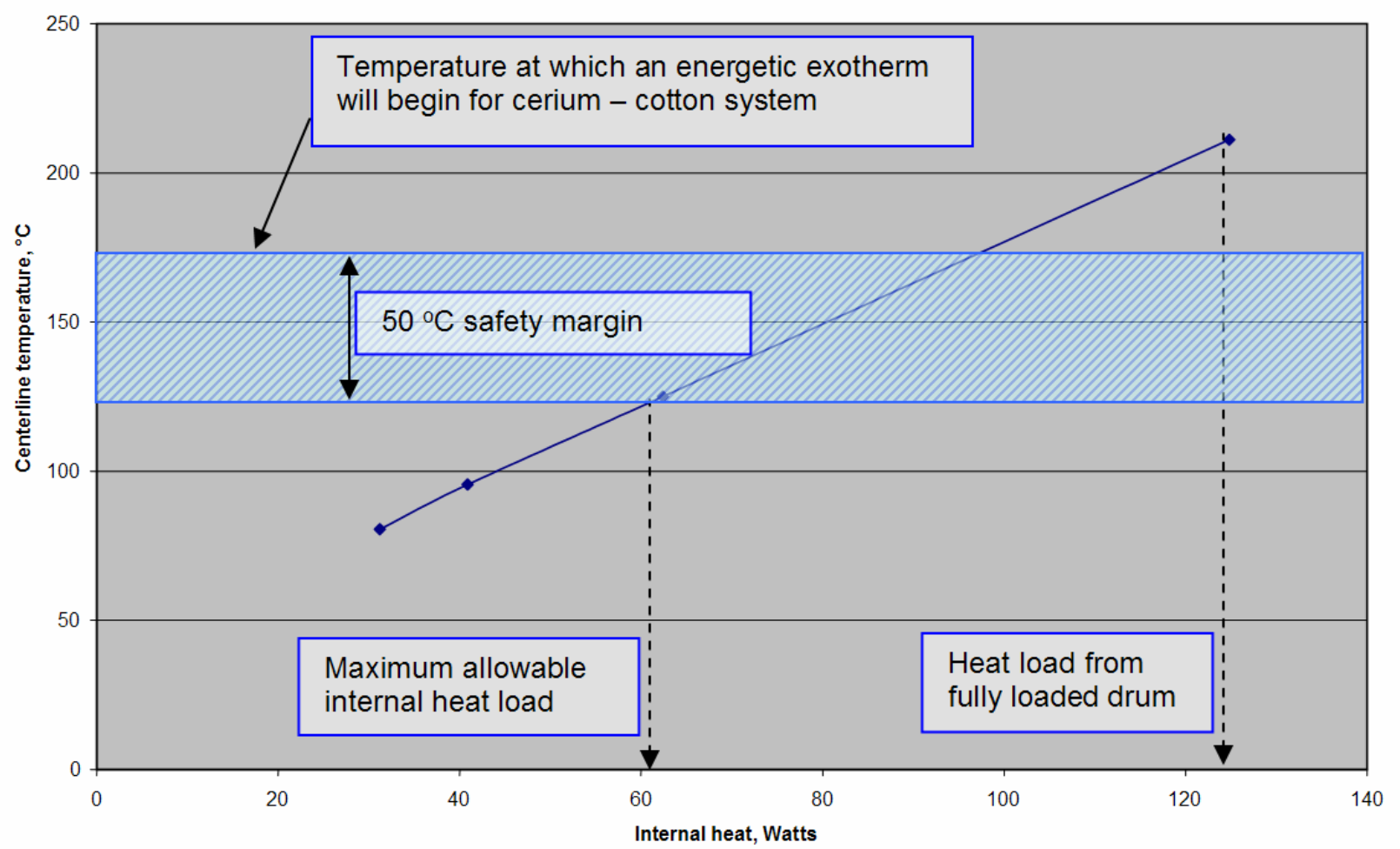

Figure 5.8. Predicted Temperature for Drum of Cerium-Cotton Waste

Clearly, if no reaction heat is dissipated, a fully loaded drum will cause the temperature to rise to the point where the energetic reaction begins (about $180^{\circ} \mathrm{C}$ ). Even half loaded with cloths, the internal heat generation will cause the temperature to rise to unacceptably high levels. As such, it was concluded that a safe configuration could not be guaranteed if heat-generating reactions were occurring within the drum at expected storage conditions. Efforts were then focused on finding combinations of cloth materials and decontamination solutions that would not self-heat, and the modeling effort was discontinued.

\subsubsection{Kinetic Effects for Simulated Stabilized Simulated Cloth Decontamination Wastes Arising from Use of Ceric Nitrate/Nitric Acid}

To develop some kinetic data, we used Osawa's strategy employing different heating rates and reaction peak maximums to develop Arrhenius reaction parameters $E_{a}$, activation energy, and $A$, the frequency factor or Arrhenius pre-exponential (Ozawa 1970). We analyzed the simulated stabilized ceric nitrate/nitric acid cotton cloth waste at DTA heating rates of $2,5,10$, and $20^{\circ} \mathrm{C} / \mathrm{min}$ to obtain the Arrhenius parameters. The exothermic peak positions are a function of the heating rate and by plotting 
the natural log of the heating rate vs the reciprocal absolute mid-point peak temperature, $\mathrm{E}_{\mathrm{a}}$ and $\mathrm{A}$ may be calculated. This allows calculation of the reaction rate constant, and the change in the rate constant with a change in temperature.

\subsection{Cotton Cloths Treated with $\mathrm{Ce}^{+4}, \mathrm{HNO}_{3}, \mathrm{Fe}^{++}$, and $\mathrm{OH}^{-}$and Analyzed under Air Heated at $2,5,10$, and $20^{\circ} \mathrm{C} / \mathrm{min}$}

A cotton cloth was treated with $\mathrm{Ce}\left(\mathrm{NO}_{3}\right)_{4}, \mathrm{HNO}_{3}, \mathrm{FeSO}_{4}$, and $\mathrm{NaOH}$ on 3/10/04 and air dried. We analyzed a 119-day old aliquot by TGA/DTA at $2^{\circ} \mathrm{C} / \mathrm{min}$. We used this slower heating rate to resolve different reaction peaks at the low temperatures and to provide data for development of a kinetic model. The $2^{\circ} \mathrm{C} / \mathrm{min}$ TGA/DTA analysis provided in Figure 5.9 shows that below $150^{\circ} \mathrm{C}$, the material endothermically loses $4.5 \mathrm{wt} \%$ in four steps and reacts exothermically in at least two significant reactions at 250 and $390^{\circ} \mathrm{C}$. Data from the two exothermic reactions were used to determine $\mathrm{E}_{\mathrm{a}}$ and $\mathrm{A}$.

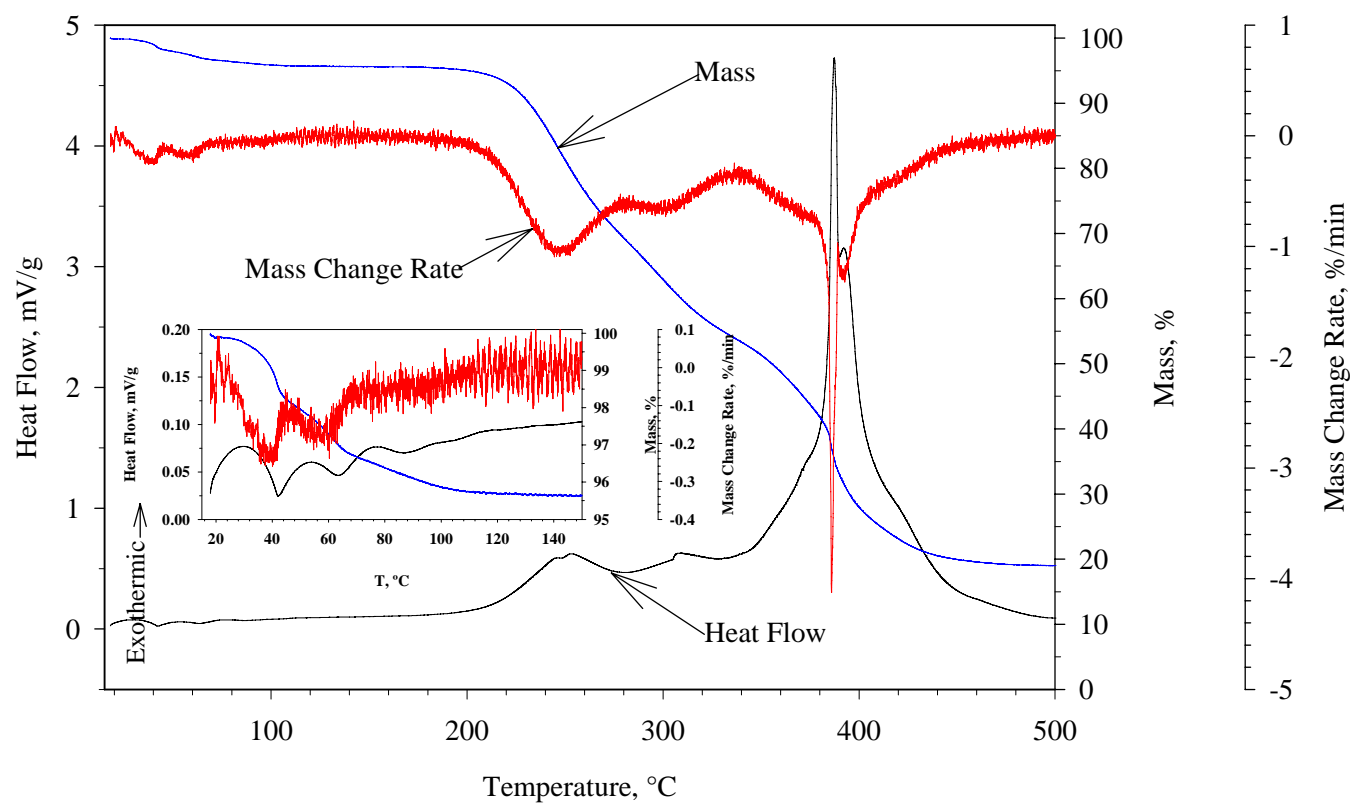

Figure 5.9. TGA/DTA-Measured Thermal Behavior of Stabilized Ceric Nitrate/Nitric Acid Cotton Cloth at $2{ }^{\circ} \mathrm{C} / \mathrm{min}$. The inset is an expansion to provide greater detail for the low temperature reactions.

A sample of the 118-day cloth was analyzed by DTA using a heating rate of $5^{\circ} \mathrm{C} / \mathrm{min}$. The enthalpy changes are provided in Figure 5.10.

The 145-day old cloth sample was analyzed by DTA using a heating rate of $10^{\circ} \mathrm{C} / \mathrm{min}$. The enthalpy changes are given in Figure 5.11. 


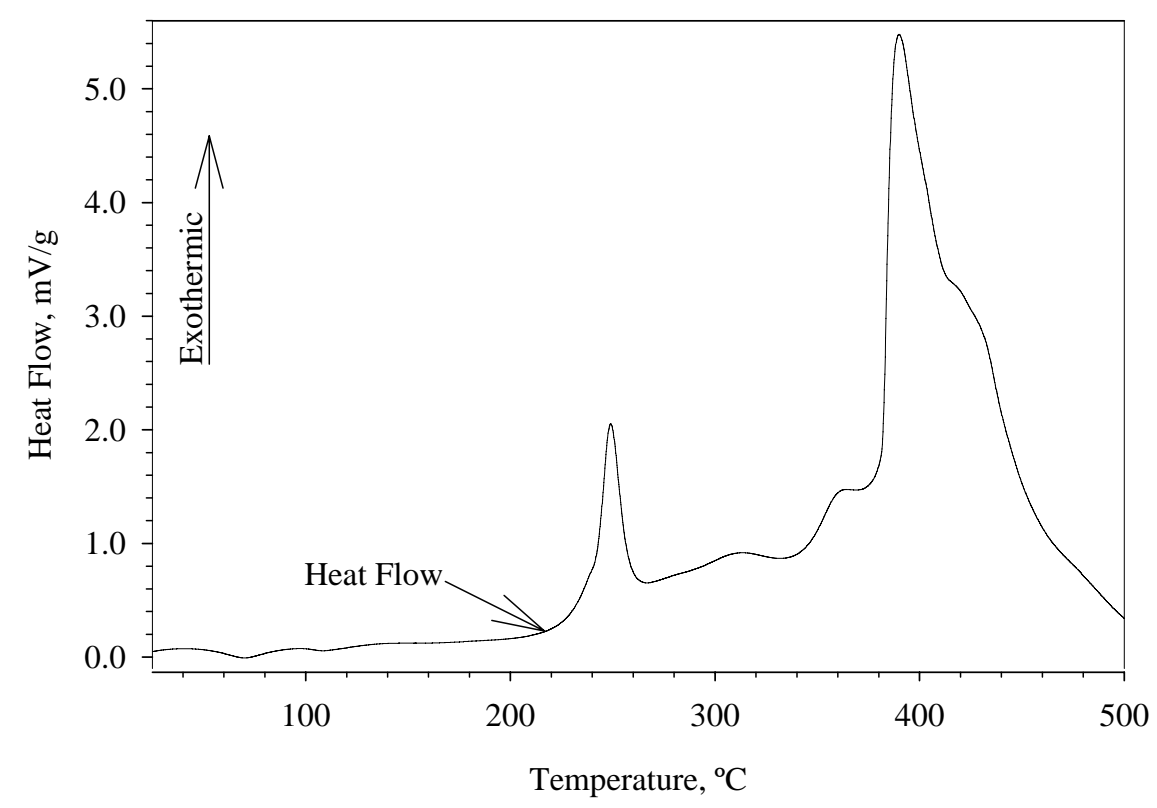

Figure 5.10. DTA-Measured Thermal Behavior of Stabilized Ceric Nitrate/Nitric Acid Cotton Cloth at $5^{\circ} \mathrm{C} / \mathrm{min}$

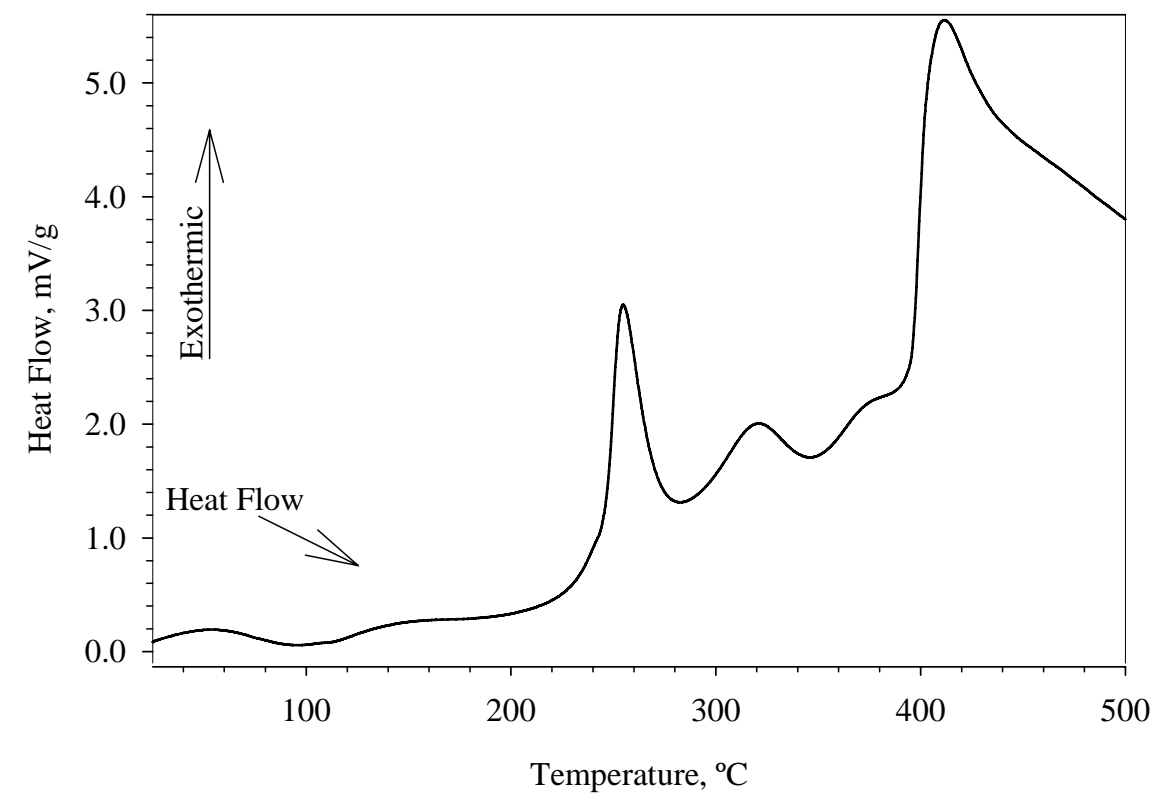

Figure 5.11. DTA-Measured Thermal Behavior of Stabilized Ceric Nitrate/Nitric Acid Cotton Cloth at $10^{\circ} \mathrm{C} / \mathrm{min}$

The 120-day old cloth sample was analyzed in the DTA using a heating rate of $20^{\circ} \mathrm{C} / \mathrm{min}$. The enthalpy changes are provided in Figure 5.12. 


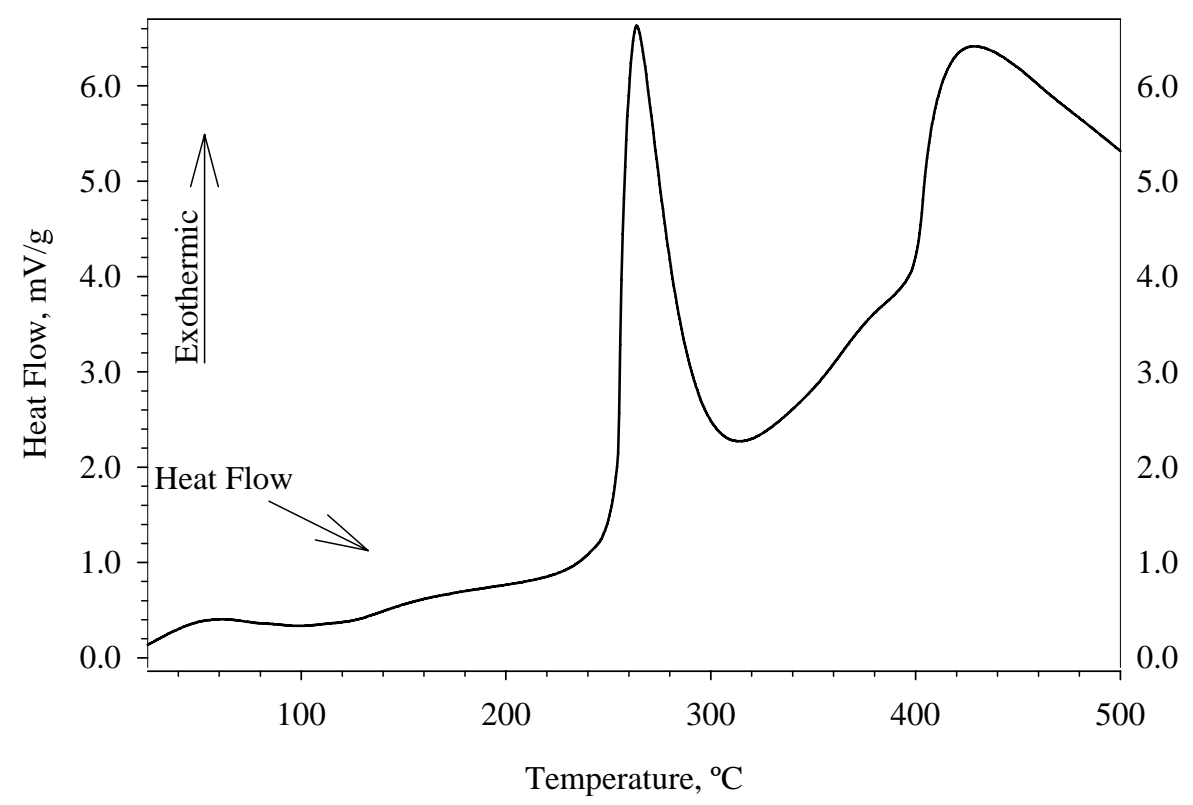

Figure 5.12. DTA-Measured Thermal Behavior of Stabilized Ceric Nitrate/Nitric Acid Cotton Cloth at $20^{\circ} \mathrm{C} / \mathrm{min}$

The effect of heat rate on the DTA peak maximums of the nominal $250^{\circ} \mathrm{C}$ and the $390^{\circ} \mathrm{C}$ exothermic reactions observed for simulated stabilized ceric nitrate/nitric acid cotton cloth waste is provided in Table 5.1. We used these data and Ozawa’s approach for determining a reaction's Arrhenius kinetic parameters.

Table 5.1. Peak Maxima for DTA-Observed Exotherms for Simulated Stabilized Ceric Nitrate/Nitric Acid Cotton Cloth Decontamination Waste

\begin{tabular}{|c|c|c|}
\hline \multirow{2}{*}{ Heating Rate, ${ }^{\circ} \mathbf{C} /$ min $^{\mid}$} & \multicolumn{2}{|c|}{ Mid-Peak Maxima ${ }^{\mathbf{~}} \mathbf{C}$} \\
\cline { 2 - 3 } & Peak 1 & Peak 2 \\
\hline 2 & 245.2 & 387.4 \\
\hline 5 & 248.9 & 389.5 \\
\hline 10 & 254.5 & 409.3 \\
\hline 20 & 263.4 & 418.0 \\
\hline
\end{tabular}

From Ozawa’s approach:

$$
E_{a}=-2.09 * R * \frac{\Delta \log (\beta)}{\Delta\left(\frac{1}{T}\right)} \mathrm{cal} / \mathrm{g}-\mathrm{mole}
$$

where $\mathrm{R}$ is the gas constant [1.987 cal/(g-mole*K)], $\beta$ is the heating rate in ${ }^{\circ} \mathrm{C} / \mathrm{min}$ or $\mathrm{K} / \mathrm{minute}$, and $\mathrm{T}$ is the temperature in Kelvin. Thus $E_{a}$ can be obtained from the slope of a plot of $\ln \beta$ vs 1/T. 
The Arrhenius frequency factor, A, was obtained from:

$$
A=\left(\beta E / R T^{2}\right) \exp (E / R T) \min ^{-1}
$$

Figure 5.13 presents the Arrhenius type plot of $\ln \beta$ vs 1/T. Based on Osawa's method, the complete Arrhenius rate equation for the reaction responsible for peak 1 is then

$$
\mathrm{K}_{1}=9.2 \mathrm{E} 10^{6} * \exp (-139883 / \mathrm{RT})
$$

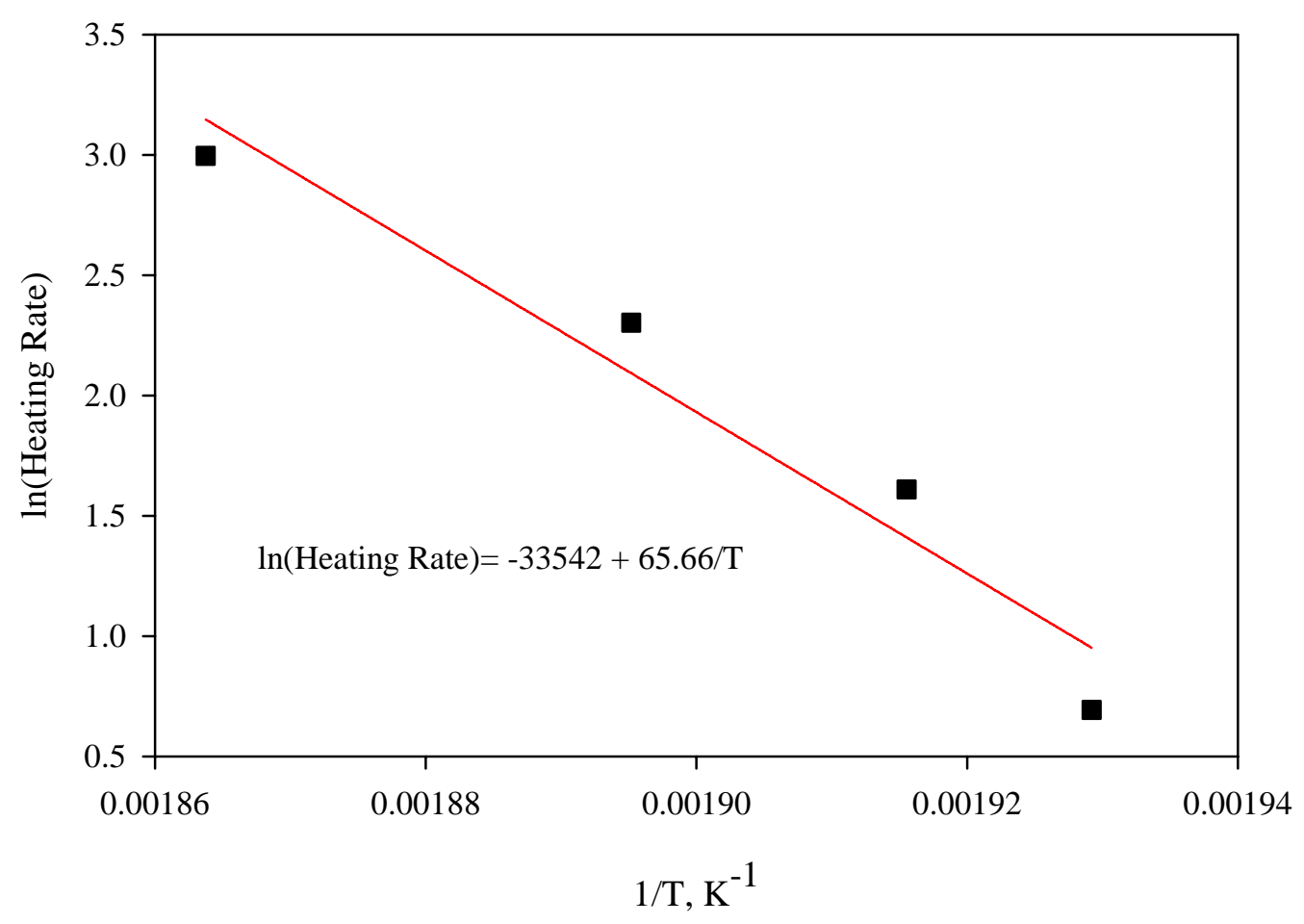

Figure 5.13. Arrhenius Plot for DTA-Observed Exothermic Reaction 1 for Stabilized Ceric Nitrate/Nitric Acid Cloth Waste

If one plots the natural logarithm of the heating rate against the reciprocal of the second peak center temperature, one obtains Figure 5.14. 


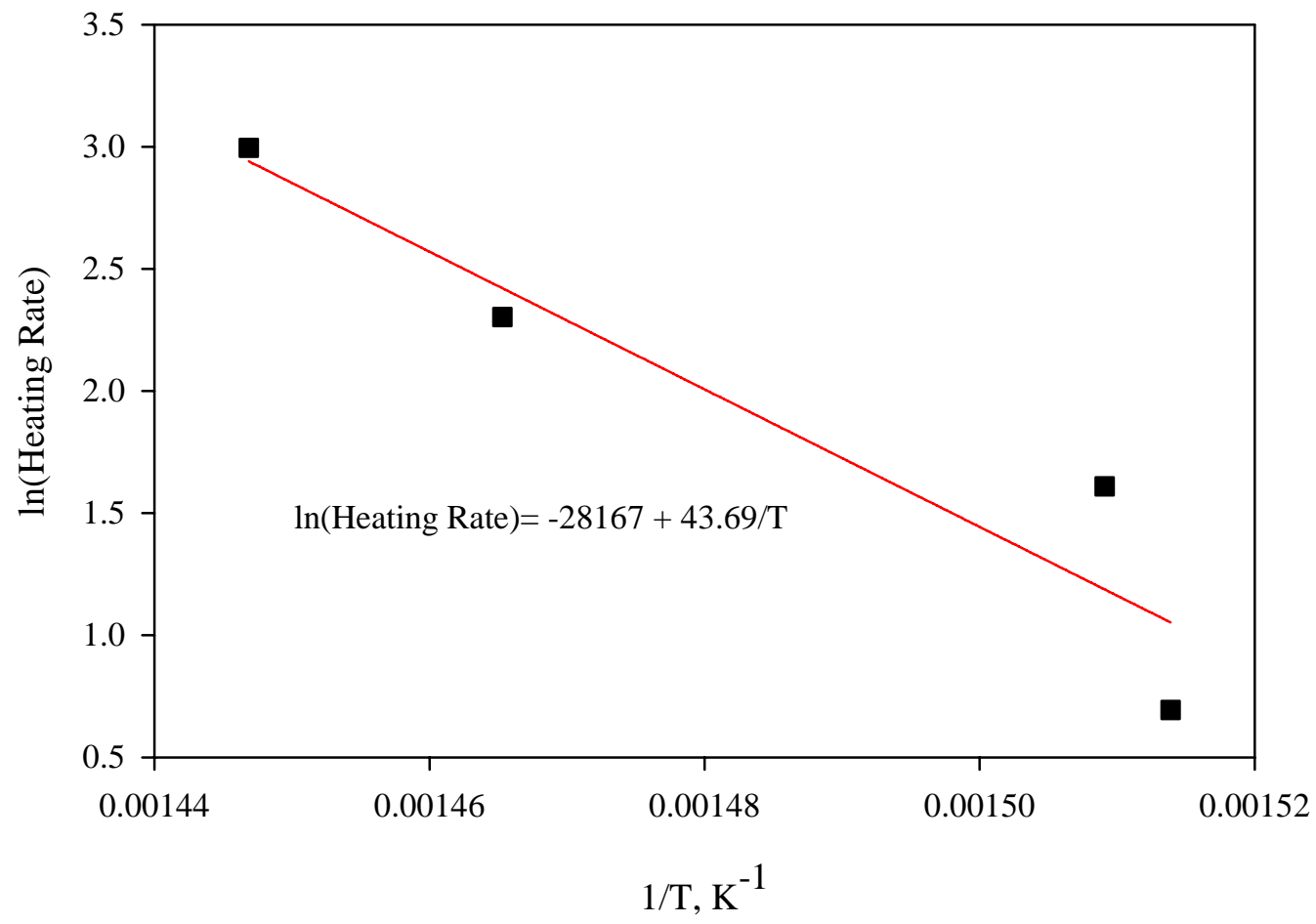

Figure 5.14. Arrhenius Plot for DTA-Observed Exothermic Reaction 2 for Stabilized Ceric Nitrate/Nitric Acid Cloth Waste

$$
\mathrm{K}_{2}=9.12 \mathrm{E} 88 * \exp (116983 / \mathrm{RT})
$$

\subsubsection{Variation of Rate Constants with Temperature}

Using the temperature dependencies of the rate constants, we calculated the rate constants at various temperatures and present them in Table 5.2.

Table 5.2. Reaction Rate Constants at Various Temperatures for DTA-Observed Exothermic Reactions for Stabilized Ceric Nitrate/Nitric Acid Cloths

\begin{tabular}{||c|c|c||}
\hline \hline Temp C & $\mathrm{K}_{1}, \mathrm{~min}^{-1}$ & $\mathrm{~K}_{2}, \mathrm{~min}^{-1}$ \\
\hline 20 & $1.14 \mathrm{E}-46$ & $2.25 \mathrm{E}-50$ \\
\hline 50 & $5.46 \mathrm{E}-37$ & $2.81 \mathrm{E}-42$ \\
\hline 100 & $2.59 \mathrm{E}-24$ & $1.12 \mathrm{E}-31$ \\
\hline 150 & $1.24 \mathrm{E}-14$ & $1.40 \mathrm{E}-23$ \\
\hline 200 & $5.36 \mathrm{E}-07$ & $3.39 \mathrm{E}-17$ \\
\hline 250 & $8.03 \mathrm{E}-01$ & $4.95 \mathrm{E}-12$ \\
\hline 300 & $1.01 \mathrm{E}+05$ & $9.07 \mathrm{E}-08$ \\
\hline 350 & $1.92 \mathrm{E}+09$ & $3.44 \mathrm{E}-04$ \\
\hline 400 & $8.44 \mathrm{E}+12$ & $3.84 \mathrm{E}-01$ \\
\hline
\end{tabular}


For unit concentrations of reagents, the reciprocal of the rate constant is a measure of the time required for complete reaction.

At $20^{\circ} \mathrm{C}$ and with unit reactant concentrations, reaction 1 will be complete in $6.8 \times 10^{45}$ min and reaction 2 will require $4.44 \times 10^{49} \mathrm{~min}$. Reactions 1 and 2 are most likely a direct reaction between nitrates and the substrate cloth molecules.

\subsubsection{Thermal Behavior of Ceric Nitrate/Nitric Acid 86\% Cotton/14\% Polyester Cloth Waste}

With the results of our experimental thermoanalytical and our thermal modeling of the eventual waste package for stabilized ceric nitrate/nitric acid cotton cloth waste indicating that a potential thermal reactivity risk may exist in the short-term ( $<149$ days), we investigated the reactivity of ceric nitrate/nitric acid cotton cloths prior to reduction and neutralization because 1 ) they are the immediate product of the ceric nitrate/nitric acid decontamination process and 2) their thermal sensitivity will assist in developing an understanding of the parameters that control the reactivity hazard of the reduced and neutralized ceric nitrate/nitric acid waste.

As shown in Figure 5.15, 2-day old, dried, ceric nitrate/nitric acid soaked 86\% cotton/14\% polyester cloths begin to react in air exothermically near $110^{\circ} \mathrm{C}$ after or during an apparent small endothermic mass loss beginning upon heating and completing just before the onset of a very rapid exothermic reaction at $180^{\circ} \mathrm{C}$. The rapidity of this latter gas-producing reaction indicates that, once started, it could have a significant impact on operational safety.

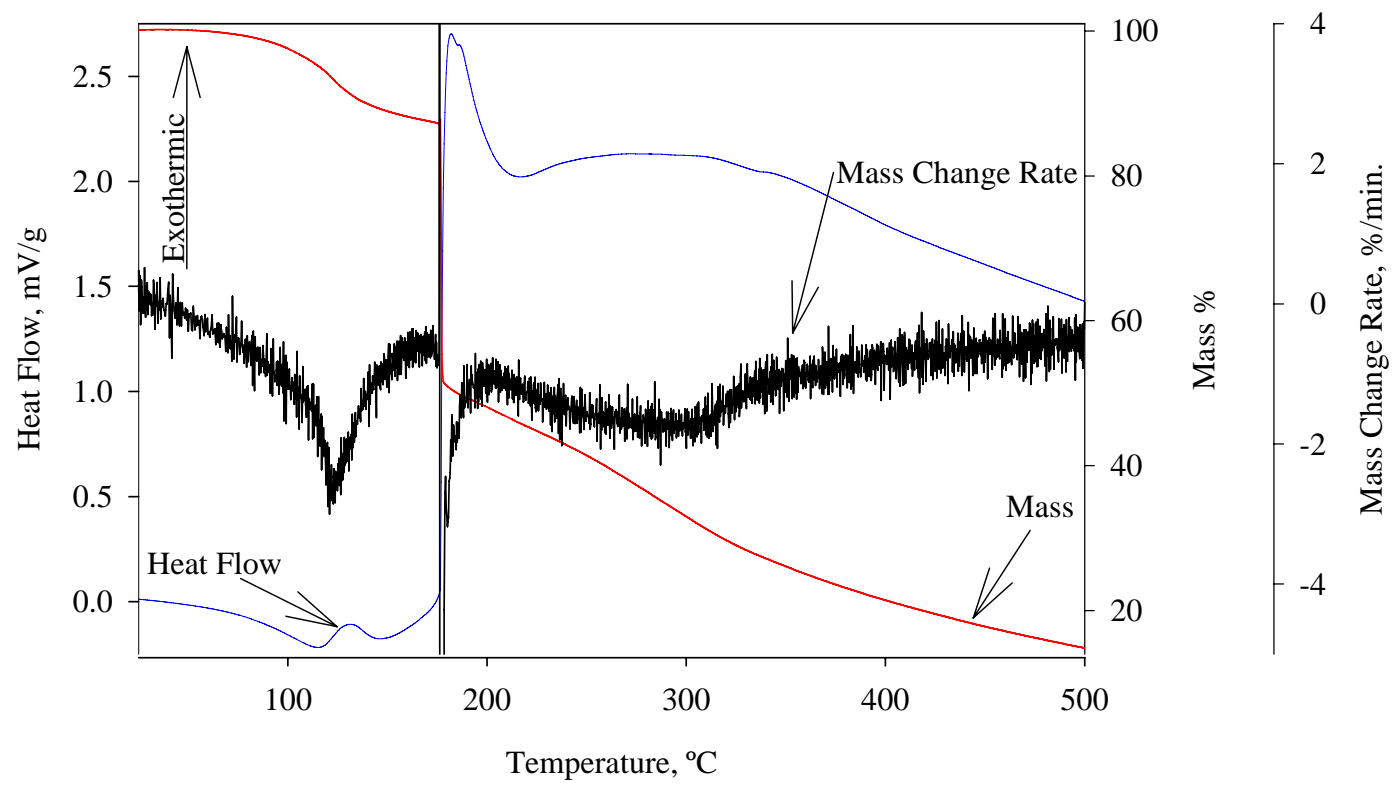

Figure 5.15. TGA/DTA-Measured Thermal Behavior of 2-Day Old, Dried, Ceric Nitrate/Nitric Acid Cotton Cloth in Air at $10^{\circ} \mathrm{C} / \mathrm{min}$ 
Dried, ceric nitrate/nitric acid soaked cotton cloth heated under adiabatic conditions begins to support a self-sustaining reaction beginning at $60^{\circ} \mathrm{C}$ as shown in Figure 5.16. The age of the material does not have much effect on the onset temperature for 3- and 14-day old samples of the same cloth. Both materials appear to encounter a quenching reaction near $100^{\circ} \mathrm{C}$ which could be due to evaporation of either water or nitric acid. Heating to $110^{\circ} \mathrm{C}$ initiates another self-sustaining reaction. This reaction stops near $160^{\circ} \mathrm{C}$ for the 3-day old material; however it again begins to react after being heated another $10^{\circ} \mathrm{C}$. Thereafter both materials continue to self-heat. The pressure for the 3-day old material follows the self-heat profile suggesting that the observed reactions are gas producers. Unfortunately, the pressure transducer malfunctioned during the analysis of the 14 day old material.

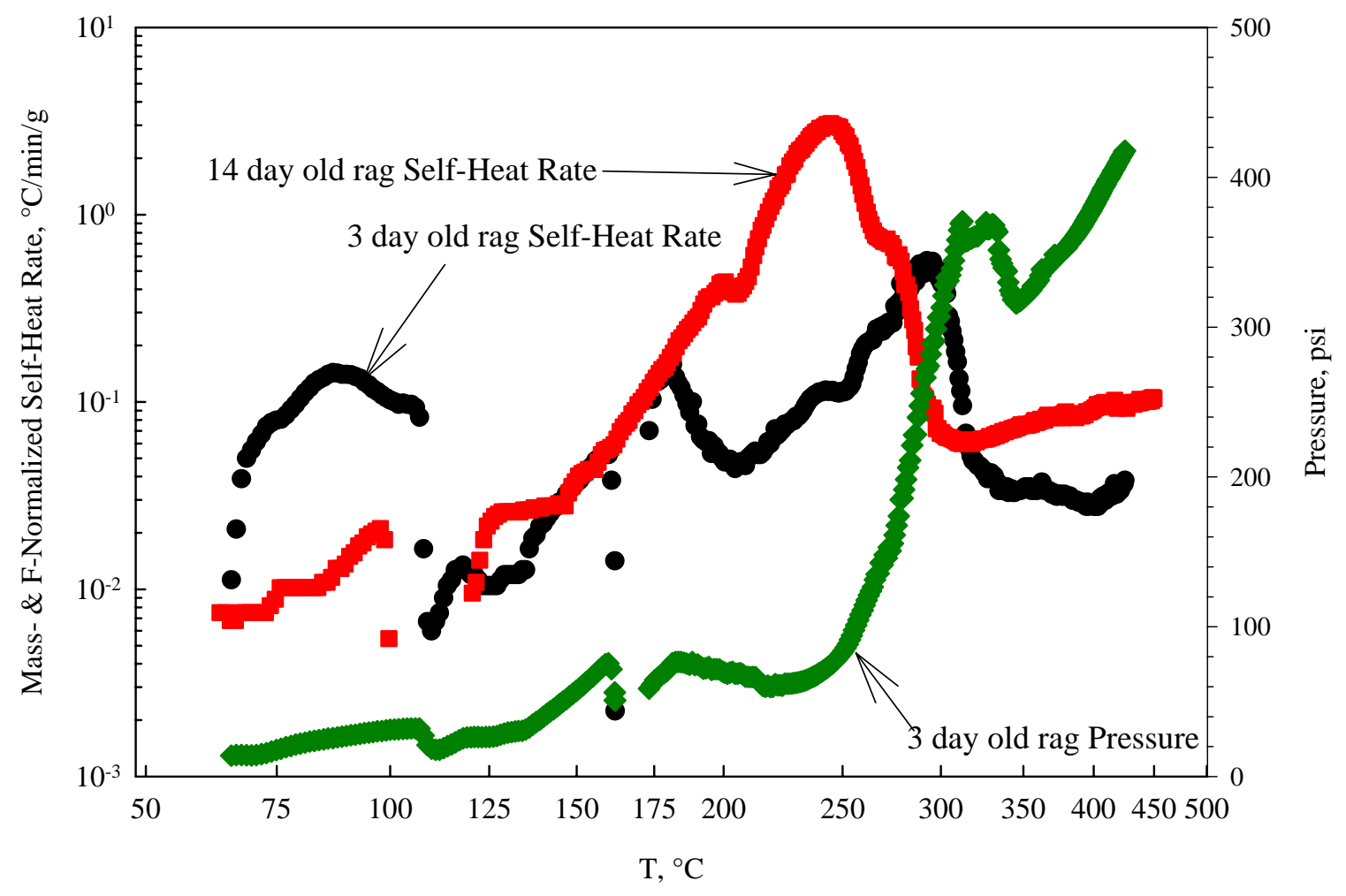

Figure 5.16. ARC-Measured Thermal Behavior of Air-Dried Ceric Nitrate/Nitric Acid 86\% Cotton/14\% Polyester Cloths as Measured by ARC

Comparison of the two analyses presented in Figure 5.16 finds differences in behaviors of the two ages of ceric nitrate/nitric acid cotton cloth above $175^{\circ} \mathrm{C}$. The older material continues to rapidly self-heat while the younger material slows before it accelerates beginning at $200^{\circ} \mathrm{C}$.

Our thermal analyses of ceric nitrate/nitric acid saturated cotton cloths indicate that up to 14 days old these materials begin reacting at $65^{\circ} \mathrm{C}$, within the $50^{\circ} \mathrm{C}$ CCPS recommended margin above the Hanford maximum observed temperature of $45^{\circ} \mathrm{C}$. Our DTA results indicate that should the material reach a temperature of $180^{\circ} \mathrm{C}$, a very rapid gas-producing reaction can occur. Our results thus indicate that the thermal reactivity risks of these materials should be managed or mitigated. 


\subsubsection{Thermal Reactivity of Ceric Nitrate/Nitric Acid Synthetic Cloths}

Because of the observed thermal sensitivity of cotton cloths used for removing spent ceric nitrate/nitric acid, we considered alternative sorbent materials for removing the Pu-laden decontamination solution as a path for mitigating the potential waste stability risk arising from use of the ceric nitrate/nitric acid decontamination technology. As a mitigation strategy, we investigated two polyamide/polyester cloths, in $50 \% / 50 \%$ and $20 \% / 80 \%$ relative compositions, in combination with ferrous sulfate reduction of the $\mathrm{Ce}^{4+}$ and sodium hydroxide neutralization of the nitric acid.

\subsubsection{Thermal behavior of Stabilized Ceric Nitrate/Nitric Acid with 50\% Polyamide/50\% Polyester cloth waste}

The thermal behavior of as-received 50\% polyamide/50\% polyester is provided in Figure 5.17. The cloth does not decompose at a measurable rate until heated to $350^{\circ} \mathrm{C}$ whereupon it endothermically loses $80 \%$ of its mass. As the cloth is heated, the heat flow data indicates that several endothermic reactions occur without mass loss; likely reactions include melting, crystal changes, and formation of solid solutions. The cause of the large endotherm beginning upon the start of heating is unknown because of the absence of a mass loss; usually reactions in this temperature range are caused by water evaporation. The TGA/DTA analyses indicate that the $50 \%$ polyamide $/ 50 \%$ polyester cloth alone will not contribute to a thermal hazard for decontamination wastes arising from their use.

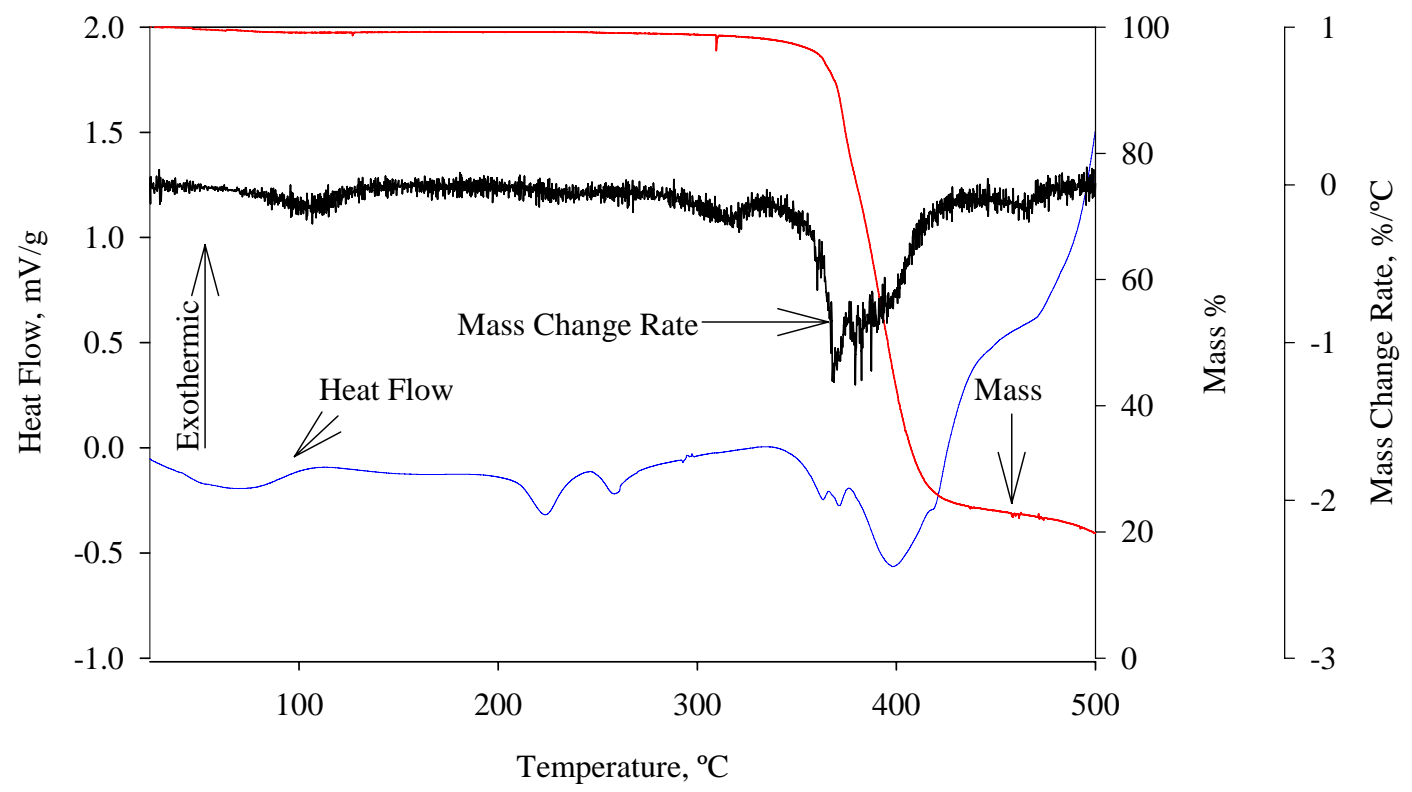

Figure 5.17. TGA/DTA-Measured Thermal Behavior of As-Received 50\% Polyamide $/ 50 \%$ Polyester Cloth at $10^{\circ} \mathrm{C} / \mathrm{min}$

The $10^{\circ} \mathrm{C} / \mathrm{min}$, DTA-measured thermal behavior of stabilized (reduced and neutralized) ceric nitrate/nitric acid with 50\% polyamide/50\% polyester cloths is provided in Figure 5.18. This analysis indicates only slight endothermic behavior or little or no exothermic reaction of this stabilized synthetic cloth until significant exothermic reactions begin at $200^{\circ} \mathrm{C}$. After $200^{\circ} \mathrm{C}$ three exothermic reactions, at $\sim 270^{\circ} \mathrm{C}$, 
$340^{\circ} \mathrm{C}$, and $390^{\circ} \mathrm{C}$, are observed. Because the onset of exothermic behavior is $>100^{\circ} \mathrm{C}$ above the nominal highest Hanford shaded storage temperature $\left(45^{\circ} \mathrm{C}\right)$, the rule-of-thumb for application of DTA for identifying reactivity hazards, the DTA results suggest that this potential decontamination waste stream poses little or no thermal reactivity risk. However, it must be recognized that age of interaction of the synthetic cloth with the ceric nitrate/nitric acid was not evaluated.

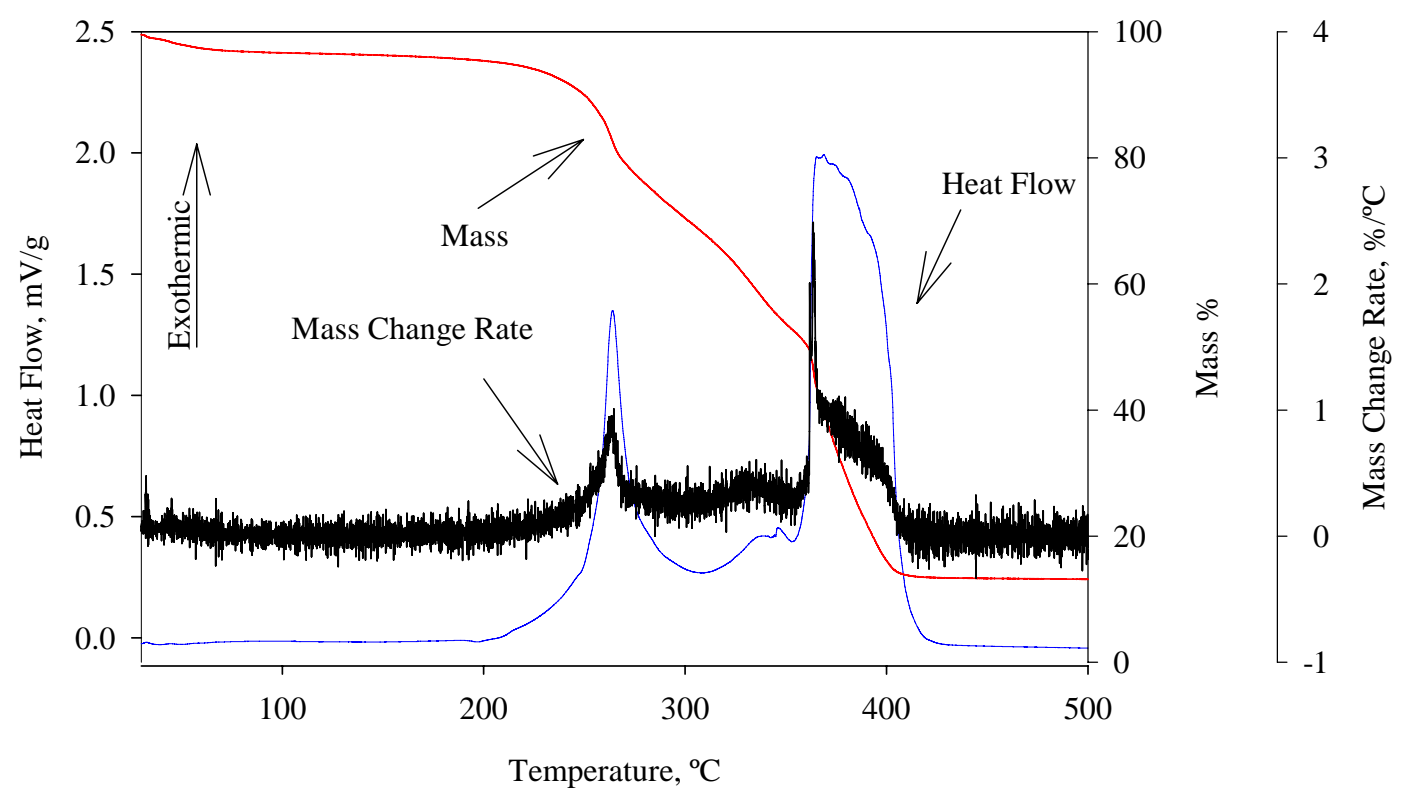

Figure 5.18. DTA-Measured Thermal Behavior of Stabilized Ceric Nitrate/Nitric Acid 50\% Polyamide $/ 50 \%$ Polyester Cloth at $10^{\circ} \mathrm{C} / \mathrm{min}$

Consistent with DTA results, the ARC also gave encouraging results for mitigating the thermal reactivity risks of wastes arising from using ceric nitrate/nitric acid with the $50 \%$ polyamide $/ 50 \%$ polyester cloth to decontaminate Pu-gloveboxes. As shown in Figure 5.19, the ARC did not observe a self-sustaining reaction until the simulated stabilized ceric nitrate/nitric acid with $50 \%$ polyamide/ $50 \%$ polyester cloth waste was heated to $170^{\circ} \mathrm{C}$. This onset temperature is much greater than the CCPS's ARC-rule-of-thumb $50^{\circ} \mathrm{C}$ used to identify thermally reactive systems.

It is interesting that the ARC-observed oxidation of the stabilized ceric nitrate/nitric acid with $50 \%$ polyamide $/ 50 \%$ polyester cloth simulated waste proceeds in two distinct steps as suggested by the DTA. The ARC measured peak maxima for the first observed exothermic reaction were 210 and $230^{\circ} \mathrm{C}$ for the duplicate analyses. The DTA-measured first exothermic reaction peak maximum was $270^{\circ} \mathrm{C}$, or 70 to $40^{\circ} \mathrm{C}$ greater than the ARC-observed maximum.

Our thermoanalytical results indicate that the risk from disposal of wastes arising from the ceric nitrate/nitric acid system could be mitigated by using $50 \%$ polyamide $/ 50 \%$ polyester cloths to remove the decontamination solution from the glovebox walls. This is with the caveat that we do not know the effects of aging which could be important based on our testing of the use of cotton cloths to collect the decontamination solution. 


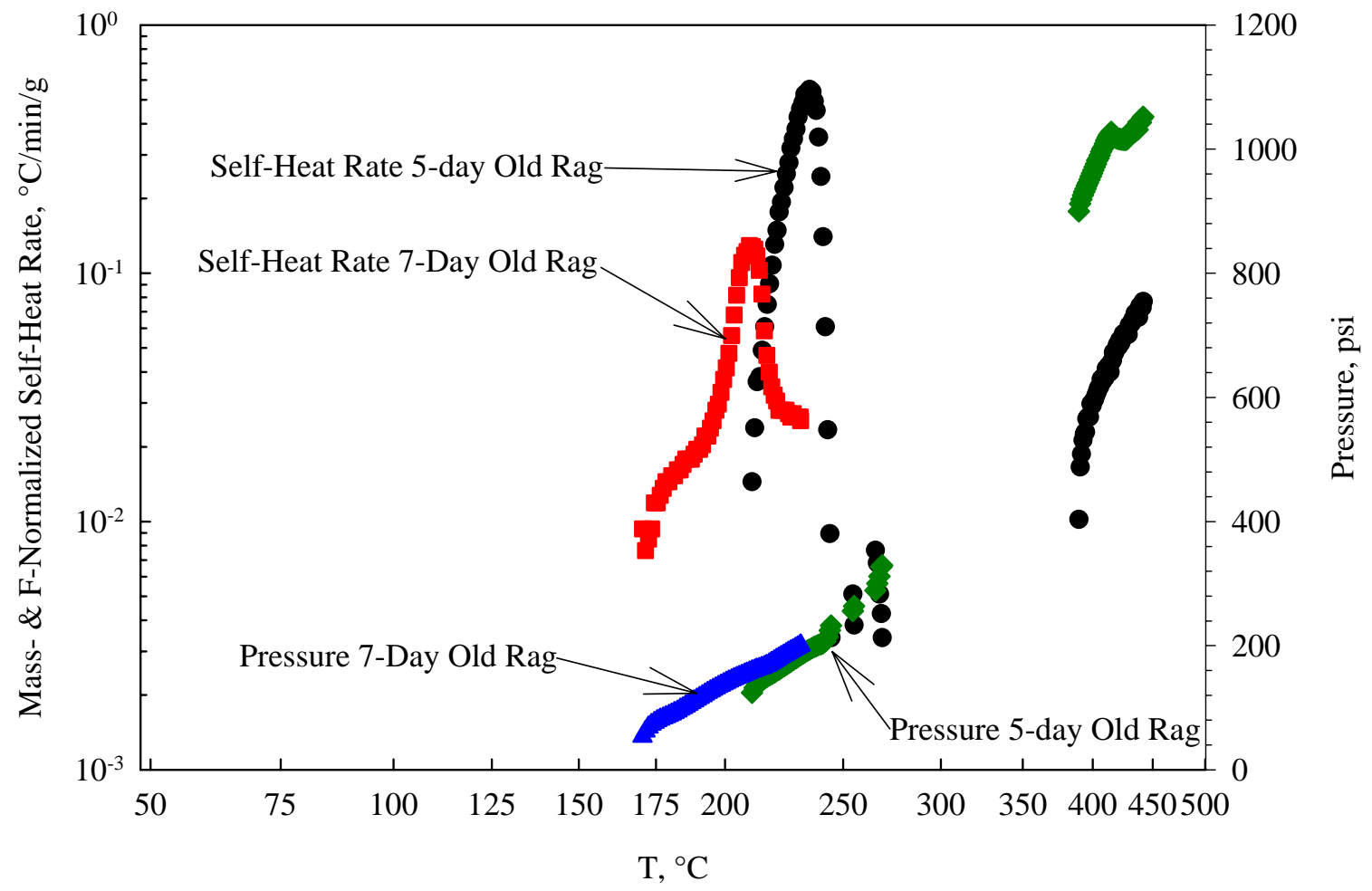

Figure 5.19. ARC-Measured Thermal Behavior of Dried, Stabilized Ceric Nitrate/Nitric Acid Soaked 50\% Polyamide/50\% Polyester Cloth

\subsubsection{Thermal Behavior of Ceric Nitrate/ $\mathrm{HNO}_{3}$ with $20 \%$ Polyamide/80\% Polyester Cloth Waste}

In a parallel effort to identify a cloth for removing the spent Pu-containing ceric nitrate/nitric acid from the glovebox, we investigated $20 \%$ polyamide/ $80 \%$ polyester. For this investigation, we only used ARC.

The ARC again gave encouraging results with respect to the thermal stability of stabilized ceric nitrate/nitric acid cloth simulated waste. Figure 5.20 shows that a nominal $2.5 \mathrm{~g}$ sample will begin to react at an ARC-observed onset temperature of $190^{\circ} \mathrm{C}$ which is $>50^{\circ} \mathrm{C}$ above the maximum observed Hanford temperature of $45^{\circ} \mathrm{C}$, the CCPS's rule-of-thumb for identifying a potential thermal reactivity hazard,.

As with the $50 \%$ polyamide $/ 50 \%$ polyester cloth, our ARC analysis indicates that using the synthetic $20 \%$ polyamide/80\% polyester cloth to collect the used ceric nitrate/nitric acid decontamination solution will mitigate the potential thermal reactivity hazard that we identified for similar cotton cloth wastes. 


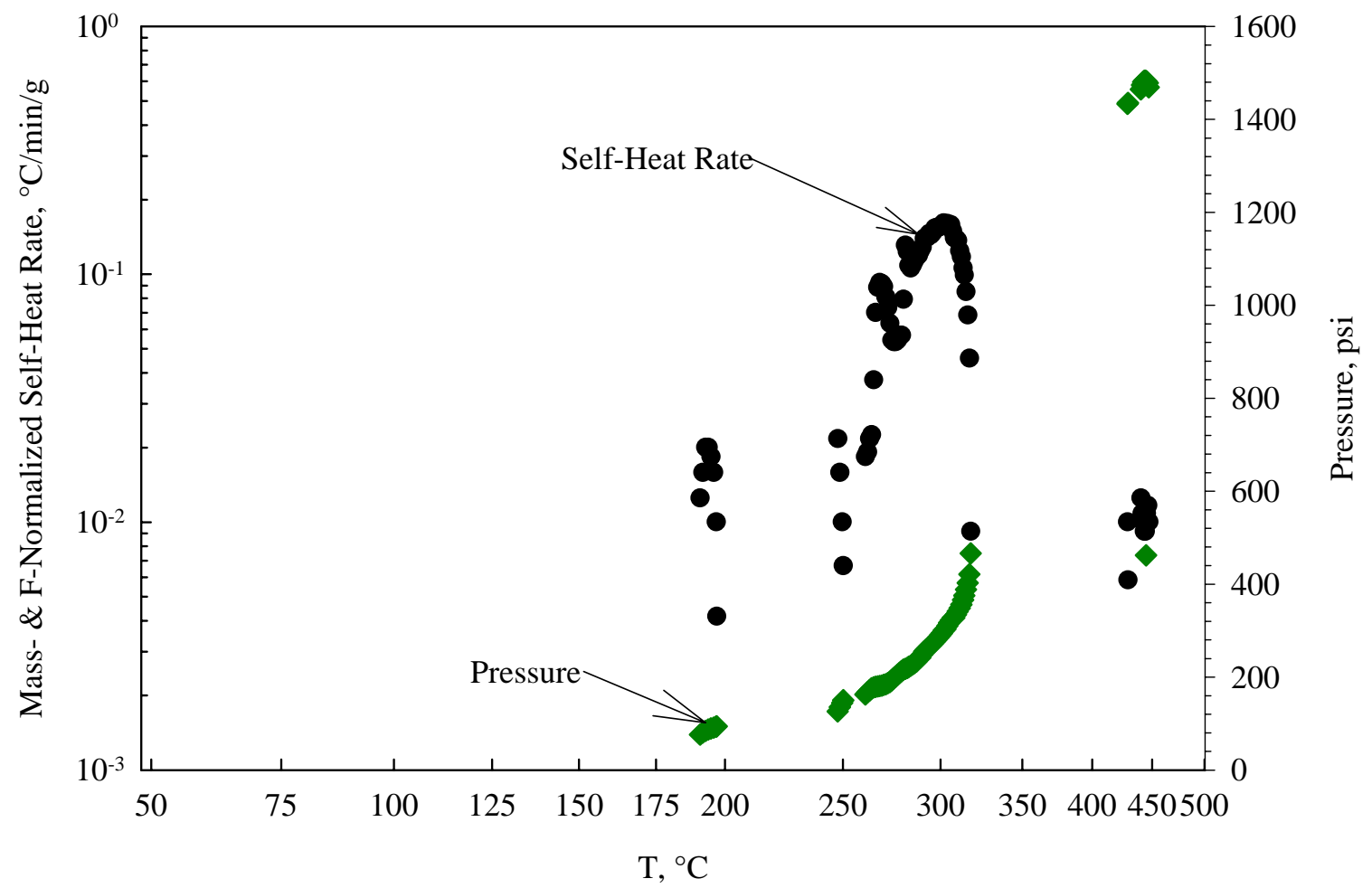

Figure 5.20. ARC-Measured Thermal Behavior of Ceric Nitrate/

Nitric Acid 20\% Polyamide/80\% Polyester Cloth

\subsubsection{Conclusions Regarding Thermal Reactivity of Cloth Wastes Arising from Ceric Nitrate/Nitric Acid Decontamination of Gloveboxes}

Our thermoanalytical and thermal modeling studies have shown that a potential thermal hazard exists for wastes arising from decontaminating gloveboxes with ceric nitrate/nitric acid and removing the used Pucontaining decontamination solution with $86 \%$ cotton $/ 14 \%$ polyester cloths. Our studies also indicate that using synthetic cloths of $20 \% / 80 \%$ or $50 \% / 50 \%$ polyamide/polyester instead of primarily cotton cloths is a potential approach for mitigating the risk of using the ceric nitrate/nitric acid decontamination technology. However, the effect of aging the polyamide/polyester rags with the ceric nitrate/nitric acid has not been fully investigated.

\subsection{Thermal Behavior of Simulated Potential Wastes Arising from the Use of RadPro ${ }^{\circledR}$ Decontamination Agents}

As described earlier, the RadPro ${ }^{\circledR}$ decontamination process is performed in several steps:

1. Decontaminate the surface with a buffered acidic degreaser;

2. Rinse with a nitric acid-based rinsate, remove the mixed decontamination and rinsate solution with sorbent material, and neutralize the acid in the cloth; 
3. Spray the decontaminated surface with an emulsifier;

4. After the specified dwell time, rinse the surface with the rinsate solution, remove using sorbent material, and neutralize the acid in the cloth.

To evaluate the thermally stability of potential RadPro waste forms, we prepared representative RadPro solutions provided in Table 5.3 from the RadPro supplied solutions whose MSDS compositions are provided in Table 2.2. We investigated sorbent materials and the effect of neutralization using TGA/DTA and ARC.

Table 5.3. Representative RadPro Solutions Used for Testing

\begin{tabular}{|l|l|l||}
\hline Solution Identification & Solution Composition, vol\% & Description \\
\hline \hline RadPro A & $75 \%$ RadPro ${ }^{\circledR} 0200 / 25 \%$ RadPro ${ }^{\circledR} 0300$ & Decontamination Solution \\
\hline RadPro B & $33 \%$ RadPro A)/67\% RadPro C & Decontamination + Rinsate \\
\hline RadPro C & $10 \%$ RadPro ${ }^{\circledR} 0300 / 90 \%$ DIW & Rinsate \\
\hline RadPro D & RadPro $^{\circledR} 0100$ & Emulsifying Solution \\
\hline RadPro E & $67 \%$ RadPro C/33\% RadPro D & Emulsifier + Rinsate \\
\hline
\end{tabular}

The sorbent materials tested were $100 \%$ cotton cloths (provided by Fluor) rather than the $86 \%$ cotton/14\% polyester cloths used for the ceric nitrate studies, $50 \%$ polyamide $/ 50 \%$ polyester, and $20 \%$ polyamide/80\% polyester. We investigated the neutralizing agents sodium hydroxide and sodium carbonate. Table 5.3 also provides the identifications that we assigned to each representative RadPro solution tested.

\subsubsection{Thermal Behavior of Dried RadPro ${ }^{\circledR}$ Decontamination Solution (RadPro A) with Saturated Cotton Cloth}

The RadPro decontamination solution (RadPro A) is an aqueous mixture of hydrochloric acid, ammonium fluoride, citric acid, nitric acid, and proprietary buffering agents. The fuels in this mix include ammonium ion, citrate, and potentially the buffering agents if they are organic. We studied the dried decontamination solution soaked cotton cloth to provide some insights into the factors that could control the thermal reactivity of RadPro ${ }^{\circledR}$ process cloth wastes. These cloths are potentially the most reactive based on the expected higher concentration of oxidants than the cloth arising after rinsing the surface (e.g., RadPro B, C, and E). 
Table 5.4. MSDS-Provided Compositions of RadPro ${ }^{\circledR}$ Solutions

\begin{tabular}{|c|c|c|c|c|c|}
\hline \multicolumn{6}{|c|}{ RadPro ${ }^{\circledR}$ Solutions } \\
\hline \multicolumn{2}{|c|}{ RadPro $^{\circledR} 0100$} & \multicolumn{2}{|c|}{ RadPro $^{\circledR} 0200$} & \multicolumn{2}{|c|}{ RadPro $^{\circledR} 0300$} \\
\hline Ingredient & $\begin{array}{l}\text { Concentration, } \\
\% \\
\end{array}$ & Ingredient & $\begin{array}{l}\text { Concentration, } \\
\%\end{array}$ & Ingredient & $\begin{array}{l}\text { Concentration, } \\
\%\end{array}$ \\
\hline $\begin{array}{l}\text { Ethylene } \\
\text { glycol } \\
\text { monobutyl } \\
\text { ether }\end{array}$ & $5-15$ & $\begin{array}{l}\text { Hydrochloric } \\
\text { acid }\end{array}$ & $1-5$ & Nitric Acid & $5-25$ \\
\hline Triethylamine & $0-1$ & $\begin{array}{l}\text { Ammonium } \\
\text { fluoride }\end{array}$ & $2-5$ & $\begin{array}{l}\text { Chemical } \\
\text { buffering } \\
\text { agents and } \\
\text { water }\end{array}$ & ? \\
\hline Isopropanol & $0-2$ & Citric acid & $1-3$ & & \\
\hline $\begin{array}{l}\text { Potassium } \\
\text { hydroxide }\end{array}$ & $1-5$ & & & & \\
\hline $\begin{array}{l}\text { Other } \\
\text { emulisifiers, } \\
\text { surfactants, } \\
\text { organic } \\
\text { sequestrants, } \\
\text { and water }\end{array}$ & ? & & & & \\
\hline
\end{tabular}

A cotton rag was soaked in RadPro A on 7/21/04, dried for 24 hours in a flowing air stream at ambient temperature, and run on the DTA instrument on 08/11/04 (21 days). Figure 5.21 shows an initial endothermic $8 \%$ mass loss occurring between ambient and $125^{\circ} \mathrm{C}$ likely due to residual water and possibly some of the two volatile acids, $\mathrm{HCl}$ and $\mathrm{HNO}_{3}$. At $125^{\circ} \mathrm{C}$ there is a small exothermic peak likely continuing to $190^{\circ} \mathrm{C}$ where another endothermic reaction apparently occurs. The combined mass losses between 125 and $210^{\circ} \mathrm{C}$ is 28 mass\%. Chemicals such as ammonium fluoride and organics may have lower vapor pressures and are likely not eliminated in the room temperature drying process. At $210^{\circ} \mathrm{C}$, a strong exothermic reaction begins and exhibits a maximum at $290^{\circ} \mathrm{C}$.

The ARC, as shown in Figure 5.22, observed self-propagating exothermic reactivity in the dried decontamination solution soaked cotton cloth beginning near $70^{\circ} \mathrm{C}$, within $50^{\circ} \mathrm{C}$ of Hanford's maximum temperature of $45^{\circ} \mathrm{C}\left(113^{\circ} \mathrm{F}\right)$. This first reaction continues beyond about $100^{\circ} \mathrm{C}$ but another exothermic reaction begins near $105^{\circ} \mathrm{C}$. This reaction continues to about $225^{\circ} \mathrm{C}$ where another series of exothermic reactions continue. The ARC indicates that at adiabatic conditions, a dried cotton cloth soaked in the RadPro $^{\circledR}$ decontamination solution will instigate a self-supporting reaction at $70^{\circ} \mathrm{C}$. 


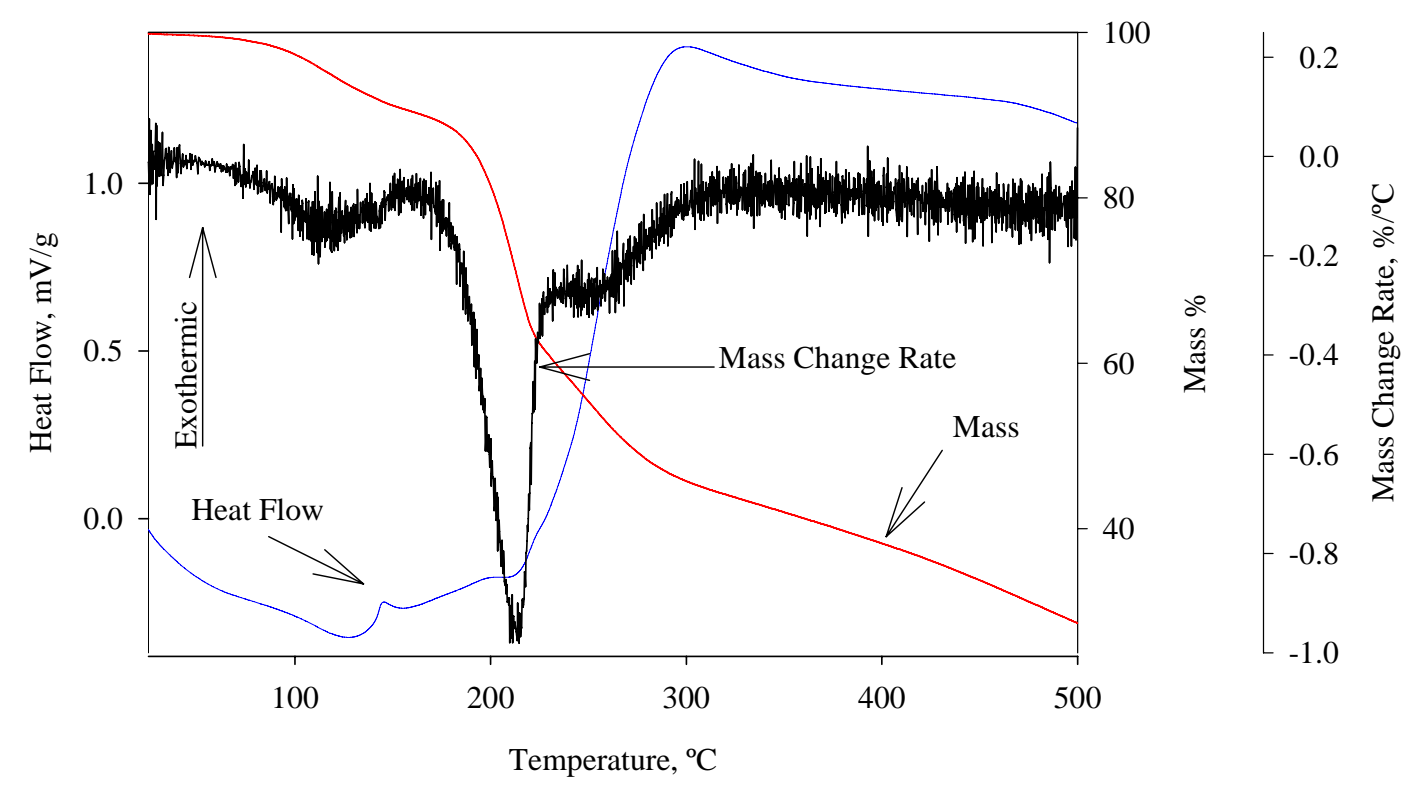

Figure 5.21. TGA/DTA-Measured Thermal Sensitivity of Simulated RadPro A Decontamination Solution Waste at $10^{\circ} \mathrm{C} / \mathrm{min}$

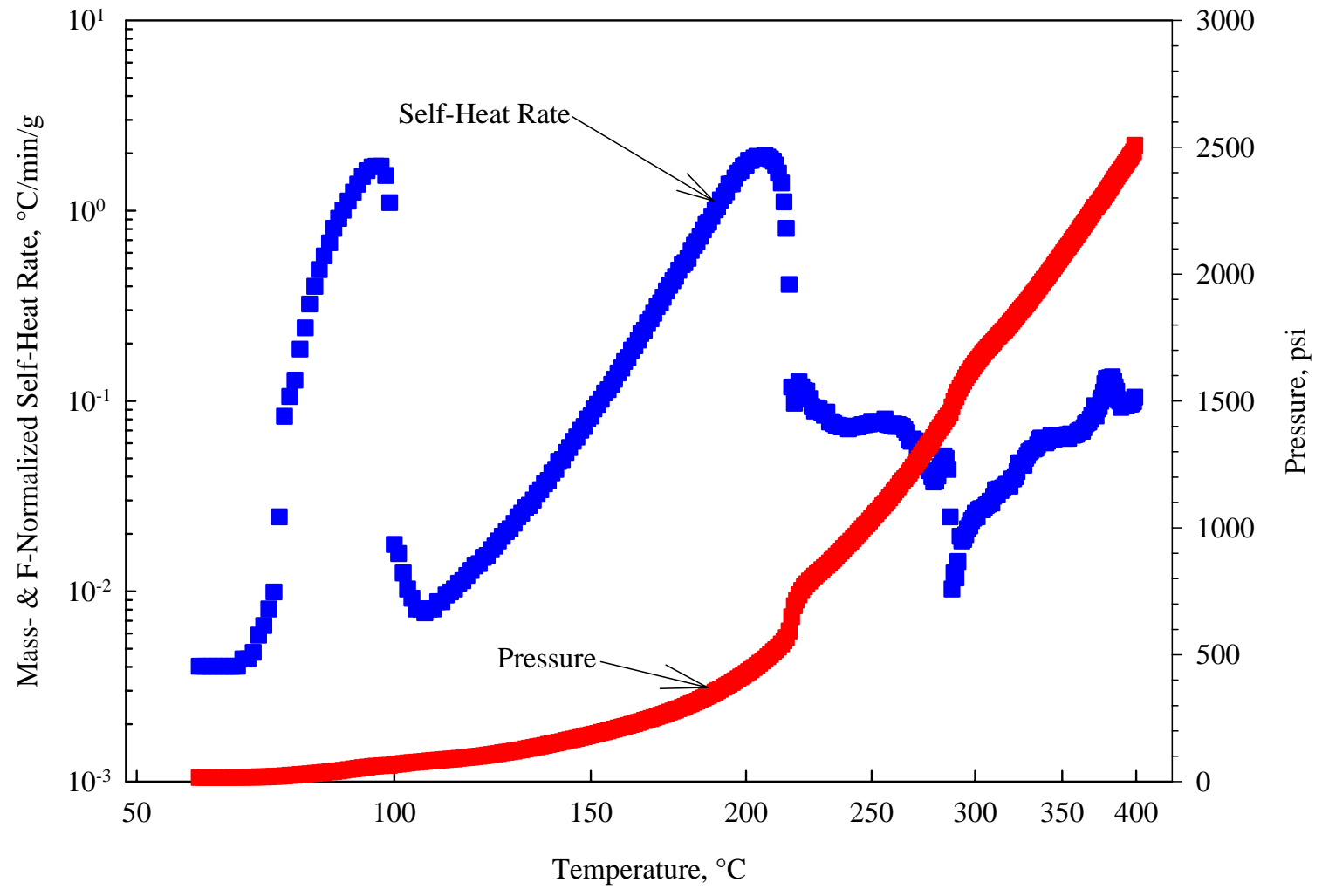

Figure 5.22. ARC-Measured Thermal Sensitivity of Dried RadPro Decontamination Solution Saturated 100\% Cotton Cloth 


\subsubsection{Thermal Behavior of Neutralized RadPro ${ }^{\circledR}$ Decontamination Solution Saturated Cotton Cloth}

In the manufacturer recommended treatment process, the sorbent materials containing the mixed decontamination-rinsate solution are neutralized with base. To assess the thermal reactivity hazards of this waste stream, we investigated the thermal stability of Fluor-provided 100\% cotton cloths saturated with decontamination solution and neutralized with sodium hydroxide and sodium carbonate. We used the RadPro decontamination solution rather than the mixed decontamination-rinsate solution that should arise from the RadPro decontamination process because we believed, based on its higher expected nitrate concentration, that it would be more reactive with cotton.

\subsubsection{Thermal Behavior of Sodium Hydroxide Neutralized RadPro Decontamination Solution Saturated Cotton Cloth}

We used the ARC to investigate the thermal reactivity of the hydroxide-neutralized RadPro decontamination solution (RadPro A). As shown in Figure 5.23, in our first analysis (3-day old material) the ARC found that neutralization with sodium hydroxide delayed the onset temperature from $70^{\circ} \mathrm{C}$ (as observed for RadPro A alone) to $170^{\circ} \mathrm{C}$ (with neutralized RadPro A). The second ARC analysis (9-day old material) found some exothermicity at $45^{\circ} \mathrm{C}$ but the reaction was not self-heating. A second reaction began at $115^{\circ} \mathrm{C}$ and sustained itself to $150^{\circ} \mathrm{C}$ where a third self-sustaining reaction began and lasted to $280^{\circ} \mathrm{C}$ where a fourth reaction began and continued to the end of the experiment. The ARC analyses indicate that neutralization significantly delays the onset temperature for significant exothermic selfsustaining reactions although the significant differences between the two analyses cannot be easily explained because there was only 6 days between the two analyses and they were performed using the same ARC. For both analyses, assuming the $45^{\circ} \mathrm{C}$ reaction in the second analysis is a spurious result, neutralization delays reaction onset to greater than the CCPS's $50^{\circ} \mathrm{C}$ rule-of-thumb difference between the ARC-observed onset temperature and the maximum process operational temperature. Therefore, no thermal reactivity hazard is indicated.

\subsubsection{Thermal Behavior of Dried Sodium Carbonate-Neutralized RadPro Decontamination Solution Saturated Cotton Cloth}

We used the ARC to investigate the thermal sensitivity of sodium carbonate-neutralized RadPro decontamination solution-(RadPro A) soaked cotton cloth. The result of our single ARC analysis is provided in Figure 5.24. As with the second ARC analysis of the sodium hydroxide neutralized RadPro A solution saturated cotton cloth, neutralization delays the onset of exothermicity to $120^{\circ} \mathrm{C}$ from $70^{\circ} \mathrm{C}$ for the unneutralized cloth. Note that in air, the sodium hydroxide neutralizing agent will be converted to sodium carbonate as the hydroxide absorbs $\mathrm{CO}_{2}$ from the air. As with the hydroxide neutralization, the carbonate neutralization increases the ARC-observed onset beyond the CCPS's $>50^{\circ} \mathrm{C}$ difference rule-ofthumb. 


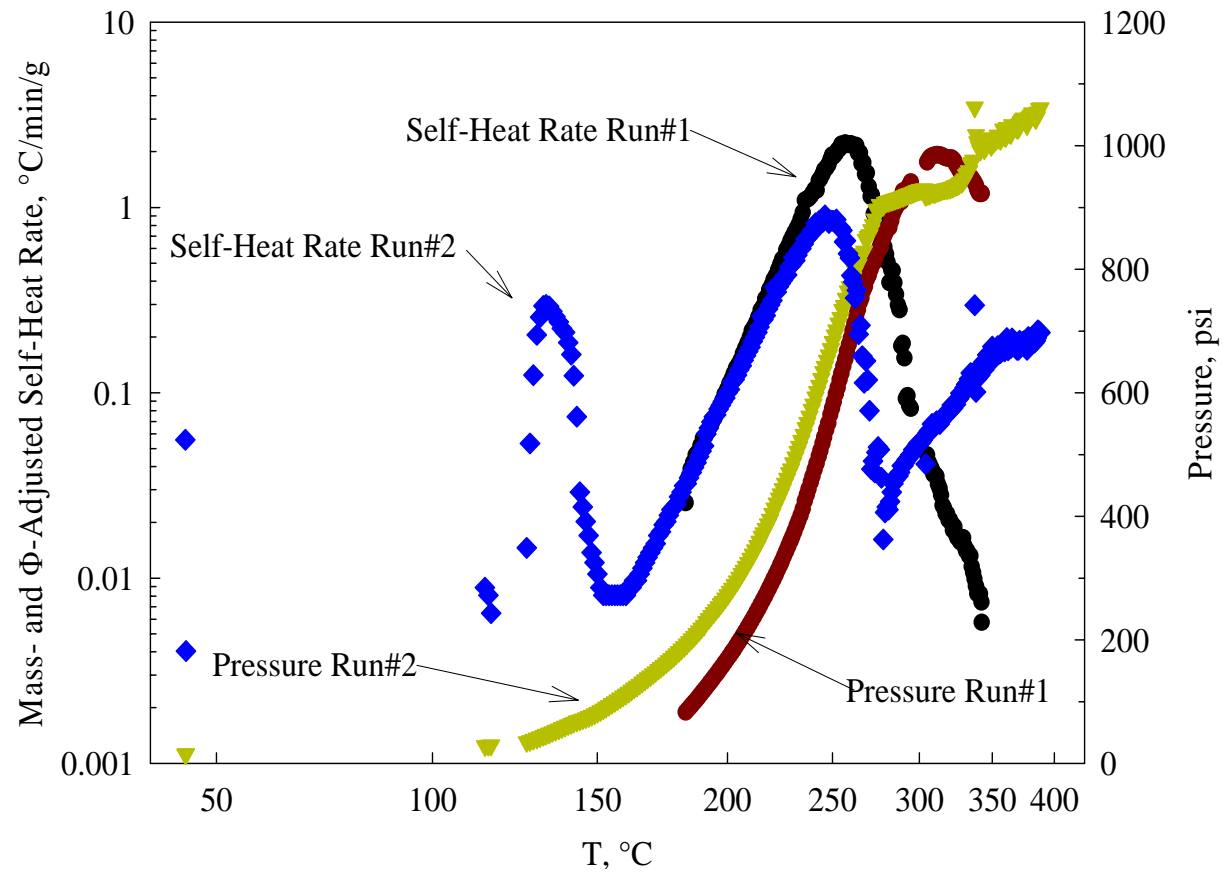

Figure 5.23. ARC-Measured Thermal Behaviors of Dried, Sodium Hydroxide Neutralized RadPro ${ }^{\circledR}$ Decontamination Solution Saturated Cotton Cloth

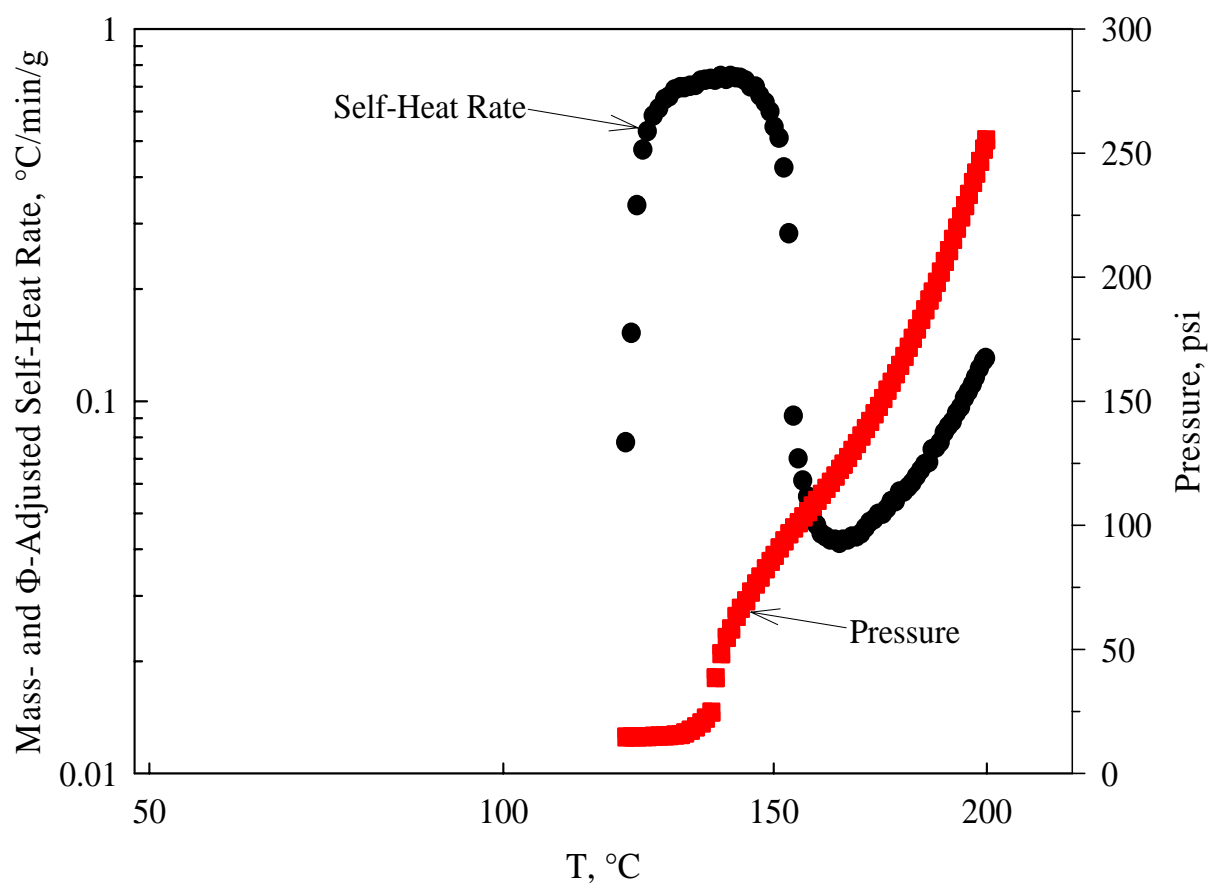

Figure 5.24. ARC-Measured Thermal Behavior of Sodium Carbonate Neutralized RadPro Decontamination Solution Saturated Cotton Cloth 


\subsubsection{Thermal Behavior of Dried RadPro ${ }^{\circledR}$ Decontamination + Rinsate Saturated Cotton Cloth}

One of the expected wastes from the RadPro ${ }^{\circledR}$ decontamination process is sorbent material containing both the decontamination and rinsate solutions (RadPro B=RadPro A + RadPro C). For this part of the study, we prepared two samples. The first was prepared by saturating an $86 \%$ cotton/ $14 \%$ polyester cloth with a mixture of $33 \%$ decontamination solution and $67 \%$ rinsate. The second was prepared by spraying a coupon of cleaned 304 stainless steel (SST) with one volume of decontamination solution followed by two volumes of rinsate.

With respect to the decontamination solution, the combined decontamination/rinsate solution should increase the nitrate content and the chemical buffering agents present in the rinsate. The rinsate is $10 \%$ RadPro 03/90\% water. RadPro 03 is 5-25\% nitric acid with unknown amounts of chemical buffering agents and water.

A cotton rag was soaked in a 33\% RadPro decontamination/67\% rinsate solution (RadPro B) on 7/27/04, dried at ambient temperature in flowing air, and analyzed as a 14-day old cloth using TGA/DTA in air on 08/10/04. Comparison of the TGA/DTA-observed reaction profile of a cotton cloth saturated with a mixture of decontamination and rinsate solutions shown Figure 5.25 with the analogous reaction profile of decontamination solution/cotton cloth provided in Figure 5.26 shows a similar reaction profile as would be expected with the same ingredients. The decontamination/rinsate mixture cloth exhibits a more distinct exotherm with a peak maximum near $130^{\circ} \mathrm{C}$ than does the decontamination solution alone. The $130^{\circ} \mathrm{C}$ onset of this reaction is within the CCPS's $100^{\circ} \mathrm{C}$ rule-of-thumb safety margin for DSC or DTA relative to the $45^{\circ} \mathrm{C}$ Hanford maximum temperature.

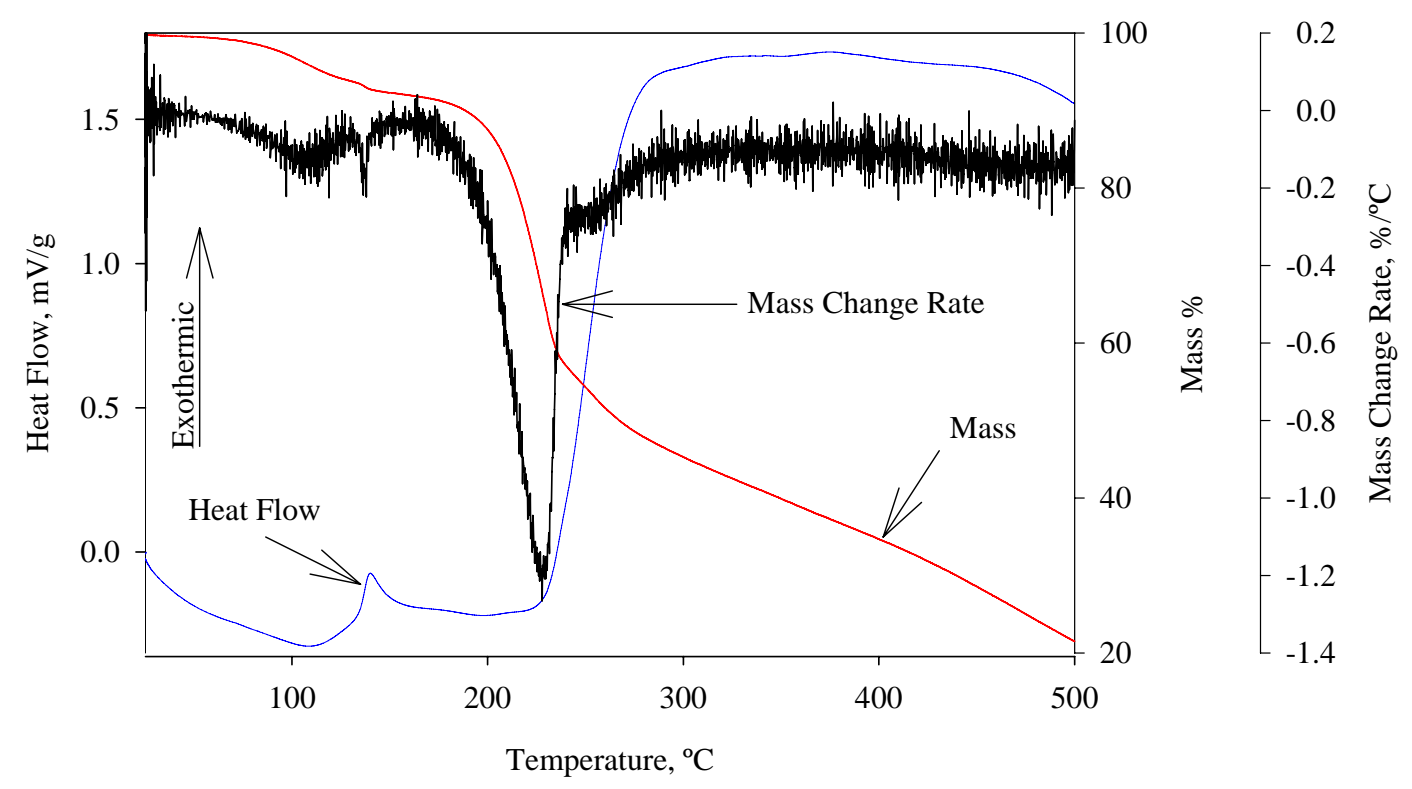

Figure 5.25. TGA/DTA-Measured Thermal Behavior of 33\% RadPro ${ }^{\circledR}$ Decontamination/ $67 \%$ Rinsate Saturated Cotton Cloth Waste at $10^{\circ} \mathrm{C} / \mathrm{min}$ 
The supplier of the RadPro solutions claimed that the mixture of decontamination solution and rinsate solution's (RadPro B) reactivity with cotton rags would be greatly reduced after the solution contacted stainless steel. The TGA/DTA analysis of RadPro B solution after treatment of stainless steel, shown in Figure 5.26, found similar behavior to that of a cotton cloth soaked only with decontamination solution (RadPro A alone). In agreement with the supplier's claim, the reaction observed at $130^{\circ} \mathrm{C}$ for the RadPro $\mathrm{B}$ solution is greatly diminished after treating SST. It is also less prominent than observed for the decontamination solution alone.

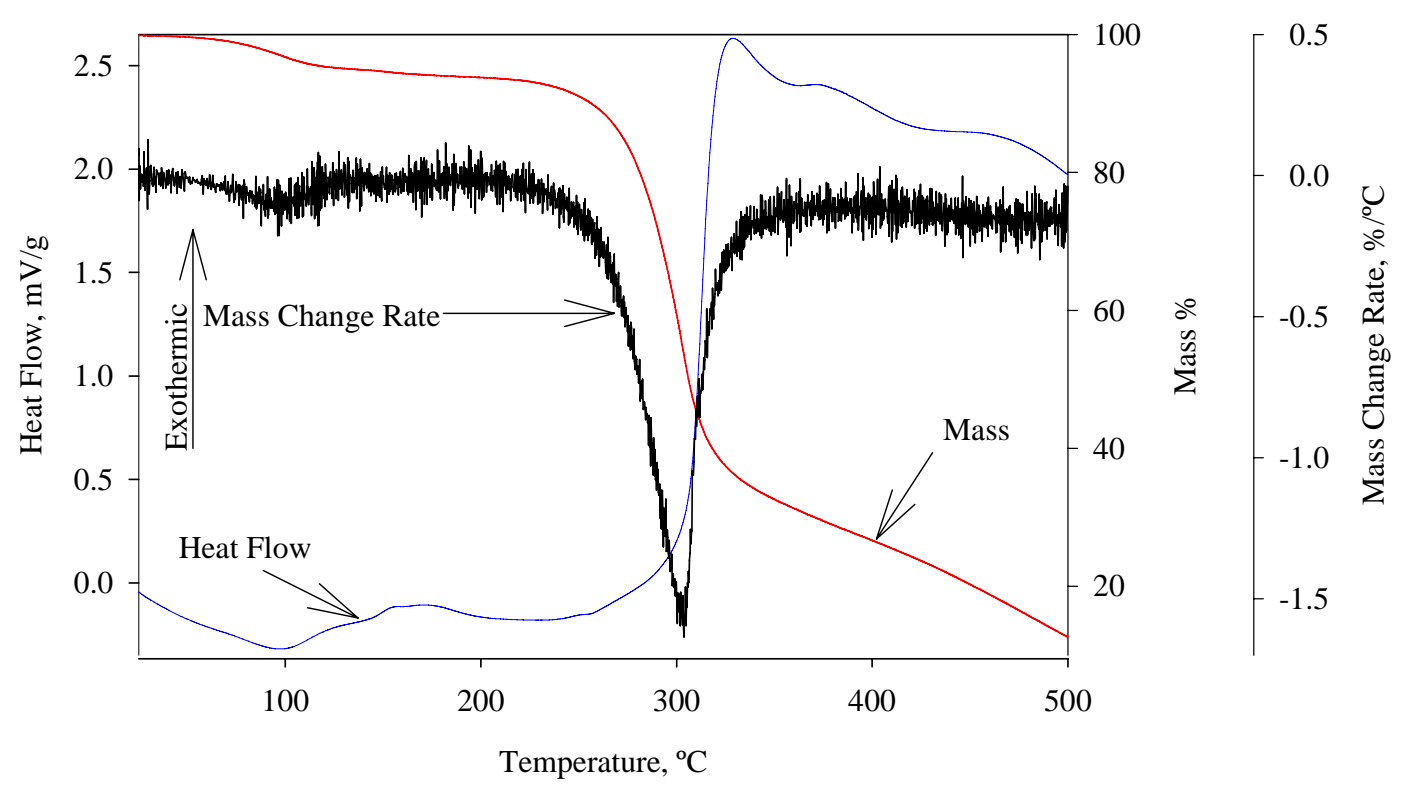

Figure 5.26. TGA/DTA-Measured Thermal Behavior of Dried RadPro ${ }^{\circledR}$ Decontamination + Rinsate (RadPro B) After Treating Stainless Steel Saturated Cotton Cloth at $10^{\circ} \mathrm{C} / \mathrm{min}$

In comparison to a cotton cloth saturated with RadPro decontamination solution, the ARC found reduced thermal sensitivity and reactivity for both cotton clothes saturated with combined decontamination-rinsate solution; see Figure 5.27. The observed onset temperature was later, $90^{\circ} \mathrm{C}$ compared to $70^{\circ} \mathrm{C}$. The magnitude of the initial self-sustaining reaction was slightly less $0.5^{\circ} \mathrm{C} / \mathrm{min} / \mathrm{g}$ compared to $2^{\circ} \mathrm{C} / \mathrm{min} / \mathrm{g}$. 


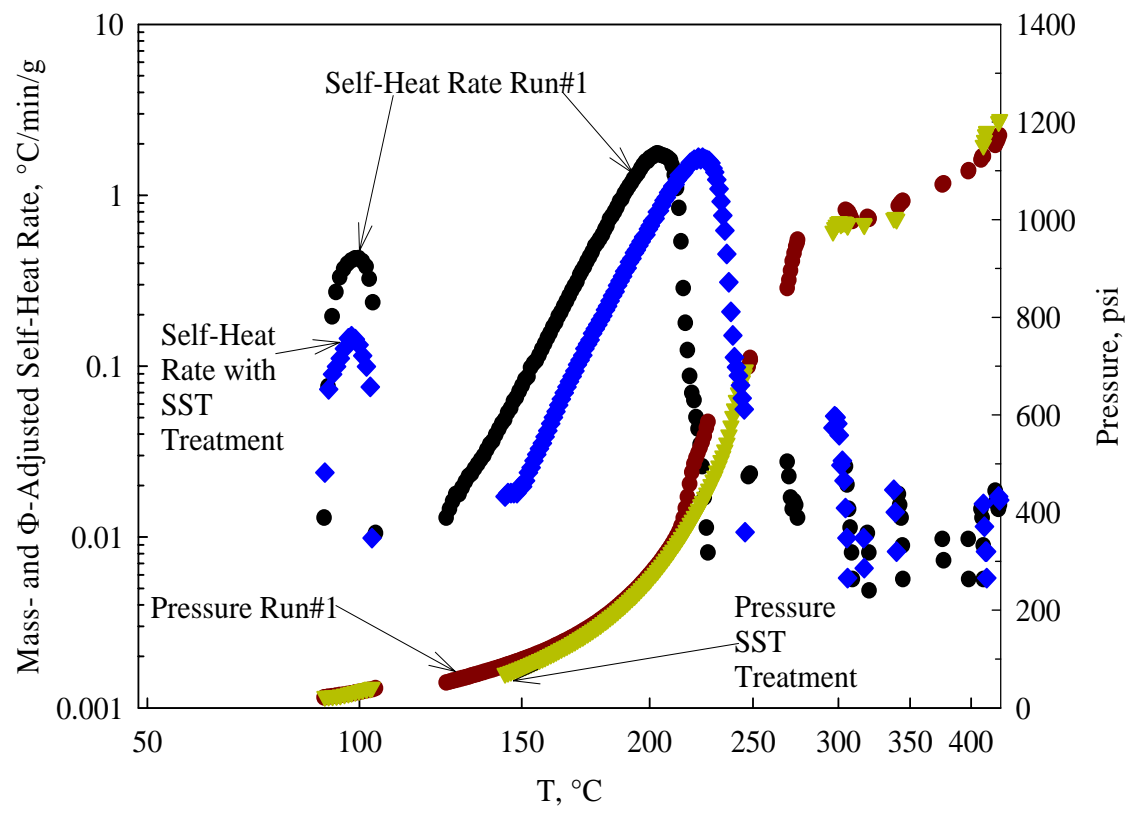

Figure 5.27. ARC-Measured Thermal Sensitivity of Dried Cotton Cloths Saturated with 33\% RadPro Decontamination/67\% Rinsate Solution Either by Soaking or by Removing from an SST Coupon

The ARC observed no significant difference between the behavior of the cotton cloth created by soaking or by removing the decontamination and rinsate solutions after treating a SST coupon, as shown in Figure 5.27. The differences between the DTA and the ARC results regarding the lessened DTAobserved at $130^{\circ} \mathrm{C}$ due for the SST test may arise from the higher sensitivity of the ARC.

Although diluting the decontamination solution with rinsate did delay the observed onset of a selfsustaining reaction to $90^{\circ} \mathrm{C}$, it remains within the respective CCPS $50^{\circ} \mathrm{C}$ and $100^{\circ} \mathrm{C}$ rule-of-thumb safety margins for ARC-measured, and DSC- and DTA-measured-onset temperatures. This suggests that wastes containing this mixed solution waste without neutralization could potentially begin reacting if exposed to Hanford's maximum temperature $45^{\circ} \mathrm{C}$.

\subsubsection{Thermal Behavior of RadPro ${ }^{\circledR}$ Rinsate (RadPro C) Saturated Cotton Cloth}

We used TGA/DTA to investigate the thermal reactivity of RadPro rinsate (RadPro C) saturated cotton cloth and found similar behavior between this material and decontamination solution-saturated cotton and cotton saturated with mixed decontamination-rinsate solution. As shown in Figure 5.28, when heated an endothermic reaction begins immediately, and near $120^{\circ} \mathrm{C}$ an exotherm begins. The significant $60 \%$ mass loss begins at $200^{\circ} \mathrm{C}$ with the DTA seeing little or no endothermic or exothermic behavior. Near $250^{\circ} \mathrm{C}$, the DTA sees the start of a significant exotherm; normally the mass change rate correlates with exothermic behavior, however in this instance the DTA and TGA do not correlate. Comparison with the TGA/DTA analyses presented in Figure 5.21, Figure 5.25, and Figure 5.26 shows similar thermal behavior. 


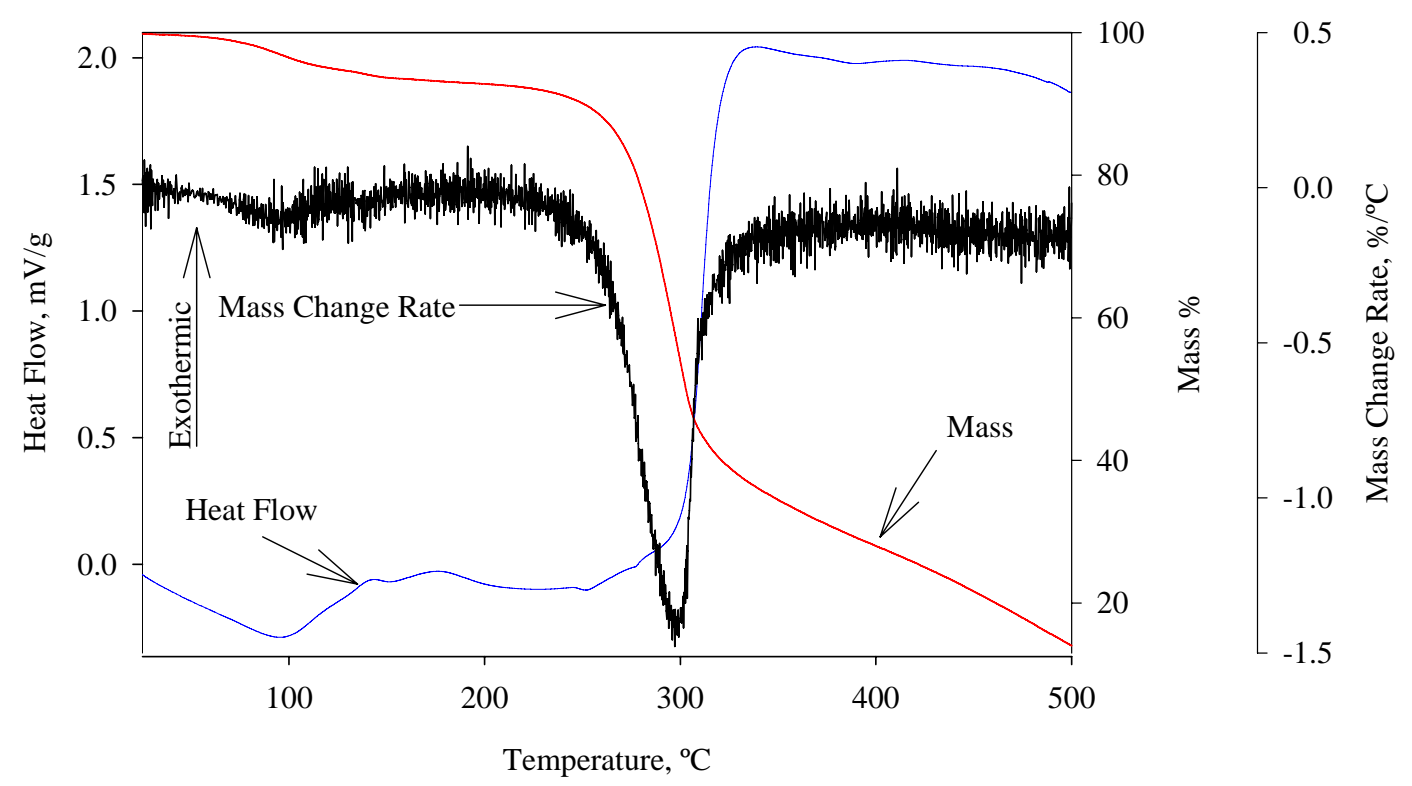

Figure 5.28. TGA/DTA-Measured Thermal Behavior of RadPro ${ }^{\circledR}$ Rinsate Saturated Cotton Cloth at $10^{\circ} \mathrm{C} / \mathrm{min}$ in Air

\subsubsection{Thermal Behavior of Dried RadPro ${ }^{\circledR} 01$ Saturated Cotton Cloth}

RadPro 0100 is the emulsifier used as the final treatment used for the final treatment of the decontaminated surface. After treatment with RadPro 0100, the surface is rinsed with the rinsate. RadPro 0100 is 5-15\% ethylene glycol monobutyl ether, 0-1\% triethylamine, $0-2 \%$ isopropanol, $1-5 \%$ potassium hydroxide, and possibly other emulsifiers, surfactants, organic sequestrants, and water. Use of RadPro 0100 introduces more fuel but apparently no more oxidant into the waste stream.

The alkaline aqueous solutions of the ether, the amine, and the alcohol are very good organic solvents and degreasers. The triethylamine is a water soluble solvating agent, useful for binding metal ions in solution. The various emulsifiers, surfactants, and other water soluble chelators are useful in binding to and suspending both ions and particles thereby increasing product loading into the aqueous phase. One predicts no low temperature reactivity of this solvent in rags and reduced high temperature reactivity. DTA results are presented in Figure 27.

A cotton rag was soaked in RadPro 0100 (RadPro D) on 7/28/04, dried at ambient temperature, and analyzed using TGA/DTA on 08/10/04 (13 days). As Figure 5.29 shows, little or no exothermicity occurs until heated to $310^{\circ} \mathrm{C}$. This last exotherm is likely due to air reacting with the cotton. The apparent absence of exothermic behavior in the absence of an oxidant other than air is not unexpected. 


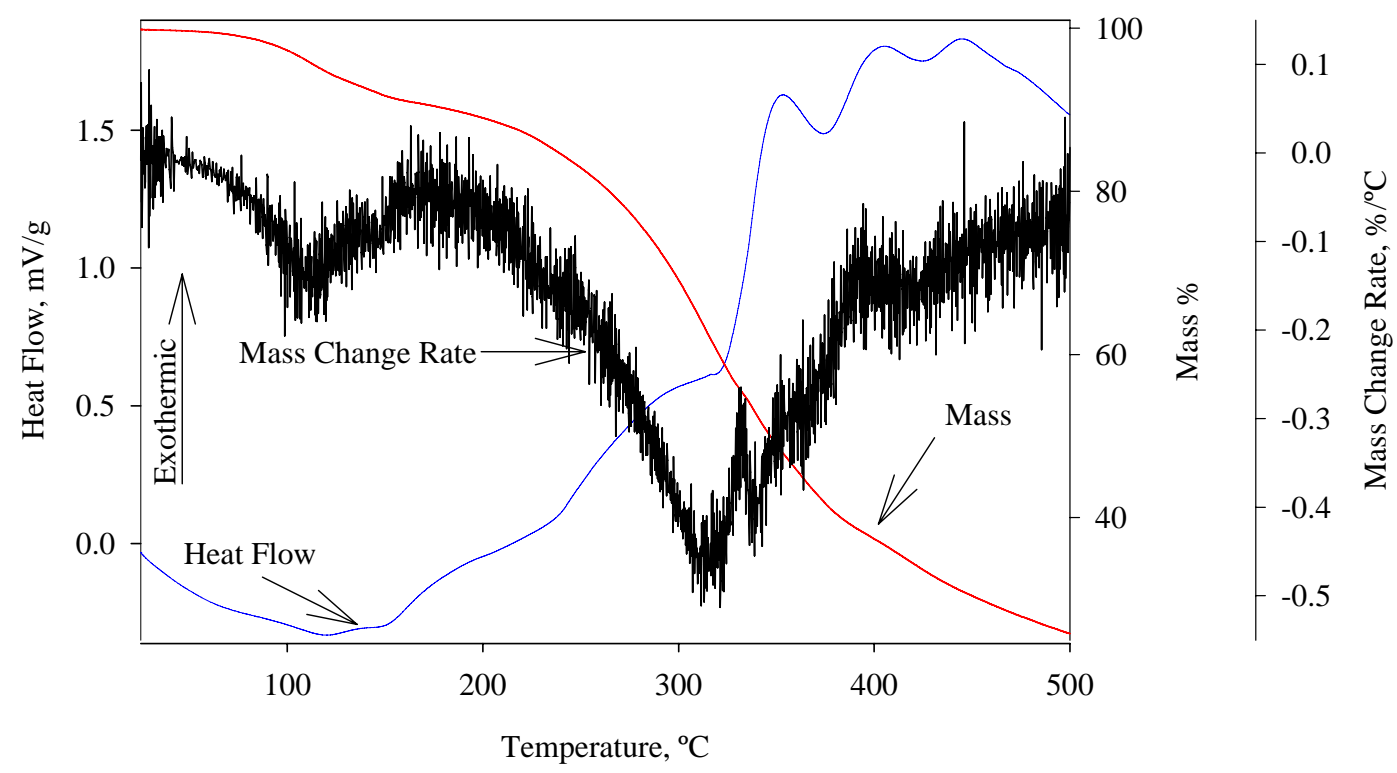

Figure 5.29. TGA/DTA-Measured Thermal Behavior of Dried, RadPro ${ }^{\circledR} 01$ Saturated Cotton Cloth at $10^{\circ} \mathrm{C} / \mathrm{min}$

\subsubsection{Thermal Behavior of Dried, RadPro ${ }^{\circledR}$ Emulsifier + Rinsate Saturated Cotton Cloth}

One of the wastes arising from the RadPro decontamination process is sorbent material containing both RadPro 0100 (RadPro D) and rinsate (RadPro C) or RadPro E. RadPro E contains the materials found in RadPro 0100 combined with nitric acid but in a lower concentration. To investigate the thermal reactivity of this waste, we prepared a solution of $67 \%$ rinsate/33\% RadPro 0100, saturated sorbent materials with the mixed solution, air dried at ambient conditions on 7/28/2004, and analyzed by DTA on 8/10/2004 (13 days).

The TGA/DTA results presented in Figure 5.30 show endothermic behavior immediately upon heating as observed for all the RadPro solution saturated cotton cloths, an exothermic reaction between 180 and $210^{\circ} \mathrm{C}$, and an exothermic reaction beginning at $250^{\circ} \mathrm{C}$ similar to that observed for the mixed decontamination-rinsate solution (Figure 5.29). No low temperature exothermicity is observed for this material. 


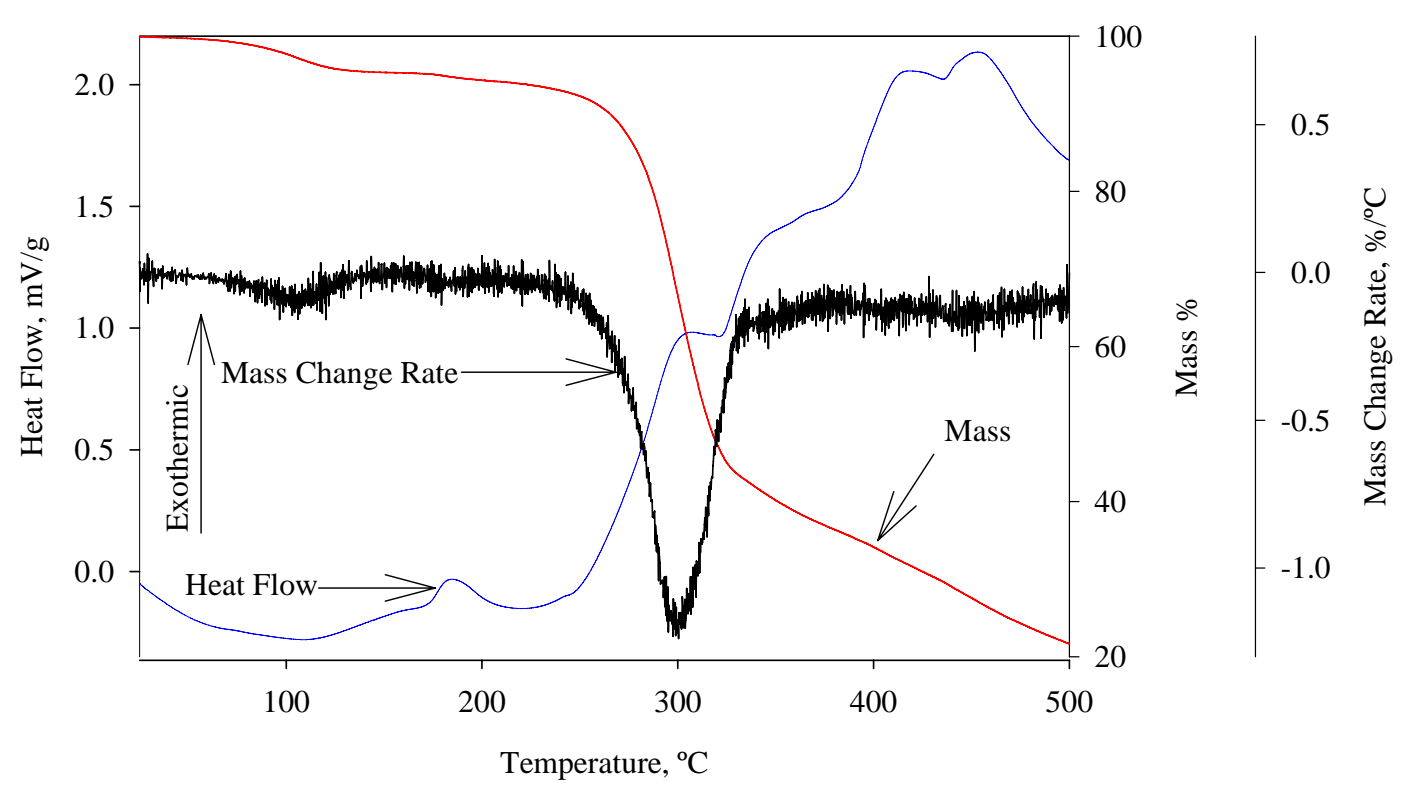

Figure 5.30. TGA/DTA-Measured Thermal Behavior of Dried RadPro ${ }^{\circledR}$ Emulsifier + Rinsate Saturated Cotton Cloth at $10^{\circ} \mathrm{C} / \mathrm{min}$ in Air

\subsubsection{Thermal Behavior of Nominal Mixture of Cloth Wastes Arising from RadPro Decontamination Process}

The RadPro decontamination process as described earlier will produce two waste types likely in equal mass and volume. The first is the neutralized decontamination-rinsate solution cloth (i.e., RadPro 02 and RadPro 03) and the second type is the cloth containing the mixed RadPro 0100 emulsifier and rinsate. To investigate the reactivity of this system, we used the ARC to measure an equal-mass mixture of sodium hydroxide neutralized decontamination solution (RadPro A) soaked cotton cloth and RadPro 0100-rinsate soaked cotton cloth.

The results of this ARC analysis are provided in Figure 5.31. The ARC observed two short-lived reactions at 70 and $90^{\circ} \mathrm{C}$ possibly consistent with the second analysis ARC-observed behavior of the sodium hydroxide-neutralized decontamination solution cotton cloth. The ARC next finds a reaction beginning at $125^{\circ} \mathrm{C}$ which continues to $150^{\circ} \mathrm{C}$ when another reaction begins. The $150^{\circ} \mathrm{C}$ reaction continues to $290^{\circ} \mathrm{C}$ where another reaction begins which continues to the end of the experiment.

The ARC analysis found two short lived reactions within $50^{\circ} \mathrm{C}$ of the Hanford maximum temperature but these reactions in the packed container rapidly died. A significant reaction occurred at $125^{\circ} \mathrm{C}$ which was capable of supporting a self-sustaining reaction to very high temperatures and producing significant amounts of gas. 


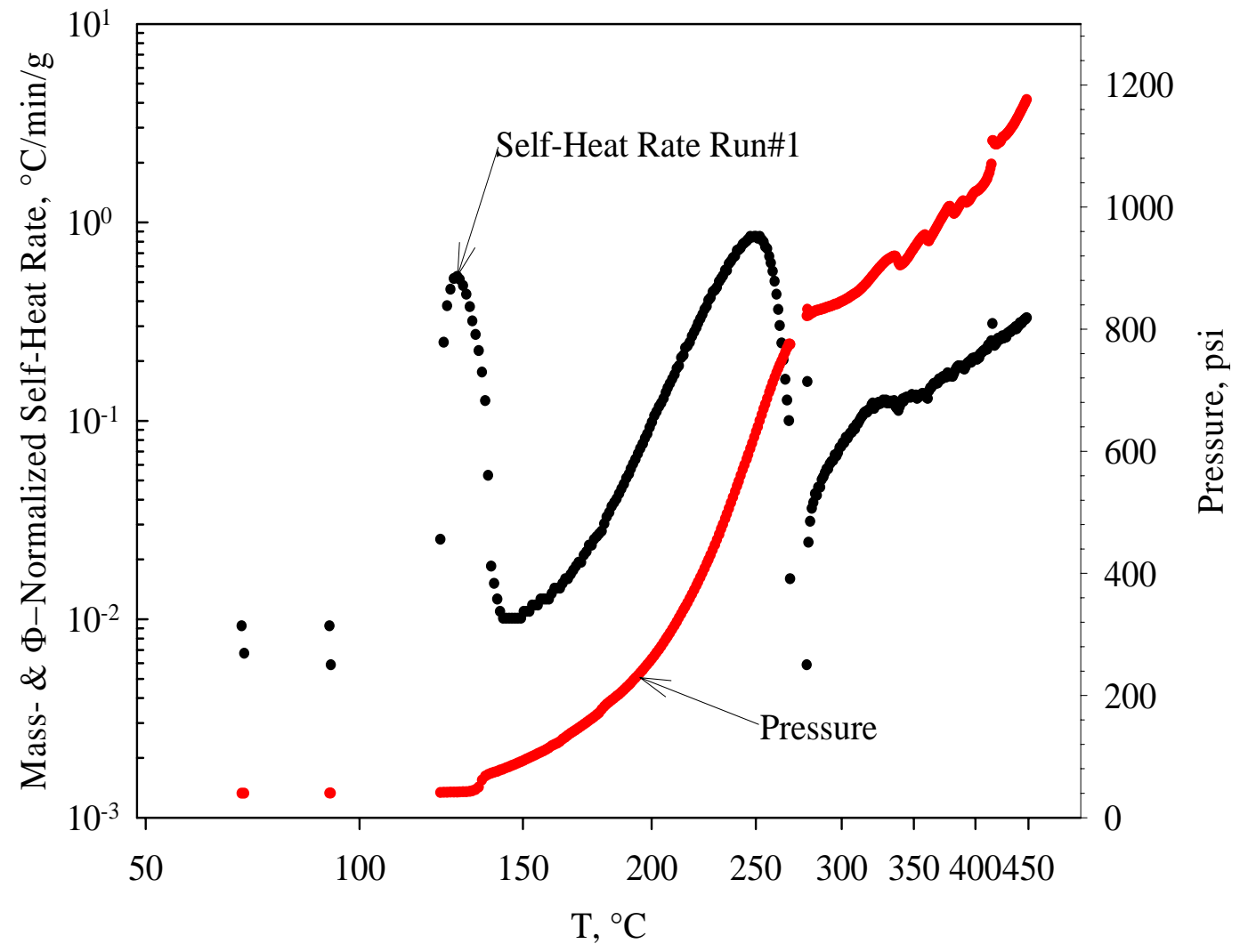

Figure 5.31. ARC-Measured Thermal Behavior of a Mixture of $1.26 \mathrm{~g}$ Dried RadPro 0100 Saturated Cotton Cloth + Sodium Hydroxide-Neutralized RadPro Decontamination Solution (RadPro A) Saturated Cotton Cloth

\subsubsection{Thermal Behavior of RadPro ${ }^{\circledR}$ Solutions Saturated Synthetic Cloth}

With the success that we had with synthetic polyamide-polyester cloths as chemically stable sorbent materials for ceric nitrate/nitric acid, we investigated the $20 \%$ and $50 \%$ polyamide and remainder polyester cloths as sorbents for the RadPro solutions. We did a limited number of experiments with the ARC, concentrating on using the TGA/DTA as a screening tool, and we used the TGA/DTA to study only the $50 \%$ polyamide/ $50 \%$ polyester cloth.

\subsubsection{Thermal Behavior of RadPro Decontamination Solution Saturated 20\% Polyamide/80\% Polyester cloth}

The results of our ARC analysis of dried RadPro decontamination solution (RadPro A) saturated 20\% polyamide/80\% polyester cloth is presented in Figure 5.32. The ARC scan indicated a self-sustaining reaction beginning at $80^{\circ} \mathrm{C}$ and continuing to $150^{\circ} \mathrm{C}$ where it expired. A second reaction began at $200^{\circ} \mathrm{C}$ and lasted to $250^{\circ} \mathrm{C}$. A series of reactions then began at $300^{\circ} \mathrm{C}$ and continued until the experiment was complete. This experiment indicates that in contrast to the ceric nitrate/nitric acid system, 20\% polyamide/80\% polyester supports exothermic reactions, as does cotton with RadPro A, and will not 
mitigate the risk of thermal reactivity for the RadPro decontamination process by the CCPS's $50^{\circ} \mathrm{C}$ ruleof-thumb rule for identifying reactive systems is applicable.

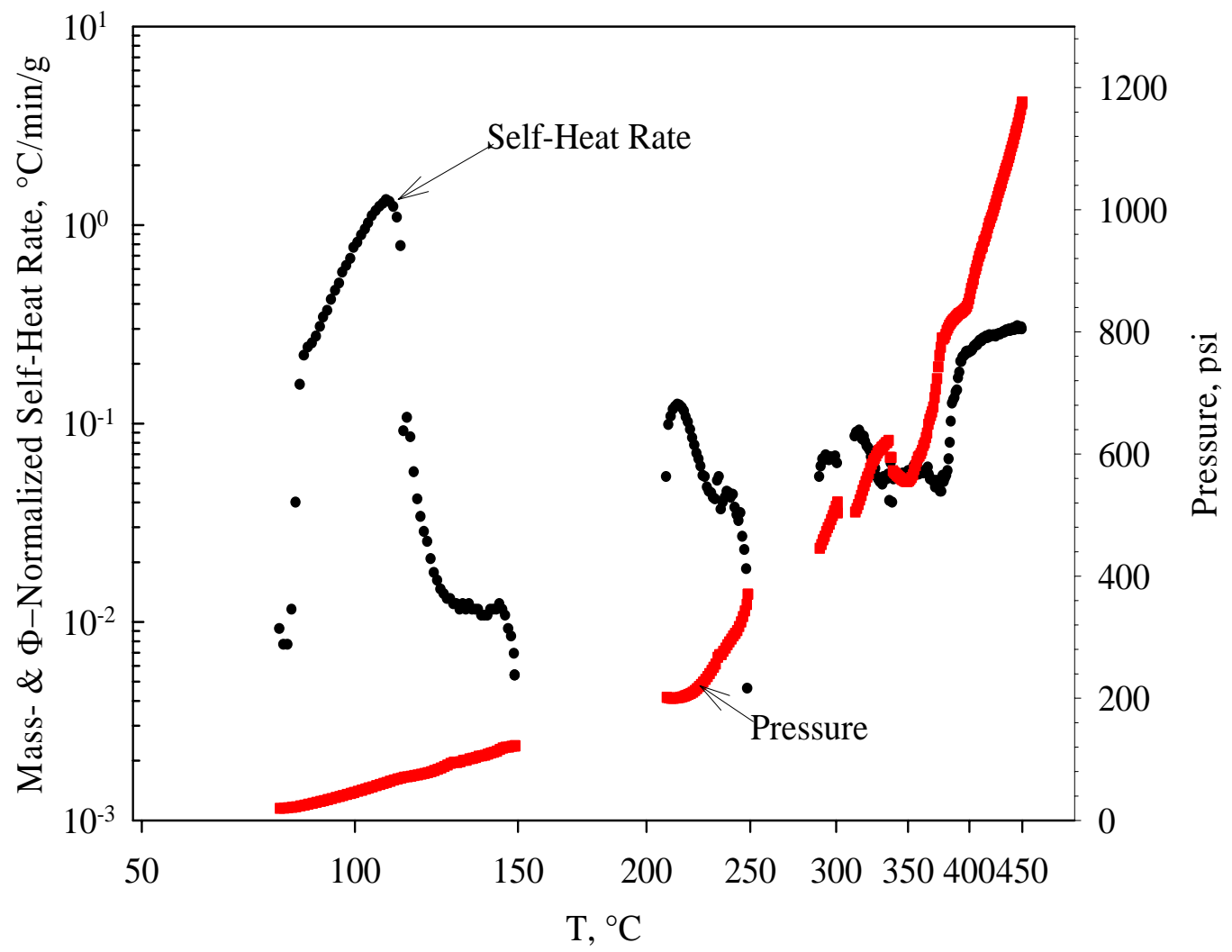

Figure 5.32. ARC-Measured Thermal Behavior of Dried, RadPro Decontamination Solution Saturated 20\% Polyamide/80\% Polyester Cloth

\subsubsection{Thermal Behavior of Sodium-Carbonate Neutralized RadPro Decontamination Solution Saturated 20\% Polyamide/80\% Polyester}

To determine the effect of neutralization on the thermal stability of RadPro decontamination solution (RadPro A) saturated synthetic cloth, we neutralized a $20 \%$ polyamide/80\% polyester cloth saturated with RadPro decontamination solution and neutralized with sodium carbonate. We provide the results of the ARC analysis in Figure 5.33.. 


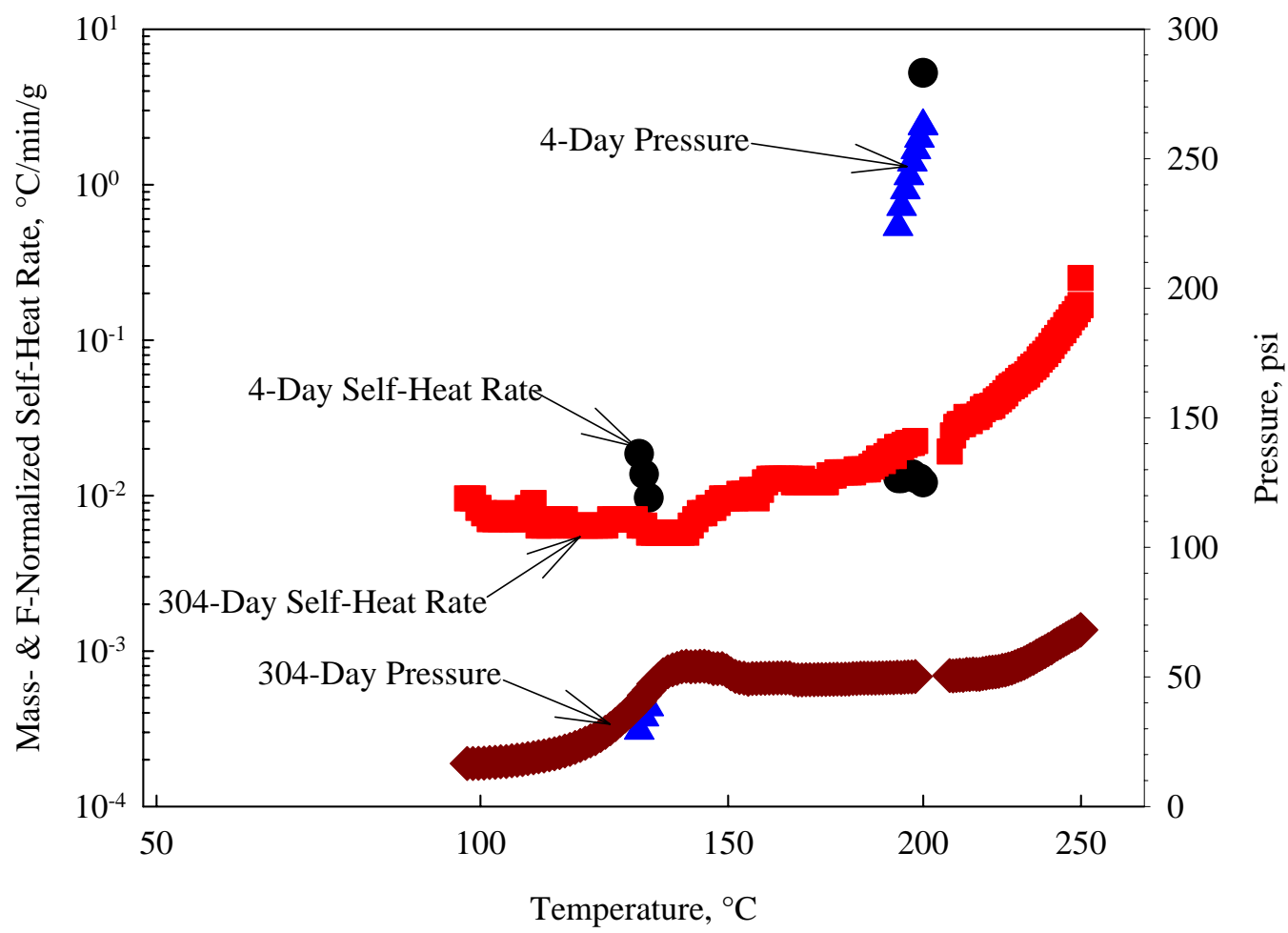

Figure 5.33. Arrhenius Plot of ARC-Measured Thermal Sensitivity of 4 and 304-Day Old Sodium Carbonate-Neutralized RadPro Decontamination Solution (RadPro A) Saturated 20\% Polyamide/80\% Polyester Synthetic Cloth

Figure 5.33 shows 1) that 4-day old sodium carbonate-neutralized RadPro decontamination solution saturated $20 \%$ polyamide $/ 80 \%$ polyester cloth begins to react at $135^{\circ} \mathrm{C}$ and again at $190^{\circ} \mathrm{C}$ after the first reaction dies and 2) the 304-day old cloth begins to react at $95^{\circ} \mathrm{C}$ and reacts with sufficient heat and sufficiently fast to sustain a reaction to $250^{\circ} \mathrm{C}$ where we stopped the experiment. The reaction rate at $250^{\circ} \mathrm{C}$ appears to be accelerating.

Comparison of the neutralized cloth reactivity to those of the unneutralized cloth Figure 5.32 indicates that neutralization changes the reaction profile by delaying reaction onset and dampening the reaction rate, although, the older neutralized material will continue to react with an accelerating reaction rate. These results indicate that using synthetic cloths and neutralizing them offers some short-term benefits with respect to cotton cloths, however, the aged neutralized synthetic cloth has a lower ARC-measured onset temperature than the equivalent cotton cloth. The lower reaction rates may be of some benefit depending on the waste package's ability to dissipate heat. The ARC-measured onset temperature of $95^{\circ} \mathrm{C}$ for the older cloth is $50^{\circ} \mathrm{C}$ of Hanford's maximum measured temperature of $45^{\circ} \mathrm{C}$.

\subsubsection{Thermal Behavior of RadPro Decontamination Solution Saturated 50\% Polyamide/50\% Polyester cloth}

We used the TGA/DTA to investigate the thermal stability of 50\% polyamide/50\% polyester cloth air dried after being soaked with RadPro decontamination solution. PNNL prepared the RadPro A solution soaked synthetic cloth on 7/29/04, dried it at ambient temperature in flowing air, and analyzed it by 
TGA/DTA on 08/04/04 (6 days), 8/16/04 (18 days), and 9/9/04 (42 days). The results of the first analysis are typical and are presented in Figure 5.34.

As shown in Figure 5.34, upon heating the DTA observes an endotherm and loses about $2 \mathrm{wt} \%$. There appears to be a small exotherm occurring simultaneously with the endotherm with a peak maximum near $100^{\circ} \mathrm{C}$. Beginning at $115^{\circ} \mathrm{C}$ a significant exothermic reaction occurs causing a $10 \%$ loss. The material is relatively stable until $280^{\circ} \mathrm{C}$ where the material loses another $50 \%$ of its mass. The significant exotherm at $115^{\circ} \mathrm{C}$ is within the CCPS's $100^{\circ} \mathrm{C}$ DTA-rule-of-thumb of Hanford's maximum temperature of $45^{\circ} \mathrm{C}$.

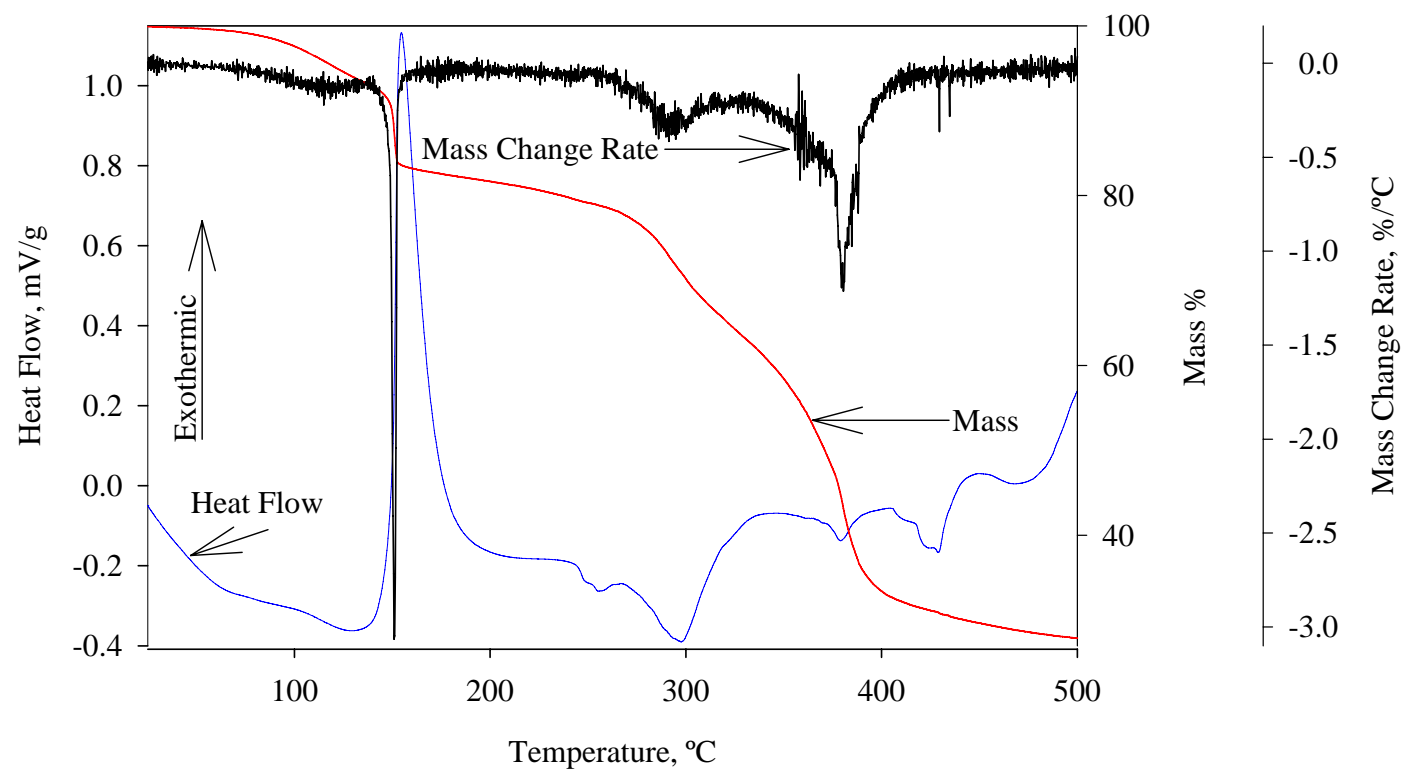

Figure 5.34. TGA/DTA-Measured Thermal Behavior of RadPro ${ }^{\circledR}$ Decontamination Solution Saturated 50\% Polyamide/50\% Polyester Synthetic Cloth at $10^{\circ} \mathrm{C} / \mathrm{min}$

There was little aging effect for the reactivity of RadPro decontamination solution saturated $50 \%$ polyamide/50\% polyester cloth as shown in Figure 5.35. The temperature where the first small exotherm is observed may occur at higher temperatures based on a comparison of the first and last analyses. The effect of aging after the significant $160^{\circ} \mathrm{C}$ exotherm is undetectable.

\subsubsection{Thermal Behavior of Mixed RadPro Decontamination and Rinsate Solution Saturated in $50 \%$ Polyamide $/ 50 \%$ Polyester cloth}

PNNL prepared a 50\% polyamide/50\% polyester cloth saturated with RadPro B, a mixture of 33\% RadPro decontamination solution (RadPro A)-67\% rinsate (RadPro C), on 7/29/04, dried at ambient temperature, and analyzed on the TGA/DTA on 08/11/04 (13 days); the results of that analysis are presented in Figure 5.36. Not unexpectedly given the nature of the similar solution compositions, the TGA/DTA-observed thermal behavior is similar to the decontamination solution saturated cloth. 


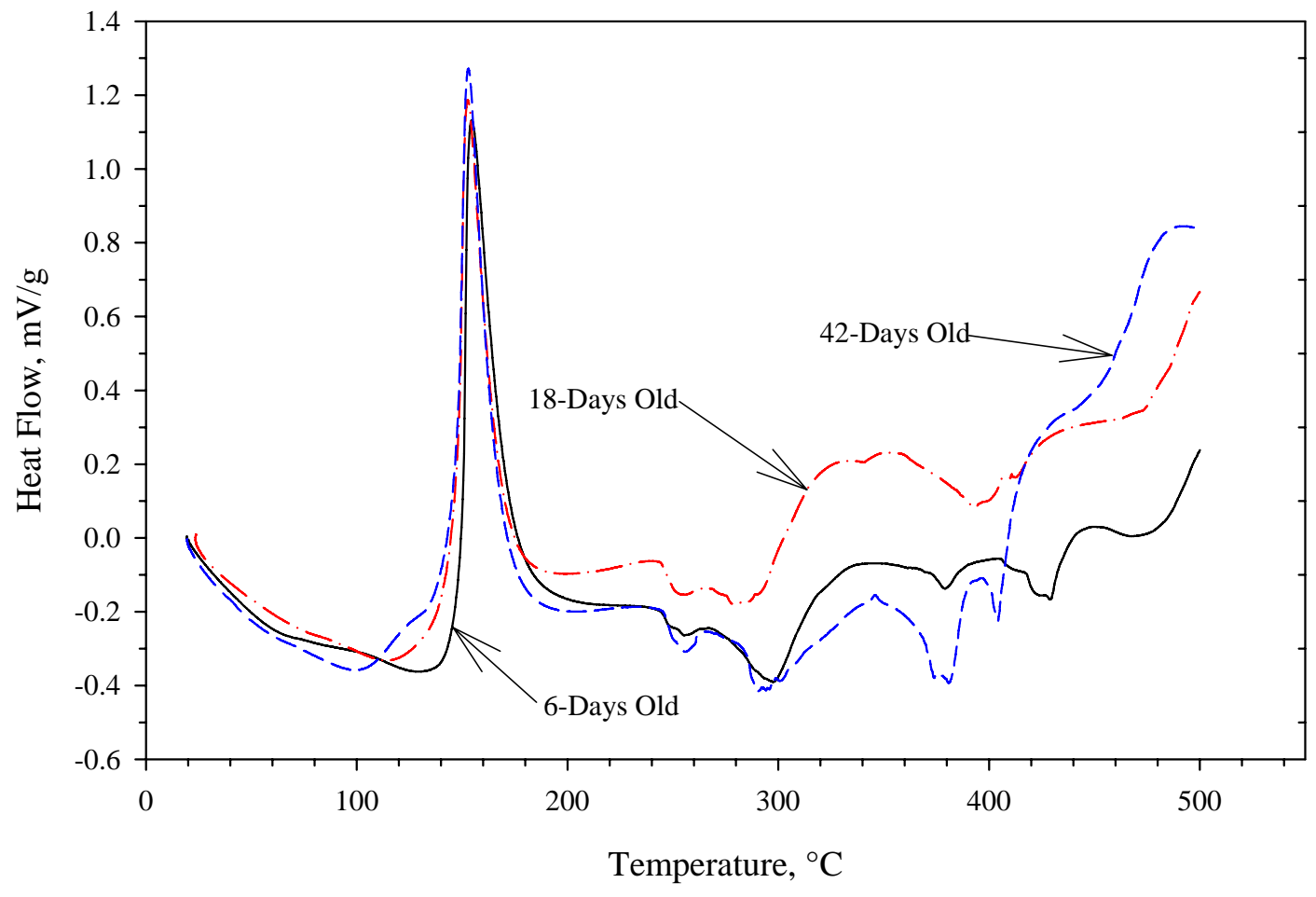

Figure 5.35. DTA-Measured Thermal Behavior of Air-Dried RadPro Decontamination Solution Saturated 50\% Polyamide/50\% Polyester Cloth at 6, 18, and 42 Days

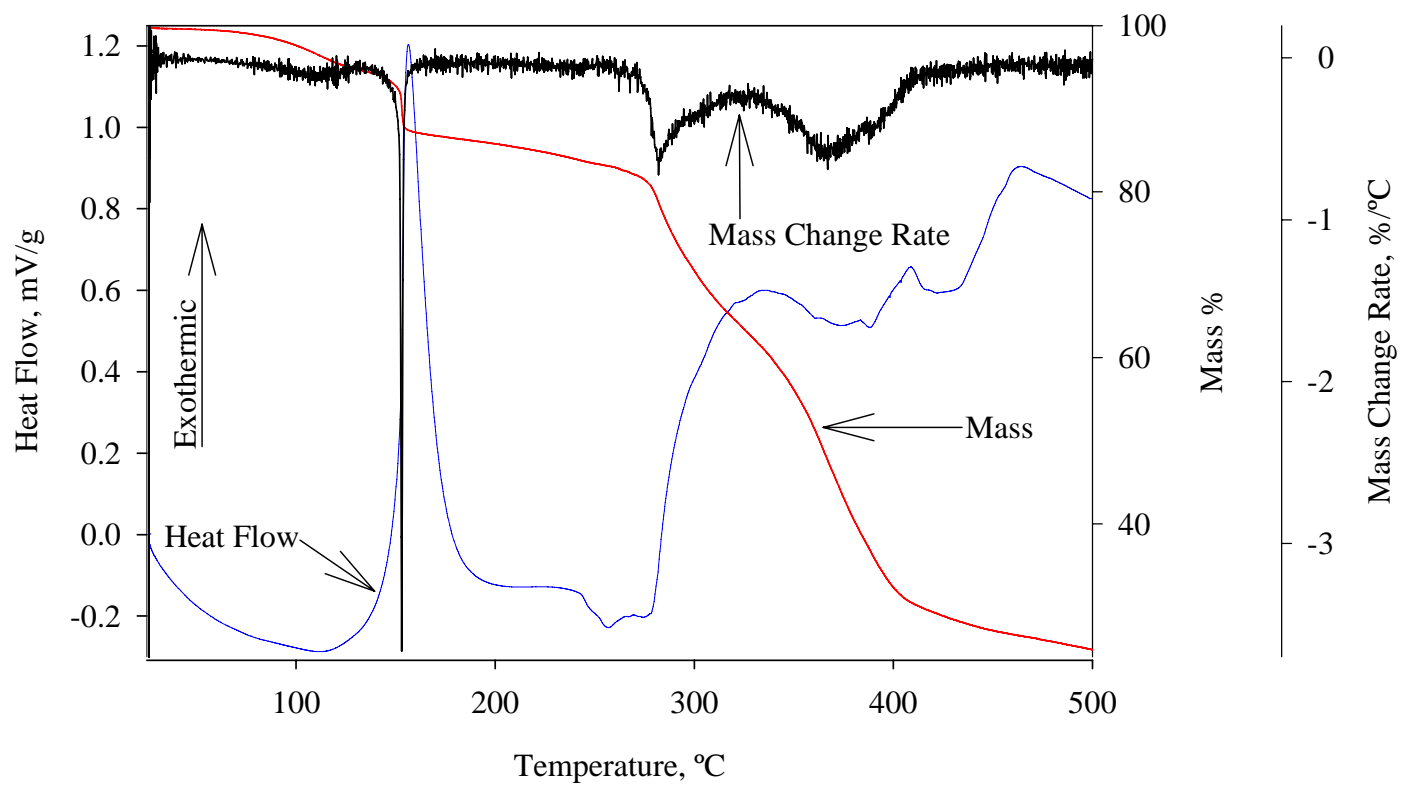

Figure 5.36. TGA/DTA-Measured Thermal Behavior of Mixed RadPro Decontamination-Rinsate Solution at $10^{\circ} \mathrm{C} / \mathrm{min}$ 
Figure 5.36 shows a general endotherm below $140^{\circ} \mathrm{C}$ with a sharp exotherm centered at $156^{\circ} \mathrm{C}$ which is characteristic of nitric acid reactions. A small amount of exothermic activity is seen above $290^{\circ} \mathrm{C}$ which is characteristic of oxygen reactions on organic substrates. This analysis suggests that waste arising from the RadPro decontamination and rinse steps will exhibit low temperature reactivity (within $100^{\circ} \mathrm{C}$ of Hanford maximum temperature) assuming that sorbed water that serves as an endothermic heat sink will fully evaporate.

\subsubsection{Thermal Behavior of RadPro Rinsate Saturated 50\% Polyamide/50\% Polyester cloth}

To gain an understanding of the factors that contribute to the potential thermal reactivity of the RadPro decontamination system wastes, we investigated the thermal behavior of a dried $50 \%$ polyamide- $50 \%$ polyester cloth saturated with RadPro rinsate (RadPro C) prepared on 7/29/04, dried at ambient temperature, and analyzed on the TGA/DTA in air on 08/04/04 (6 days old) and by the ARC.

The results of this TGA/DTA analysis provided in Figure 5.37 show similar reactivity to that observed for decontamination and decontamination-rinsate solutions with an initial endothermic small mass loss between ambient and $120^{\circ} \mathrm{C}$ and a sharp exotherm with a small mass loss beginning near $120^{\circ} \mathrm{C}$ and having a peak maximum at $175^{\circ} \mathrm{C}$. A series of small endotherms begins at $190^{\circ} \mathrm{C}$. At $370^{\circ} \mathrm{C}$ an apparently endothermic decomposition losing 60 mass $\%$ begins. Above $420^{\circ} \mathrm{C}$, it appears that additional exothermic activity begins, although changes in the nature of the residual material and the associated changes in heat capacities confound the interpretation of DTA-observed behavior.

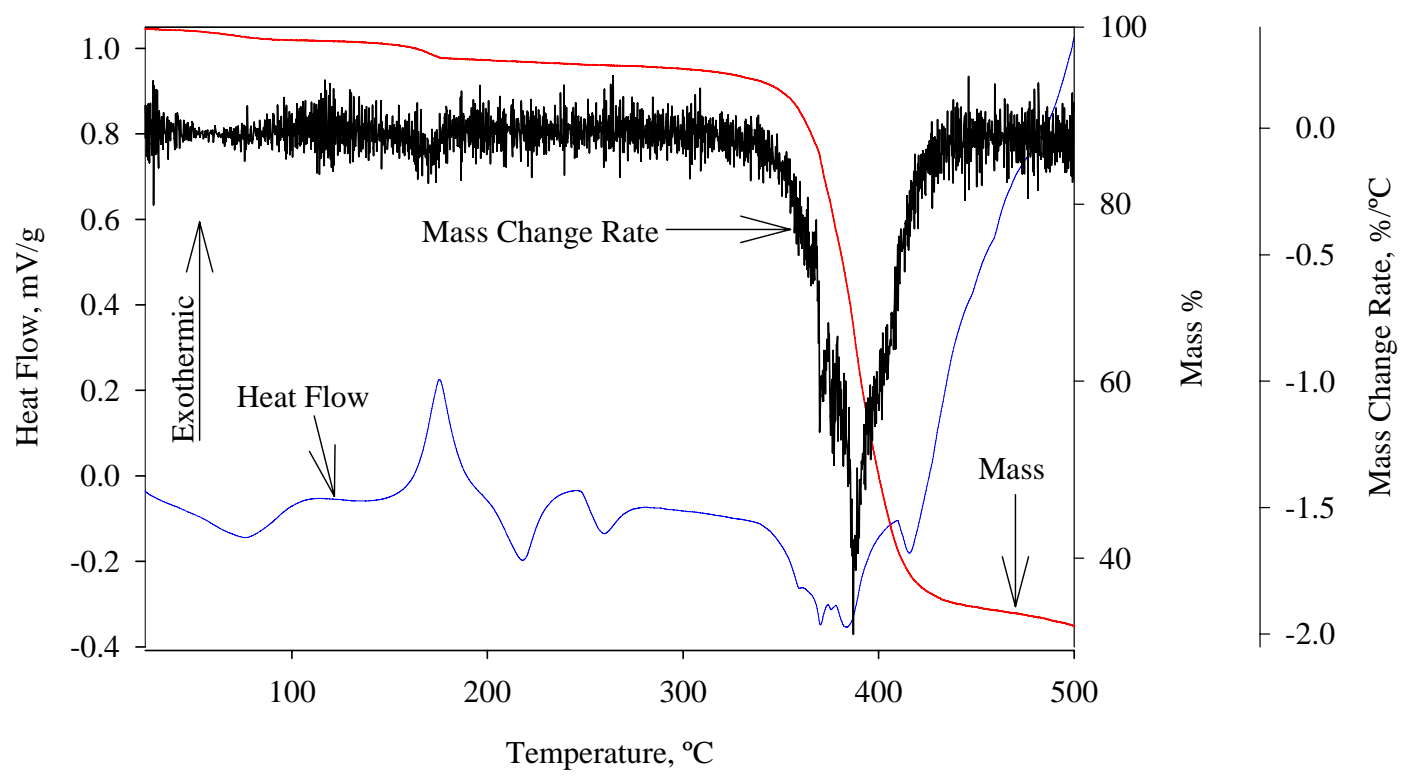

Figure 5.37. TGA/DTA-Measured Thermal Behavior of Dried RadPro Rinsate Saturated $50 \%$ Polyamide $/ 50 \%$ Polyester Cloth at $10^{\circ} \mathrm{C} / \mathrm{min}$

The above results are not unexpected since RadPro C contains 10\% RadPro 03 and 90\% de-ionized water. There is initially only 0.5 to $2.5 \mathrm{v} / \mathrm{v} \%$ nitric acid in RadPro C. The residual nitric acid concentration is very small compared to RadPro A or B. 
The ARC observed significant reactivity and gas production at $80^{\circ} \mathrm{C}$ for both the 5- and 25-day old samples of the dried, rinsate-saturated 50\% polyamide-50\%polyester cloth (Figure 5.38). The 5-day old material exhibited two significant self-sustaining reactions at 80 and $130^{\circ} \mathrm{C}$ with the two reactions producing $600 \mathrm{psi}$ by the end of the second at $230^{\circ} \mathrm{C}$. For the 25-day old material, the second reaction observed for the 5-day sample did not sustain itself, rather it would begin and die suggesting endothermic reactions such as observed by the DTA after the $120^{\circ} \mathrm{C}$ reaction. In both experiments the $80^{\circ} \mathrm{C}$ ARCobserved reaction is within $50^{\circ} \mathrm{C}$ of the Hanford's maximum temperature $45^{\circ} \mathrm{C}\left(113^{\circ} \mathrm{F}\right)$ and thus of safety concern.

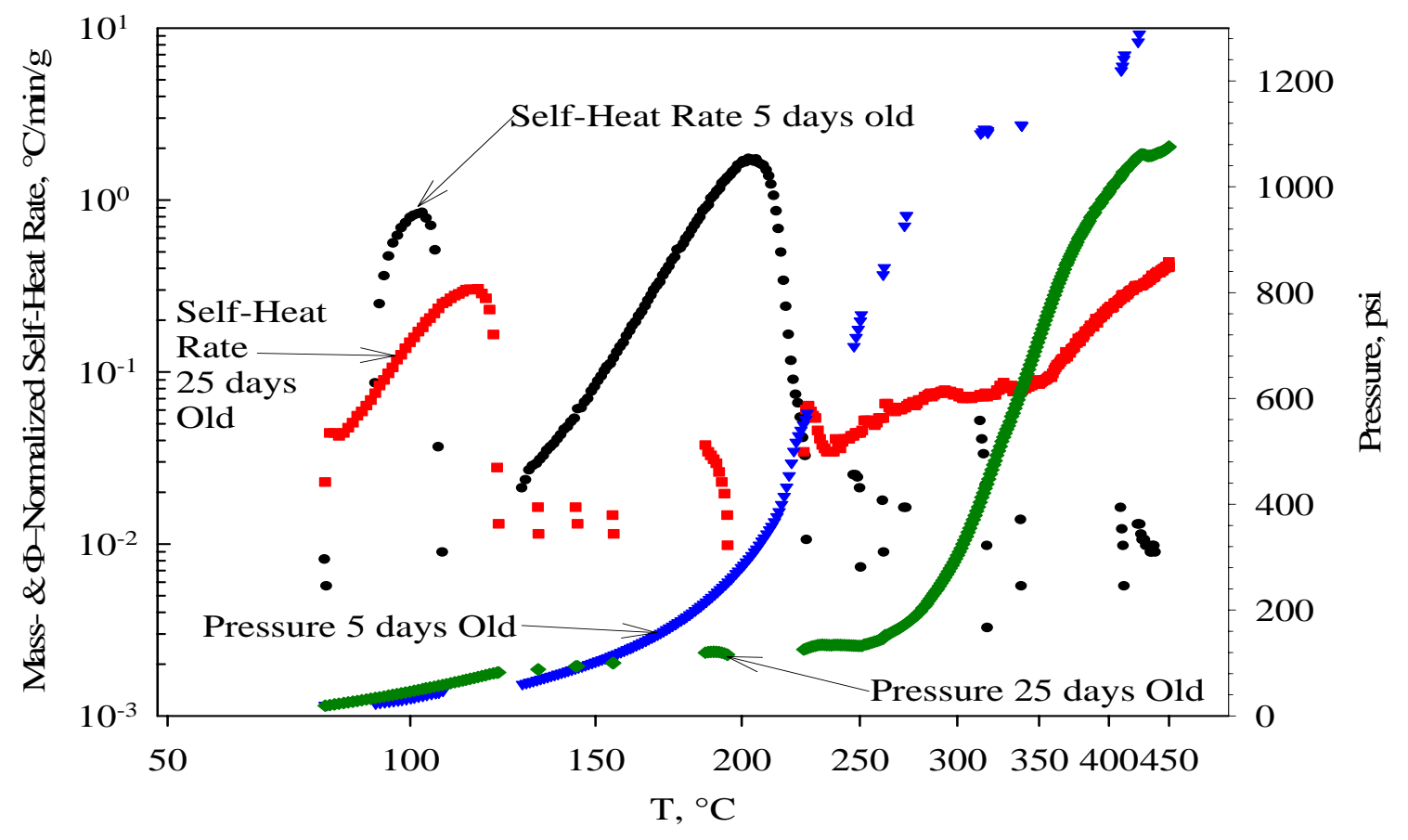

Figure 5.38. ARC-Measured Thermal Behavior of RadPro Decontamination-Rinsate Solution Saturated 50\% Polyamide/50\% Polyester Cloth

\subsubsection{Thermal Behavior of Mixed RadPro Decontamination and Rinsate Solution Saturated 50\% Polyamide/50\% Polyester cloth}

To study the thermal sensitivity of waste arising from RadPro emulsifier and synthetic cloth, we saturated a 50\% polyamide-50\% polyester cloth with RadPro 0100 emulsifier on 7/29/04, dried it at ambient temperature in flowing air, and analyzed it using TGA/DTA on 08/05/04 (6 days old). The make-up of RadPro 0100 are provided in Table 2.2. The residual material within the cloth after drying will be a mixture of organics and proprietary chemicals which likely are not oxidizing agents.

As shown in Figure 5.39 the TGA/DTA observed many endothermic mass losses as it was heated to $500^{\circ} \mathrm{C}$ at $10^{\circ} \mathrm{C} / \mathrm{min}$ in air. Initially there was an endothermic mass loss of $10 \%$ to $190^{\circ} \mathrm{C}$ but without the characteristic exotherm at $170^{\circ} \mathrm{C}$ likely due to nitrate reaction with the cloth. This reaction is followed by two small endotherms. At $320^{\circ} \mathrm{C}$ another endothermic reaction occurs but shortly after its onset at $360^{\circ} \mathrm{C}$ 
an exothermic reaction begins causing most of the $50 \%$ mass loss observed between 320 and $500^{\circ} \mathrm{C}$. This DTA experiment indicates that a 50\% polyamide / 50\% polyester cloth saturated with the RadPro 0100 emulsifier does not pose a reactivity risk at potential Hanford storage conditions. However, before proceeding with unneutralized RadPro 0100 saturated synthetic cloths, ARC testing is recommended.

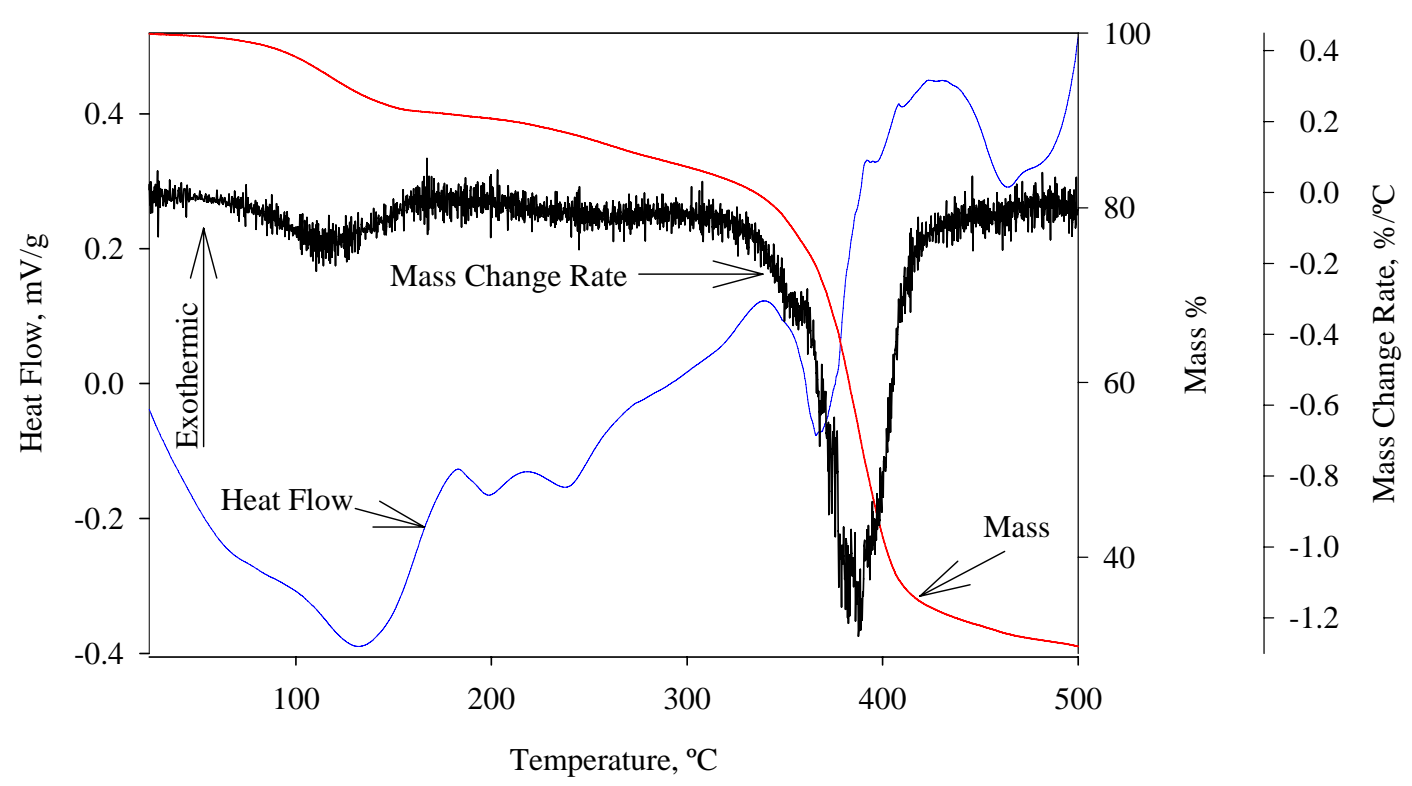

Figure 5.39. TGA/DTA-Measured Thermal Behavior of RadPro 0100 Saturated $50 \%$ Polyamide- $50 \%$ Polyester at $10^{\circ} \mathrm{C} / \mathrm{min}$ in Air

\subsubsection{Thermal Behavior of Mixed RadPro Emulsifier and Rinsate Solution Saturated 50\% Polyamide/50\% Polyester cloth}

One of the likely wastes arising from the RadPro decontamination process is a sorbent material containing RadPro E, a mixture of 33\% emulsifier and 67\% rinsate (RadPro C and RadPro D). To determine whether $50 \%$ polyamide- $50 \%$ polyester with sorbed emulsifier-rinsate solution is thermally stable at expected or potential Hanford storage conditions, we saturated some of this cloth with the emulsifierrinsate solution, air dried it on 7/29/04, and analyzed it using TGA/DTA on 08/06/04 (8 days). The resulting cloth would contain mixtures of the organics provided in Table 2.2 for RadPro 0100 mixed with nitric acid and proprietary buffers of RadPro C.

The TGA/DTA-measured thermal behavior of the emulsifier-rinsate saturated synthetic cloth is presented in Figure 5.40. As observed for all of the other RadPro solution saturated synthetic cloths, the cloths lose mass endothermically upon heating. Two small endothermic reactions occur at 180 and $240^{\circ} \mathrm{C}$ with minimal mass loss. At $290^{\circ} \mathrm{C}$ an exothermic reaction begins causing a nominal $10 \%$ mass loss. At $340^{\circ} \mathrm{C}$ an endothermic reaction occurs and at $360^{\circ} \mathrm{C}$ an exothermic reaction occurs as the preceding endothermic reaction continues. The combined mass losses for these two reactions are about $50 \%$. The absence of low temperature reactivity $\left(<150^{\circ} \mathrm{C}\right)$ is encouraging with respect to potential Hanford storage conditions with its maximum $45^{\circ} \mathrm{C}\left(113^{\circ} \mathrm{F}\right)$. Before using this strategy, we recommend confirmation with ARC 
using freeze-dried materials to assure the absence of confounding endothermic reactions for long-term projections.

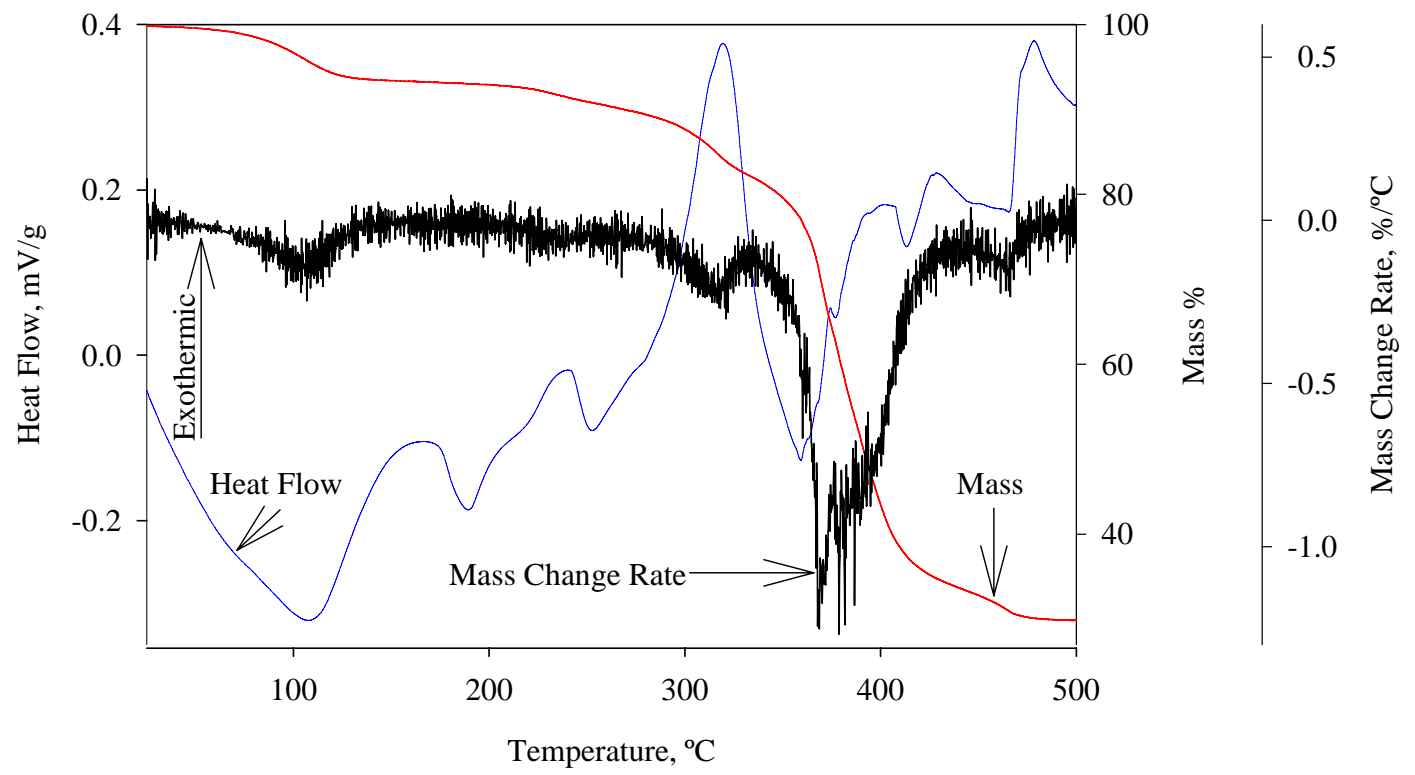

Figure 5.40. TGA/DTA-Measured Thermal Behavior of RadPro Emulsifier-Rinsate Solution Saturated 50\% Polyamide-50\% Polyester Cloth at $10^{\circ} \mathrm{C} / \mathrm{min}$ in Air

\subsubsection{Summary/Conclusions Regarding Thermal Sensitivity of RadPro Wastes}

To identify a thermally stable waste form for this RadPro ${ }^{\circledR}$ decontamination technology, we used TGA/DTA and ARC to investigate various sorbent materials and neutralization agents. The sorbent materials tested were $100 \%$ cotton cloths (provided by Fluor) rather than the $86 \%$ cotton/14\% polyester cloths used for the ceric nitrate studies, $50 \%$ polyamide/50\% polyester, and $20 \%$ polyamide/ $80 \%$ polyester. We investigated neutralizing RadPro process solution-saturated sorbents with sodium hydroxide and sodium carbonate.

We found that by neutralizing RadPro decontamination solution cotton cloths (the expected most reactive material) with sodium hydroxide or sodium carbonate, we could reduce or potentially mitigate thermal reactivity risks at maximum Hanford waste storage conditions $\left(45^{\circ} \mathrm{C}\right)$.

The ARC found that the 3-day old sodium hydroxide neutralized cotton cloth began to react at $170^{\circ} \mathrm{C}$ while the 9-day old material began to react significantly at $115^{\circ} \mathrm{C}$; the ARC observed a non-sustaining reaction at $45^{\circ} \mathrm{C}$. The latter exhibited similar behavior to the analogous carbonate neutralized cotton cloth. This similarity in reactivity after exposure of the sodium hydroxide neutralized cloth is expected since hydroxide reacts with carbon dioxide in air to form sodium carbonate. Assuming that the ARCobserved non-sustaining low temperature $\left(<100^{\circ} \mathrm{C}\right)$ reactions for the neutralized cotton cloths will not sustain themselves, neutralization appears to be an approach for mitigating the reactivity hazard of RadPro wastes. 
In contrast to our ceric nitrate results, in our ARC-experiments, we found little benefit from substituting polyamide/polyester cloths for cotton although we did see a delay in ARC-measured onset temperature for the synthetic cloths. Sodium carbonate-neutralization of the synthetic cloths had some short-term benefits delaying ARC-measured reaction onset to $135^{\circ} \mathrm{C}$. However after 300 days of storage in a plastic bag, the ARC-measured onset dropped to $95^{\circ} \mathrm{C}$ nominally less than the onset measured for equivalent cotton cloth. The reaction rates were less but capable of heating the sample to much higher temperatures. Using synthetic cloths with neutralization does not appear to offer much promise of reducing the thermal sensitivity of RadPro wastes.

The TGA/DTA results for the emulsifier wastes (25\% RadPro 01/75\% rinsate) indicate that both cotton and $50 \%$ polyamide $/ 50 \%$ polyester do not react in the $10^{\circ} \mathrm{C} / \mathrm{min}$ DTA with the RadPro solution below $160^{\circ} \mathrm{C}$; the synthetic cloth appears to be slightly more stable beginning to react at $180^{\circ} \mathrm{C}$ compared to $160^{\circ} \mathrm{C}$ with $100 \%$ cotton. To assure thermal stability, neutralization is recommended.

\subsection{Thermal Behavior of Glygel}

Glygel implements the ceric-decontamination technology as a gel. The process involves treating a Pucontaminated surface with a mixture of ceric ammonium nitrate, nitric acid, silica gel, and an organic surfactant. The gel adheres the ceric nitrate decontamination agent to the metal's surface, allowing a longer reaction time than liquid sprays that run off walls and ceilings. The treatment mixture dries or gels, and the gel is then removed from the surface either by brushing or, as we plan, with a vacuum cleaner.

Glygel is thixotropic. Application of the decontamination agent takes advantage of this property. Glygel is first agitated to liquefy the product, and then the TA 96 surfactant is added. At the completion of application, the motor from the mixer is wiped with a cotton rag. Liquid Glygel is sprayed or brushed onto the surface to be decontaminated. In the absence of shear forces, Glygel quickly returns to a gel. The gel is left to dry for up to 24 hours where it turns to dry flakes. The dried gel is collected in a vacuum cleaner using a scraper to remove dried gel from surfaces if necessary. The walls are wiped with a cloth to remove any remaining gel.

To determine the thermal stability of Glygel and potential mitigation approaches, we used simultaneous TGA/DTA, MS of evolved gases, and ARC. We studied ceric ammonium nitrate (the principal active component in Glygel), Glygel without surfactant, Glygel with surfactant, Glygel with filter media from two hand-held vacuum cleaners, neutralized Glygel, and Glygel mixed with a heat-absorbing diluent.

\subsubsection{Thermal Behavior of Ceric Ammonium Nitrate}

Ceric ammonium nitrate is one of the primary constituents in Glygel and as such could have a significant role in the reactivity of spent Glygel. We used both TGA/DTA and ARC to investigate its thermal behavior.

The TGA/DTA analysis for ceric ammonium nitrate provided in Figure 5.41 shows a succession of three endothermic reactions at 215,230 , and $250^{\circ} \mathrm{C}$, causing an $80 \%$ mass loss. The ARC analysis shown in Figure 5.42 indicates that a self-sustaining exothermic reaction begins at $195^{\circ} \mathrm{C}$. 
The likely cause for the difference in the observed behavior may arise from differences between the two instruments. In the TGA/DTA, the product gases are swept away and do not have an opportunity to react either with themselves or with the residual solids. In the ARC, the gas remains in the sample container at temperature, thus providing the opportunity for the gases to react with one another or with the remaining solids. If its decomposition is similar to $\mathrm{NH}_{4} \mathrm{NO}_{3}, \mathrm{~N}_{2} \mathrm{O}$ and $\mathrm{H}_{2} \mathrm{O}$ result at $250^{\circ} \mathrm{C}$ but at $>300^{\circ} \mathrm{C} \mathrm{N}_{2}, \mathrm{O}_{2}$, and $\mathrm{H}_{2} \mathrm{O}$ arise (Greenwood and Earnshaw 1994).

The DTA-observed behavior indicates that ceric ammonium nitrate does not pose a thermal reactivity risk because only endotherms occur; however, if one considers ammonium nitrate, which has no exothermic low-temperature reactions observed by the DTA but which can be used as an explosive at certain conditions, we cannot discount the potential reactivity of ceric ammonium nitrate under pressurized conditions or when present in massive quantities with poor thermal transport. This latter point is demonstrated by the ARC analysis of ceric ammonium nitrate.

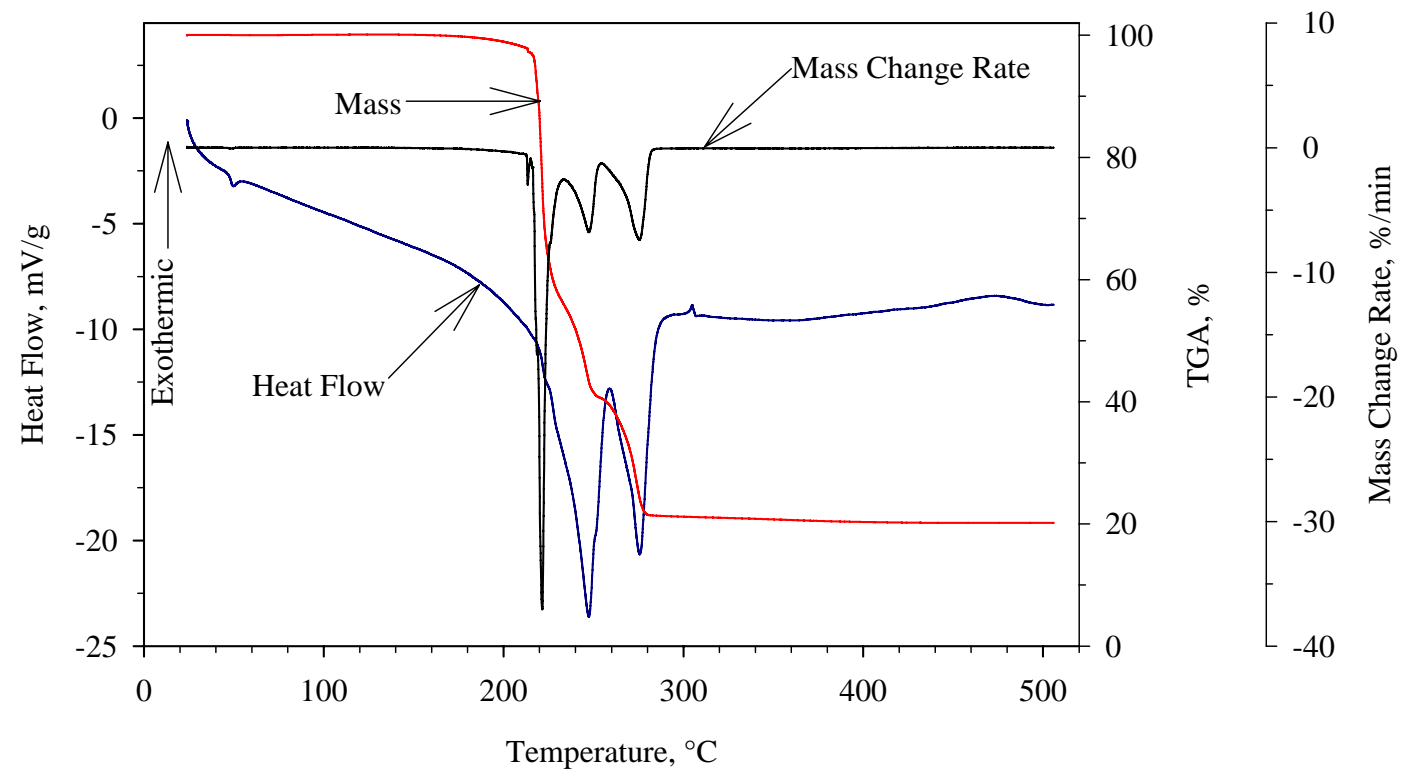

Figure 5.41. TGA/DTA-Measured Thermal Behavior of Ceric Ammonium Nitrate at $5^{\circ} \mathrm{C} / \mathrm{min}$ in Air

\subsubsection{Thermal Behavior of Glygel without Surfactant}

Although not typical of the applied Glygel, we studied Glygel without the required additive surfactant to better understand the factors that control the reactivity of Glygel. Glygel without surfactant is composed of ceric ammonium nitrate, nitric acid, and fused silica. Of these ingredients, potential energetic reactions could occur between ammonium ion and nitrate from the nitric acid or the ceric ammonium nitrate. This section provides the results of thermoanalytical studies. 


\subsubsection{TGA/DTA-Measured Thermal Behavior of Glygel Without Surfactant}

Our $10^{\circ} \mathrm{C} / \mathrm{min}$ TGA/DTA study of Glygel without surfactant as shown in Figure 5.43 found two or three endothermic reactions below $140^{\circ} \mathrm{C}$ followed by an exotherm beginning near $190^{\circ} \mathrm{C}$, which is followed by an endothermic reaction beginning at $240^{\circ} \mathrm{C}$.

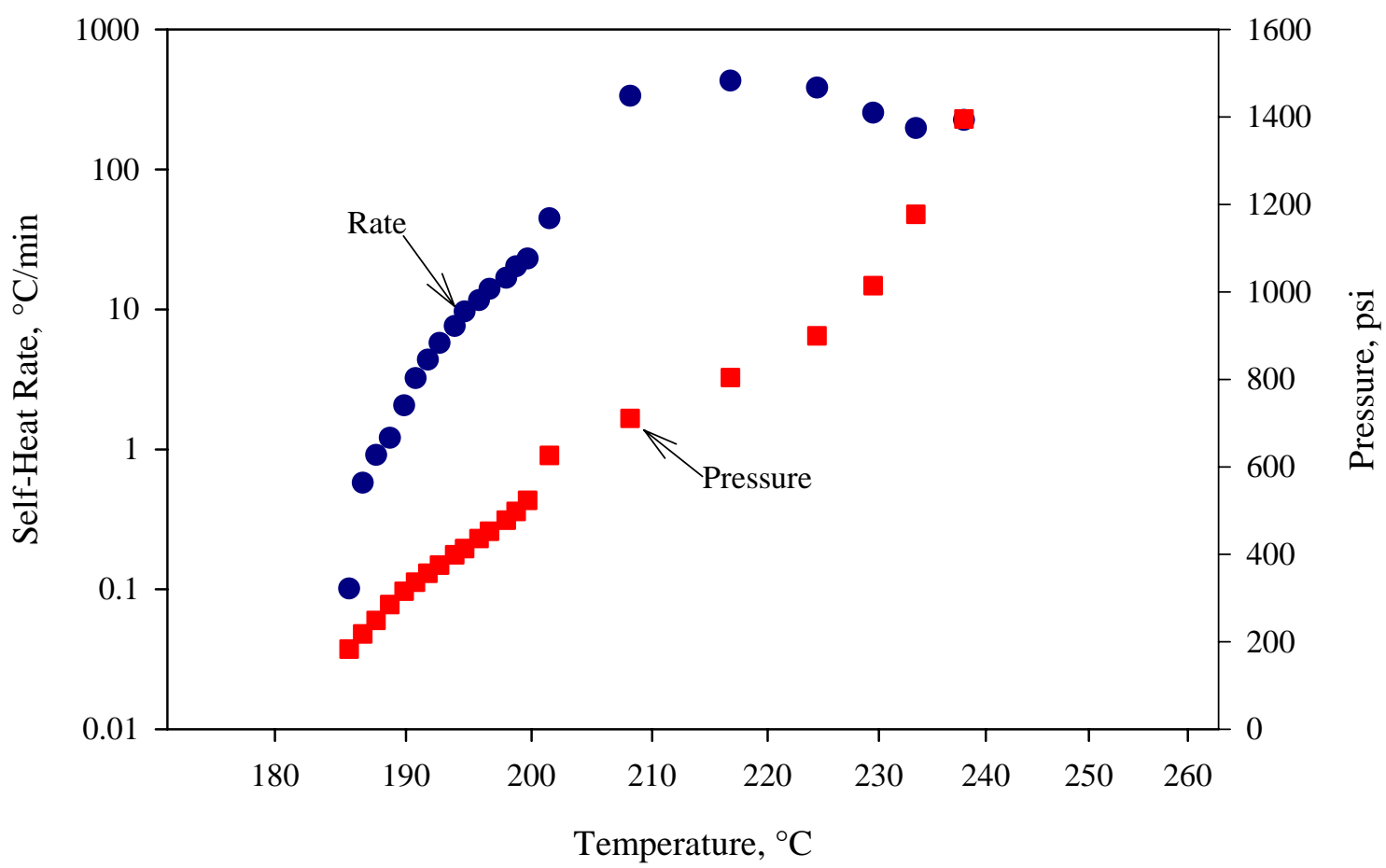

Figure 5.42. ARC-Measured Thermal Behavior of Ceric Ammonium Nitrate

Below $140^{\circ} \mathrm{C}$ the Glygel without surfactant lost 10 mass\% principally as water. The MS analysis of the evolved gases presented in Figure 5.44 indicates that these losses are due to different types of water (mass 18). The $190^{\circ} \mathrm{C}$ exothermic reaction and the subsequent $240^{\circ} \mathrm{C}$ endothermic reaction losses of 10 and 40 mass\%, respectively, produce $\mathrm{NO}, \mathrm{N}_{2} \mathrm{O}$, and water; we did not monitor for $\mathrm{NO}_{2}$ mass 46 amu. This suggests that an oxidation-reduction reaction is occurring between the oxidant $\mathrm{NO}_{3}{ }^{-}$(and possibly $\mathrm{Ce}^{+4}$ ) and reductant $\mathrm{NH}_{4}{ }^{+}$. Thermal decomposition of ammonium nitrate, $\mathrm{NH}_{4} \mathrm{NO}_{3}$, forms $\mathrm{N}_{2} \mathrm{O}$ at $\sim 200^{\circ} \mathrm{C}$ (Wiberg 2001, p 645). Usually oxidation-reduction reactions are exothermic, and we cannot without further study explain the indication that such reaction products are formed in this material endothermically at $240^{\circ} \mathrm{C}$. To eliminate a potential fuel source, we did not use an organic degreaser on the stainless steel coupon surface before applying the Glygel to prepare the Glygel without surfactant.

The thermal studies show ceric ammonium nitrate and Glygel without surfactant (i.e., ceric ammonium nitrate in the presence of nitric acid and silica) behave differently. Possible explanations for increased reactivity of Glygel include the catalytic behavior of the silica and the reaction between nitric acid and ammonium ion to produce the additional DTA-observed exothermicity in Glygel. Although scientifically intriguing, unraveling the various factors controlling these differences was beyond the scope of this work and report. 


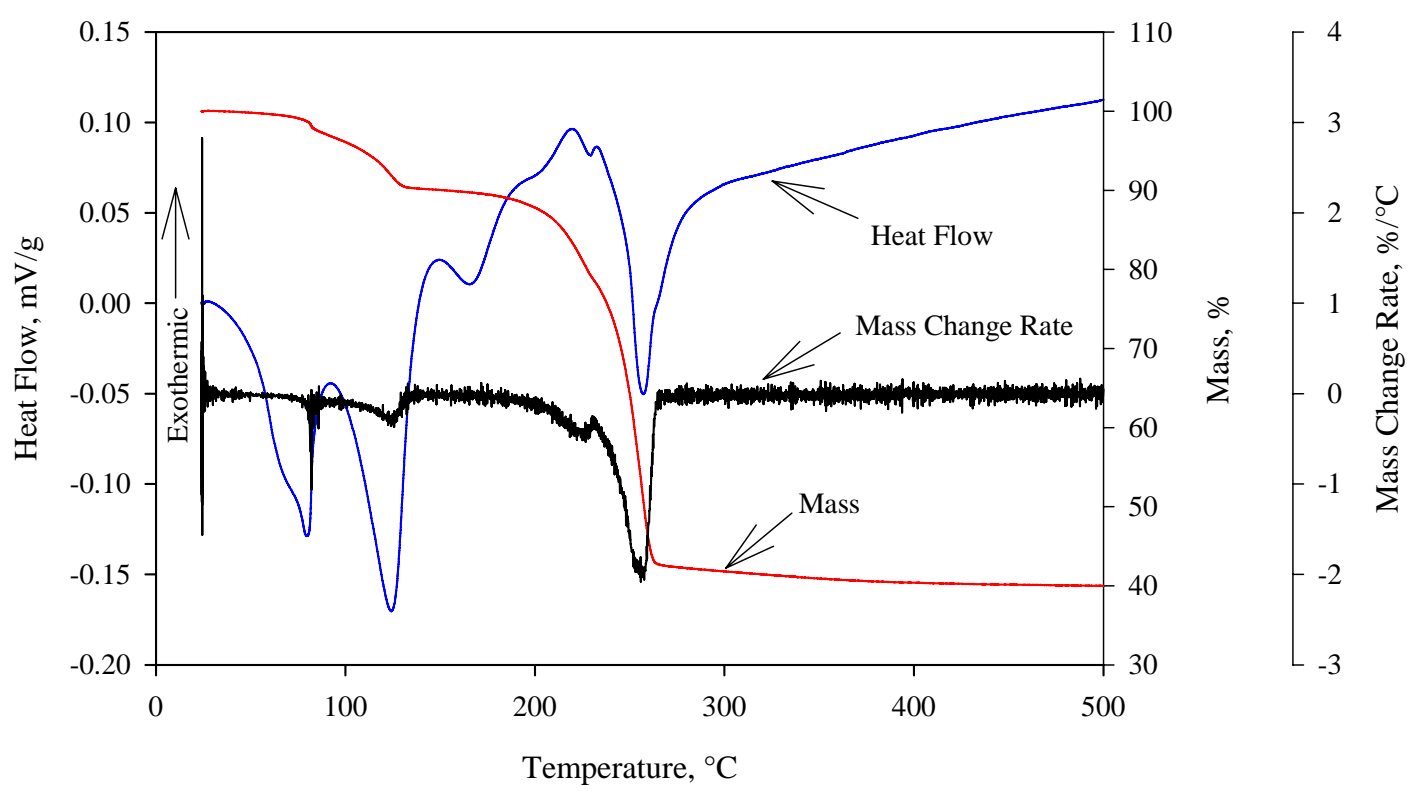

Figure 5.43. TGA/DTA-Measured Thermal Behavior of Glygel Without Surfactant in Air at $10^{\circ} \mathrm{C} / \mathrm{min}$

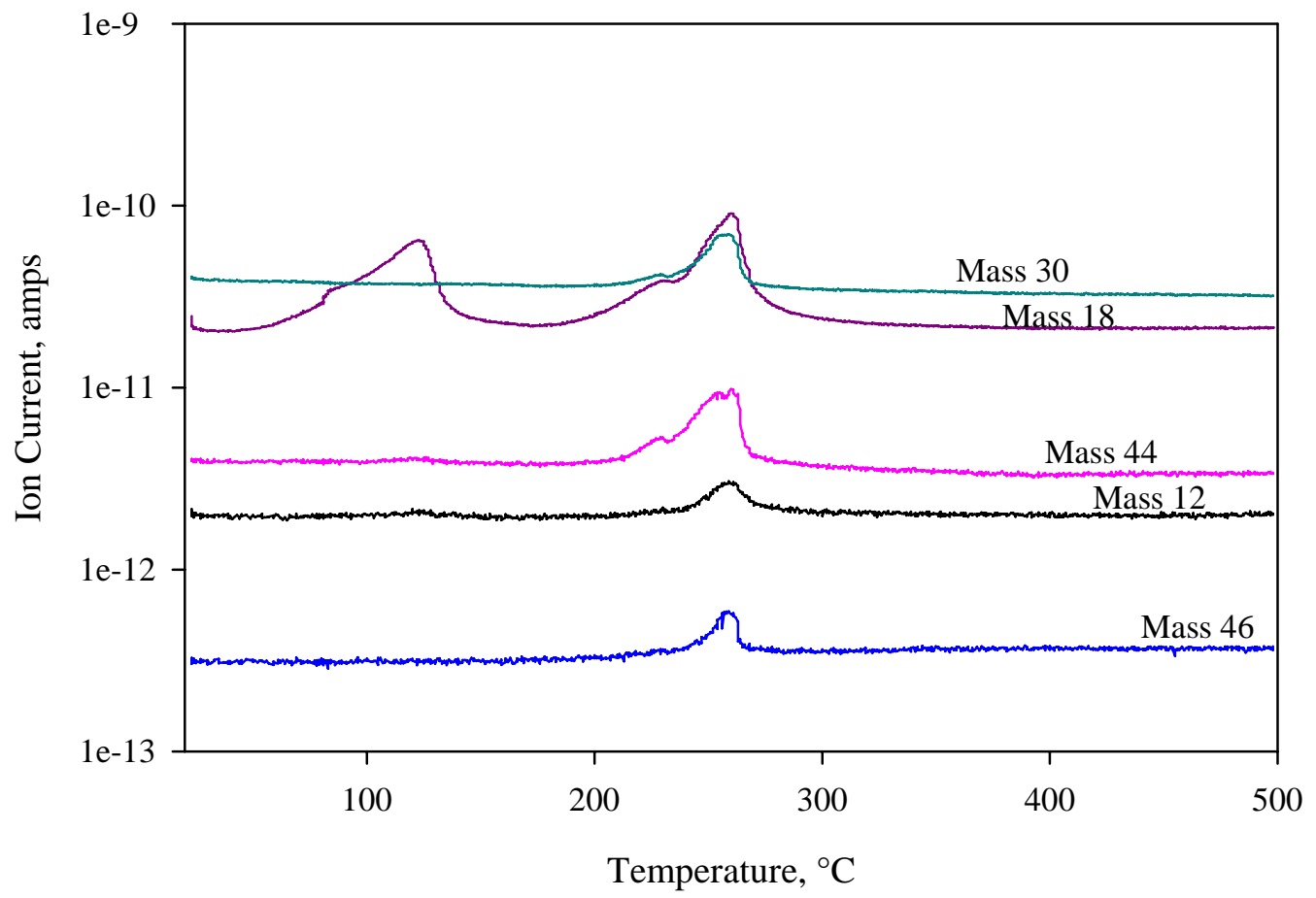

Figure 5.44. MS-Measured Evolved Gas Composition from Glygel Without Surfactant in Air at $10^{\circ} \mathrm{C} / \mathrm{min}$ 
Our TGA/DTA/MS studies of Glygel without surfactant found that at low temperatures, endothermic water-producing reactions predominate; however, near $190^{\circ} \mathrm{C}$, an exothermic reaction begins producing products that would be expected for reactions between nitrate and ammonium ion. This indicates that for a thermal runaway reaction to occur within this matrix, the various types of water extant in the silica gel first would have to be driven off through evaporation. In addition, the $190^{\circ} \mathrm{C}$-onset exothermic reaction satisfies the CCPS's recommended $100^{\circ} \mathrm{C}$ safety margin between DTA-observed exothermic onset and the process's maximum operating temperature of $45^{\circ} \mathrm{C}$.

\subsubsection{ARC-Measured Thermal Behavior of Glygel without surfactant}

We performed three ARC experiments to determine the thermal sensitivity of Glygel without surfactant. The first two tested air-dried material and the third used freeze-dried.

The ARC analyses shown in Figure 5.45 found that air-dried Glygel without surfactant behaves similarly to ceric ammonium nitrate with ARC-observed onsets of 187 and $176^{\circ} \mathrm{C}$ compared to $195^{\circ} \mathrm{C}$ for ceric ammonium nitrate. Given that Glygel without surfactant began as ceric ammonium nitrate, nitric acid, and silica, it would be expected to behave similarly unless the nitric acid is a more effective oxidant than the nitrate within the ceric ammonium nitrate.

The ARC analysis of $3 \mathrm{~g}$ of freeze-dried Glygel without surfactant found that thoroughly dried Glygel begins to react at $75^{\circ} \mathrm{C}$ which is lower than the air-dried samples. These reactions are short-lived, but without additional testing, we will not know whether a larger sample size will provide enough heat to drive the reactions that are observed at 75 and $98^{\circ} \mathrm{C}$. However, the gap between 100 and $175^{\circ} \mathrm{C}$ is a large one. The freeze-dried Glygel without surfactant experiment suggests that water contained within Glygel does help prevent low temperature reactions, although this would indicate that nitric acid and silica participate in the oxidation of ammonium ion.

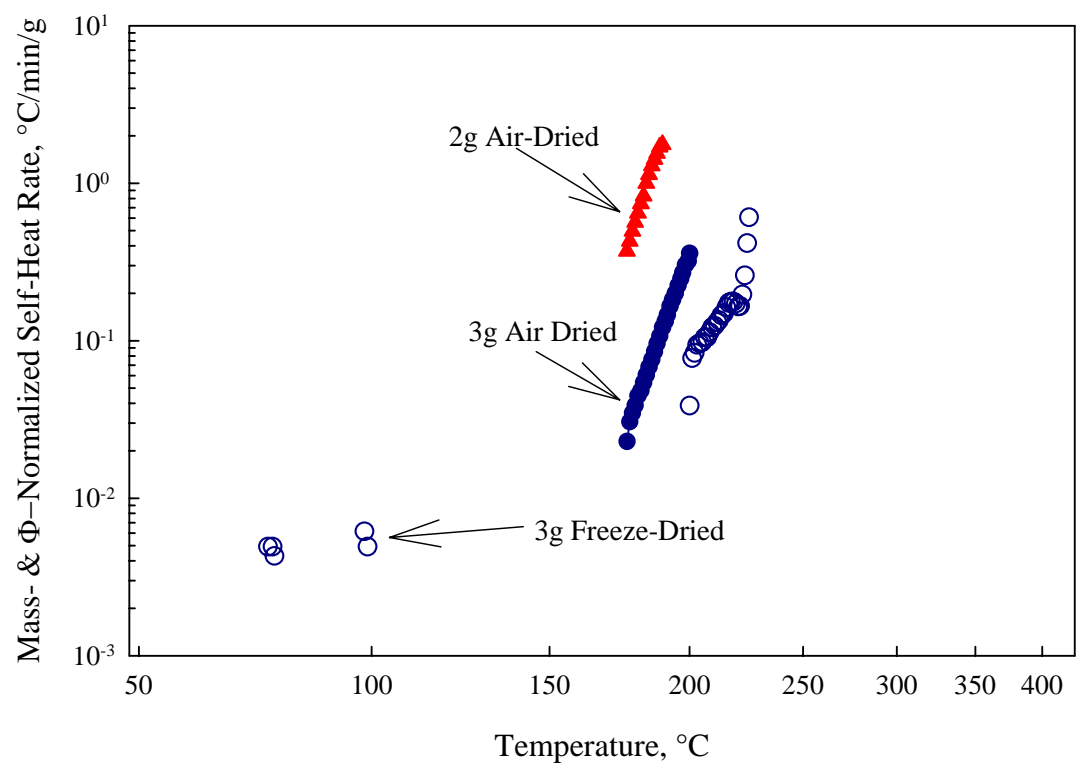

Figure 5.45. Arrhenius Plot of ARC-Measured Thermal Sensitivity of Air-Dried and Freeze-Dried Glygel Without Surfactant 


\subsubsection{ARC-Measured Thermal Behavior of Glygel with surfactant}

In actual use, a surfactant is added to the ceric ammonium nitrate, nitric acid, and silica gel mixture in Glygel. The addition of the surfactant adds an organic diethylene glycol monohexyl ether or alternatively named 2-(2-n-Hexyloxyethoxy)ethanol according to the MSDS. Such addition adds a second fuel to the Glygel.

As with the Glygel without surfactant, we used TGA/DTA/MS and ARC to measure the thermal behavior of Glygel with surfactant to determine the effects of adding surfactant to the reactive Glygel mixture.

\subsubsection{TGA/DTA/MS-Measured Thermal Behavior of Glygel with Surfactant}

As shown in Figure 5.46, Glygel with surfactant exhibits the same two endothermic mass losses of nominally 5 and 10 mass\% below $140^{\circ} \mathrm{C}$ as observed for Glygel without surfactant; however, near $150^{\circ} \mathrm{C}$ a strong exotherm occurs. For Glygel without surfactant, its first DTA-observed exotherm was at $190^{\circ} \mathrm{C}$ and was not as strong as with the surfactant. A second exotherm is indicated by the shoulder on the larger peak near $210^{\circ} \mathrm{C}$. The combined exotherms caused the sample to lose another 40 mass\%. The exotherms are followed by an endotherm at $240^{\circ} \mathrm{C}$.

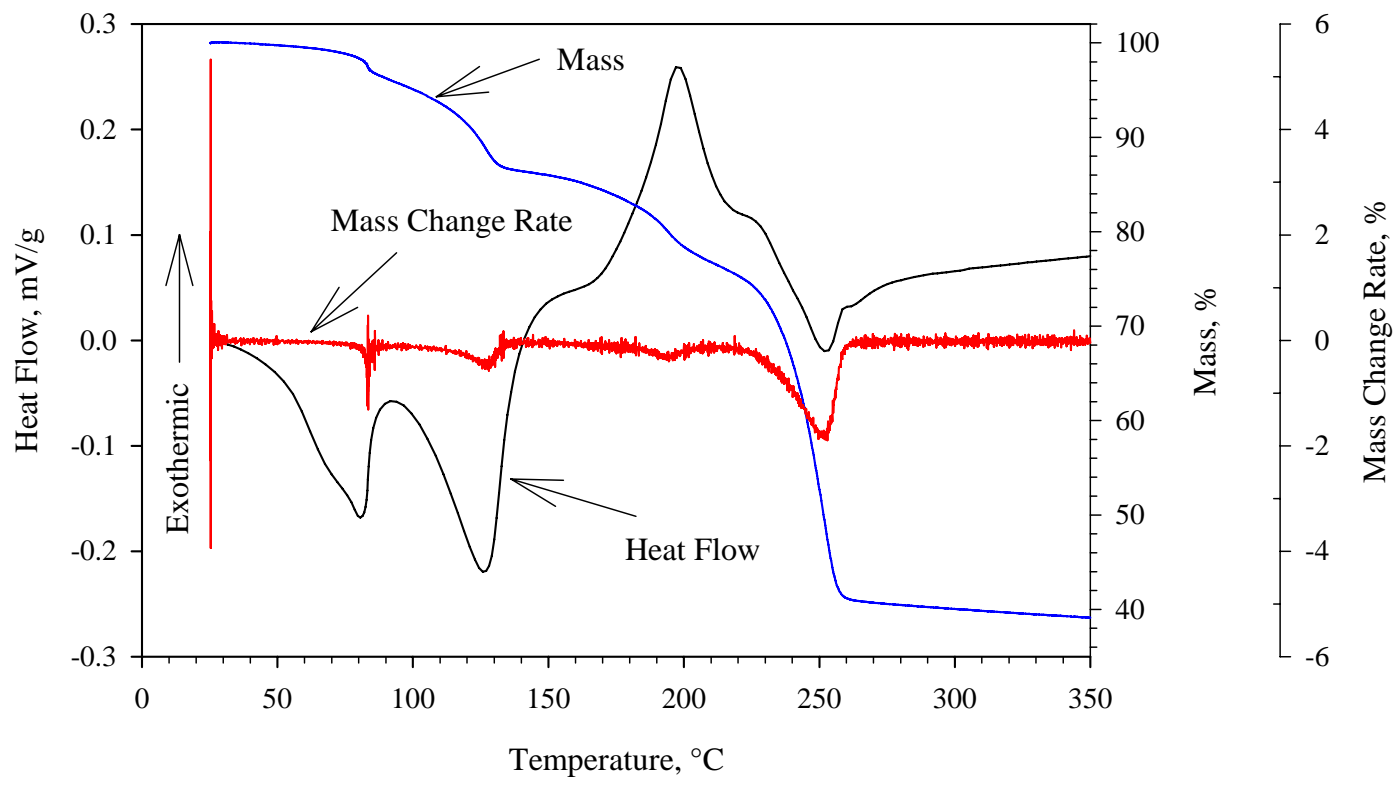

Figure 5.46. TGA/DTA-Measured Thermal Behavior of Glygel with Surfactant in Air at $10^{\circ} \mathrm{C} / \mathrm{min}$

We did a second TGA/DTA analysis at $5^{\circ} \mathrm{C} / \mathrm{min}$ of Glygel with surfactant using a different instrument. Figure 5.47 presents the results of that experiment. At $5^{\circ} \mathrm{C} / \mathrm{min}$, the two endotherms seen at $10^{\circ} \mathrm{C} / \mathrm{min}$ below $140^{\circ} \mathrm{C}$ merge into a single peak with a $12 \%$ mass loss, and the exothermic peak at $190^{\circ} \mathrm{C}$ is now a small endotherm with another $10 \%$ loss. We do not have an explanation for the differences. The final endotherm that causes a $40 \%$ mass loss begins near $240^{\circ} \mathrm{C}$ as observed before. 


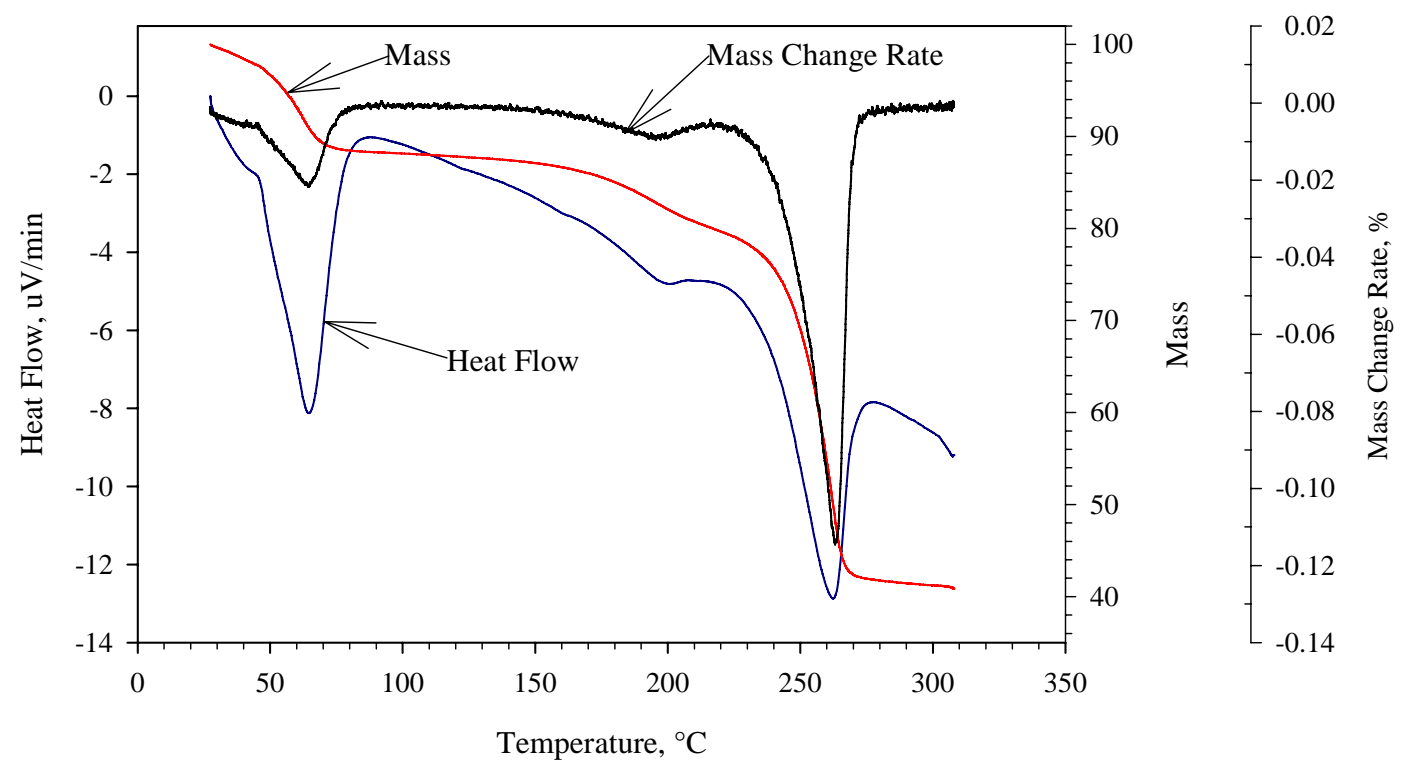

Figure 5.47. TGA/DTA Measured Thermal Behavior of Glygel with surfactant at $5^{\circ} \mathrm{C} / \mathrm{min}$ in $\mathrm{Ar}$

As with the Glygel without surfactant, we monitored the gas species released from the Glygel with surfactant whose masses are provided in Table 5.5. Table 5.5 shows the significant gases observed. Masses 64, 46, 38, 37, 35, 35, 23, 19, 15, 12, and 2 were not observed. Masses 32, 28, 20, 16, and 14 are not provided in Table 5.5 because they are singly or doubly charged constituents of air (oxygen or nitrogen) or the argon cover gas.

Before embarking on a discussion about the identities of the evolved gases, we need to explain or at least discuss the non-Gaussian appearance of the evolved gases' peaks. For exothermic reactions, the sample temperature can exceed the program temperature and will provide a asymmetric appearance; however, there is another explanation for this behavior. To determine what caused the temperature of the sample to exceed the program temperature, we plotted temperature versus time and discovered that the instrument would heat up beyond the program temperature and then would compensate and would drop below the program temperature, resulting in a declining amplitude temperature differential until the two temperatures became the same.

Inspection of Figure 5.48 shows that, as with the Glygel without surfactant (Figure 5.44), water was the predominant gas evolved below $140^{\circ} \mathrm{C}$. There also appears to be some mass 40 (possibly $\mathrm{C}_{3} \mathrm{H}_{4}$ ) evolved (above the Ar mass 40 background) simultaneously, which would indicate decomposition of the surfactant or reaction of the surfactant with nitrate. This is suggested by erratic waves in the NO release occurring simultaneously with these other two gases. Above $150^{\circ} \mathrm{C}$, water (mass 18) and NO (mass 30), mass 40 and mass $44\left(\mathrm{CO}_{2}, \mathrm{~N}_{2} \mathrm{O}\right.$ or $\left.\mathrm{C}_{3} \mathrm{H}_{8}\right)$, are released. This suggests that if $\mathrm{N}_{2} \mathrm{O}$ is the source of the mass 44 peak, the oxidation-reduction reactions are occurring between the organic and ammonium fuels present in the mixture, which is consistent with the exothermic reactions observed between 150 and $240^{\circ} \mathrm{C}$; alternatively, the $\mathrm{N}_{2} \mathrm{O}$ could arise from thermal decomposition of ammonium nitrate. 
Table 5.5. Mass Spectrometer Observed Masses of Potential Gaseous Species from Glygel

\begin{tabular}{|c|c|}
\hline AMU & Potential species \\
\hline 2 & $\mathrm{H}_{2}{ }^{+}$ \\
\hline 12 & $\mathrm{C}^{+}$ \\
\hline 14 & $\mathrm{~N}^{+}, \mathrm{N}_{2}{ }^{++}, \mathrm{CH}_{2}{ }^{+}$ \\
\hline 15 & $\mathrm{CH}_{3}{ }^{+}$ \\
\hline 16 & $\mathrm{O}^{+}, \mathrm{CH}_{4}{ }^{+}$ \\
\hline 17 & $\mathrm{NH}_{3}{ }^{+}, \mathrm{OH}^{+}$ \\
\hline 18 & $\mathrm{H}_{2} \mathrm{O}^{+}$ \\
\hline 19 & $\mathrm{~F}^{+}$ \\
\hline 20 & $\mathrm{Ar}^{++}$ \\
\hline 23 & $\mathrm{Na}^{+}$ \\
\hline 28 & $\mathrm{~N}_{2}^{+}, \mathrm{CO}^{+}, \mathrm{C}_{2} \mathrm{H}_{4}{ }^{+}, \mathrm{H}_{2} \mathrm{CO}^{+}$ \\
\hline 30 & $\mathrm{NO}^{+}, \mathrm{C}_{2} \mathrm{H}_{6}{ }^{+}$ \\
\hline 32 & $\mathrm{O}_{2}{ }^{+}, \mathrm{S}^{+}, \mathrm{CH}_{3} \mathrm{OH}^{+}$ \\
\hline 35 & $\mathrm{Cl}^{+}$ \\
\hline 36 & $\mathrm{C}_{3}^{+}, \mathrm{HCl}^{+}$ \\
\hline 37 & $\mathrm{C}_{3} \mathrm{H}^{+}$, \\
\hline 38 & $\mathrm{C}_{3} \mathrm{H}_{2}{ }^{+}$ \\
\hline 40 & $\mathrm{Ar}^{+}, \mathrm{C}_{3} \mathrm{H}_{4}{ }^{+}$ \\
\hline 42 & $\mathrm{C}_{3} \mathrm{H}_{6}{ }^{+}$ \\
\hline 44 & $\mathrm{CO}_{2}{ }^{+}, \mathrm{N}_{2} \mathrm{O}^{+}, \mathrm{C}_{3} \mathrm{H}_{8}{ }^{+}$ \\
\hline $\mathrm{C}_{5} \mathrm{H}_{4}{ }^{+}, \mathrm{SO}_{2}{ }^{+}$ \\
\hline
\end{tabular}

The TGA/DTA/MS analysis of Glygel with surfactant indicates that exothermic reactions occur at temperatures as low as $150^{\circ} \mathrm{C}$. The DTA-measured onset temperature of $150^{\circ} \mathrm{C}$ is slightly greater than the $100^{\circ} \mathrm{C}$ CCPS-recommended safety margin between DTA-measured onset temperatures and the maximum process operating temperature. The results of these simultaneous analyses are also conflicting and confound the conclusions; additional studies are required to resolve the conflicts.

\subsubsection{ARC-Measured Thermal Behavior of Glygel with Surfactant}

We performed two ARC analyses of the PFP-supplied air-dried Glygel with surfactant using 1- and 3-g samples. We limited the first ARC analysis of dried Glygel to $200^{\circ} \mathrm{C}$. As shown in Figure 5.49, the ARC observed self-heating starting at $116^{\circ} \mathrm{C}$ for this 1-g sample. In our second experiment, also presented in Figure 5.49 , self-heating was observed at $81^{\circ} \mathrm{C}$ for the 3-g sample but rapidly quit and began again when heated to $90^{\circ} \mathrm{C}$. This reaction after a slight hesitation began accelerating and eventually leads to a third 
reaction at $170^{\circ} \mathrm{C}$, which continued to accelerate. This third reaction produced sufficient gas at $250^{\circ} \mathrm{C}$ to rupture the sample container rated for 4000 psi.

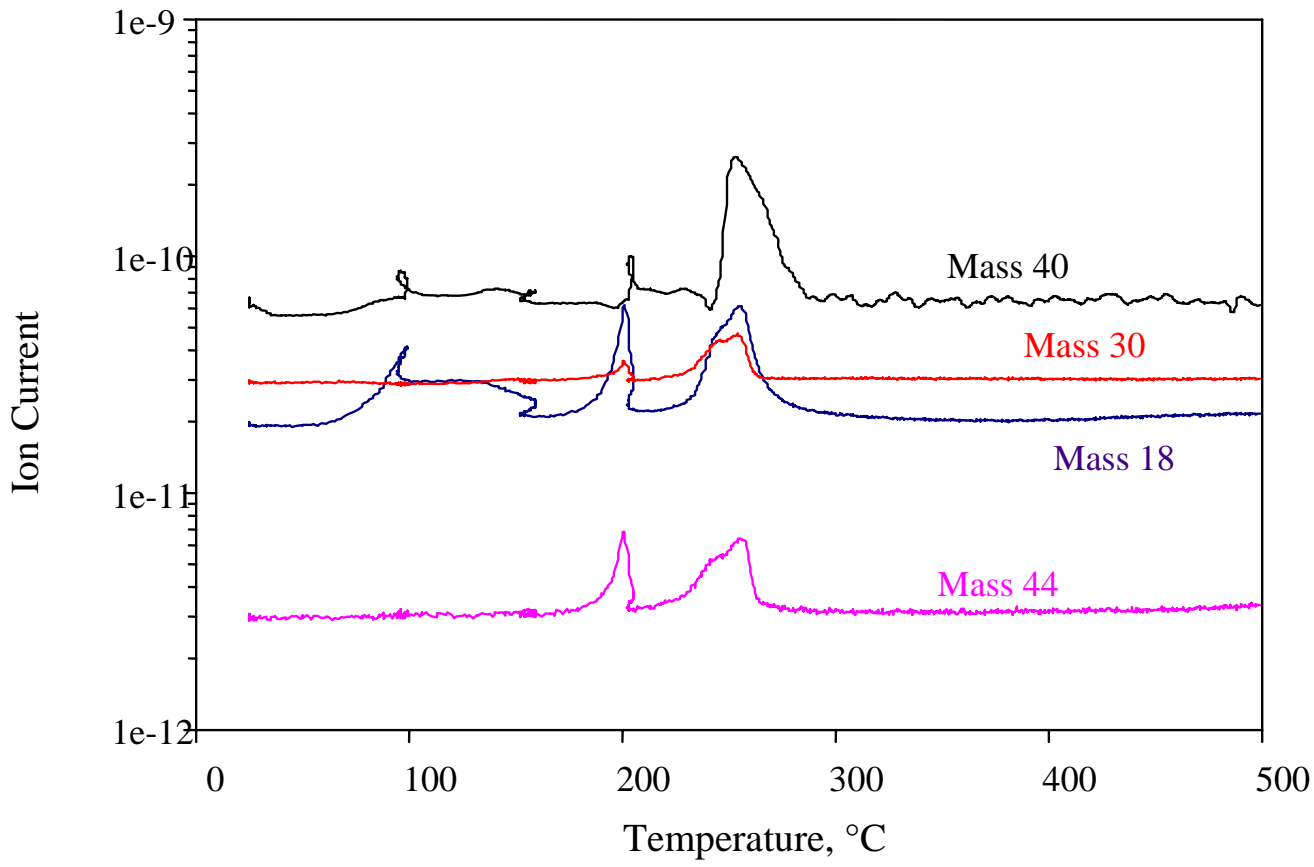

Figure 5.48. Masses $18\left(\mathrm{H}_{2} \mathrm{O}\right), 30(\mathrm{NO}), 40\left(\mathrm{C}_{3} \mathrm{H}_{4}\right)$, and $44\left(\mathrm{CO}_{2}, \mathrm{~N}_{2} \mathrm{O}, \mathrm{C}_{3} \mathrm{H}_{8}\right)$ in Evolved Gas During TGA/DTA Analysis of Glygel with Surfactant in Air at $10^{\circ} \mathrm{C} / \mathrm{min}$

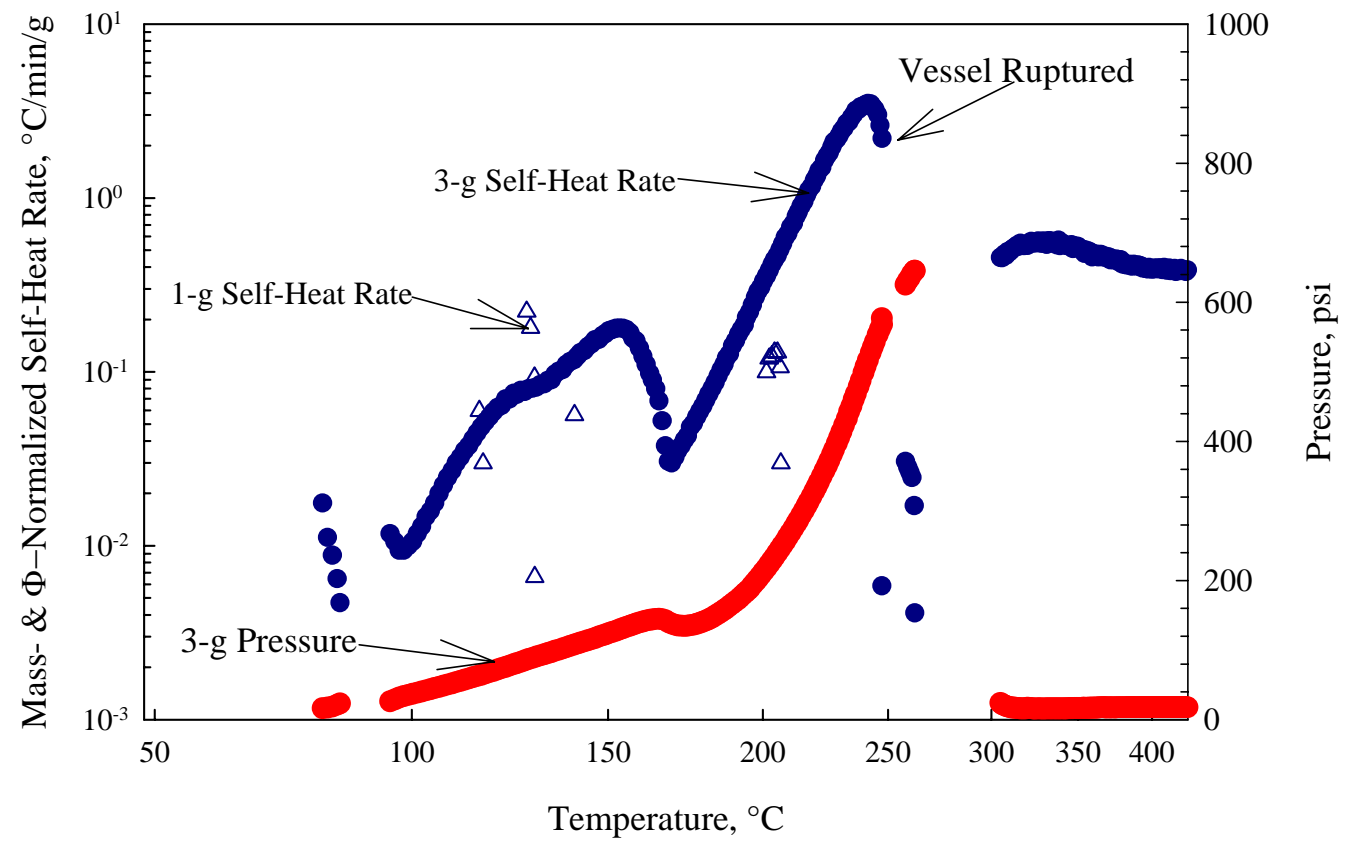

Figure 5.49. Arrhenius Plot of ARC-Measured Thermal Behavior of Dried PFP-Supplied Glygel with Surfactant 
The ARC testing indicates that Glygel with surfactant is capable of supporting self-sustaining and accelerating reactions beginning at $80^{\circ} \mathrm{C}$ for a 3-g sample in an adiabatic sealed environment. The rupture of the ARC test sample container also illustrates the importance of preventing a thermal runaway in Glygel.

To determine if Glygel with surfactant would pose a greater thermal reactivity risk if retained water evaporates over time, we freeze-dried some of the PNNL-prepared Glygel with surfactant. The thermal sensitivity before and after freeze-drying was measured to $250^{\circ} \mathrm{C}$. Figure 5.50 provides a comparison from the results of the two experiments. This comparison shows that freeze drying reduces the onset temperature by $10^{\circ} \mathrm{C}$ from 86 to $76^{\circ} \mathrm{C}$. These results indicate, as expected, that Glygel's thermal sensitivity will increase if the Glygel dries.

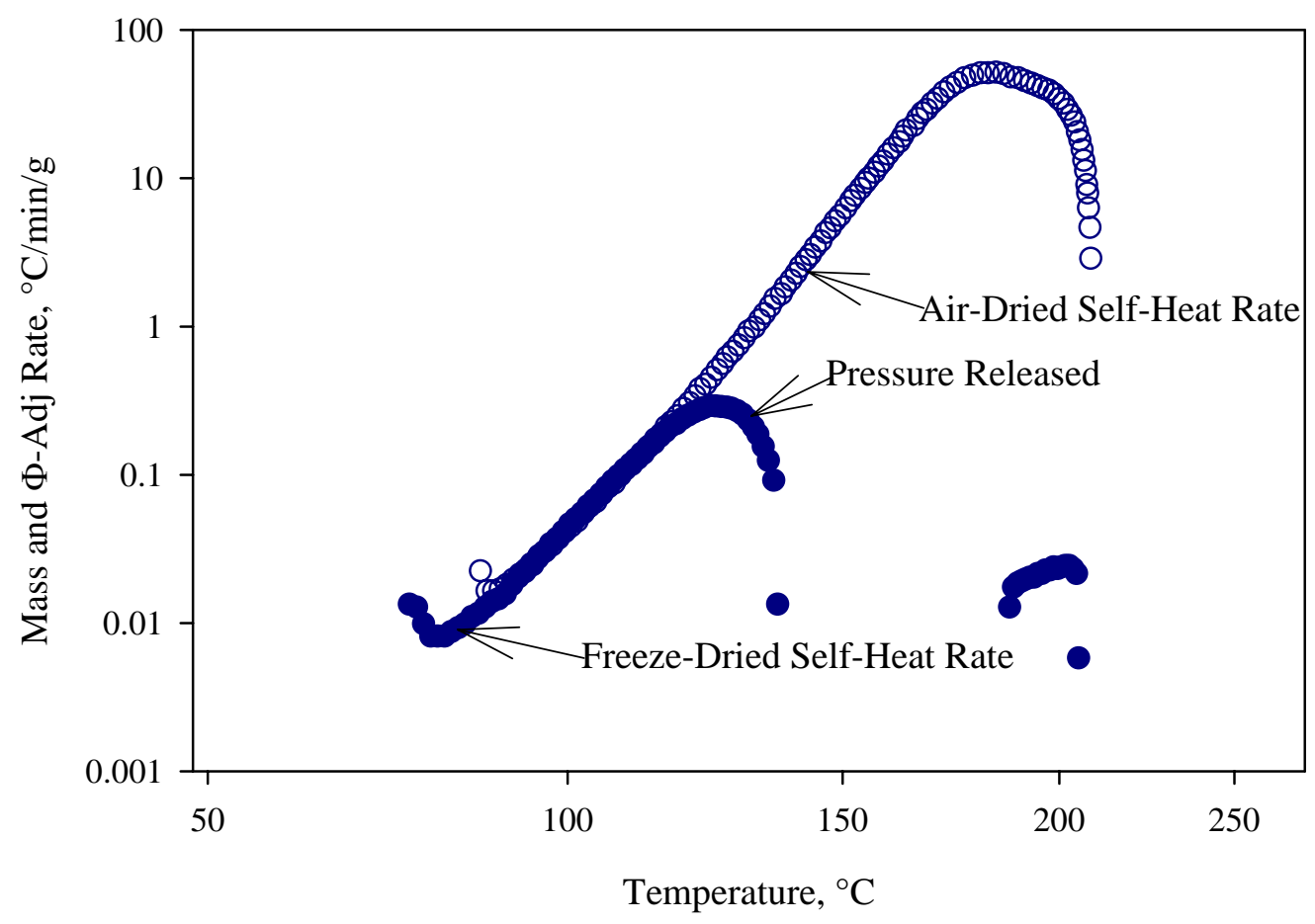

Figure 5.50. Arrhenius Plot Comparison of ARC-Measured Thermal Sensitivity of Freeze-Dried Glygel with Surfactant

\subsubsection{Thermal Behavior of Sodium Carbonate-Diluted Glygel with Surfactant}

One potential approach to mitigating the thermal reactivity associated with Glygel is to mix the spent Glygel with a diluent such as sodium carbonate. Sodium carbonate is particularly attractive because it has several hydrates that require heat to decompose. For example, the decahydrate and heptahydrate decompose at 32 and $35^{\circ} \mathrm{C}$, respectively. The monohydrate loses its water at $100^{\circ} \mathrm{C}$. Each gram of water lost by evaporation will require at least $2250 \mathrm{~J}$. Sodium carbonate also can serve to neutralize the acid, which may also mitigate Glygel's thermal reactivity though it will not eliminate the nitrate available for oxidation. 
To maximize the carbonate's waters of hydration, we exposed available sodium carbonate to $100 \%$ relative humidity for several days at room temperature. We then mixed Fluor-provided Glygel and sodium carbonate decahydrate 1:1 by weight. The total sample mass was $6 \mathrm{~g}$, containing $3 \mathrm{~g}$ of Glygel.

The unexpected result was that low-temperature self-heating was observed beginning at $75^{\circ} \mathrm{C}$ in Run 1 and $85^{\circ} \mathrm{C}$ in Run 2 as shown in Figure 5.51. The self-heat rates were also very similar to those observed for Glygel itself, which is unexpected because of the increased heat capacity of the mixture with no increase in heat production. We are unsure whether the $45^{\circ} \mathrm{C}$-reaction observed in Run 1 is genuine because it was not observed by the second analysis. Otherwise, the two analyses are near-duplicates of one another. With respect to onset temperature, they are also very similar to Glygel with surfactant but without any sodium carbonate diluent. At $100^{\circ} \mathrm{C}$, the self-heat rate slows dramatically, likely because of decomposition of the sodium carbonate monohydrate. Sodium carbonate dilution appears to significantly slow the Glygel reactions that occur between $100^{\circ} \mathrm{C}$ and $150^{\circ} \mathrm{C}$.

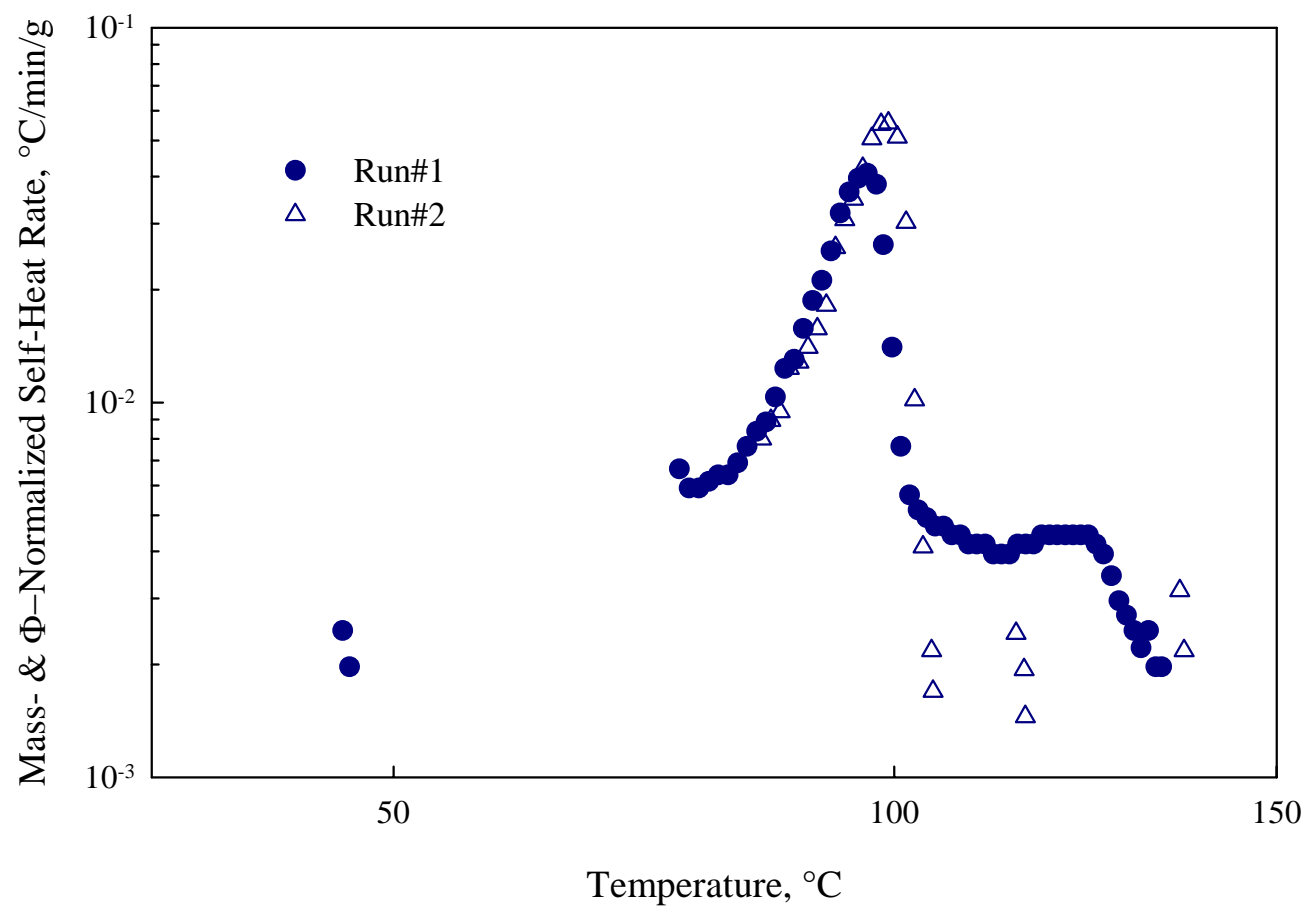

Figure 5.51. Arrhenius Plot of ARC-Measured Thermal Sensitivity of PFP-Supplied Glygel with Surfactant in a 1:1 Mass Ratio Mixture with Sodium Carbonate

Dilution by sodium carbonate offers little benefit, based on these two experiments, because it fails to increase Glygel's ARC-measured reaction onset temperature to $50^{\circ} \mathrm{C}$ above the maximum Hanford temperature of $45^{\circ} \mathrm{C}$. It does, however, offer promise as an effective approach for mitigating the consequences of a thermal runaway reaction because of its dampening effect above $100^{\circ} \mathrm{C}$.

One potential explanation for the absence of a benefit at low temperatures in the ARC analysis may be the result of the way that the ARC operates. If the ARC does not observe a reaction, it will supply heat to the system to raise the system's temperature. If a low-temperature endothermic reaction occurs, the instrument will supply the heat needed to raise the sample temperature to the target level. In the case of sodium carbonate, however, the Hanford environment could heat the spent Glygel above the low- 
temperature dehydrations and heat the Glygel waste to within $50^{\circ} \mathrm{C}$ of the ARC-observed onset temperature.

\subsubsection{Thermal Behavior of Glygel-Filter Media Mixtures}

Current plans are to collect spent Glygel using handheld vacuum cleaners. The original planned approach was to remove the filled vacuum filter from the vacuum and dispose of the combined Glygel and filter together. To evaluate this disposal approach, we used TGA/DTA/MS and ARC to determine the thermal behavior of Glygel and filter media mixtures.

TGA/DTA/MS-Measured Thermal Behavior of Glygel-Filter Media Mixture. To investigate the thermal stability of Glygel with vacuum filter media by TGA/DTA/MS, we tested a mixture of $5 \mathrm{mg}$ of Shark filter media and 85 mg PFP-prepared Glygel. This small amount of filter media dramatically changes the TGA/DTA results from those of Glygel alone. Comparison of the TGA/DTA results in Figure 5.52 with Figure 5.46 illustrates this dramatic difference. The experiment with filter media finds not only the normal endotherms below $140^{\circ} \mathrm{C}$ and the exotherm at $190^{\circ} \mathrm{C}$, but now a very rapid (almost instantaneous) reaction at $210^{\circ} \mathrm{C}$. This rapid reaction is likely caused by reaction of the filter media with nitrate. The rate of this last reaction indicates that the consequences of this reaction would be significant. Our ARC experiments strongly support this conclusion from the TGA/DTA experiment.

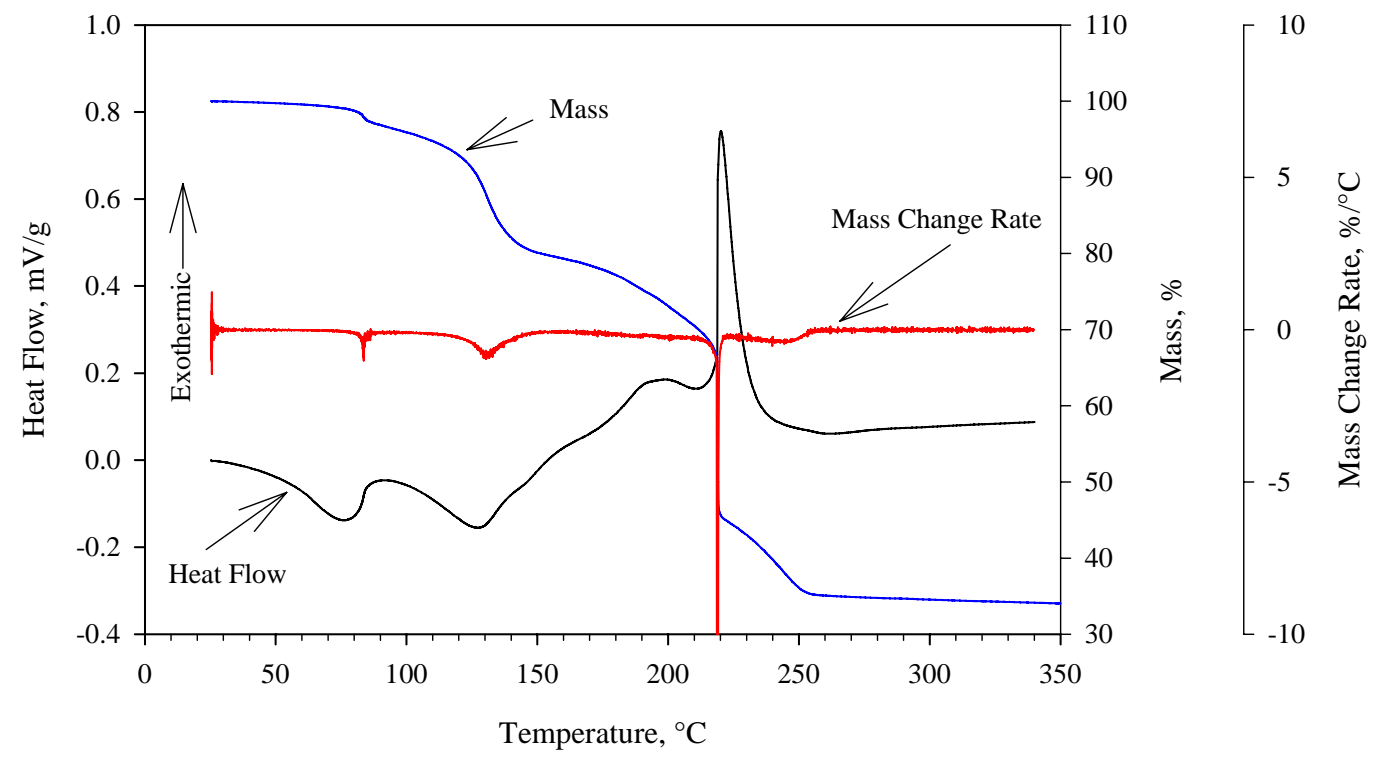

Figure 5.52. TGA/DTA-Measured Thermal Behavior of Mixture of Glygel with Surfactant and Filter Media

The MS analysis of the evolved gases provided in Figure 5.53 indicates the mixture of Glygel and filter media reacts in nominally four steps. The MS found the customary release of water vapor between 80 and $140^{\circ} \mathrm{C}$. The products from oxidation by nitrate begin at about $120^{\circ} \mathrm{C}$. Gases observed were mass 30 (nitric oxide), mass 18 (water), mass 44 (carbon dioxide), mass 12 (carbon atoms), and mass 46 (nitrogen dioxide). The MS also observed reactions at 180,220 , and $240^{\circ} \mathrm{C}$. 
The TGA/DTA/MS study showed Glygel mixed with filter media is a much more reactive system than the system without filter. Oxidation-reduction reactions begin near $120^{\circ} \mathrm{C}$, which is less than the CCPS's recommended DTA $100^{\circ} \mathrm{C}$ rule-of-thumb safety margin from Hanford's maximum temperature of $45^{\circ} \mathrm{C}$ $\left(113^{\circ} \mathrm{F}\right)$. These studies also indicate that should a self-propagating reaction capable of heating the mixture to where Glygel and the filter media reacts, consequences could be significant if the $220^{\circ} \mathrm{C}$ reaction is a significant gas producer.

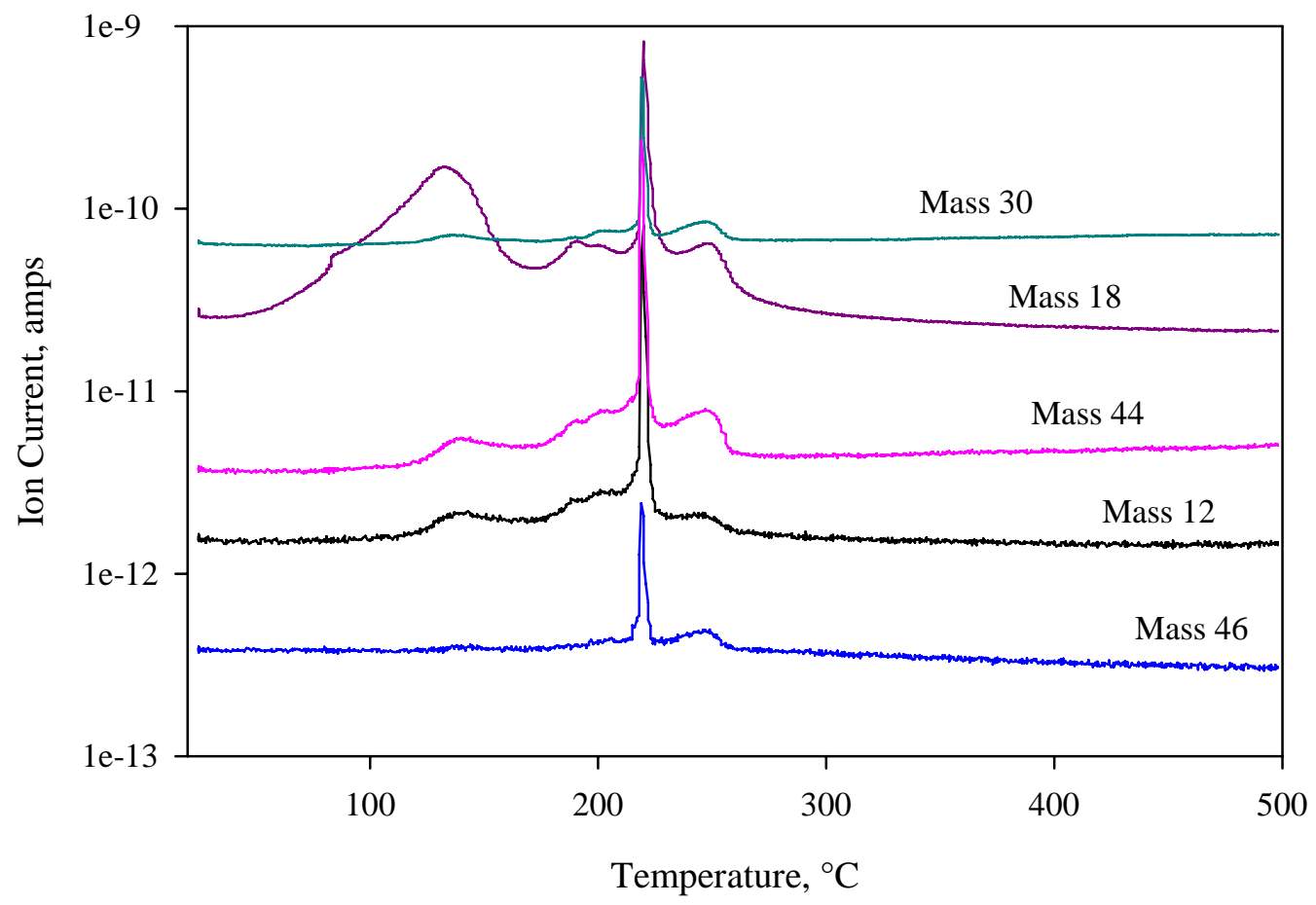

Figure 5.53. Masses $12(\mathrm{C}), 18\left(\mathrm{H}_{2} \mathrm{O}\right), 30(\mathrm{NO}), 44\left(\mathrm{CO}_{2}, \mathrm{~N}_{2} \mathrm{O}, \mathrm{C}_{3} \mathrm{H}_{8}\right)$, and $46\left(\mathrm{NO}_{2}\right)$ in Evolved Gas During TGA/DTA Analysis of Glygel with Surfactant/Filter Media in Ar at $10^{\circ} \mathrm{C} / \mathrm{min}$

ARC-Measured Thermal Behavior of Glygel-Filter Media Mixture. For the ARC study of Glygelfilter media mixtures, we performed two experiments using 8- and 2-g samples having the same mass ratios of Glygel to filter media (without its plastic ring) as found in a Glygel-filled filter. Figure 5.54 provides the results of those two experiments.

The ARC found a self-heating reaction beginning at $71^{\circ} \mathrm{C}$ for the 8 -g sample and $76^{\circ} \mathrm{C}$ for the 2-g sample. Both the 8-g and 2-g experiments continued until their sample containers catastrophically failed; Figure 5.55 and Figure 5.56 provide pictures of the sample containers for the 8- and 2-g experiments, respectively. The sudden loss of containment suggests a change in mechanism or the onset of another more rapid reaction than that being observed by the ARC for both samples, although both are approaching $10^{\circ} \mathrm{C} /$ min before the containers rupture. This suggests that very fast reactions followed the ones monitored by the ARC (Figure 5.14). The very fast nature of this reaction is consistent with the very rapid $210^{\circ} \mathrm{C}$ reaction observed by the TGA/DTA/MS. 
The ARC studies indicate that the Glygel-filter media mixture is thermally sensitive with a nominal $70^{\circ} \mathrm{C}$ onset temperature. This ARC-observed onset temperature is less than the CCPS rule-of-thumb safety margin of $>50^{\circ} \mathrm{C}$ from the process's maximum temperature. The ARC studies also show that should a reaction occur, it will have much greater consequences than the reaction of Glygel alone. Extra precautions are required for managing the thermal reactivity hazard of Glygel mixed with vacuum filter media to prevent thermal runaway.

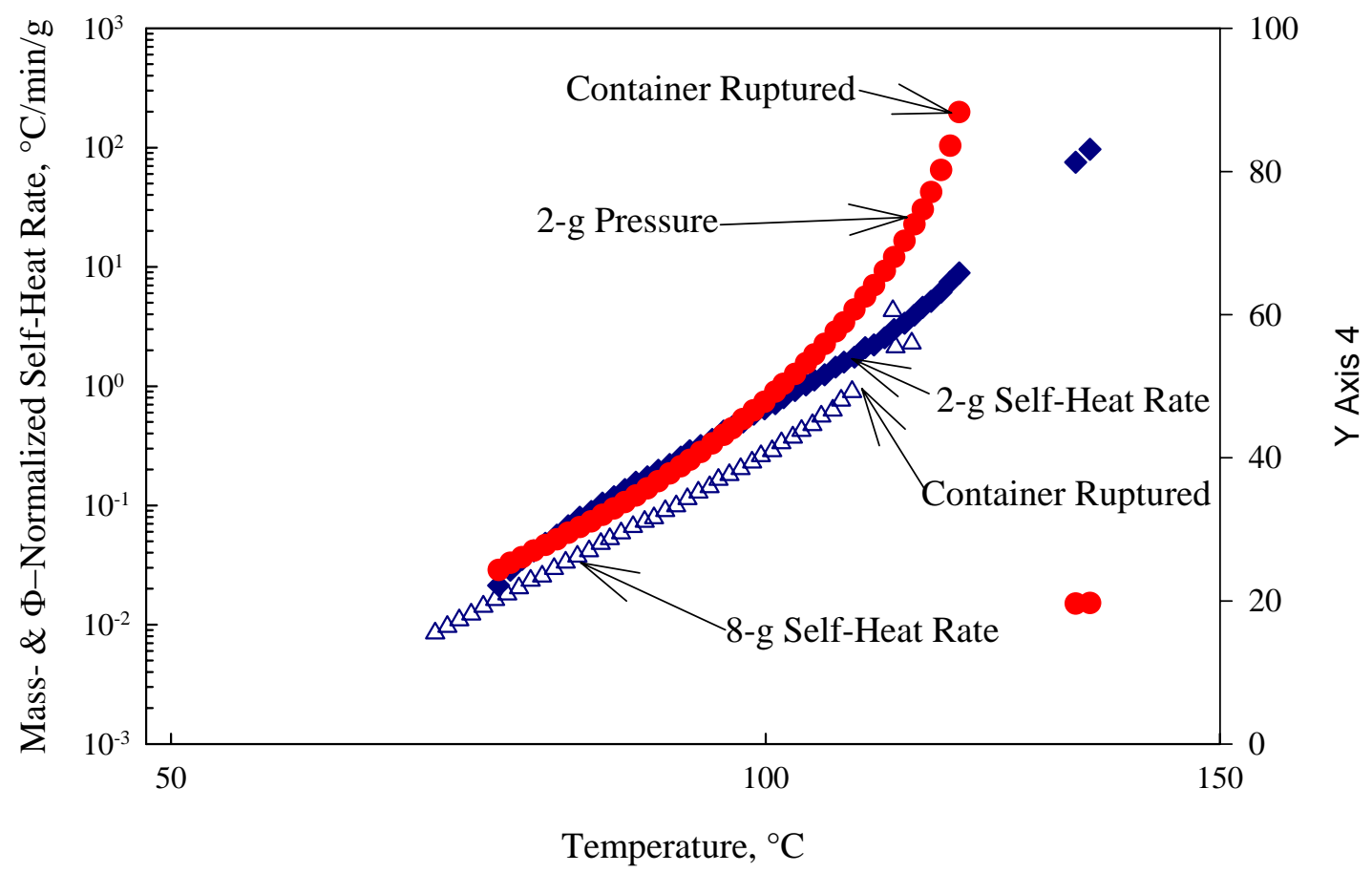

Figure 5.54. Arrhenius Plot of ARC-Measured Thermal Sensitivity of Dried Glygel with Filter Media

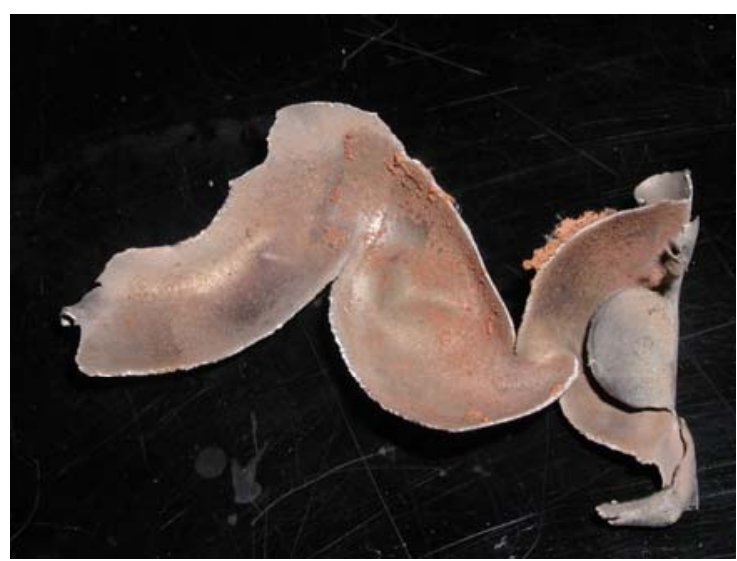

Figure 5.55. Sample Container After 8-g ARC Analysis of Glygel-Filter Media Mixture

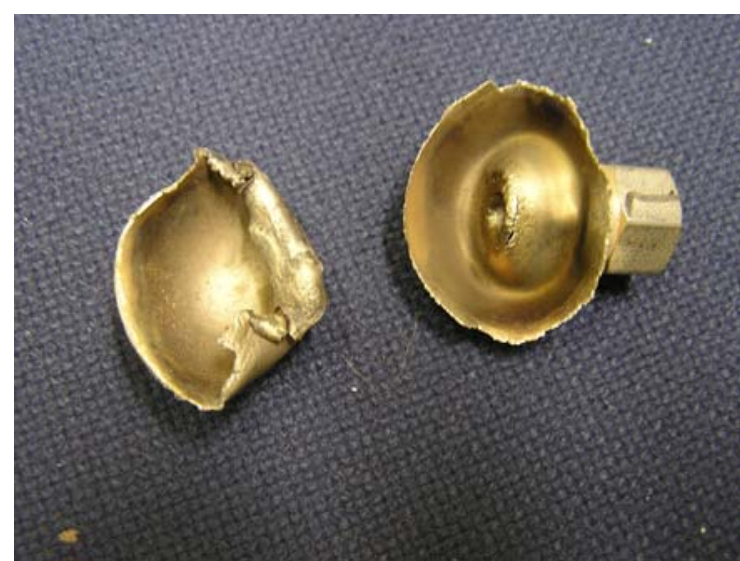

Figure 5.56. Sample Container after 2-g ARC Analysis of Glygel-Filter Media Mixture 


\subsubsection{Thermal Behavior of Glygel on Cotton Cloth}

The last potential waste of interest is cotton cloth used to wipe up Glygel either during decontamination operations or during Glygel's preparation where the mixing rotor would be wiped with a cotton cloth. We used the ARC to study the thermal sensitivity of a PFP-prepared Glygel-containing cotton cloth.

The ARC, as shown in Figure 5.57 found that a cotton cloth saturated with Glygel will begin to react near $105^{\circ} \mathrm{C}$ and will react vigorously. This initial reaction reached $\Phi$ - and mass-normalized self-heating rates of over $100^{\circ} \mathrm{C} / \mathrm{min}$; it is worth noting that the ARC can only maintain adiabaticity up to $15^{\circ} \mathrm{C} / \mathrm{min}$; therefore, the system is no longer adiabatic and is losing heat. A second reaction begins near $200^{\circ} \mathrm{C}$.

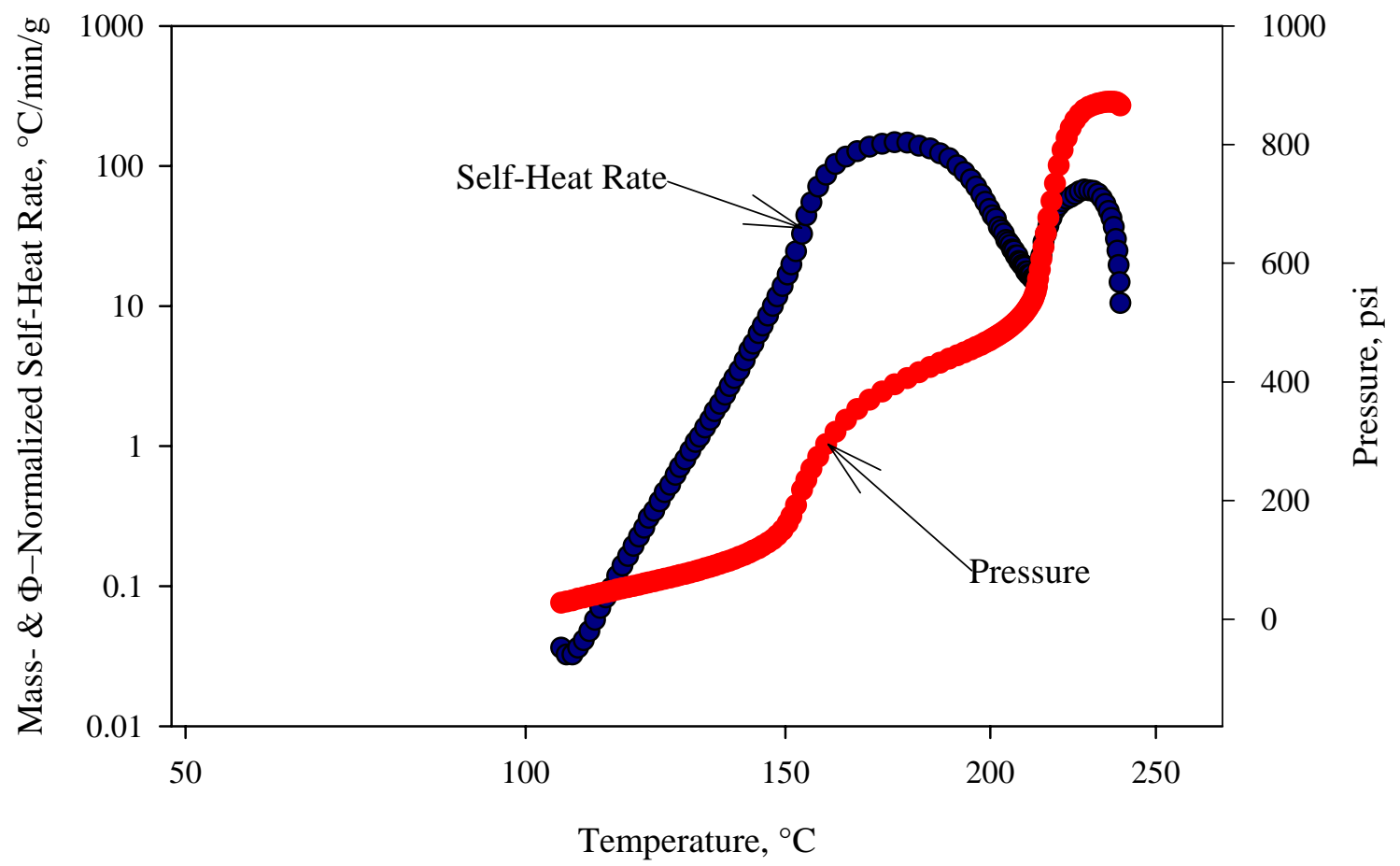

Figure 5.57. Arrhenius Plot of ARC-Measured Thermal Sensitivity of Glygel on Cotton Cloth

The ARC analysis of cotton cloths soaked with Glygel indicates that the glygel does not begin to react until heated to $105^{\circ} \mathrm{C}$, which is $>50^{\circ} \mathrm{C}$ from Hanford's maximum recorded temperature of $45^{\circ} \mathrm{C}\left(113^{\circ} \mathrm{F}\right)$. This is $10^{\circ} \mathrm{C}$ more than the CCPS's rule-of-thumb difference between ARC-onset temperature and maximum process temperature. The ARC results indicate that once a reaction begins, it will reach significant reaction rates; however, the reaction and gas-production rates were not significant enough to cause failure of the ARC sample container as the tests with Glygel and the filter did.

\subsubsection{Conclusions Regarding the Thermal Stability of Potential Glygel Decontamination Process Wastes}

Our TGA/DTA/MS and ARC analyses of simulated potential Glygel decontamination process wastes indicate that most of the wastes will be thermally sensitive with ARC-observed onset temperatures near $70^{\circ} \mathrm{C}$. Without added surfactant, Glygel is much less thermally sensitive than with added surfactant with 
significant reactivity beginning near $170^{\circ} \mathrm{C}$; using surfactant is the manufacturer's recommended approach. When mixed with filter media, Glygel can be particularly reactive, exhibiting rapid heating with significant gas production.

\subsection{Thermal Behavior of Simulated Aspigel Wastes}

Because our studies of Glygel indicated that surfactant contributed to low-temperature $70^{\circ} \mathrm{C}$ reactivity, we decided to use a similar decontamination product, Aspigel, which needs no surfactant to be effective. According to the MSDS provided by the manufacturer, CEA VALRHO, Aspigel 100 (Aspigel) is composed of ceric ammonium nitrate, nitric acid, silica, alumina, and water. This composition differs from Glygel in the addition of alumina and the absence of a proprietary surfactant.

In Aspigel, the only fuel is ammonium ion, and the only oxidant other than oxygen is cerium (IV) and nitrate from the ceric ammonium nitrate and the nitric acid. As shown in Figure 5.42, the ARC finds that ceric ammonium nitrate begins to react at $195^{\circ} \mathrm{C}$, suggesting that Aspigel should not support a selfsustaining reaction unless heated to $\geq 195^{\circ} \mathrm{C}$, well above the Hanford maximum temperature of $45^{\circ} \mathrm{C}$ $\left(113^{\circ} \mathrm{F}\right)$.

\subsubsection{Thermal Behavior of Aspigel}

As described in Section 4.1.4, Fluor prepared and provided several samples of Aspigel and two different vacuum cleaner filter media saturated with Aspigel. The Fluor-provided samples were 1) Aspigel, which fell from the stainless steel test coupons upon drying (collected after 24 h), 2) 24-h-dried Aspigel removed from the coupons by vacuuming into a Shark vacuum filter, 3) 24-h-dried Aspigel removed from the coupons using a DataVac vacuum, 4) Aspigel collected after 48 h of drying, and 5) a cotton cloth used to wipe the propeller used to fluidize and mix the Aspigel before it was applied. Potentially confounding the investigation was the degreaser containing butoxyethanol and sodium hydroxide used on the stainless steel coupons before their treatment with Aspigel; this may have inadvertently introduced another fuel. In addition to studying the provided samples, we evaluated neutralization as a potential strategy for mitigating the ARC-observed low-temperature reactivity discussed in Section 5.4.1.1.

This section provides the results of our TGA/DTA and ARC studies to determine the thermal stability of Aspigel and potential Aspigel waste mixtures with respect to Hanford's maximum temperature of $45^{\circ} \mathrm{C}$ $\left(113^{\circ} \mathrm{C}\right)$, the anticipated maximum temperature of Aspigel waste during storage before eventual disposal.

\subsubsection{Thermal Behavior of Aspigel Alone}

Aspigel will be the predominant component in the wastes arising from the use of Aspigel to decontaminate the PFP's Pu-gloveboxes. We used ARC and TGA/DTA to investigate the thermal sensitivity of the Aspigel collected after treating the stainless steel coupons.

Fluor used TGA/DTA/MS to analyze the Aspigel and gain some chemical understanding of the nature of the reactions as they occurred. The TGA/DTA results are provided in Figure 5.58, and the MS results are provided in Figure 5.59. 


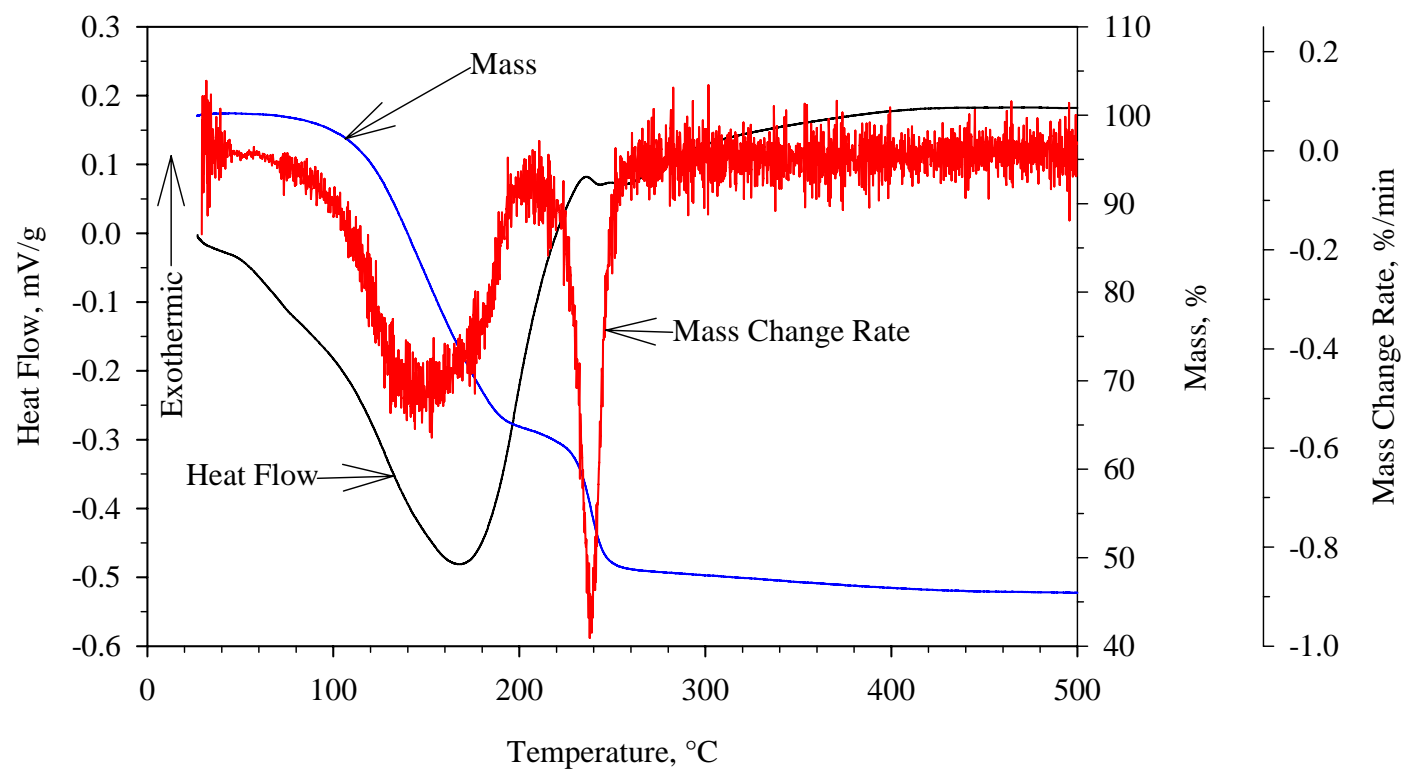

Figure 5.58. Fluor TGA/DTA Measured Thermal Behavior of Aspigel at $10^{\circ} \mathrm{C} / \mathrm{min}$ in Argon

To identify potential gaseous products by MS, we measured ion currents for mass/e ratios of $2\left(\mathrm{H}_{2}\right), 12$ (C), $14(\mathrm{~N}), 15(\mathrm{NH}), 16\left(\mathrm{NH}_{2}\right), 17\left(\mathrm{NH}_{3}, \mathrm{OH}\right), 18\left(\mathrm{H}_{2} \mathrm{O}\right), 19,20,23,28\left(\mathrm{CO}, \mathrm{N}_{2}\right), 30(\mathrm{NO}), 32\left(\mathrm{O}_{2}\right), 35$, $36,37,38,40,44\left(\mathrm{CO}_{2}, \mathrm{~N}_{2} \mathrm{O}\right), 46\left(\mathrm{NO}_{2}\right)$, and 64 . Of these, only reaction products with mass/e ratios of $15,18,30,44$, and 46 were significant.

The TGA/DTA analysis shows an endothermic 35\% mass loss from ambient to $190^{\circ} \mathrm{C}$. As shown in Figure 5.59, water (mass 18) is released throughout this initial reaction. Although not evident from the mass loss or mass change rate data, beginning near $140^{\circ} \mathrm{C}$ and concurrently with the release of water, the MS sees mass 15, likely NH from decomposition of ammonium ion, mass 30 (NO), and mass $46\left(\mathrm{NO}_{2}\right)$. The latter two indicate the reaction of nitrate with ammonium in the absence of organics, given the absence of reaction between ceric ion and ammonium ion in ceric ammonium nitrate. Beginning near $195^{\circ} \mathrm{C}$, an exothermic reaction causing a mass loss of another $20 \%$ that produces ammonia (mass 15 ), water, mass 30 (likely NO), mass 44 (likely $\mathrm{N}_{2} \mathrm{O}$ assuming no carbon in the Aspigel), and mass $46\left(\mathrm{NO}_{2}\right)$. Although the TGA/DTA does not report a reaction beginning at $140^{\circ} \mathrm{C}$, the MS results show that an oxidation-reduction reaction is occurring concurrently with the release of water from the Aspigel. 


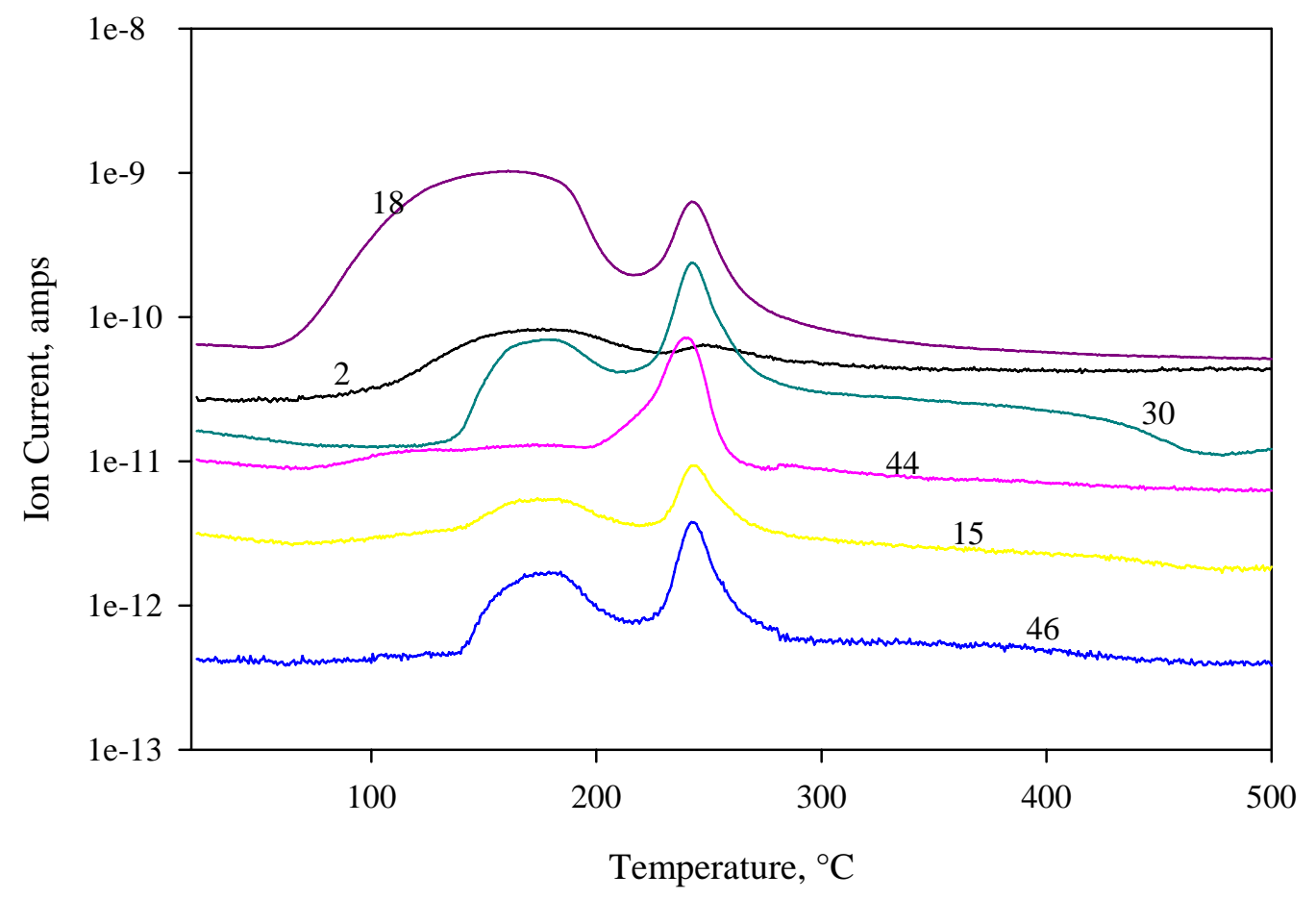

Figure 5.59. Selected MS-Identified Components Produced During TGA/DTA of Aspigel at $10^{\circ} \mathrm{C} / \mathrm{min}$ in Argon

It is clear that $\mathrm{H}_{2} \mathrm{O}, \mathrm{H}_{2}, \mathrm{NO}$, and $\mathrm{NO}_{2}$ are major chemical products. One of the potential reaction pathways is:

$$
2 \mathrm{NH}_{4} \mathrm{NO}_{3}+2 \mathrm{HNO}_{3}=5 \mathrm{H}_{2} \mathrm{O}+3 \mathrm{NO}+\mathrm{NO}_{2}+\mathrm{O}_{2}
$$

We find that the products of Equation 4.1 are a match both qualitatively and semi-quantitatively with the mass spectrometry results. It is believed the hydrogen in the mass spectrum is part of the cracking pattern for water. Oxygen was not reported from the mass spectrometer analysis because of a small but erratic oxygen background, most probably stemming from an atmospheric leak.

PNNL analyzed the Aspigel by both TGA/DTA and ARC. The $5^{\circ} \mathrm{C} / \mathrm{min}$ TGA/DTA results are provided in Figure 5.60, and the ARC results are provided in Figure 5.61. Qualitatively, the PNNL TGA/DTA results are partially consistent with Fluor's. The initial endothermic reaction that causes the Aspigel to lose $55 \%$ of its mass occurs between ambient and $110^{\circ} \mathrm{C}$ when heated at $5{ }^{\circ} \mathrm{C} / \mathrm{min}$ compared to $35 \%$ and $190^{\circ} \mathrm{C}$, respectively, when heated at $10^{\circ} \mathrm{C} / \mathrm{min}$. In contrast, the PNNL DTA observed an endothermic reaction beginning at $170^{\circ} \mathrm{C}$ compared to an exothermic reaction in the Fluor analysis at $190^{\circ} \mathrm{C}$; the endothermicity of this reaction is not consistent with the ARC results (Figure 5.63), which indicate exothermicity at $170^{\circ} \mathrm{C}$. The complex nature of the $170^{\circ} \mathrm{C}$ reaction indicated by the MS results is more evident at $5^{\circ} \mathrm{C} / \mathrm{min}$ than in the $10^{\circ} \mathrm{C} / \mathrm{min}$ experiment as shown by the shoulders on the mass change rate and heat-flow curves. 


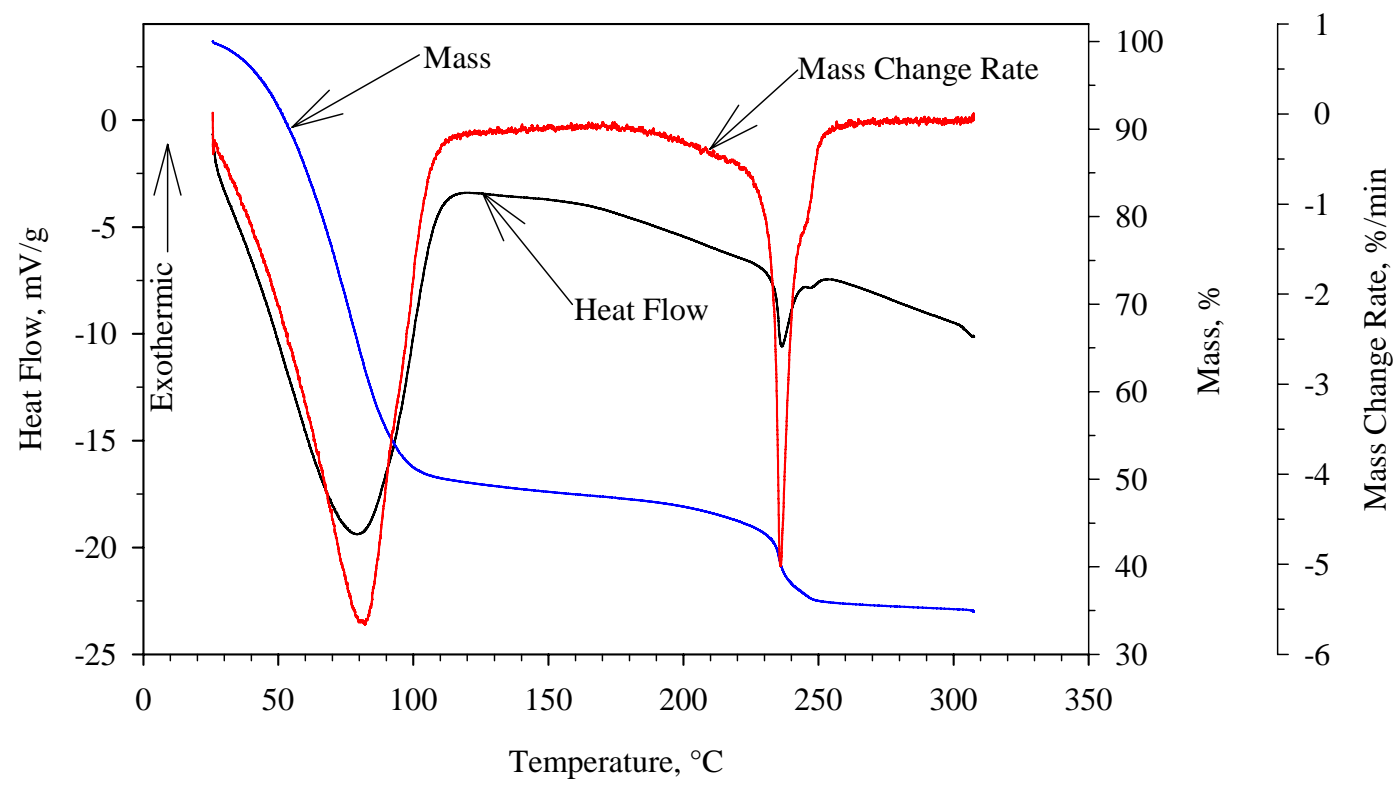

Figure 5.60. PNNL TGA/DTA-Measured Thermal Behavior of Aspigel at $5^{\circ} \mathrm{C} / \mathrm{min}$

We performed a series of experiments with the ARC, varying the amount of Aspigel in the sample container beginning with about $3 \mathrm{~g}$ and finishing with two 10-g analyses. As shown in Figure 5.63, the Aspigel collected from the tarp and Aspigel recovered from the Shark Vacuum exhibited unsustainable low temperature $70^{\circ} \mathrm{C}$ exothermicity, suggesting that insufficient material was present to support a selfsustaining reaction. To evaluate this hypothesis, we used a full bomb containing $9.5 \mathrm{~g}$ of Aspigel. For the 3-g samples, there was a significant temperature gap between the last observed low-temperature reaction at $140^{\circ} \mathrm{C}$ and the onset of the reaction characteristic of ceric ammonium nitrate at $190^{\circ} \mathrm{C}$.

We approached our larger sample-size investigation of the low-temperature reactions cautiously to assure that we did not reach the ceric ammonium nitrate reaction regime. We programmed our initial experiment to stop at $110^{\circ} \mathrm{C}$. The 9.5 -g experiment showed that the previously observed low-temperature reactions that started and stopped would sustain themselves under adiabatic conditions, provided sufficient mass is present.

We became bolder with our second experiment and programmed the ARC above the previously observed maximum temperature achieved by the 3-g samples to $140^{\circ} \mathrm{C}$. This experiment found that Aspigel will support a self-sustaining reaction capable of heating itself to $140^{\circ} \mathrm{C}$. We extrapolate from these results that large batches would be capable of supporting a reaction capable of reaching the faster reaction regime of ceric ammonium nitrate. 


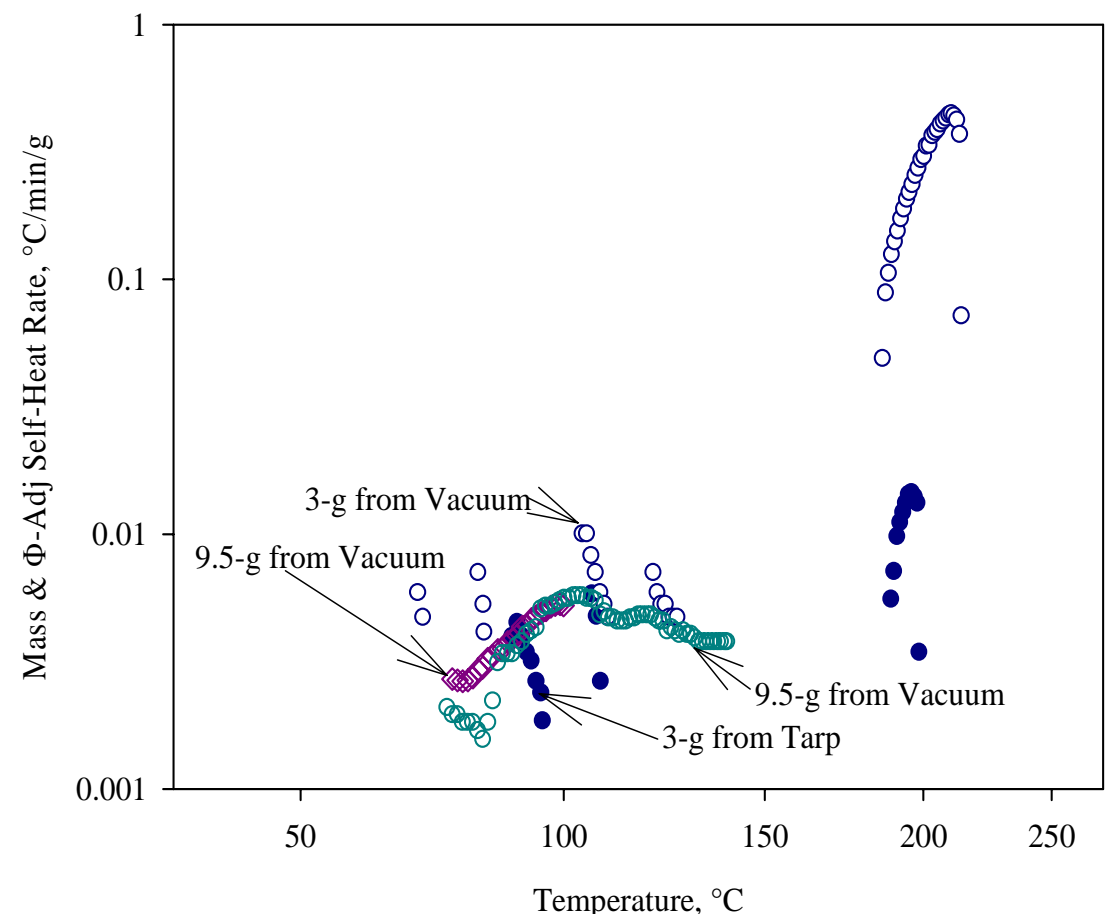

Figure 5.61. Arrhenius plot of ARC-Measured Thermal Sensitivity of Aspigel Samples

The DTA/TGA/MS results indicate that reactions between nitric acid and ammonium ion or nitrate and ammonium ion (assuming no organics in Aspigel) occur at temperatures up to $220^{\circ} \mathrm{C}$ with the lowest observed exothermic reaction at $190^{\circ} \mathrm{C}$. Consistent with these results, the ARC found low-temperature reactions beginning as low as $70^{\circ} \mathrm{C}$. Extrapolating the larger mass experiments, the low-temperature reactions under adiabatic conditions appear capable of heating Aspigel to a temperature where the ARCobserved rapid ceric ammonium nitrate self reaction will occur.

\subsubsection{Thermal Behavior of Sodium Carbonate-Neutralized Aspigel}

To determine if neutralization improves the thermal stability of Aspigel, we neutralized the Fluorprovided Aspigel recovered from the DataVac filter with saturated sodium carbonate solution. As shown by comparing Figure 5.62 with Figure 5.61, neutralization significantly delays the ARC-measured onset temperature from $70^{\circ} \mathrm{C}$ to $130^{\circ} \mathrm{C}$ and thus accomplishes the desired $>50^{\circ} \mathrm{C}$ gap in onset temperature from the expected maximum storage temperature of $45^{\circ} \mathrm{C}$. Neutralization therefore is an approach to mitigate the observed risk for Aspigel alone. 


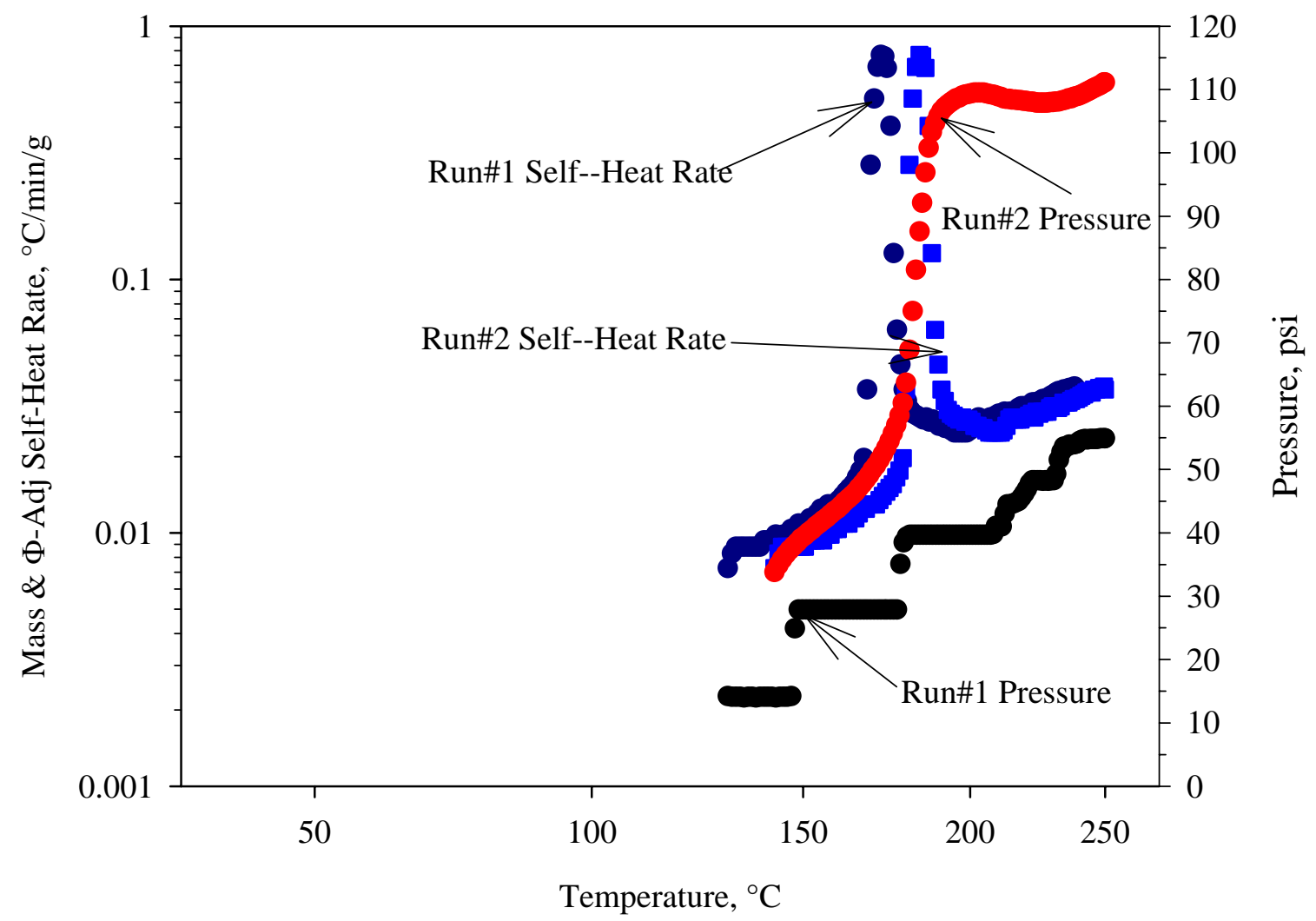

Figure 5.62. Arrhenius Plot of ARC-Measured Thermal Sensitivity of Sodium Carbonate-Neutralized Aspigel Recovered from DataVac3 Filter

\subsubsection{Thermal Behavior of Aspigel Sorbed on Cotton Cloth}

One of the wastes that will arise from the Aspigel decontamination process is the sorbent materials used to clean the propeller that mixes the Aspigel. The mixing is done to make Aspigel flow and be sprayable. Though the propeller wipe could be a non-radioactive waste, it will be a mixture of sorbent material, ceric ammonium nitrate, nitric acid, and the inert materials silica and alumina. Based on the results in our ceric nitrate and RadPro evaluations showing low-temperature reactivity between cotton and nitrates, the Aspigel/cotton wastes have the potential to be reactive.

\subsubsection{Thermal Sensitivity of Aspigel in Cotton Cloth Used to Wipe Mixing Rotor}

For the field demonstration of Aspigel, an overhead rotary mixer was used to liquefy the Aspigel. At the conclusion of the application test, the rotor was wiped clean with a cotton cloth. This cloth was brought back to the laboratory, and portions of the cloth with visible Aspigel were cut from the rest of the cloth and allowed to air dry. Drying changed the color of the Aspigel on the cloth from dark yellow to white.

Pieces of this cloth were transferred to the ARC sample holder and weighed. The relative amounts of cloth and Aspigel were not determined and were most certainly different for the two samples analyzed. In Figure 5.63, we see self-heating at $66^{\circ} \mathrm{C}$ and $67^{\circ} \mathrm{C}$ for both of the 3-g samples of Aspigel on cotton. 


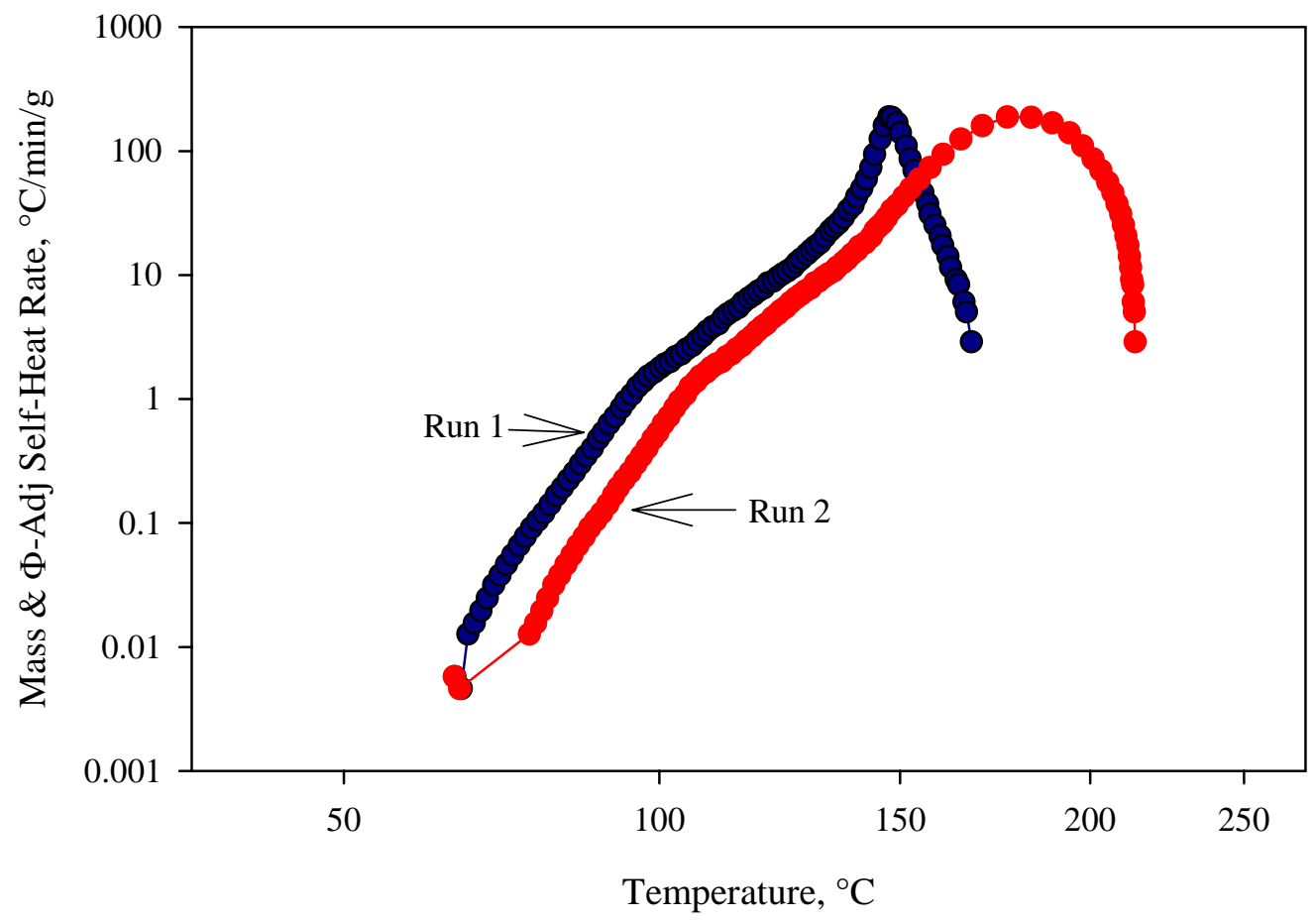

Figure 5.63. Arrhenius Plot of ARC-Measured Thermal Behavior of Aspigel Sorbed in Cotton Cloth

Using the CCPS's $50^{\circ} \mathrm{C}$ safety margin rule-of-thumb for ARC onset temperatures and our ARC results, it appears that an unneutralized cotton cloth used to remove residual Aspigel could not be safely stored at potential storage conditions at Hanford.

\subsubsection{Thermal Sensitivity of Neutralized Aspigel in Cotton Cloth}

To investigate neutralization of the acid as a mitigation strategy to eliminate the low-temperature reactivity of Aspigel with cotton seen in Figure 5.63, we neutralized a piece of cotton cloth that had contained Aspigel for 90 days. Sodium hydroxide was used for neutralization. Its thermal sensitivity was determined using the ARC. The result of that ARC analysis of a $3.1 \mathrm{~g}$ sample is presented in Figure 5.64.

Neutralized Aspigel/cotton cloth continues to exhibit some low-temperature reactivity with an observed onset temperature for the first reaction at $75^{\circ} \mathrm{C}$; however that reaction is short-lived, and the second does not begin until $120^{\circ} \mathrm{C}$. Because this cotton cloth was 90 days old when the experiment was performed and given the initially increasing then decreasing reactivity of cotton cloth containing nitrates observed in the ceric nitrate testing, the effects of age are unknown with this test. It is interesting that the pressure is increasing after the start of this reaction as the self-heat rate slows, suggesting that the production of gas requires heat. The results of this experiment are not definitive, although they suggest that tightly packed 90-day old Aspigel-containing cotton cloth could be stable even with the $75^{\circ} \mathrm{C}$ short-lived reaction; a more extensive analysis such as the thermal analysis used in the ceric nitrate study is required to assess the hazard of the low-temperature reaction. Using the CCPS's $>50^{\circ} \mathrm{C}$ safety margin between ARC onset and maximum process temperature rule-of-thumb, the $120^{\circ} \mathrm{C}$-onset reaction does not pose a thermal reactivity risk. 


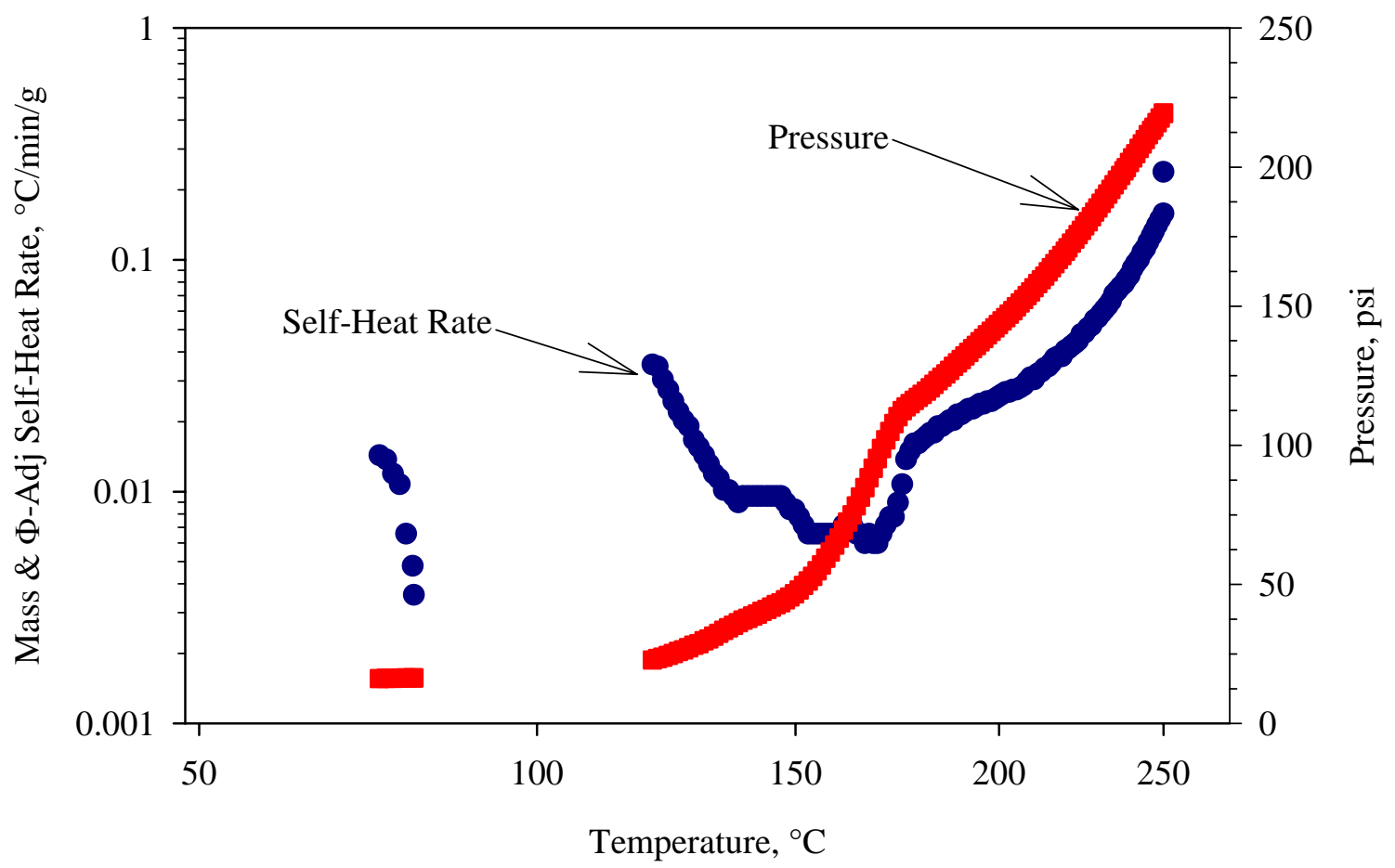

Figure 5.64. Arrhenius Plot of ARC-Measured Thermal Sensitivity of Neutralized 90-day old Aspigel on Cotton Cloth Used to Clean Mixing Rotor

\subsubsection{Thermal Sensitivity of Aspigel Mixed with Vacuum Filter Media}

Current plans are to collect the Aspigel used to decontaminate the glovebox using a small vacuum cleaner. The Aspigel will be removed from the vacuum contained in the vacuum filter and disposed of. Two different vacuum cleaners are being considered, the Shark and the DataVac 3. Using ARC, we investigated the thermal behavior of mixtures of Aspigel and the associated two filter media saturated with Aspigel during the Aspigel preparation.

\subsubsection{Thermal Sensitivity of Aspigel Mixed with DataVac 3 Vacuum Filter Media}

Aspigel collected from the Data Vac 3 filter was combined with the inner and outer filter media in weights proportional to the total weight of Aspigel and individual weights of the two filters. These ratios were $82.3 \mathrm{wt} \%$ Aspigel, $10.3 \mathrm{wt} \%$ inner filter media, and $7.3 \mathrm{wt} \%$ outer filter media. Duplicate ARC thermal analyses were performed on 2-g samples with the results shown in Figure 5.65. Self-heating was observed from the start temperature of $50^{\circ} \mathrm{C}$ and continued throughout the runs to $250^{\circ} \mathrm{C}$. Pressure increase indicated gaseous products formed from the reactions. Compared to Aspigel alone, adding DataVac 3 filter media reduces the onset temperature from $70^{\circ} \mathrm{C}$ to $50^{\circ} \mathrm{C}$ and increases the reaction rate; thus, in total, the combination of Aspigel and DataVac 3 filter media poses a greater thermal risk than Aspigel alone. The increased reactivity likely is because of the increased fuel content. 


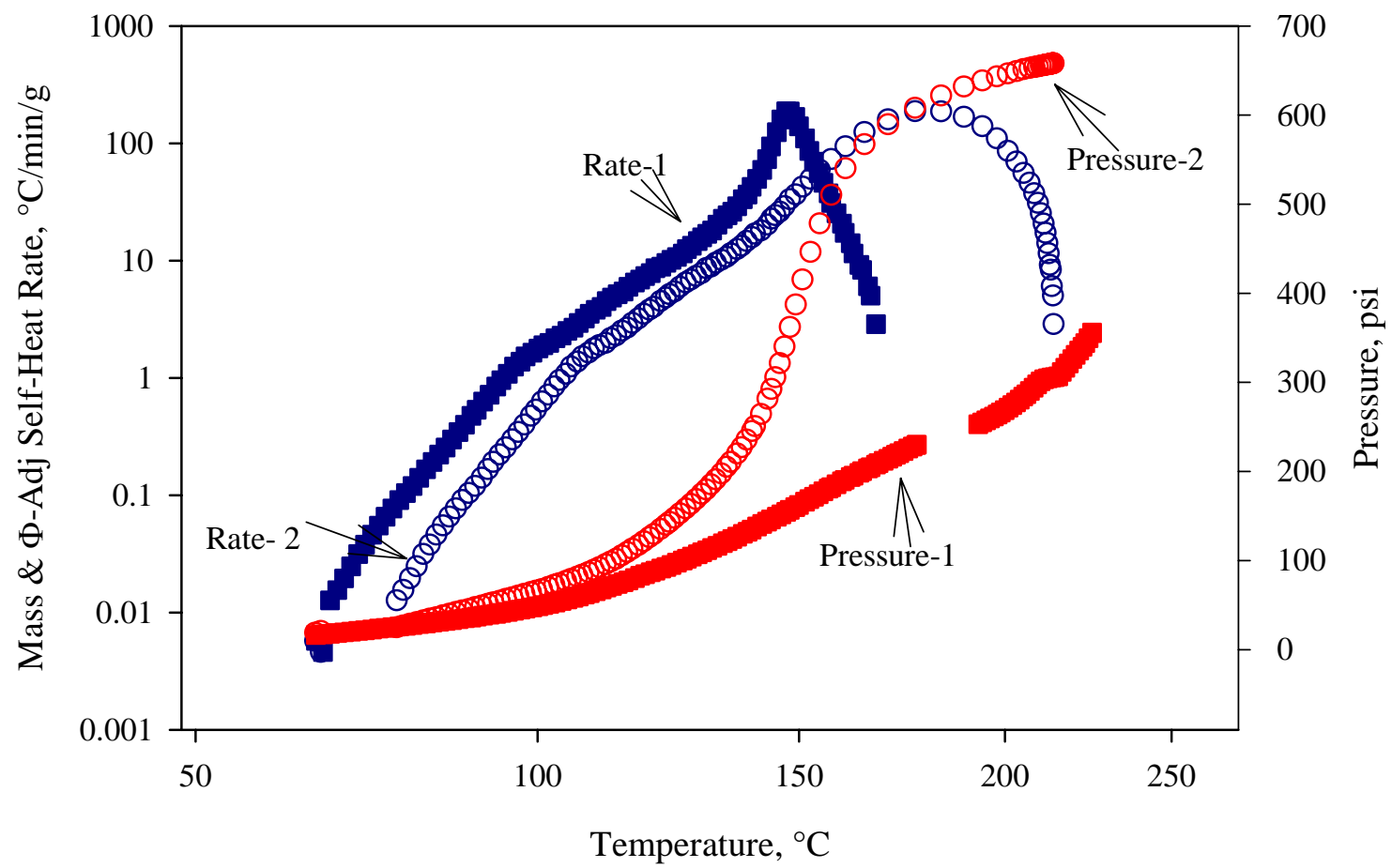

Figure 5.65. Arrhenius Plot of ARC-Measured Thermal Behavior of Aspigel with DataVac 3 Inner and Outer Filters

During the actual glovebox decontamination process, inner filters might be discarded when full of Aspigel while outer filters could be reused. To investigate this scenario, ARC samples with $88.9 \mathrm{wt} \%$ Aspigel and $11.1 \mathrm{wt} \%$ inner filter media were prepared and analyzed. As can be seen in Figure 5.66, beginning at $50^{\circ} \mathrm{C}$, self-heating was observed throughout the analysis. The inner filter media qualitatively exhibits similar thermal behavior to the inner + outer filter media. However, for Run 1 , the reaction rate was faster with the inner filter media alone suggesting that the intimacy of the Aspigel within the inner media may enhance the reaction rate; however, for Run 2, the rate is similar, suggesting that no difference exists between the two filter media.

\subsubsection{Thermal Sensitivity of Neutralized Aspigel and DataVac 3 Filter Media}

To investigate the effectiveness of neutralization of the acid to mitigate the low-temperature reactivity observed in Figure 5.66, we used ARC to measure the thermal sensitivity of sodium carbonate-neutralized Aspigel mixed with sodium carbonate-neutralized DataVac3 filter in mass proportions found in a full filter. The results of that analysis are presented in Figure 5.67. Neutralizing the mixture results in a delay in the onset of the reaction compared to the unneutralized mixture, $85^{\circ} \mathrm{C}$ and $100^{\circ} \mathrm{C}$ versus $50^{\circ} \mathrm{C}$ for the unneutralized test. In both experiments with sodium carbonate, the start and stop reactions are likely attributable to small sample size. In the second 2.6-g experiment, a non-sustaining low-temperature $\left(50^{\circ} \mathrm{C}\right)$ reaction occurs but has insufficient rate and power to sustain itself. 


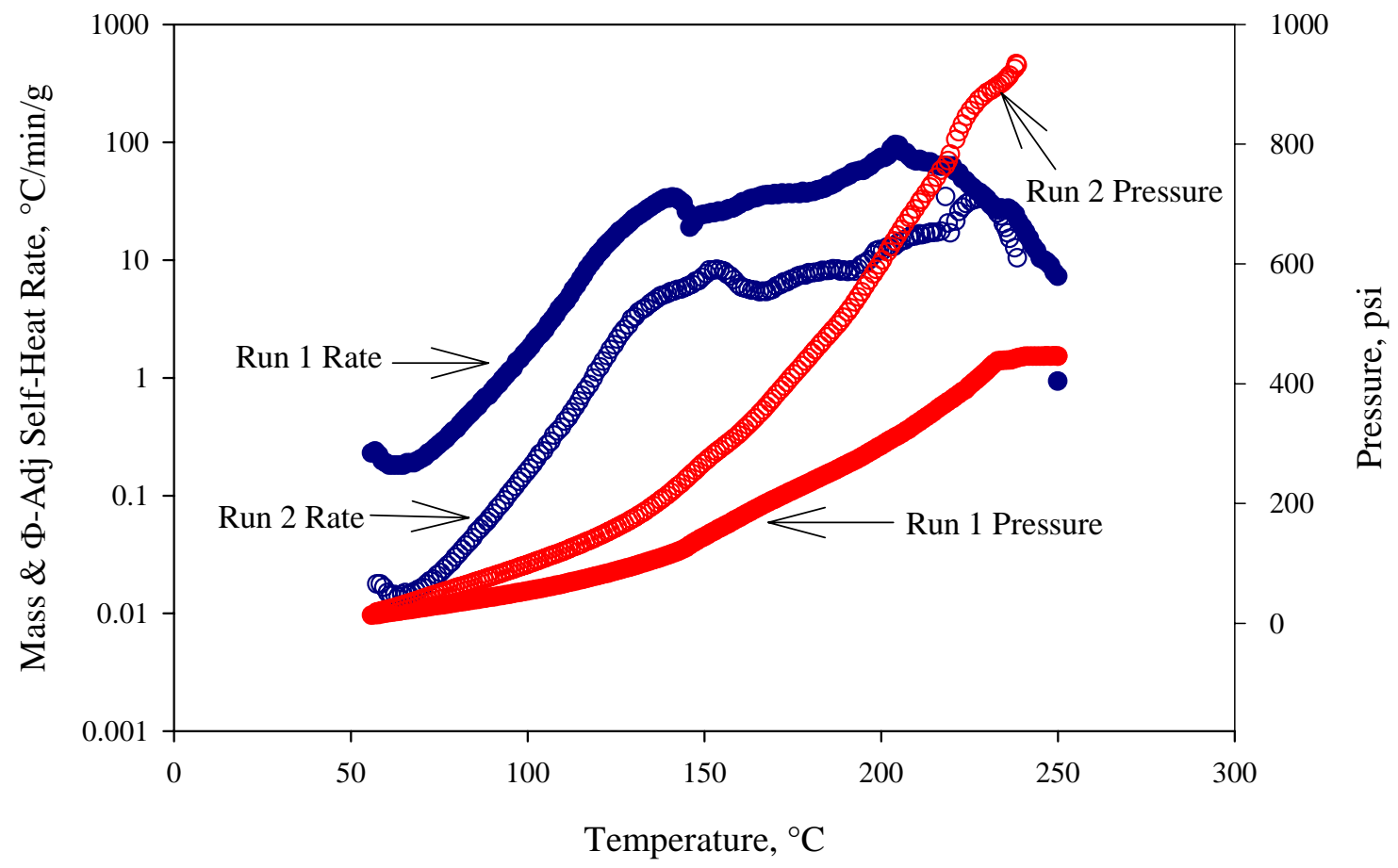

Figure 5.66. Arrhenius Plot of ARC-Measured Thermal Behavior of Aspigel on DataVac 3 Inner Filter

Neutralization of Aspigel/DataVac 3 filter mixtures appears to have some benefit with respect to disposal of Aspigel. The ARC-measured onset temperature is delayed from $50^{\circ} \mathrm{C}$ to between 85 and $100^{\circ} \mathrm{C}$, assuming that the factor that prevented the second experiment's low-temperature reaction from continuing remains operational throughout the waste's life. The reaction rate slows from a maximum of near $100^{\circ} \mathrm{C} / \mathrm{min} / \mathrm{g}$ to $1^{\circ} \mathrm{C} / \mathrm{min} / \mathrm{g}$; the importance of this appreciable reduction would require thermal modeling of the waste package to fully evaluate. 


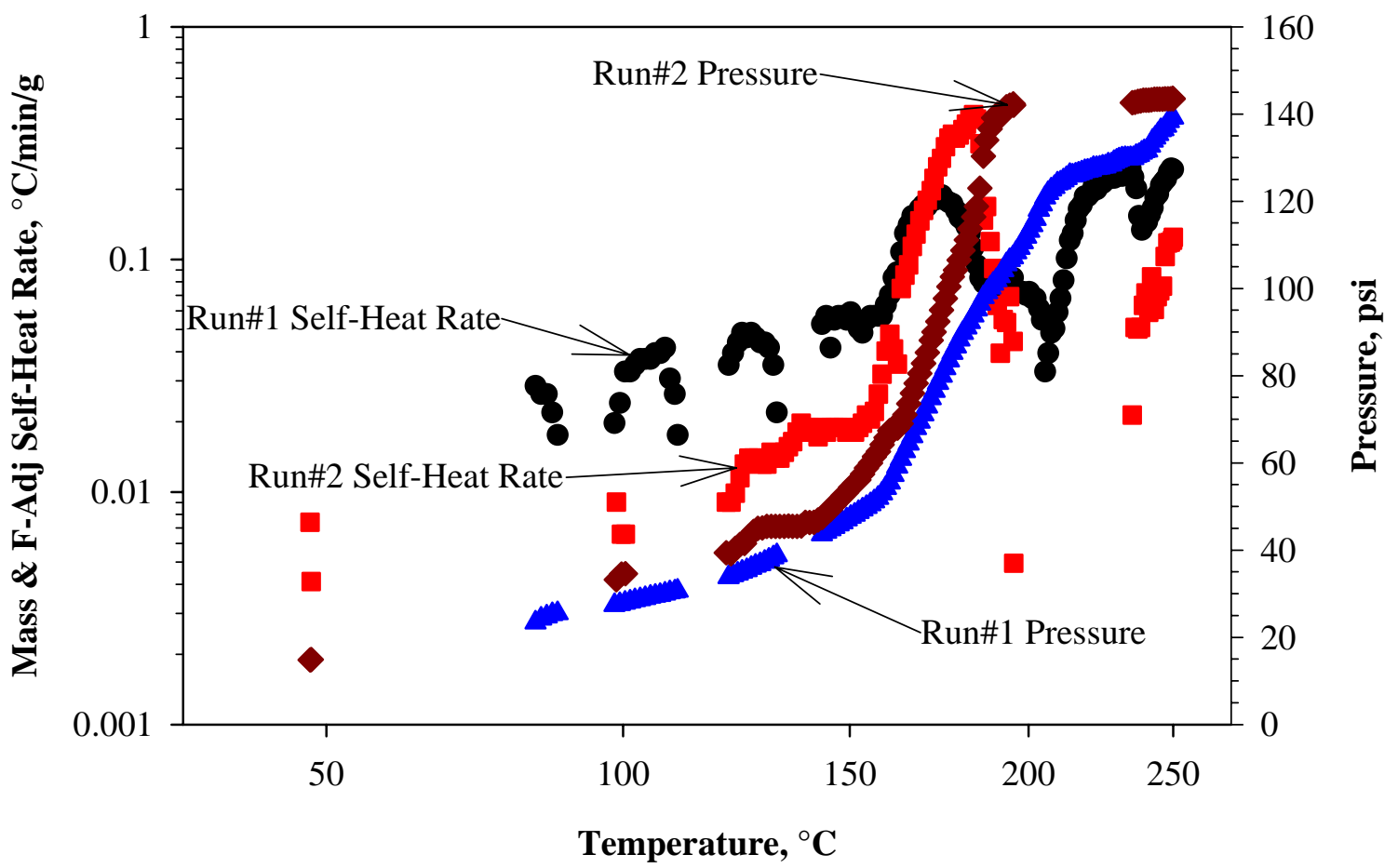

Figure 5.67. Arrhenius Plot of ARC-Measured Thermal Sensitivity of Sodium Carbonate-Neutralized Aspigel and Sodium Carbonate-Neutralized DataVac 3 Filter. Run\#1 used a 0.14-g filter + $1.2 \mathrm{~g}$ Aspigel, and Run\#2 used a 0.25-g filter + $2.4 \mathrm{~g}$ Aspigel.

\subsubsection{Thermal Sensitivity of Aspigel Mixed with Shark Vacuum Filter Media}

The other vacuum cleaner that is being considered for collecting spent Aspigel in the gloveboxes is the Shark vacuum cleaner. We used ARC to determine the thermal sensitivity of a representative mixture of Aspigel based on the mass ratio of Aspigel and paper filter media; we did not consider the heavy plastic filter ring susceptible to thermal attack by the active oxidants in Aspigel.

The results of our ARC analyses of the Aspigel with and without Shark filter is provided in Figure 5.68. The onset temperature drops from $90^{\circ} \mathrm{C}$ to $70^{\circ} \mathrm{C}$, and the self-heat rate increases from a maximum $\Phi$ adjusted rate of $0.04^{\circ} \mathrm{C} / \mathrm{min} / \mathrm{g}$ to $14^{\circ} \mathrm{C} / \mathrm{min} / \mathrm{g}$ with the filter media present. Our ARC results indicate that the thermal reactivity risk increases with filter media present.

\subsubsection{Residual Gases}

Our infrared (IR) analysis of the ARC residual gases from the Shark filter media, the cotton cloth, and the neutralized Aspigel DataVac filter media shows that the $\mathrm{N}_{2} \mathrm{O}, \mathrm{CO}_{2}, \mathrm{NO}_{2}$, and traces of water remain after these experiments; see Figure 5.69. There are a number of unidentified IR peaks for the neutralized DataVac filter media experiment. The observed gases are consistent with reaction of nitrate with organic media such as should be present in the filter media and cotton. 


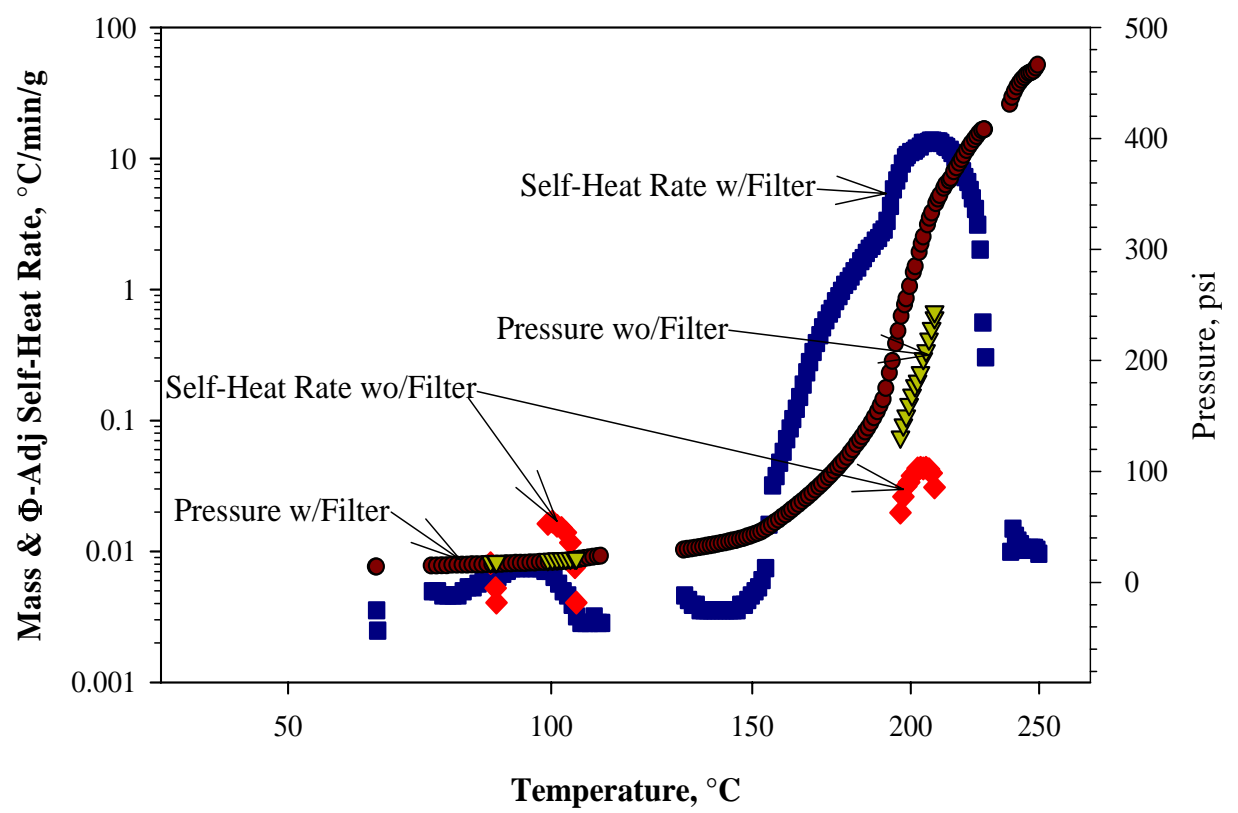

Figure 5.68. Arrhenius Plot of ARC-Measured Thermal Behavior of Aspigel with and Without Shark Vacuum Cleaner Filter

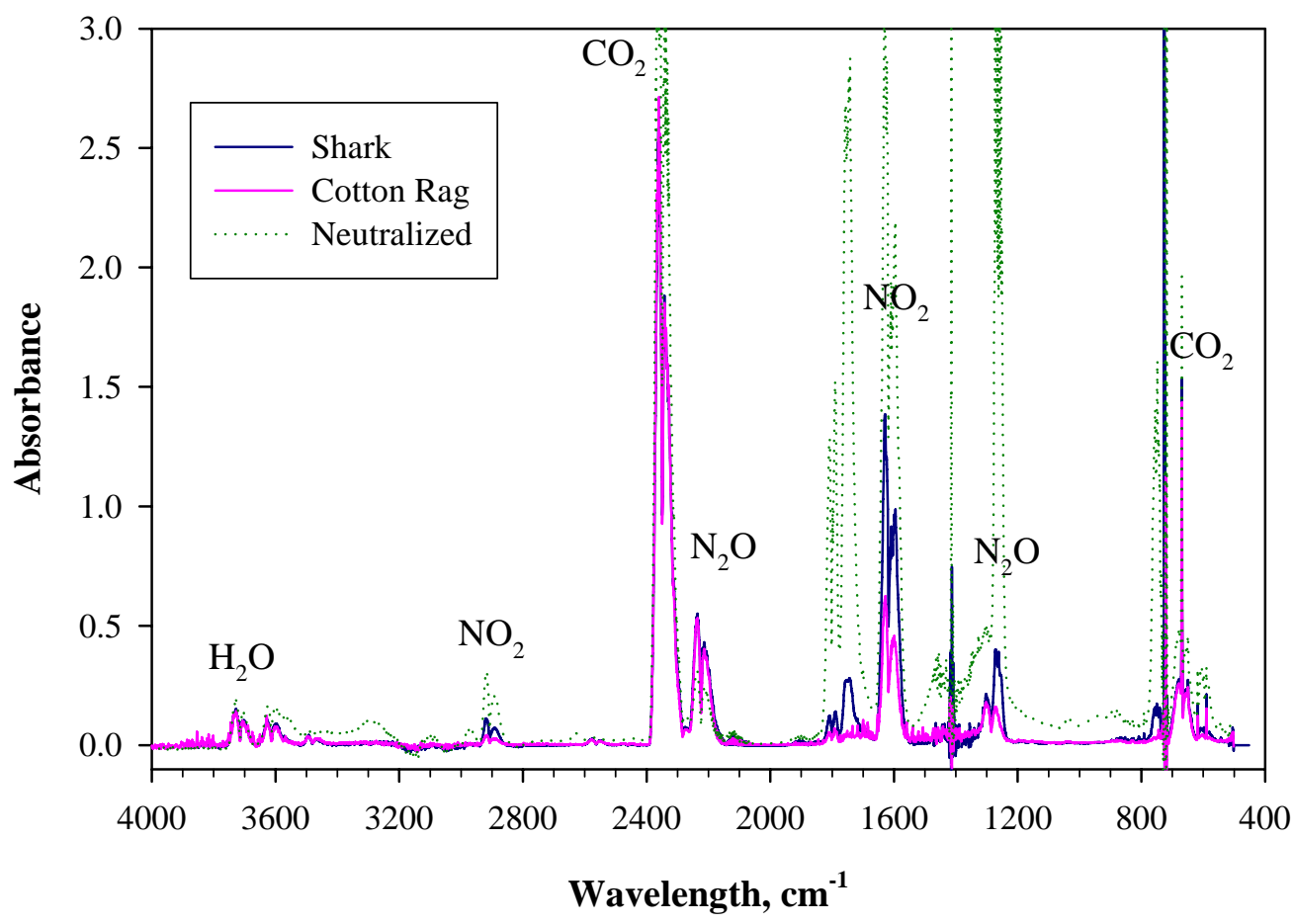

Figure 5.69. FTIR Spectra of Gas Following ARC Runs of Aspigel with Shark Filter, Cotton Cloth, and Neutralized Data Vac Filters 


\subsubsection{Bench Scale Testing of the Aspigel Waste}

With both the total mass and off gas reaction having such a large potential impact on the reactivity of the Aspigel waste, Fluor commissioned COGEMA in France to perform a bench large-scale (1.5 kg) benchscale test. COGEMA's final report for the bench scale test is provided in Appendix A.

The test design was reflected to match waste packaging conditions with the Aspigel waste collected using a hand-held vacuum cleaner. The filled vacuum cleaner was placed inside two HEPA filtered polyvinyl chloride (PVC) glovebox seal out bags. The combined waste package was heated in a constant temperature oven at $55^{\circ} \mathrm{C}\left(130^{\circ} \mathrm{F}\right)$ for 7 days with the temperatures inside the Aspigel waste monitored using a thermocouple. During these 7 days, the temperature inside the packaged vacuum cleaner did not increase, though the inside bag did discolor.

\subsubsection{Conclusions Regarding Aspigel Thermal Stability}

Our thermal studies of Aspigel, a cotton cloth containing Aspigel, and two different vacuum cleaner filter media saturated with Aspigel and the potential mitigation strategy of neutralization indicate the following:

- Aspigel will support reactions with onsets near $70^{\circ} \mathrm{C}$ that produce sufficient heat and react rapidly enough to heat the mixture to where a more rapid reaction characteristic of ceric ammonium nitrate begins;

- Aspigel reactivity is independent of the Aspigel's source whether the material has flaked off or been collected by vacuuming;

- Neutralizing Aspigel with sodium carbonate significantly delays the ARC-measured onset temperature from $70^{\circ} \mathrm{C}$ to $130^{\circ} \mathrm{C}$;

- Aspigel and filter media mixtures are more thermally sensitive, react faster, and are more energetic than Aspigel by itself with onset temperatures near $50^{\circ} \mathrm{C}$ for the DataVac 3 filters and $70^{\circ} \mathrm{C}$ for the Shark filters;

- Aspigel in cotton exhibits similar thermal sensitivity as Aspigel, beginning to react at $70^{\circ} \mathrm{C}$, but exhibits much faster reaction rates;

- Neutralization of Aspigel and DataVac 3 filter media increases the onset temperature from 60 to 85 and $100^{\circ} \mathrm{C}$ and reduces the $\Phi$ - and mass-normalized reaction rate from a maximum of $100^{\circ} \mathrm{C} / \mathrm{min} / \mathrm{g}$ at $200^{\circ} \mathrm{C}$ to $0.3^{\circ} \mathrm{C} / \mathrm{min} / \mathrm{g}$ at $240^{\circ} \mathrm{C}$;

- Neutralization of Aspigel in cotton appears to make the mixture less reactive, although a lowtemperature short-lived $70^{\circ} \mathrm{C}$-onset reaction is observed by the ARC;

- COGEMA's bench testing indicates that Aspigel waste inside a vacuum cleaner inside dual HEPA filtered bags heated to a constant temperature of $55^{\circ} \mathrm{C}\left(130^{\circ} \mathrm{F}\right)$ inside a thermostatted oven for 7 days shows no increase in temperature within the vacuum cleaner from the simulated Aspigel waste inside the container. 
In general, our ARC analyses indicate that Aspigel will begin to self-react at $<50^{\circ} \mathrm{C}$ from Hanford's maximum outside temperature. The CCPS recommends a safety margin of $>50^{\circ} \mathrm{C}$ between the ARCmeasured onset temperature and the maximum operational temperature. To meet this safety margin, drums containing Aspigel-generated waste would need to be stored inside environmentally controlled buildings.

All of these conclusions with respect to the study performed by PNNL and Fluor are confounded by the use of an organic degreaser on the stainless steel coupons before preparing the Aspigel for the thermal studies. It is possible that this residual butoxyethanol in the degreaser could reduce the thermal onset temperature and increase thermal reactivity. Our experiments with ceric ammonium nitrate, which with nitric acid are the only active agents in Aspigel (based on the MSDS), suggest only at $185^{\circ} \mathrm{C}$ or greater should reactivity exist. 


\subsection{Conclusions/Recommendations}

In support of Fluor's pursuit of an effective and safe technology for decontaminating plutoniumcontaminated gloveboxes, we investigated the thermal sensitivity of simulated waste streams arising from each of the proposed decontamination technologies to determine if the wastes would be stable at process and anticipated Hanford storage conditions. The maximum recorded temperature at Hanford was $45^{\circ} \mathrm{C}\left(113^{\circ} \mathrm{F}\right)$. It is expected that wastes will reside in $210 \mathrm{~L}$ ( 55 gal) TRU-waste drums.

The decontamination technologies investigated were ceric nitrate/nitric acid, EAI's RadPro aqueous decontamination system, and the two ceric ammonium nitrate-nitric acid-based inorganic gels Glygel and Aspigel. The nominal wastes arising from these processes were, respectively, cloths saturated with ceric nitrate/nitric acid, cloths saturated with various RadPro solutions, and inorganic gels potentially contained in vacuum cleaner filters. We also tested ceric ammonium nitrate to compare with the Glygel and Aspigel products.

The thermal stabilities of the waste products were investigated using thermal analysis toolsTGA/DTA and ARC. We used the CCPS's rule-of-thumb criteria for assessing if a thermal reactivity hazard exists. For the DTA, if the DTA-measured onset temperature was found to less than $100^{\circ} \mathrm{C}$ of the maximum process operating temperature, the CCPS recommends further investigation using more sensitive calorimetric instruments and/or potentially implementing engineering controls to prevent thermal runaway. The CCPS recommended margin between the onset of ARC-measured heating and the maximum operating temperature is $50^{\circ} \mathrm{C}$. For outside storage at Hanford, which has reached $45^{\circ} \mathrm{C}$, ARC and DTA onsets of $95^{\circ} \mathrm{C}$ and $145^{\circ} \mathrm{C}$, respectively, would be the threshold minimum safe temperatures.

\subsection{Conclusions}

Using TGA/DTA, ARC, and thermal modeling to evaluate ceric nitrate/nitric acid/cloth wastes, we concluded that:

- The originally planned reduced and neutralized (stabilized) ceric nitrate/nitric acid/cottonbased cloth decontamination waste is predicted to be thermally reactive at process and outside waste storage conditions at Hanford; the ARC-observed reaction onset temperatures were $<50^{\circ} \mathrm{C}$ from $45^{\circ} \mathrm{C}$;

- Thermal modeling indicates that filled or half-filled 210-L TRU drums filled with young, stabilized ceric nitrate cotton cloth waste would self-heat to unacceptably high center-line temperatures;

- The thermal reactivity and sensitivity increases with age up to 114 days but declines with age until, at 149 days, the ARC-measured onset reaches $170^{\circ} \mathrm{C}$;

- Using polyamide/polyester cloths improves the thermal stability of ceric nitrate decontamination cloth wastes to acceptable temperatures $\left(>120^{\circ} \mathrm{C}\right)$ based on the CCPS's rule of thumb. 
Based on our thermal stability testing of potential RadPro ${ }^{\circledR}$ cloth wastes, we concluded that:

- Neutralizing RadPro decontamination solution/cotton cloth wastes with sodium hydroxide or carbonate is required to assure thermal stability; the ARC-observed onset temperatures for simulated unneutralized and neutralized wastes are $65^{\circ} \mathrm{C}$ and $115^{\circ} \mathrm{C}$, respectively;

- Synthetic polyamide/polyester cloths improve thermal stability of unneutralized decontamination wastes to an ARC-measured onset temperature of $85^{\circ} \mathrm{C}$;

- Neutralizing RadPro decontamination wastes with sodium carbonate improves thermal stability to an ARC-measured onset temperature of $95^{\circ} \mathrm{C}$ independent of cloth type;

- Emulsifier solution/cotton cloth wastes exhibit similar thermal sensitivities in our TGA/DTA studies to decontamination solution wastes with lower reaction rates and heat production; thus, by extrapolation, neutralization should be used for the emulsifier wastes.

Our thermal studies of the ceric ammonium nitrate/nitric acid-based inorganic gel decontamination technologies, which did not investigate aging effects, indicate that:

- Adding surfactants increases thermal sensitivity and reactivity relative to surfactant free gels and should be avoided when final disposal or packaging of the waste is to be in the dried form (flakes, dry on rags or vacuum filters); e.g., Glygel;

- Surfactant-free Aspigel wastes are susceptible to self-sustaining reactions with ARCobserved onset reactions near $70^{\circ} \mathrm{C}$, which can continue to within $50^{\circ} \mathrm{C}$ of the significant ceric ammonium reaction at $190^{\circ} \mathrm{C}$;

- Aspigel is more thermally sensitive in the ARC than is its active ingredient ceric ammonium nitrate; we speculate that this difference possibly could arise from the presence of nitric acid or sodium nitrate in the neutralized Aspigel, a catalytic effect from the aluminum oxidesilicon oxide gel, or a higher susceptibility to attack by the product oxidizing gases because of a higher surface area/volume distribution of the ceric ammonium nitrate;

- Neutralization of Aspigel with sodium carbonate significantly delays the ARC-measured onset temperature to $130^{\circ} \mathrm{C}$;

- Mixtures of Aspigel and vacuum cleaner filters are more thermally sensitive (ARC onset $50^{\circ} \mathrm{C}$ ) and accelerate more rapidly than Aspigel alone;

- Neutralization of Aspigel/DataVac 3 vacuum filter mixture delays the ARC-measured onset temperature from 50 to between 85 and $100^{\circ} \mathrm{C}$ and slows the reaction rate;

- Neutralization with sodium carbonate delays the reaction onset for Aspigel-saturated cotton cloth. 


\subsection{Recommendations for Further Work}

We do not understand why there is a difference in behavior between the neutralized ceric nitrate/nitric acid cotton cloth waste and the neutralized RadPro cotton cloth waste. In both instances after neutralization, the predominant oxidizer in the cotton will be sodium nitrate and both should have similar reactivity. Possibilities include the presence of polyester in the tested ceric waste and the presence of cerium in the ceric nitrate waste, which could act as a catalyst. Further studies are recommended to resolve this scientifically-interesting apparent conundrum.

Some of the conclusions related to gel-based systems are confounded by the use of an organic degreaser on the stainless steel stainless steel coupons before preparing the Aspigel. It is possible that this residual butoxyethanol in the degreaser could reduce thermal onset and increase thermal reactivity. More tests would be needed to isolate and understand this effect.

\subsection{Related Work by Others}

In a recent independent experiment conducted by Cogema for Fluor, a prototypic waste sample was prepared by placing $1.5 \mathrm{~L}$ of Aspigel in a DataVac vacuum cleaner filter, which would be typical of a heavily loaded filter in a hand-held vacuum used to remove the dried Aspigel

material. The DataVac filter was packaged inside two polyvinyl "bag-out" bags, per the proposed decontamination procedure, and this package was maintained at $55^{\circ} \mathrm{C}$ in an oven for 7 days. The innermost part of the package temperature was monitored to determine if a reaction occurred.

Cogema observed no temperature increase during the experiment and concluded that no reactions occur at $55^{\circ} \mathrm{C}$. This result does not reveal how close the system might be to a self-sustaining reaction, but does show that it is apparently safe if the internal waste package temperature is controlled at $55^{\circ} \mathrm{C}$. 


\subsection{References}

Beyler C. 2004. Analysis of the Cause of the Fire in Glovebox 8, Room 2325, Building 371 at RFETS on 6 May 2003. Hughes Associates, Inc. Baltimore, MD.

Center for Chemical Process Safety (CCPS). 1995. Guidelines for Chemical Reactivity Evaluation and Application to Process Design. American Institute of Chemical Engineers, New York, NY.

Fuger J, and FL Oetting. 1976. The Chemical Thermodynamics of Actinide Elements and Compounds, Part 2: The Actinide Aqueous Ions. International Atomic Energy Agency, Vienna, Austria.

Greenwood NN, and A Earnshaw. 1994. Chemistry of the Elements. Pergamon Press, New York, NY.

Kurath DE, LA Bray, JH Jarrett, WE Lawrence, EJ Wheelwright, and L Petkus. 1997a.

"Decontamination of Stainless Steel Using Cerium (IV): Operational Results.” Presented at the D\&D

Exchange '97 Conference, December 1-5, 1997, Miami, FL.

Kurath DE, LA Bray, JH Jarrett, WE Lawrence, EJ Wheelwright, and L Petkus. 1997b.

"Decontamination of Stainless Steel Using Cerium (IV): Recycle and Reuse.” In: Proceedings of the Beneficial Reuse '97 Conference, August 5-8, 1997, Knoxville, TN.

Lide DR. 2004. CRC Handbook of Chemistry and Physics. $85^{\text {th }}$ Edition, CRC Press. Accessed September 2004. Available at: http://www.hbcpnetbase.com,.

Ozawa T. 1970. “Kinetic Analysis of Derivative Curves in Thermal Analysis.” J Therm. Anal. 2:301.

Pacific Northwest National Laboratory (PNNL). "Monthly and Annual Maximum Temperatures.” Hanford Meteorological Station, Richland, Washington. Accessed September 2005. Available at: http://hms.pnl.gov/products.htm.

Pourbaix M. 1966. Atlas of Electrochemical Equilibria in Aqueous Solutions. Pergamon Press, Oxford.

Richland, City of. "Plutonium Finishing Plant.” Accessed September 2005. Available at:

http://www.ci.richland.wa.us/RICHLAND/Hanford.

Ryan JL, and LA Bray. 1980. "Dissolution of Plutonium Dioxide - A Critical Review.” In: Actinide

Separations, ACS Symposium Series, 117, American Chemical Society, Washington, DC.

Scheele RD, DC Stromswold, RB Kefgen, KJ Iwamasaa, HJ Stone, RN Sell, S Rohrig, SL Stein, BK McNamara, GA Warren, WF Bonner, TA Acox, S Alkire-Mays, D Gelston, LL Kaiser, RG Anderson, MA Duffy, SJ Maheras, and PJ Weaver. 2005. Alternatives for Characterization and Removal of Deposits at the Portsmouth Gaseous Diffusion Plant. PNWD-3384, Battelle-Pacific Northwest Division, Richland, WA.

Scheele RD, JL Solbolik, RL Sell, and LL Burger. 1995. Organic Tank Safety Project: Preliminary Results of the Energetics and Thermal Behavior Studies of Model Organic Nitrate and/or Nitrite Mixtures and a Simulated Waste. PNL-10213. Pacific Northwest National Laboratory, Richland, WA.

Suresh G, VR Raju, UK Mudali, and RK Dayal. 2003. “Corrosion Assessment of Type 304L Stainless Steel in Nitric Acid.” Science and Technology 38(4):309-312. 
Turcotte R, PD Lightfoot, R Fouchard, and DEG Jones. 2003. "Thermal hazard assessment of AN and AN-based explosives.” Journal of Hazardous Materials A101:1-27.

Wiberg N. 2001. Inorganic Chemistry. Academic Press, San Diego, CA. 
Appendix A

\section{Aspigel 100: Final Report}


Appendix A: ASPIGEL 100. FINAL REPORT: CONTRACT - Subcontract C-05-P53-005, Long term reactivity test on dried flakes

S. Faure, P. Fuentes, F. Cuer, LPAD, CEA-Marcoule

Within the context of decontamination of more then 200 gloves boxes at HANFORD, CEA and COGEMA proposed in April 05 to COGEMA Engineering Corporation to use a new technique leading to the reduction of the liquid secondary effluents volume. It is based on the use of a new colloidal silica oxidizing gel containing no organic compound sprayed on metallic surfaces to decontaminate and the removal of the gel containing the pollutants without water rinsing. This process is applied as following and is called drying gel process (patent CEA/COGEMA PCT/FR02/0250., 2001).

The first spraying tests and use of ASPIGEL 100 provided by CEA and FEVDI were encouraging. The preliminary studies of the stability conducted on few milligrams dried aspigel clearly show that the dried aspigel 100 is stable below $100-120^{\circ} \mathrm{C}$. But a small exothermic reactivity over $150^{\circ} \mathrm{C}$ due to the degradation of cerium nitrate salt. CEC wanted the CEA to conduct a long term reactivity test at $55^{\circ} \mathrm{C}$ on a quantity of dried gel representative of the reality that will be stored. (>kg)

\section{Preparation of $2 \mathrm{~kg}$ of ASPIGEL 100 flakes}

All the experiments were made by spraying "ASPIGEL 100" on stainless steel 316 L surfaces .

6 films (each film surface is equal to $2 \mathrm{~m}^{2}$ ) were prepared by FEVDI (from 21 to 24 of June) by pulverization of $7 \mathrm{~kg}$ of ASPIGEL 100 on stainless steel $\left(600 \mathrm{~g} / \mathrm{m}^{2}\right)$ plates and each film was dried during 24 hours at $22^{\circ} \mathrm{C}$, with a relative humidity of $40 \%$.

We collected 2,348 kg of the dried flakes by simple brushing.

Conditioning was made week 26 and CEA received the flakes the $1^{\text {st }}$ of july. 


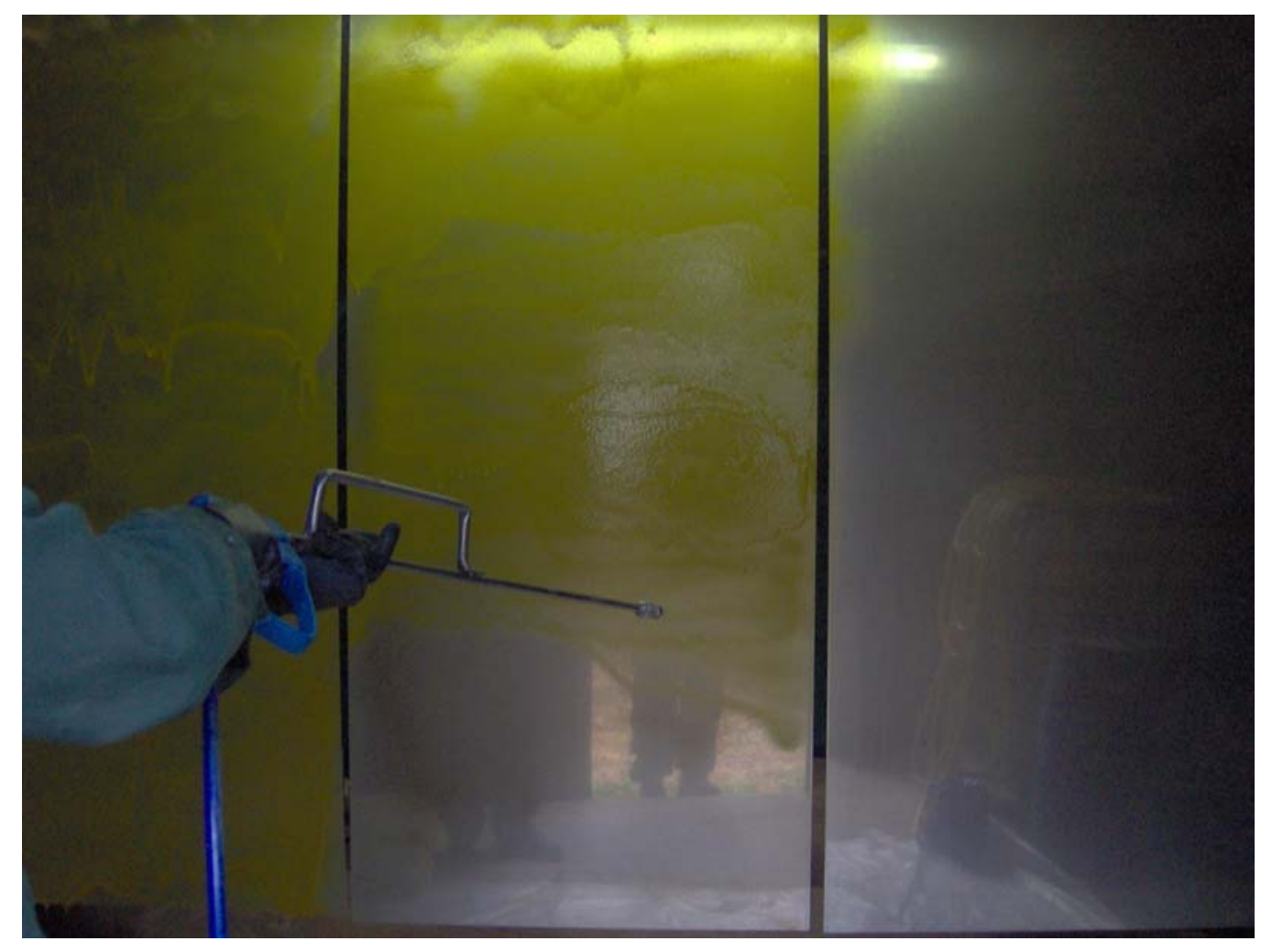

Figure 1: Spraying of Aspigel 100.

\section{7 days reactivity test}

CEA/LPAD conducted from Monday, the 18 of July to Tuesday, 26 of July. in Laboratory 871 in Marcoule with the help of the vented measuring chamber of LPAD the "reactivity test" on 1.5 liters $(1,150 \mathrm{~kg})$ of dried ASPIGEL 100 contained inside a vacuum cleaner bag and 2 plastic bags (Figure 2 and 3 ).

The experiment was conducted without air flow rate inside the chamber. 

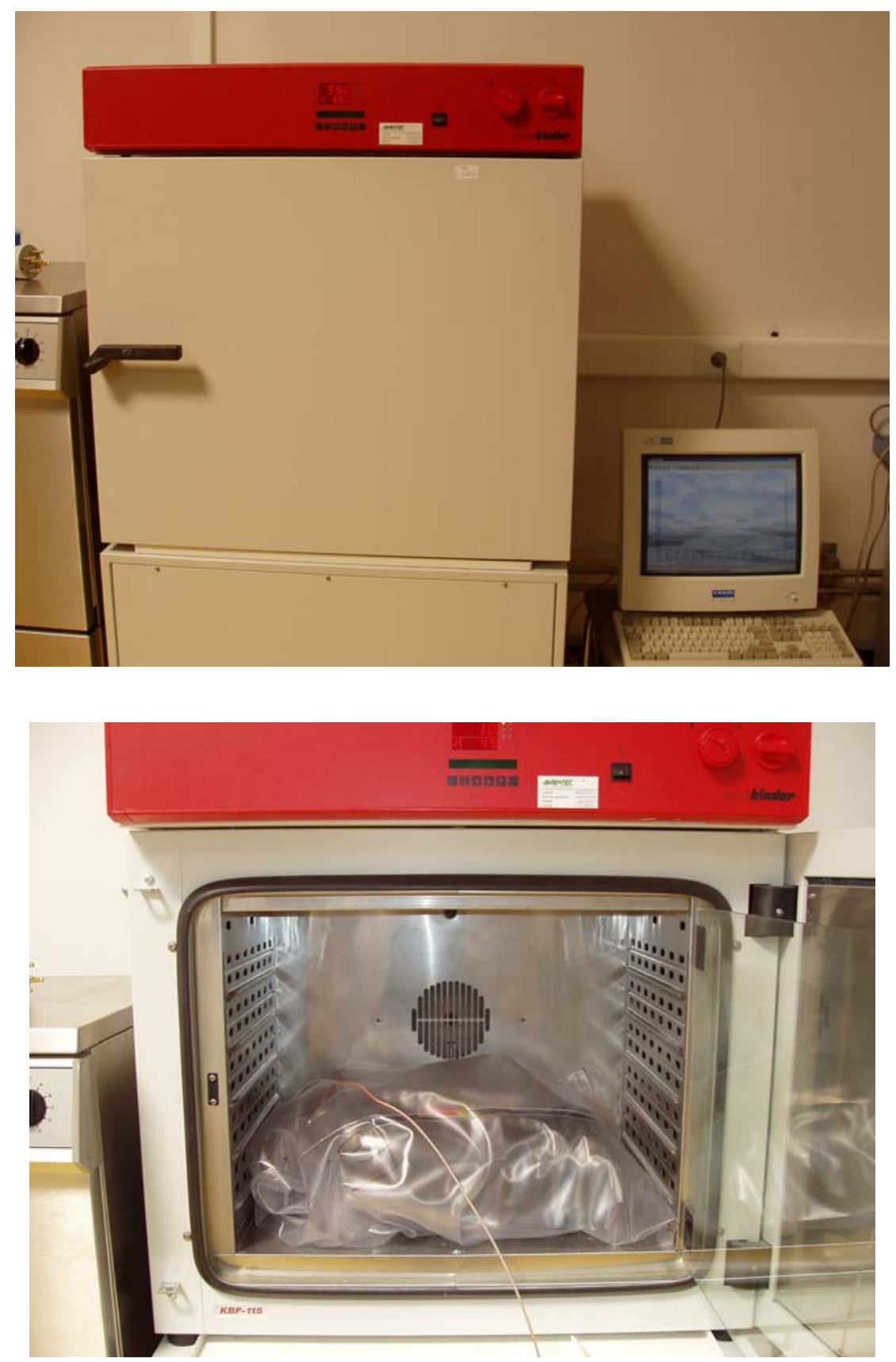

Figures 1 and 2: Climatic chamber and vacuum cleaner inside 2 PVC plastic bags

The test used the "DataVac II" vacuum cleaner sended with a 1.5 liter bag (made of poly) filled with 1.5 liters of Aspigel 100 flakes.

The vacuum filter with flakes was sealed into 2 layers of seal out bags (12 mil PVC) with Nucfill hepa filters (model Nucfil 036-A PVC or Nucfil 030) on each sealed bag. 
Thermal instrumentation (Pt- 100) was attached to monitor the internal Aspigel flakes temperature and the relative humidity. Camera took pictures each day. probe was placed inside the PVC bag.too (Fig.3 - 4).
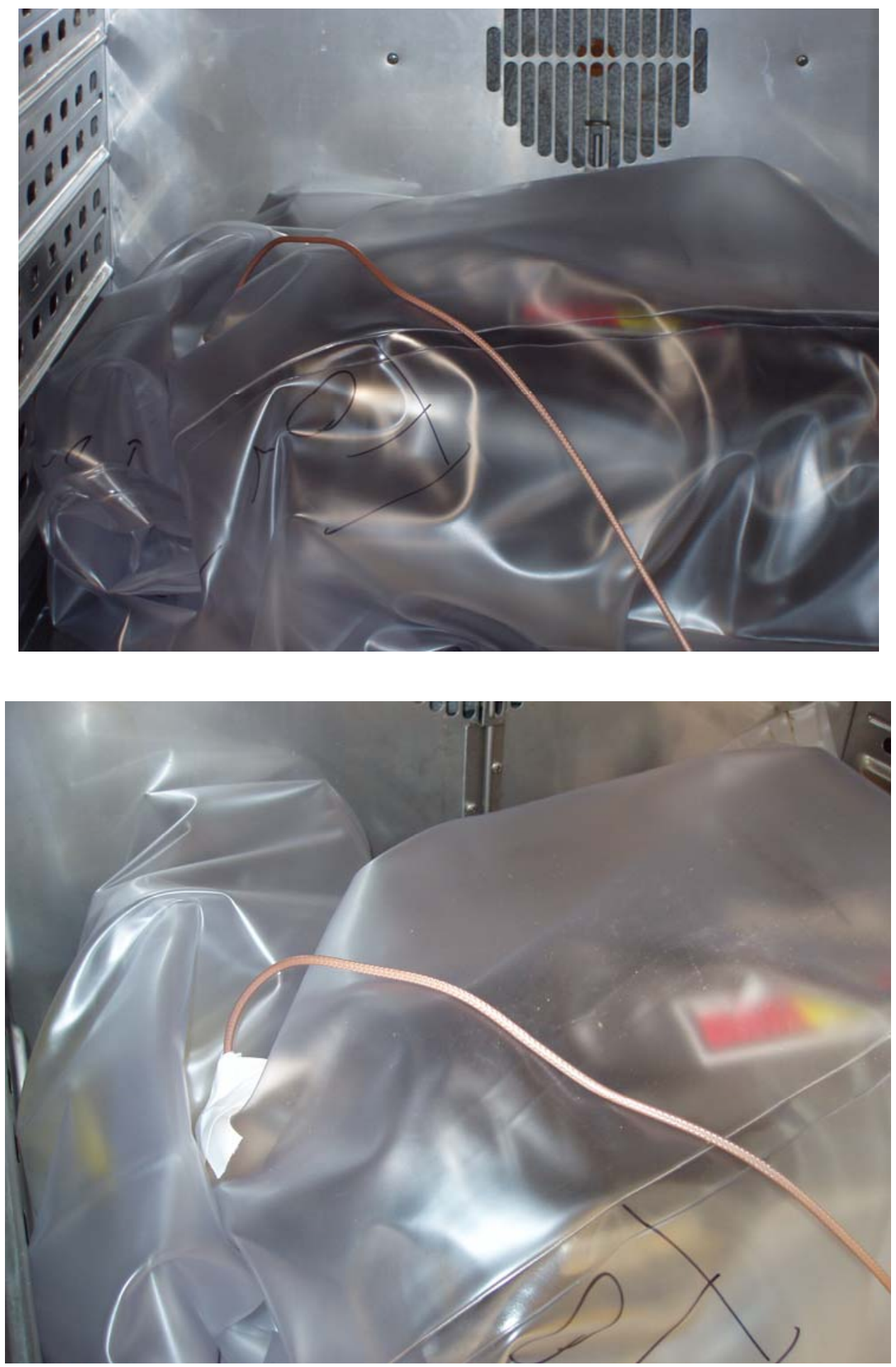
Figures 3 and 4 : Pt-100 thermal probe

The packaged vacuum with flakes inside the dual layered PVC bags was heated to 55 deg Celsius for a period of 7 days. Temperature was collected each 15 secondes and recorded. Figure 5 shows the evolution of the temperature and the relative humidity at the heart of the flakes versus time during 7 days.

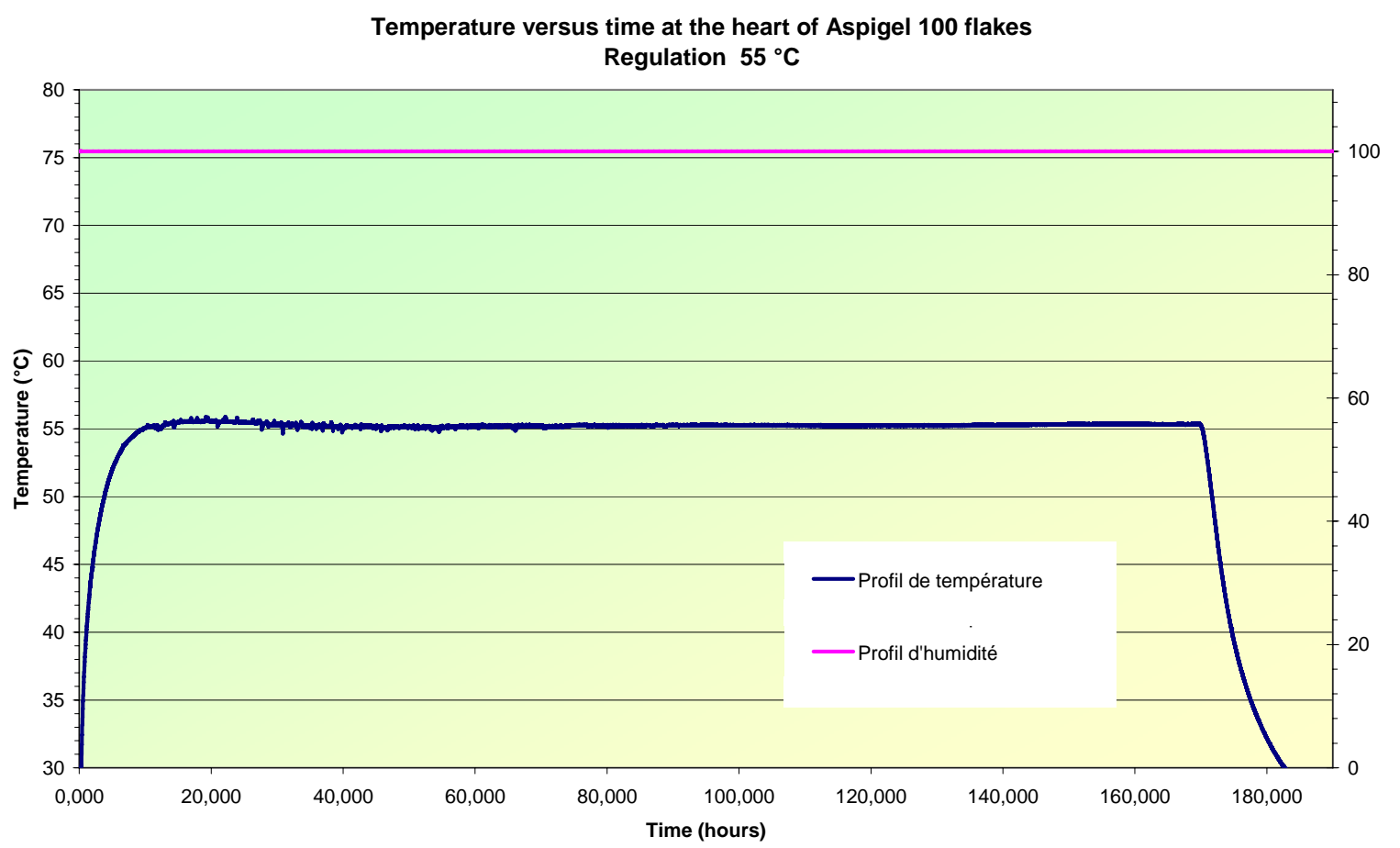

Figure 5: Temperature and relative humidity versus time at the heart of aspigel 100 flakes.

No exothermic reaction occurs that increases the temperature of the flakes. We can notice that the temperature was very stable at $55^{\circ} \mathrm{C}+/-0.2^{\circ} \mathrm{C}$ during the 7 days and 7 nights. The relative humidity is very rapidly equal to 100 because of the evaporation of residual water in an enclosed medium.

During the test; the plastic of the vacuum cleaner was very stable too. 
Only 2 major changes were observed, one on the inside PVC bag (colour) and the other on the top metallic surfaces inside the vacuum cleaner which are corroded. .

First, pictures were taken through the glass window of the climatix chamber. We noted that one of the 2 PVC bag (inside bag, first barrier) has changed from white to yellow at a time of 36 hours. (figure 6-7-8).

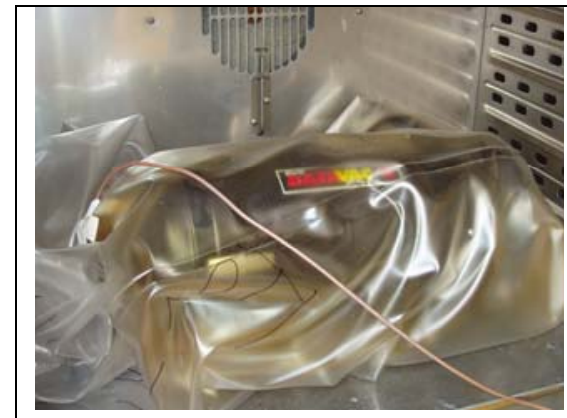

Fig. 6: After 36 hours, the inside PVC bag colour changes from white to yellow.

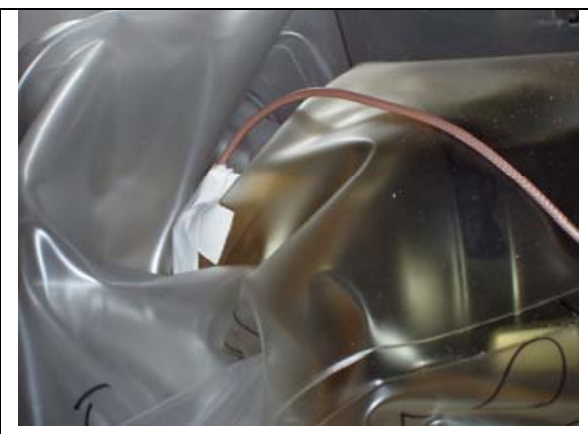

Fig. 7 : After 48 hours, no change

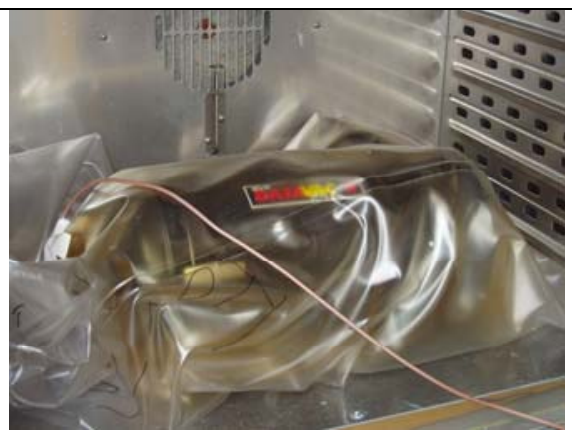

Fig. 8: After 72 hours, no change

Due to some residual quantity of nitric acid in solids flakes, one hypothesis is that some nitrous vapour coloured the first barrier of PVC. The second one PVC bag (outside bag) is transparent and stays white and no colour change is observed. By touching with our hands the 2 bags at the end of the experiment, the mechanical properties of the inside bag are the same than the ones of the outside bag.

At the end of the experiment, we stopped the heating and waited 15 hours for the go-back to room temperature inside the flakes without opening the chamber.

Then, we opened the chamber and cut the 2 bags, opened the vacuum cleaner to make observations of the inside flakes (fig. 9 to 19). 


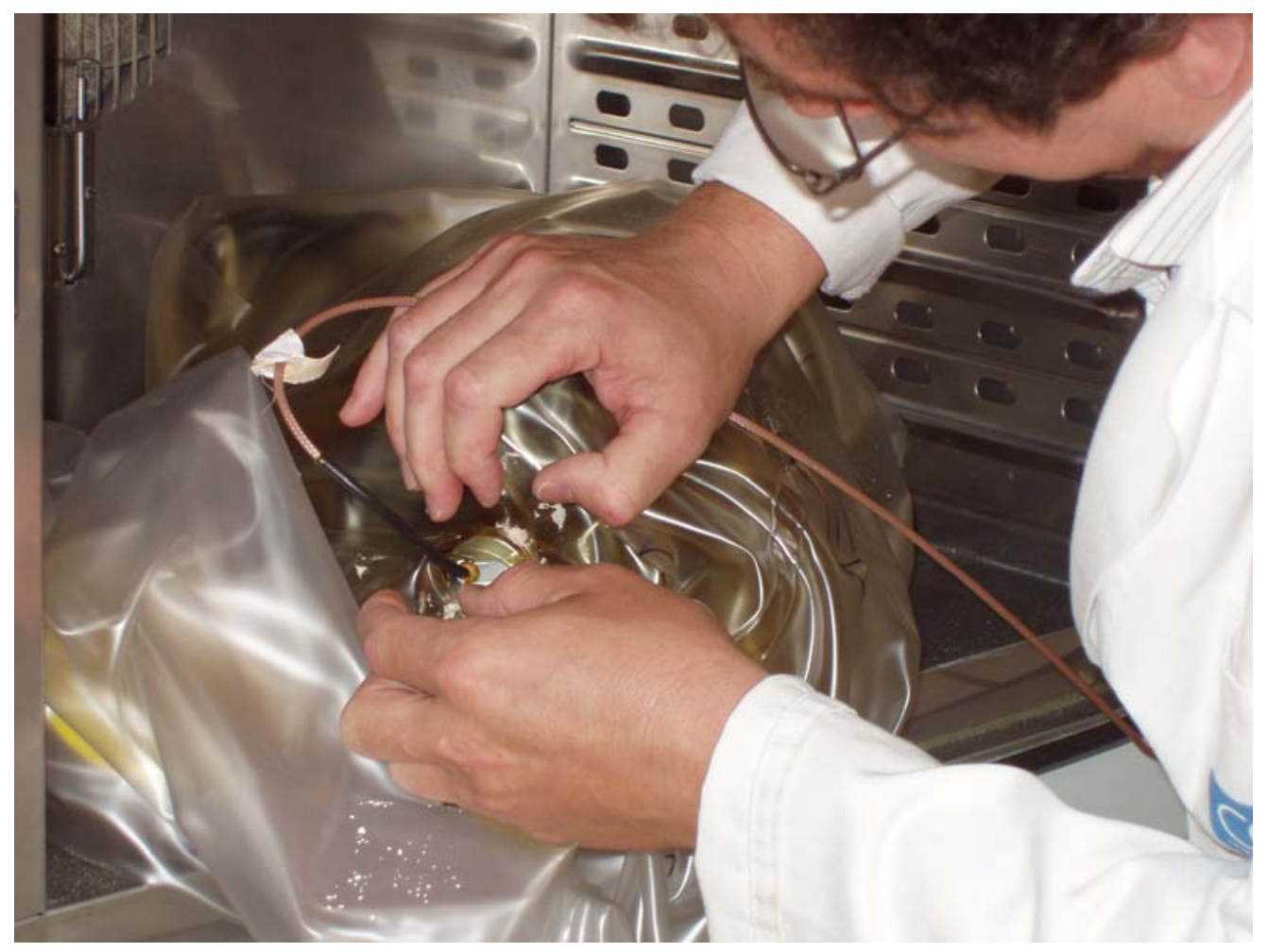

Figure 9

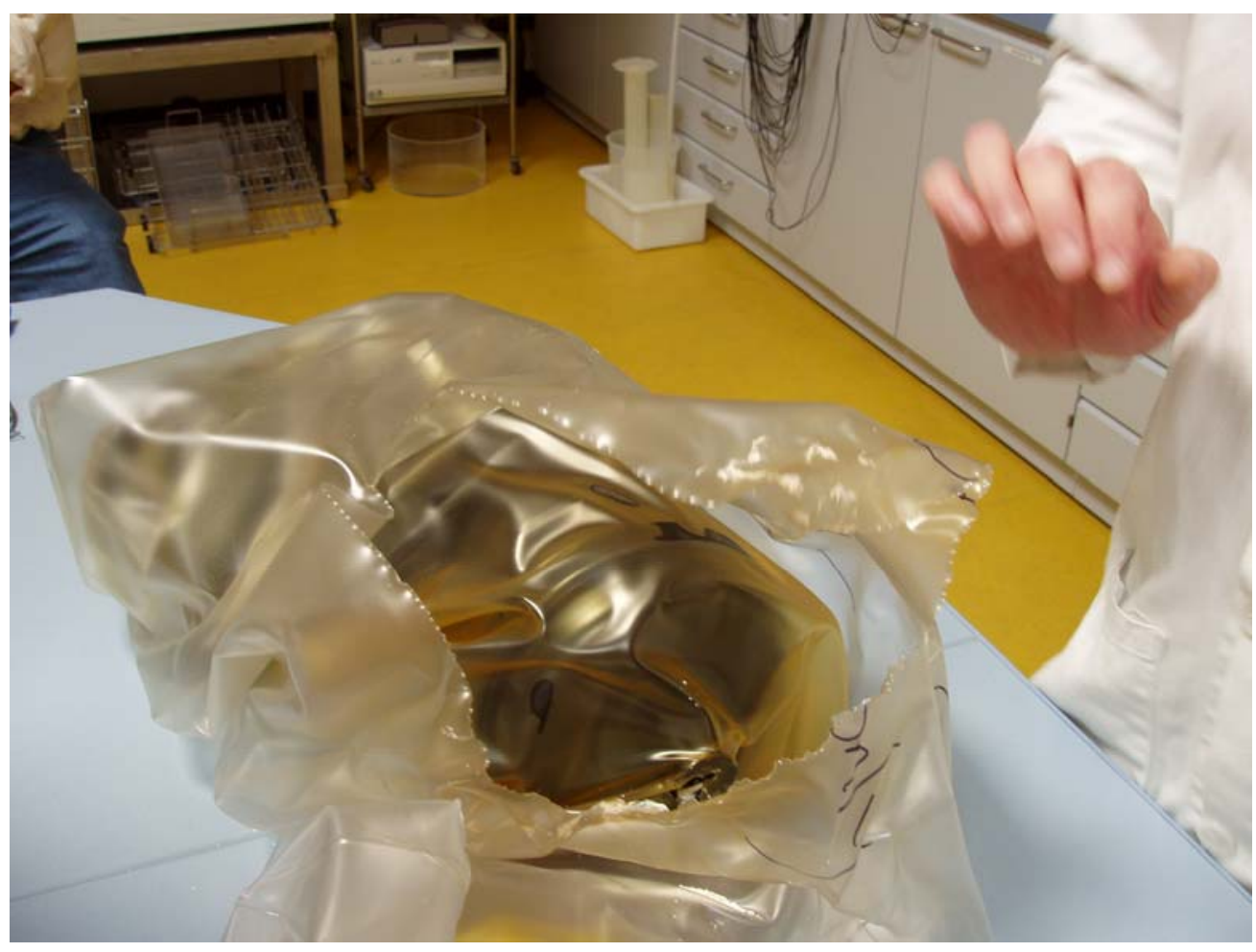

A. 7 
Figure 10

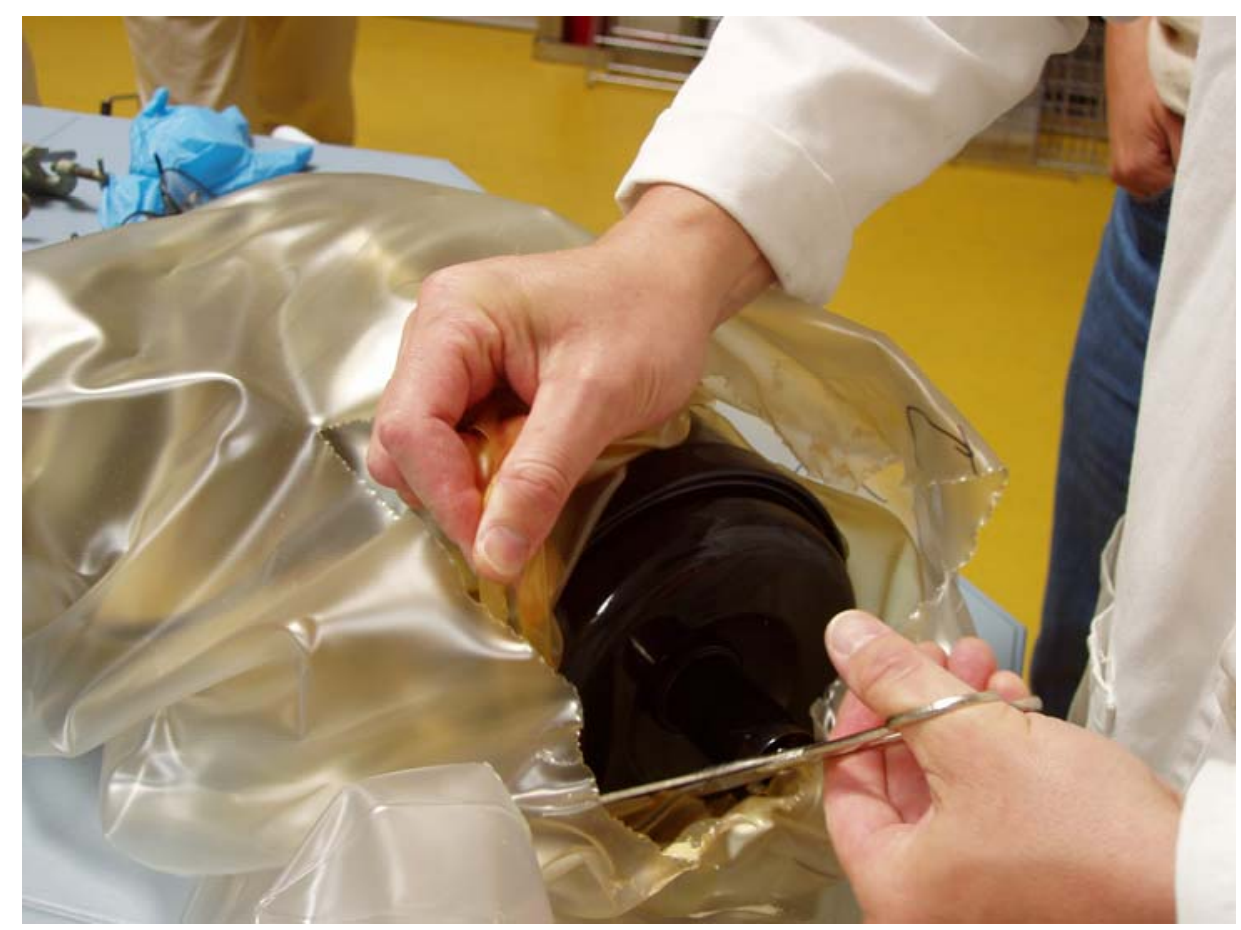

Figure 11 


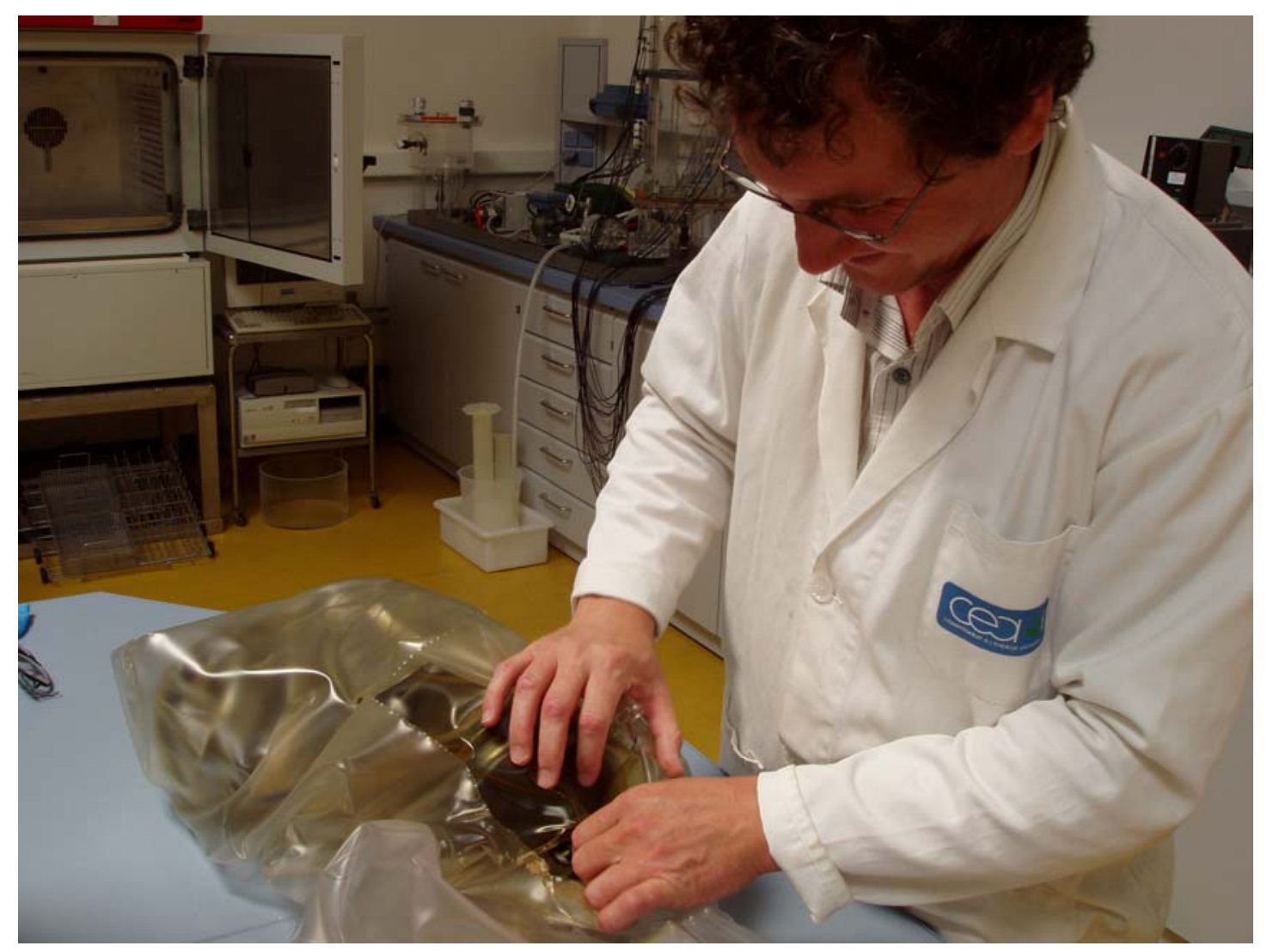

Figure 12

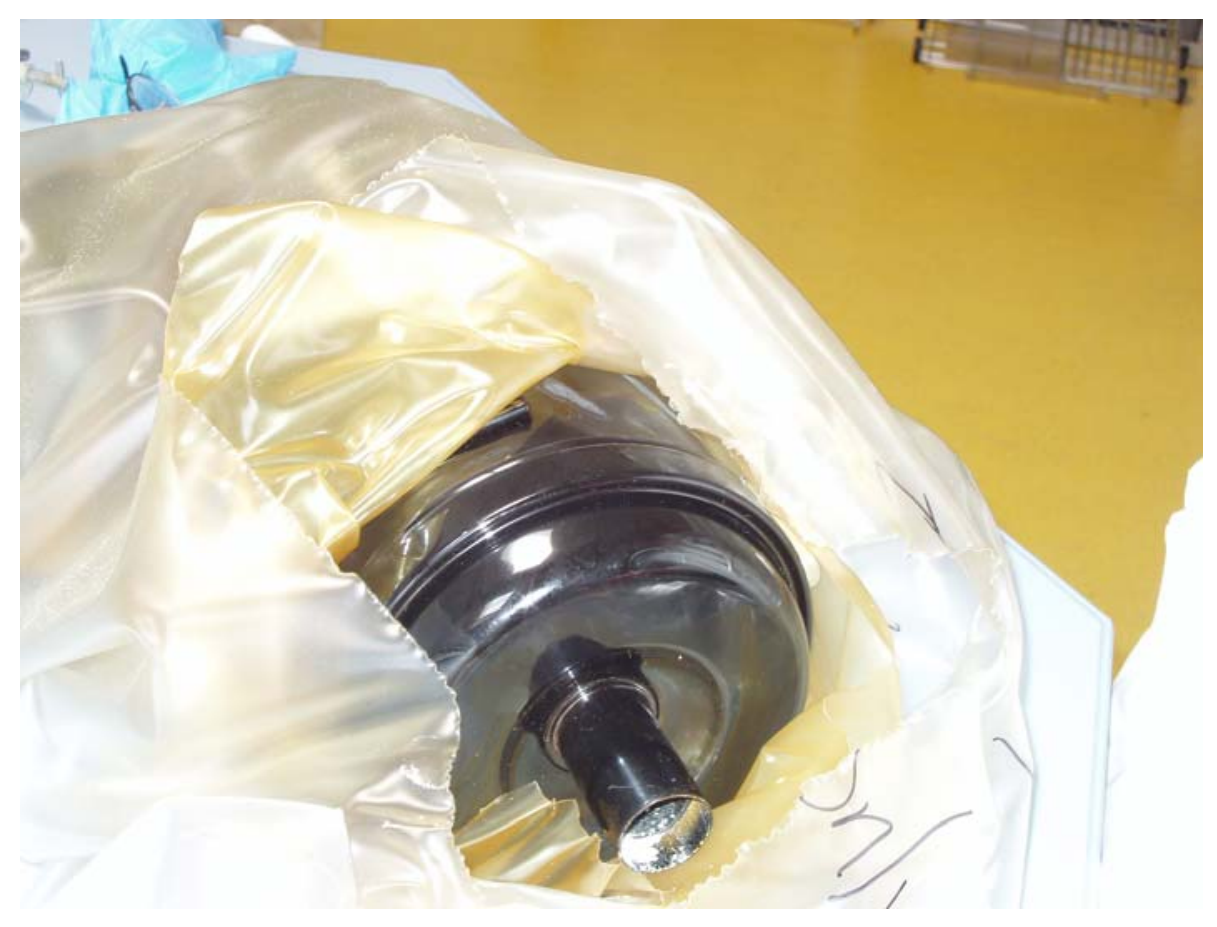


Figure 13

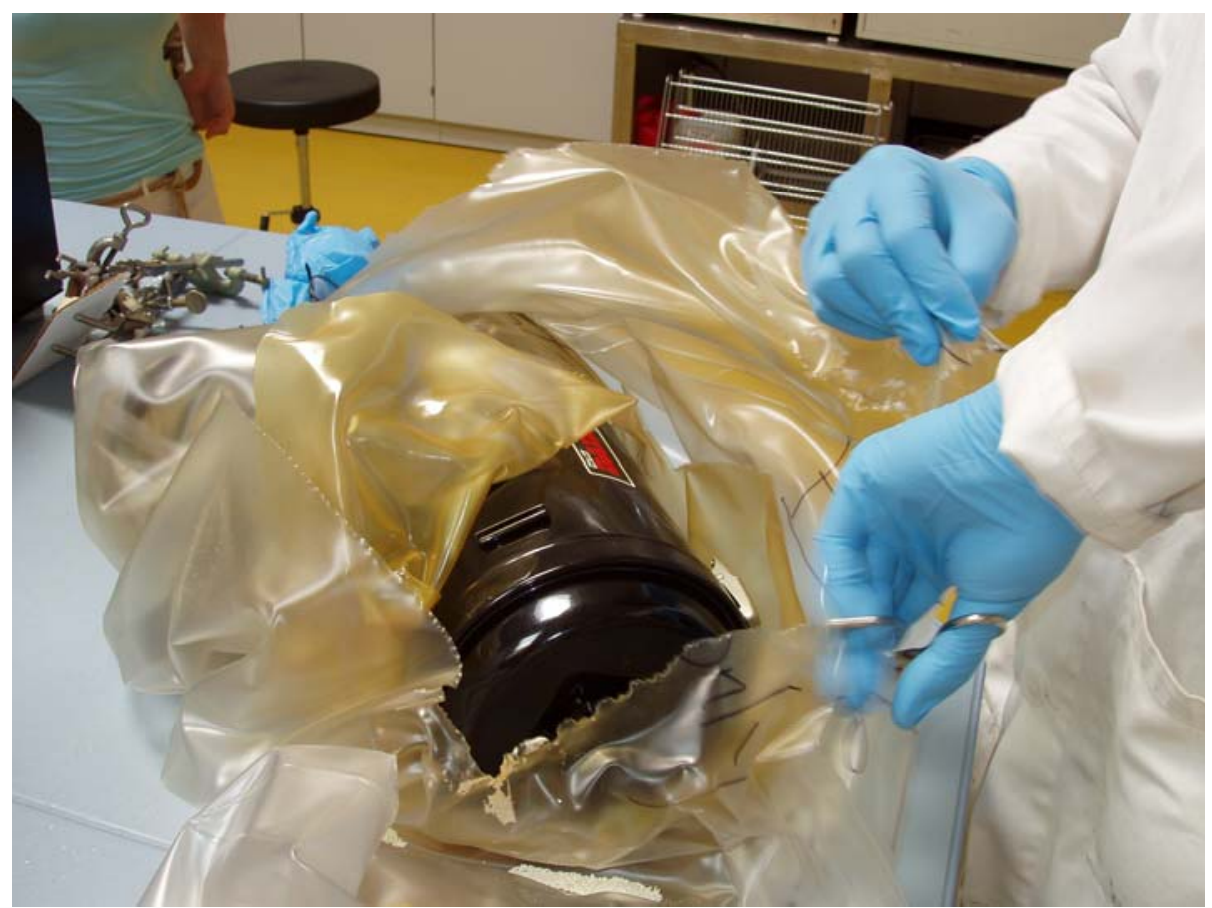

Figure 14

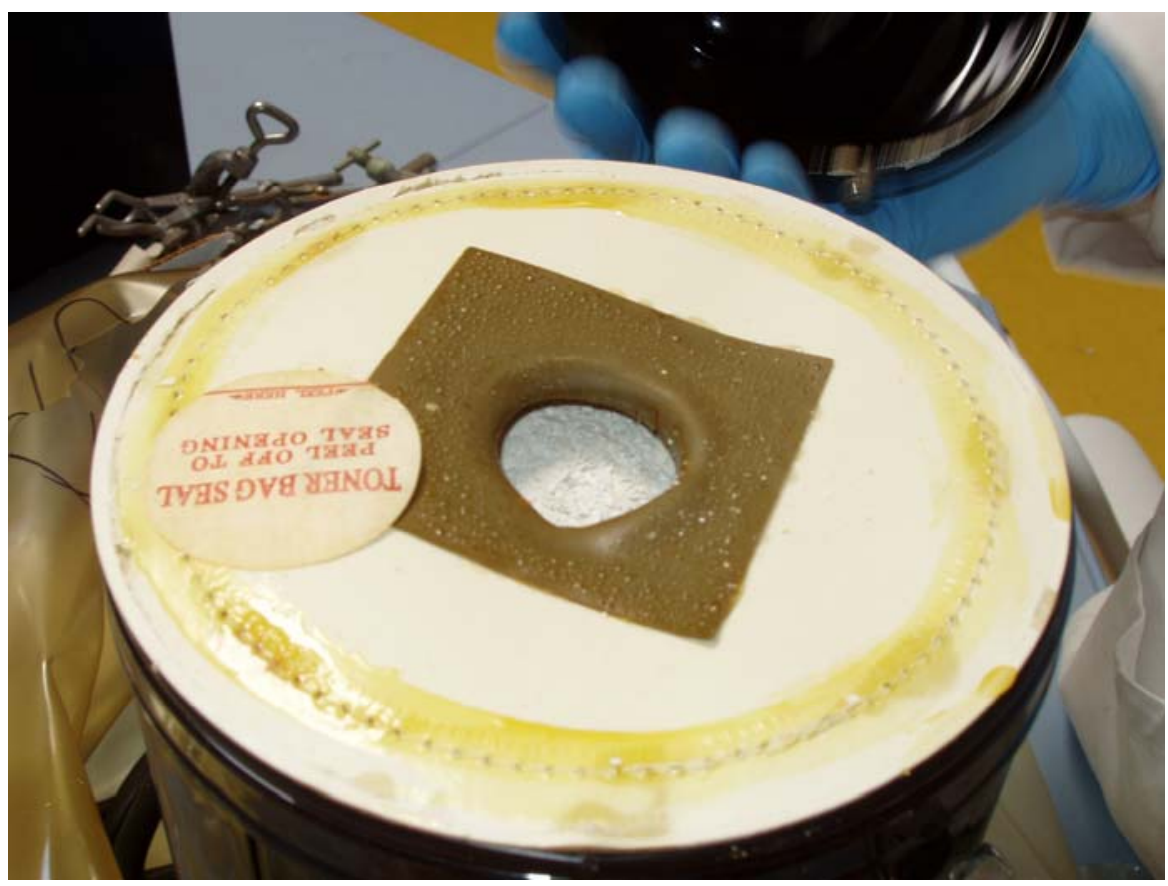

Figure 16

A.10 


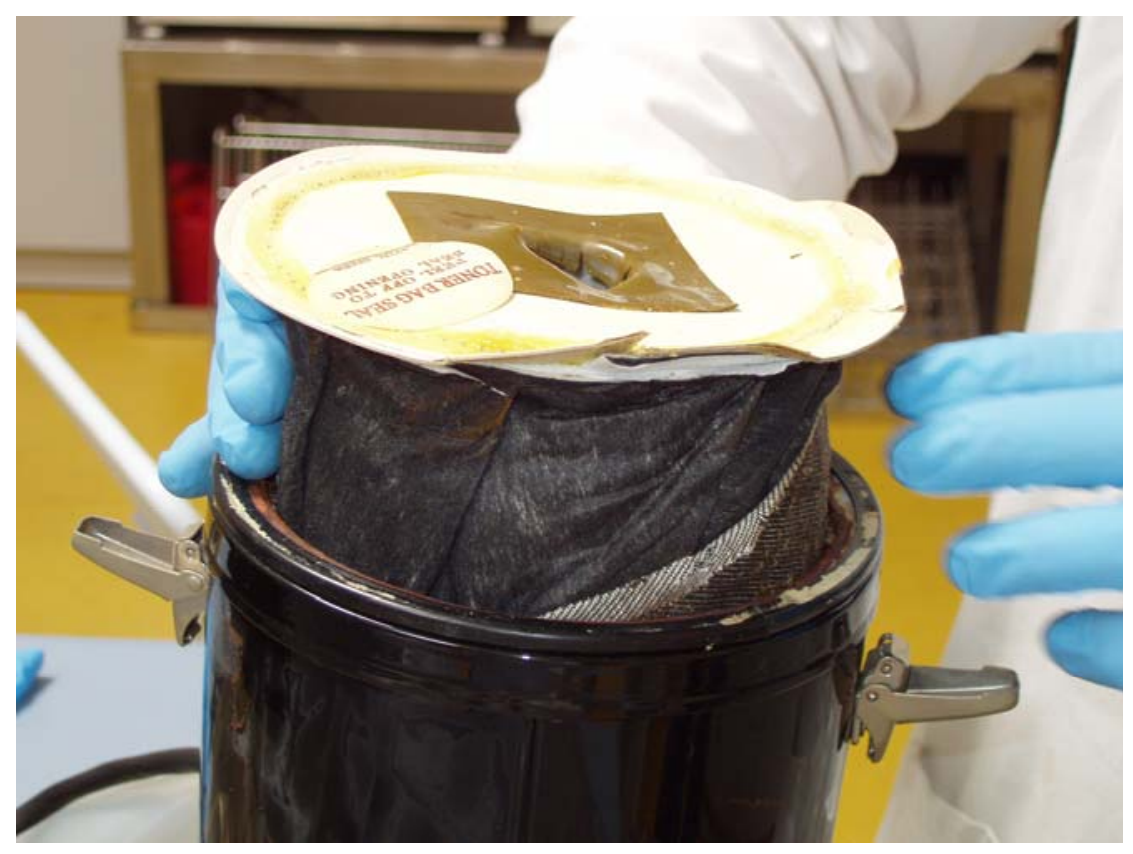

Figure 17

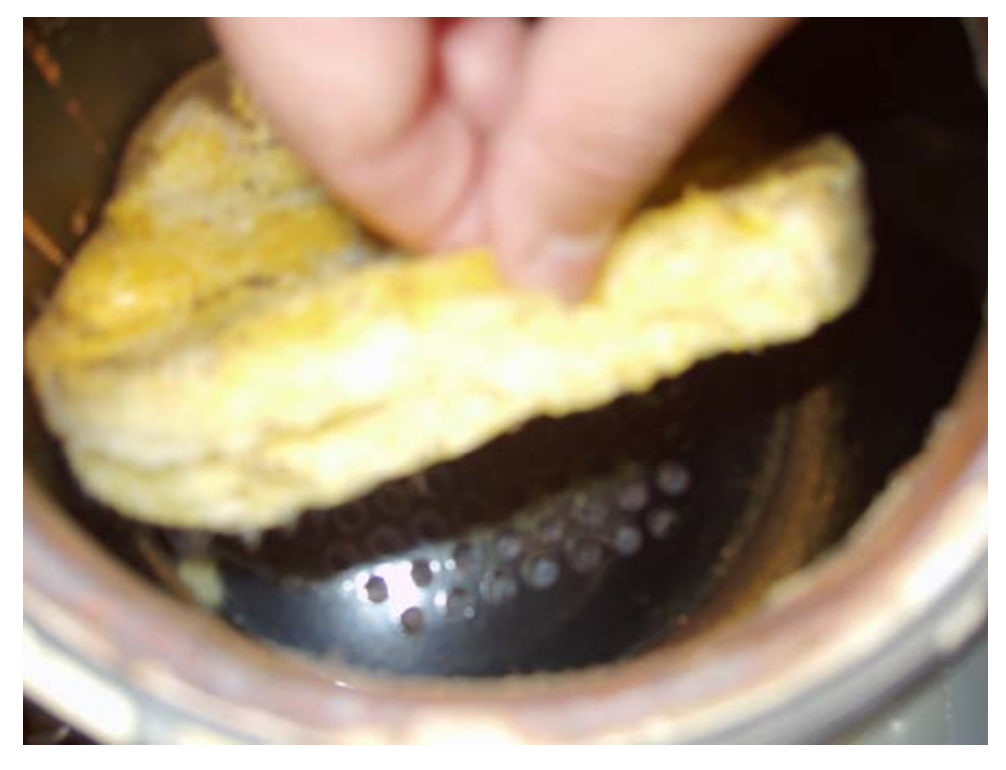

Figure 18 


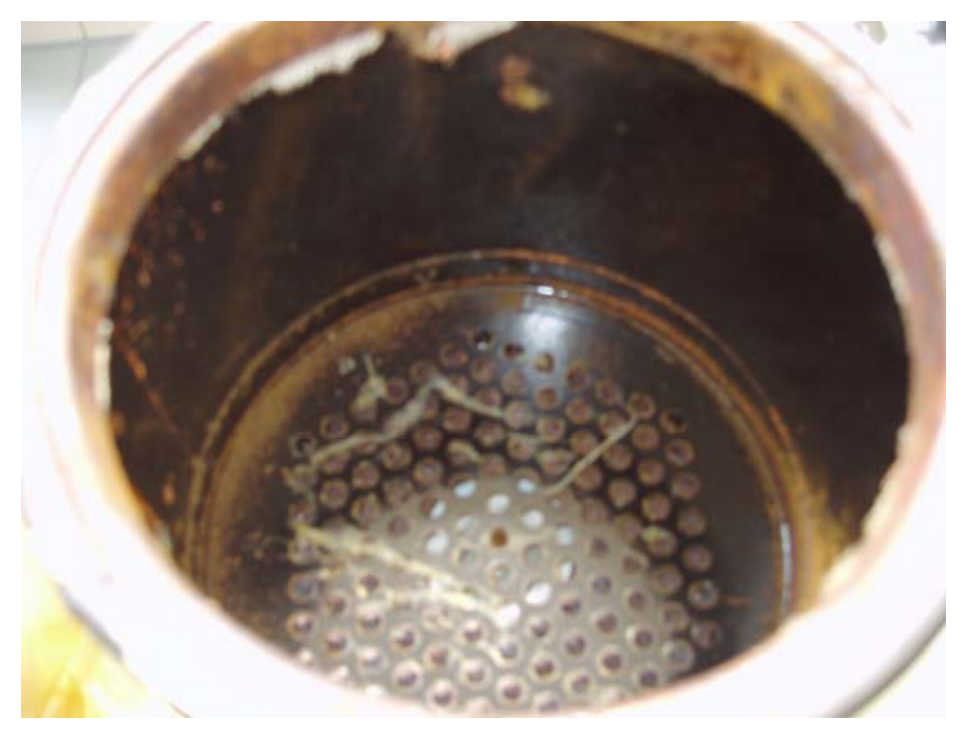

Figure 19

The second thing we observed is that some metallic parts inside the vacuum cleaner (we do not know if it was stainless steel) were a little corroded by the nitrous atmosphere but no mechanical damage was observed (Figure 20)

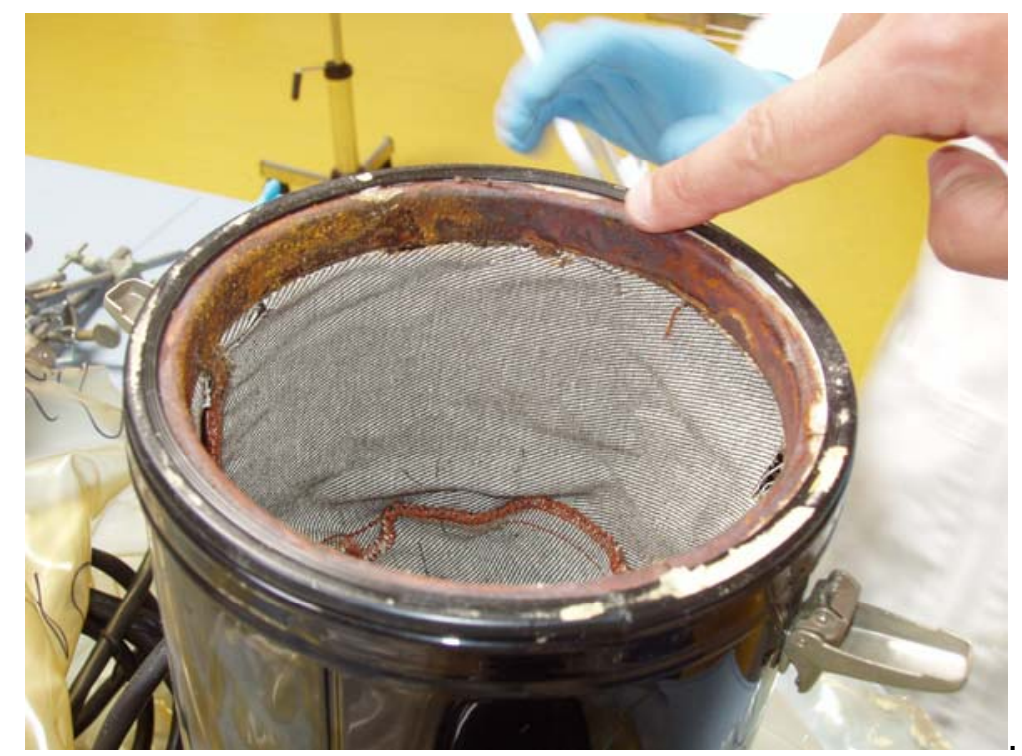

Figure 20: Top metallic surface of the vacuum cleaner corroded. 
Finally we evacuated the flakes from the cleaner bag (fig. 21). No colour changes were observed.

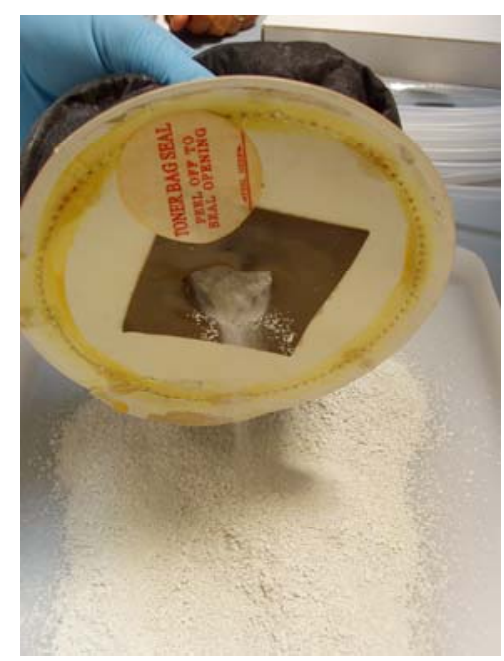

Figure 21: Dried pellets after 7 days at $55^{\circ} \mathrm{C}$.

\section{CONCLUSION:}

There is no problem as expected to store the dried gel containing Ce-ammonim nitrate at $55^{\circ} \mathrm{C}$ directly in the vacuum cleaner. No exothermic reaction occurs. 